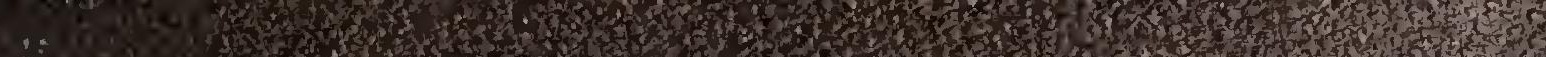

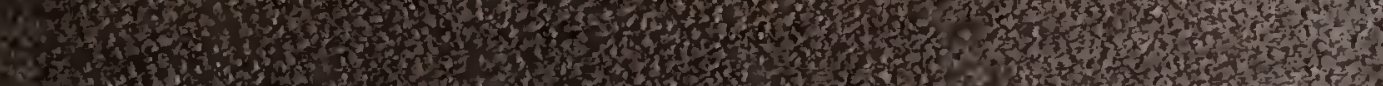

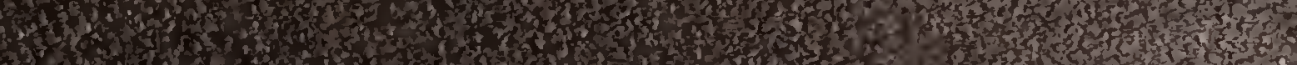

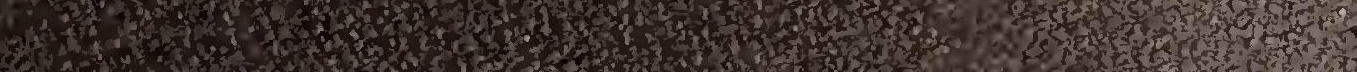

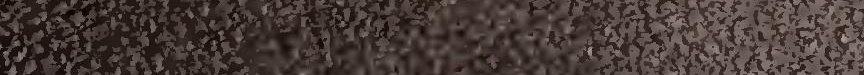
73 (f) 2.

to.
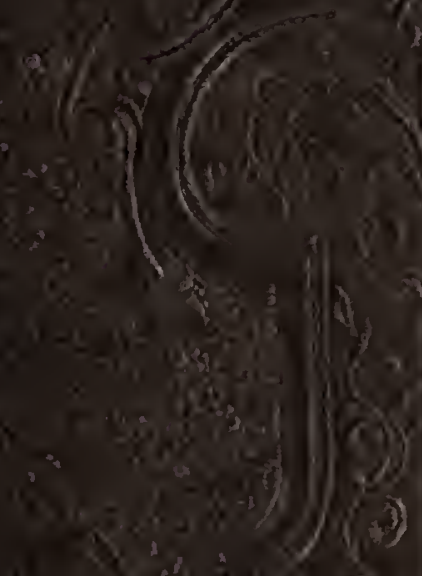

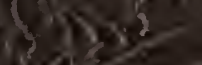

$(2)$
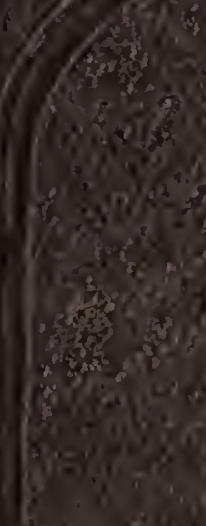

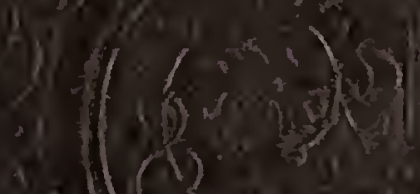 \\ $10(1)$
}

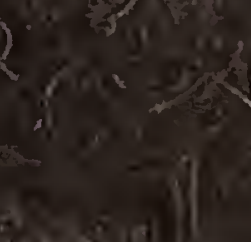

i)

$\sqrt{(10)}(0,5)$

$(3+5)$

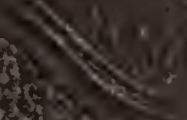

a.

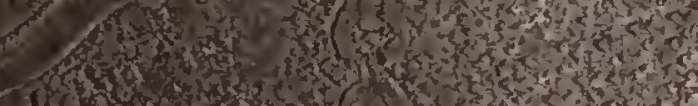
roo ${ }^{2}$. (1)

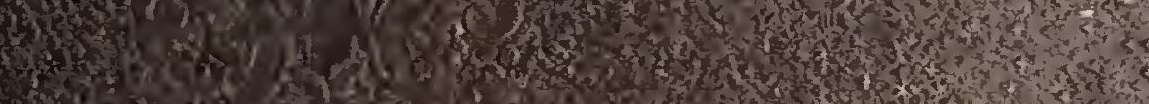

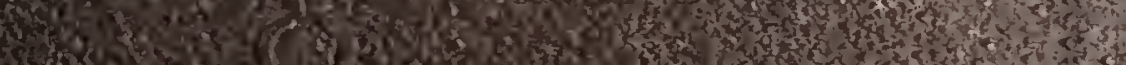

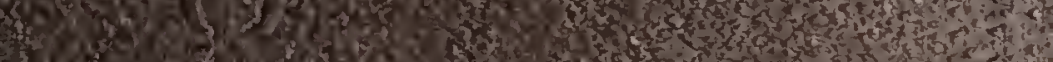

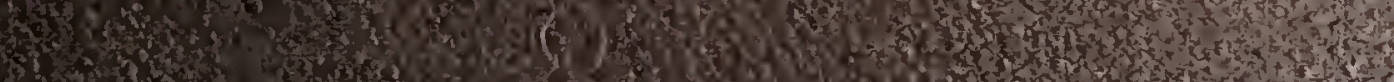

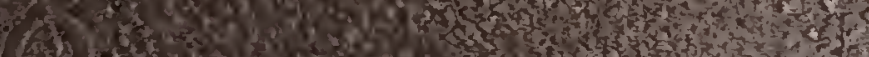

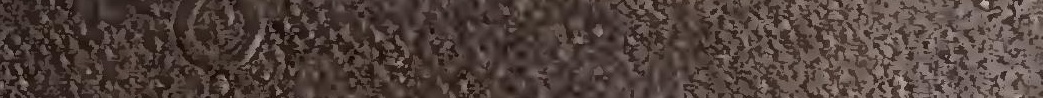

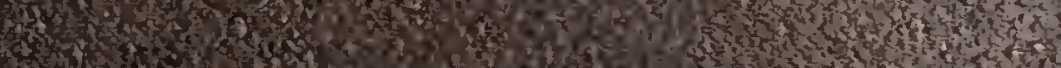

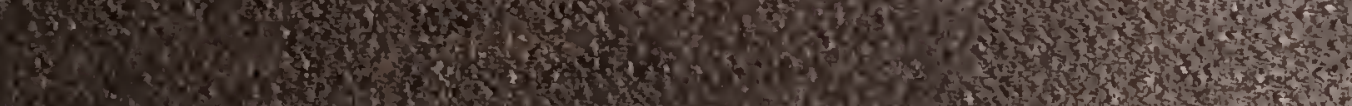

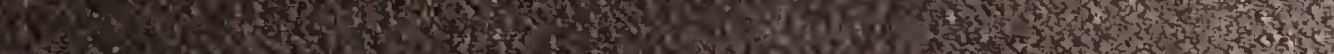

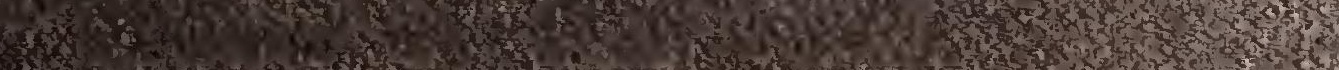

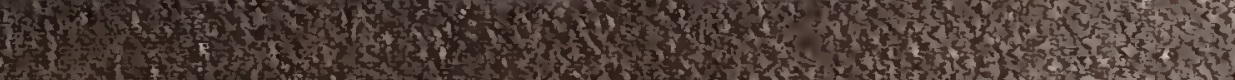

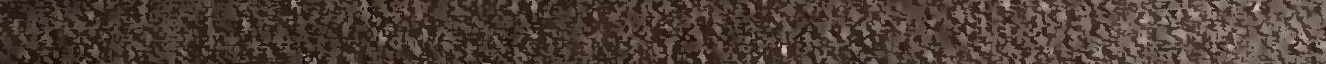

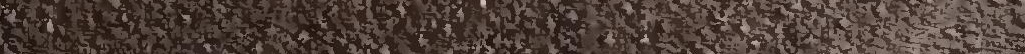


P1562396

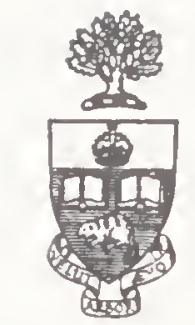

Library

of the

University of Toronto 



$$
\begin{aligned}
& 6.10 x=1 \\
& 2 w 6 \\
& t^{5}
\end{aligned}
$$

wot 
THE

WONDERS OF GEOLOGY.

VOI. I. 
T.GKOX:
R. CLAY, PRSTTER, EREAD-STREET-HILI. 



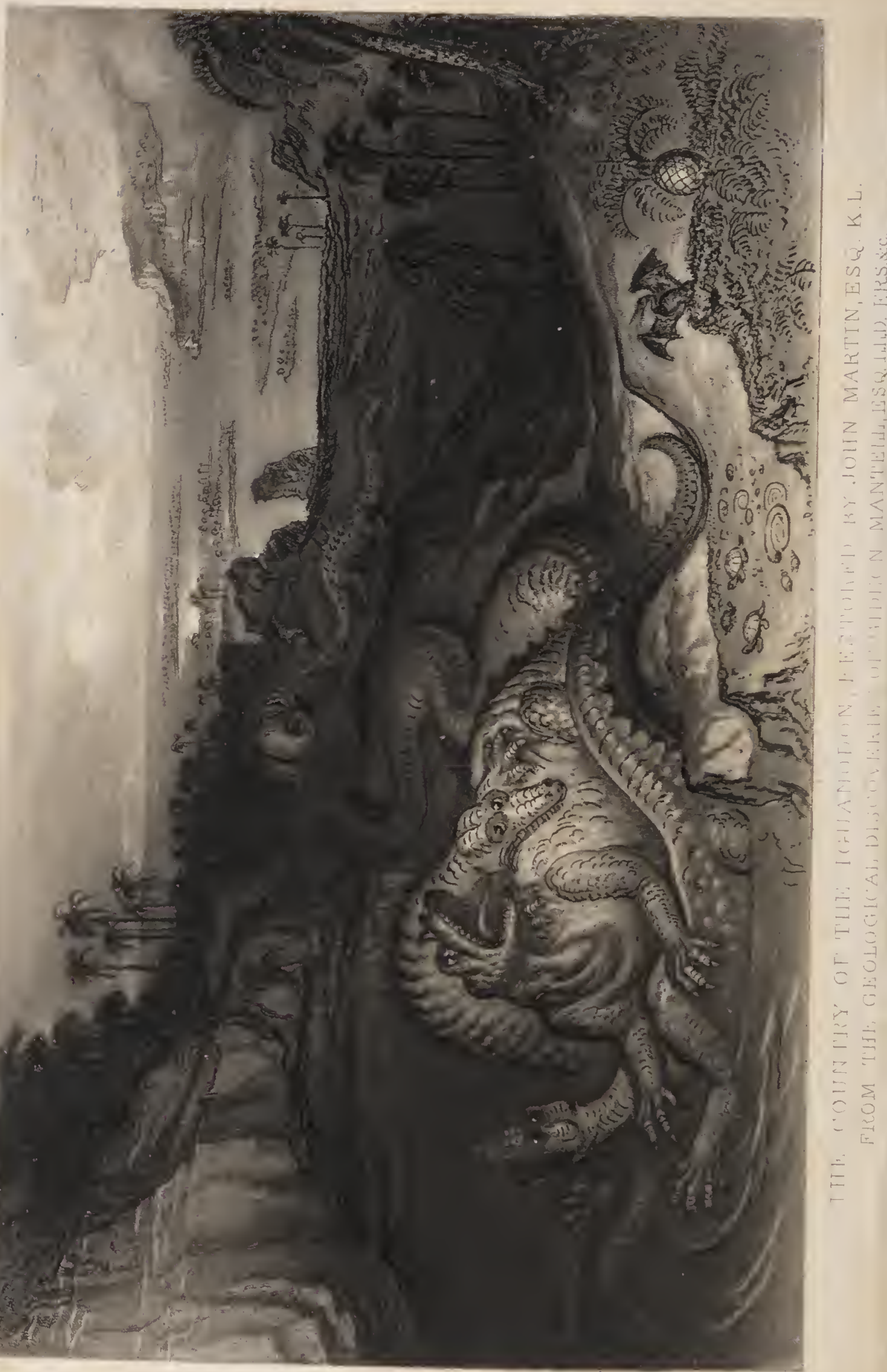


THE

\section{WONDERS OF GEOLOGY ;}

BY

\section{GIDEON MANTELL, LL.D. F.R.S.}

AUTHOR OF

THE GFOLOGY OF TIN SOLTH EAST OF I:XGIND,

FTC. ITC.

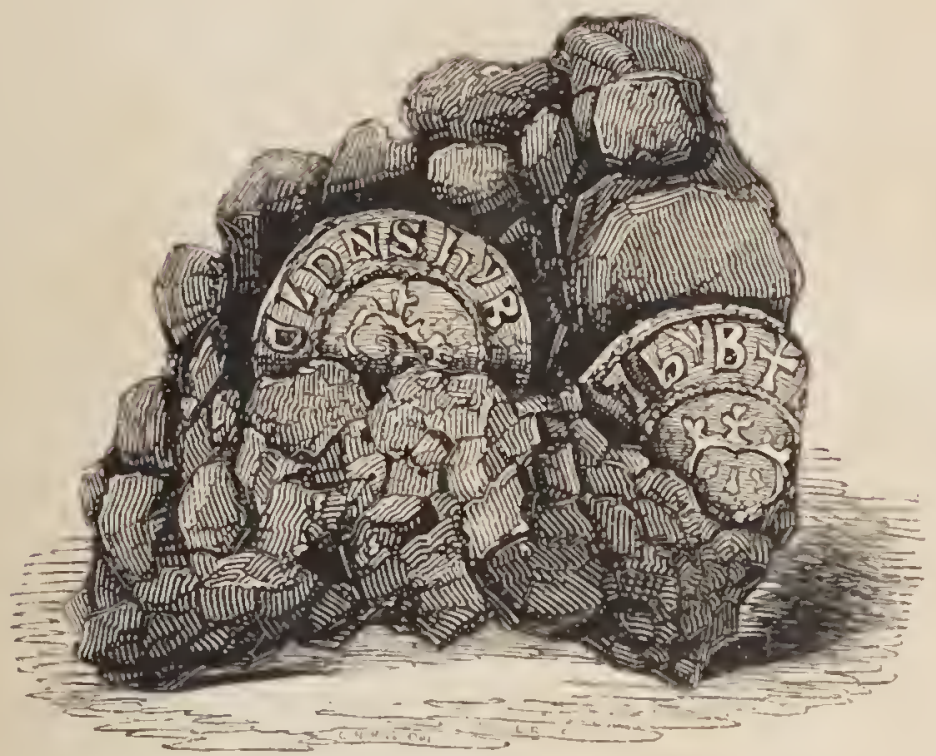

Silver Coins of Elward the First, in ironslone. Pagc 58.

"To the natural pinilosopher there is no natural object unimportant or trifling : from the least of nature's works he may learu the greatest lesson."-SiR J. F. W. Henschet.

"We know not a millionth part of the wonders of this beautiful World."-LFIOH HUNT.

VOL. I.

I.ONDON :

RELFE AND FLETCHER, CORNHILL。 
Digitized by the Internet Archive in 2018 with funding from University of Toronto 
THE

\section{WONDERS OF GEOLOGY;}

or,

A FAMILIAR EXPOSITION

oF

\section{GEOLOGICAL PHENOMENA ;}

BEING THE SUBSTANCE OF

A COURSE OF LEC'TURES DELIVERED AT BRIGHTON.

BI

\section{GIDEON MAN'TELL, LL.D. F.R.S.}

FELLOW OF TIP ROYAL, COLLEOE OF SURGEONS ;

AND OF TIF LINNEAN AND GEOLOGICAL SOCIETIES OF LONDON ANI CORNWAL; HOXORARY MEMIER OF THE PIILOMATHIC SOCIETY OF PAHIS;

GF THE ACADEMIES OF NATURAL SCIENCES OF PIILADELPIIA; AND OF AITS ANI SCIFNCES OF CONNECTICUT; OF THE GEOLOGICAL SOCIETY OF PENNSYLVANIA;

OF THE PHILOSOPHICAL INSTITUTION ON BOSTON

OF THE HISTORICAL SOCIETY OF QUEBEC ; AND OF TIE PHIIOSOIIICAL, SOCIETIES OF YORK, NEWCASTLE, ETC.

FROM NOTES TAKEN BY G. F. RICHARDSON, CURATOR OF THE MaNTELLAN MUSEUM, ETC.

VOL. I.

LONDON :

RELFE AND FLETCHER, CORNHILL. 

THE RIGHT HONOURABLE:

\title{
GEORGE EARL OF MUNSTER,
}

\author{
F.R.S. F.G.S. Sc. \&c.
}

AS A TRIBLTE OF TIE HIGHEST RESPECT ANT REGARD,

\section{可施若}

13Y IIIS I.ORDSHIP's

MOST DEVOTED SERVAXT,

GIDEON ALGERNON MANTELI.

Clat il Common,

Feb. 27, 1838. 



\section{ADVERTISEMENT.}

TuIs Publication has originated in the wish expressed by Dr. Mantell's anditors, to possess a permanent record of his Lectures; while it has at the same time been conceived, that a work which should present a familiar exposition of the principles and discoveries of Geology, encumbered with no larger share of technical details than was absolutely required by the nature of the subject, would be acceptable to the public.

The Editor, in offering this explanation, fecls that he has discharged the duty imposed on lim by 
the slender tie which connects him with the work; the pearls which it offers are not his own; he has merely supplied the string which binds them together.

$$
\text { G. F. R. }
$$

Mantellian Museum, Brighton. 


\title{
TABLE OF CONTENTS.
}

\author{
VOL. I.
}

\section{LECTURE I.}

1. Introductory Remarks. 2. Value of Scientific Pursuits. 3. Importance of Geology. 4. Naturc of Geology. 5. Harmony hetwcen Revelation and Gcology. 6. Extensive Duration of Gcologrical Periods. 7. Object of the Prescnt Course of Lectures. 8. Physical Gcography of the Eartl. 9. Geograplical Distribution of Animals. 10. Oi Vegetables. 11. Temperature of the Globc. 12. Niture of the Crust of the Eartli. 13. Composition of the Rocks and Strata. 14. Former Classification of Rocks. 15. Gcological Mutations. 16. Connexion of Geology with Astronomy. 17. Ncbular Theory of the Universe. 18. Formation of the Solar System. 19. Gascous State of the Eartl. 20. Meteorite. 21. Existing Geological Changes. 22. Effects of Streams and Rivers. 23. Deltas of the Ganges, Mississippi, \&c. 24. Rippled Sand. 25. Lewes Levels. 26. Rcmains of Man in Alluvial Deposites. 27. Pcat Bogs. 28. Subterrancan Forests. 29. Geological Effects of the Sca. 30. Bed of the Occan. 31. Currents and their effccts. 32. Tufa-Incrusting Springs. 33. Incrustations not Petrifactions, 34. Lake of the Solfatara. 35. Marble of Tabreez, in Persia. 36. Stalactites and Stalagmites. 37. Grotto of Antiparos. 38. Consolidation of Lava and Loosc Materials. 39. Destruction of Rocks by Carbonic Acid Gas. 40. Carbonic Acid in Wells and Caverns. 41. Consolidation by Iron. 42. Coins and other Works of Art in Ferruginous Breccia. 43. Recent Limcstonc of Bernuda. 44. Human Skeleton of Guirdaloupe. 45. Impressions of Human Feet in Sandstone. 46. Conglomeratc of the Isle of Ascension. 47. Drifted Sands. 48. Sand-Flood and Recent Limcstones of Cornwall. 49. Silicious Deposits. 50. The Geysers. 51. Hertfordshire Breccia. 52. Effects of Higl Tcmperature. 53. Volcanic Agency. 54. Temple of Serapis. 55. Elevation of the Coast of Chili. 56. Lifted Beach at Brighton. 57. Rise of Scandinavia. 58. Retrospect. 


\section{LECTURE II.}

1. Introductory Observations. 2. Extinction of Animals. 3. Animals extirpated by Human Agency. 4. The Apteryx Australis. 5. The Dodo. 6. The Cervus megaceros, or Irish Elk. 7. Epoch of Terrestrial Mammalia. 8. Character of the Ancient Alluvial Deposites. 9. Classification of Organic Remains. 10. Comparative Anatomy. 11. Adaptation of Structurc. 12. Osteological Characters of the Carnivora. 13. Structure of the Herbivora. 14. The Rodentia. 15. Skull and Teeth of the Rodentia. 16. Fossil Bones. 17. Fossil Elephants and Mammoths. 18. Mammotll, and Rhinoceros, imbedded in Icc. 19. Teeth of Recent, and Fossil Elephants. 20. The Mastodon. 21. Mastodons found in the Burmese Empire. 22. The Sivatherium. 23. The Megatherium. 24. The Megalonyx. 25. The Sloths. 26. Fossil Hippopotamus, and Rhinoceros. 27. The Dinotherium. 28. Bones of Carnivora in Caverns. 29. Cave of Gaylenreuth. 30. Forster's Höhle. 31. Bones found in Caverns, in Great Britain.--Kirkdalc Cave. 32. Fossil Diseased Bones of the Carnirora. 33. IIuman Bones, Sc. in the Bone Caverns. 34. Osseous Brcccia in Fissures. 35. Rock of Gibraltar. 36. Caves in Australia. 37 . Retrospect ..................................... p. 101

\section{LECTURE III.}

1. Introduction. 2. Mincral Composition of Rocks. 3. Crystallization. 4. Stratification. 5. Inclined and Vertical Strata. 6. Veins and Faults. 7. Chronological Arrangement of the Formations. 8. Tertiary Deposites. 9. Mr. Lycll's Classification. 10. Fossil Shells. 11. Mincralngical Cliaracter of the Tertiary Rocks. 12. Newer Tertiary or Pliocene. 13. The Crag. 14. The Sub-Appennines. 15. Medial Tertiary or Miocenc. 16. Ancient Tertiary or Eocene. 17. Paris Basin. 18. London Basin. 19. Islc of Sheppey. 20. Fossil Fruits of Sheppcy. 21. Upper Marine Sand. 22. Artesian Wells. 23. Hampshire or Isle of Wight Basin. 24. Alum Bay. 25. London Clay of Hants. 26. Frcsh-Water Strata of the Isle of Wight. 27. Organic Remains of the English and Paris Basins. 28. Tertiary Fossil Plants. 29. Tertiary Shells. 30. Tertiary Cephalopoda. 31. Crustacea and Fisles. 32. Fossil Birds. 33. Cuvierian Pachydermata. 34. Palæotheria and Anoplotheria. 35. Fossil Monkey. 36. Tertiary Deposites of Aix in Provence. 37. Fossil Insects. 38. Lacustrine Formation of Ciningen. 39. Fossil Fishes of Monte Bolca. 40. Tertiary Volcanoes. 41. Crater of Puy de Come. 42. Mont-Dor. 43. Fresh-Water Limestonc. 44. Summary of Geological Phencmena of Auvergne. 45. Erosion of Rocks by Torrents. 46. Extinct Volcamoes of the Rline. 47. Brown Coal or Lignite. 48. Tertiary Deposites of North America. 49. Tertiary Strata of the Andes. 50. Salt Mines of Gallicia. 51. Retrospect. 


\section{LECTURE IV.}

1. Introductory Remarks. 2. Seeondary Formations. 3. The Chalk Formation. 4. Chalk and Flint. 5. Flint Nodules. 6. Sulphuret of Iron. 7. St. Peter's Mountain. 8. The Mosesaurus, or Fossil Animal of Maestrielit. 9. Organie Remains of the rhalk. 10. Fossil Flora of the Chalk. 11. Corals, Sponges, \&e. 12. liadiaria-Crinoidea. 13. Eehinites. 14. Shells of the Chalk. 15. Cephalopoda, and Chambered Shells. 16. Belemnite and Nautilus. 17. The Ammonite. 18. Spirolinites, 19. Infusoria in Flint. 20. Crustacea. 21. Fishes of the Chalk-Sharks. 22. Fossil Salmon, or Smelt. 23. Maeropoma and otller Fishes. 24. Reptiles. 25. Review of the Charaeters of the Clialk Formation. 26. Geology of the South-east of England. 27. Geologieal Phenomena between Louclon and Brighton. 28. The Wealden. 29. Wealden Strata on the Sussex Coast. 30. Pouneeford. 31. Sub-divisions and Extent of the Wealden. 32. Quarries of Tilgate Forest. 33. Rippled Wealden Sandstone. 34. Wealden of the Isle of Wight 35. Isle of Purbeek. 36. lsle of Portland. 37. Fossils of the Wealden. 38. Palms, Yueeas, and other Fossil Plants. 39. Shells of the Wealden. 40. Sussex Marble - Fossil Cypris. 41. Fishes of the Wealden. 42. Fossil heptiles of Tilgate Forest. 43. Turtles. 44. Plesiosaurus. 45. Crocodiles. 46. Swanage Croeodile. 47. Megalosaurus. 48. Discorery of the Iguanodon. 49. Maidstone Iguanodon. 50. Diseovery of the Hyleosaurus. 51. Flying Reptiles, or Pterodactyles. 52. Fossil Birds. 53. Country of the Iguanodon. 54. Sequenee of Geologieal Events. 55. Retrospeet of Geologieal Eras. p. 296 


\title{
TABLE OF CONTENTS.
}

\author{
VOL. II.
}

LECTURE V.

1. The Fauma of the Chalk. 2. Fauna of the Wealden. 3. Site of the Country of the Iguanodon. 4. The Medial Secondary Formations. 5. Oolite or Jura Limestone. 6. Tabular View of the Oolite and Lias. 7. Geographical Distribution of the Oolite and Lias. S. Stonesfield Slate. 9. Organic Remains of Stonesfield. 10. Fossil Didelphis. 11. Comparison between the Wealden and Stonesfield Fossils. 12. Lithographic Stone of Pappenlieim. 13. Coal and Carboniferous Strata of the Oolite. 14. Geographical Distribution of the Lias. 15. Organic Remains of the Oolite and Lias. 16. Mode of Petrifaction. 17. Saliferous or New Red Sandstone System. 18. Tabular Arrangement of the Saliferous System. 19. Geographical Distribution. 20. Cheltenham Waters. 21. Rock Salt, or Brine Springs. 22. Magnesian Lime. stone, or Zechstein. 23. Conglomerates of the New Red Sandstone. 24. Organic Remains of the Saliferous Group. 25. Spiriferæ. 26. Impressions of the Fcet of Birds and Quadrupeds. 27. Organization of Reptiles. 28. Turtles. 29. Fossil Turtles. 30. Crocodiles. 31. Iclithyosauri. 32. Plesiosauri. 33. Pterodactyles. 34. Fossil Salamander. 35. Fossil Lacertæ. 36. The Age of Reptiles. 37. Objections answered. 38. Concluding Observations........... p. $37 i$ 


\section{LECTURE VI.}

1. Introduction. 2. Organic and Inorganic Kingdoms of Nature. 3. Distinction between Animals and Vegctables. 4. Nervous System and Sensation. 5. Diversity of Animal Forms. 6. Ellis's Discovcries. 7. Sponge. 8. Cilia, or Vibratile Organs. 9. Flustra. 10. Food of Infusoria. 11. Mode of Increasc of Flustra. 12. Skeletous of Polypi, or Corals. 13. Variety of Form and Structurc of Corals. 14. Geographical Distribution of Corals. 15. The Sea-Mat. 16. Sertularix, or Vesicular Corallines. 17. Gorgonia, or Sea-Fan. 18. The Red Coral. 19. T'ubipora, or Organ-pipe Coral. 20. Madrepora. 21. Actinia, or Sea-Anemone. 22. Caryophillia, \&c. 23. Fungia. 24. Astrea and Pavonia. 25. Meandrina, or Brain-Coral. 26. Corals as seen alive in the Sea. 27. Coral Reefs. 28. Coral Recf of Loo Choo. 29. Coral Islands. 30. Montgomery's Description. 31. Fossil Zoophytes. 32. Zoopliytes of the Chalk. 33. Zoophytes of the Shanklin Sand. 34. Corals of the Oolite. 35. Corals of the Older Sccondary Formations. 36. Coralline Marbles. 37. The Crinoidea, or Lily-shaped Animals. 38. Structurc of the Skeletons of Crinoidca. 39. The Lily Encrinite. 40. Pear Encrinitc of Bradford. 41. Derbyslinc Encrinital Marble. 42. Geological Distribution of the Crinoidea. 43. Concluding Remarks p. 445

\section{LECTURE VII.}

1. Introduction. 2. The Carboniferous System. 3. The Coal Measures. 4. Coal-field of Derbyshire. 5. Coalbrook Dale. 6. Coal-sliale and Vegetable Remains. 7. Mountain, or Carbonifcrous Limestone. 8. Derbyshire Lead Mines. 9. Old Red Sandstonc. 10. Geographical Distribution of the Carboniferous Strata. 11. Volcanic Rocks of the Carboniferous Epoch. 12. Organic Remains. 13. Vegetable Struc. ture. 14. Coniferous Trees. 15. Climate and Seasons indicated by Fossil Wood. 16. Vertical Trees in Carboniferous Strata. 17. Vcrtical Trees in Englisl Coal Mines. 18. Trees in Craiglcith Quarry. 19. Sections of Fossil Wood. 20. Coal. 21. Mineral Oil, Naphtha, Petroleum. 22. Bitumen, Ambcr, Mellite. 23. 'The Diamond. 24 Anthracite, Kilkenny Coal, Plumbago. 25. Pctrifaction. 26. Artificial Petrifactions. 27. Stagcs of the Pctrifactivc Proccss. 28. Hazel Nuts filled with Spar. 29. Silicification. 30. Plants of the Coal. 31. Fossil Mare's-tail. 32. Fossil Fcrns. 33. Sigillaria. 34. Lcpidodendron. 35. Fossil Lycopodium, or Club-moss. 36. Stigmaria, 37. Seed-vessels in Coal. 38. Coniferæ. 39. The Carbonifcrous Flora. 40. Modern Formations of Coal. 41. Corals and Crinoidca. 42. Mollusca of the Carboniferous System. 43. Crustacea. 44. Limulus, or King-crab. 45. Trilobites. 46. Eycs of Trilobitcs. 47. Insects of the Coal. 48. Fishes of the Carboniferous System. 49. Rctrospective Summary of the Flora of the ancient World p. 520 


\section{LECTURE VIII.}

1. Introductory Remarks. 2. The Silurian System. 3. The Cambrian Slate System. 4. Organic Remains of the Transition Series. 5. Slate and Greywacke. 6. Metamorphic, or Primary Rocks. 7. Micaschist, and Gneiss. 8. Granite. 9. Volcanic Agency. 10. Vesuvius. 11. Modern Eruptions of Vesuvius. 12. Volcanic Products of Vesuvius. 13. Etna. 14. Phlegrean Fields-Lipari Isles. 15. Volcano of Kirauea. 16. Stewart's Visit to the Volcano of Kirauea. 17. Earthquakes. 18. Volcanic Isle in the Medicerranean. 19. Organic Remairs beneath Lava. 20. Ice preserved by red-hot Lava. 21. Herculaneum and Pompeii. 22. Silliman on the Nature of Geological Evidence. 23. Basalt, or Trap. 24. Staffa-Fingal's Cave. 25. The Giants' Causeway. 26. Rocks altered by contact with Basalt. 27. Granite Veins. 28. Metamorphic Changes in Rocks. 29. Metalliferous Veins. 30. Copper Ore of New Brunswick. 31. The Sapphire, Ruby, and Emerald. 32. Review of the Silurian and Slate Systems. 33. Review of the Metamorphic Rocks. 34. Organic Remains in Primary Rocks? ? 35. Relative Age of Mountains. 36. Changes in the Animal and Vegetable Kingdom. 37. Successive Development of Animals and Vegetables. 38. Geological Effects of Mechanical and Chemical Action. 39. Geological Effects of Vital Action. 40. General Inferences. 41. Final Causes. 42. Astronomical Relation of the Solar System.-Conclusion ......................... p. 602 


\section{WONDERS OF GEOLOGY.}

\section{LECTURE I.}

1. Introductory Remarks. 2. Value of Scientific Pursuits. 3. Importance of Geology. 4. Nature of Geology. 5. Harmony between Revelation and Gcology. 6. Extensive Duration of Geological Periods. 7. Object of the Present Course of Lectures. 8. Physical Geograplyy of the Earth. 9. Geographical Distribution of Animals. 10. Of Vegetables. 11. Temperature of the Globe. 12. Nature of the Crust of the Eartli. 13. Composition of the Rocks and Strata. 14. Former Classification of Rocks. 15. Geological Mutations. 16. Connexion of Geology with Astronomy. 17. Nebular Theory of the Universe. 18. Formation of the Solar Systcm. 19. Gaseous State of the Earth. 20. Meteorite. 21. Existing Gcological Changes. 22. Effects of Streams and Rivers. 23. Dclta of the Ganges, Mississippi, \&ic. 24. Rippled Sand. 25. Lewes Lcvels. 26. Remains of Man in Alluvial Deposits. 27. Peat Bogs. 28. Subtcranean Forests. 29. Geological Effects of the Sea. 30. Bed of the Occan. 31. Currents and their effects. 32. Tufa-Incrusting Springs. 33. Lake of the Solfatara. 34. Marble of Tabreez, in Persia. 35. Stalactites and Stalagmites. 36. Grotto of Antiparos. 37. Consolidation of Lava and Loose Materials. 38. Destruction of Rocks by Carbonic Acid Gas. 39. Carbonic Acid in Wells and Caverns. 40. Consolidation by Iron. 41. Coins and other Works of Art in Ferruginous Breccia. 42. Recent Limestone of Bermuda. 43. Human Skeleton of Guadaloupe. 44. Impressions of Human Feet in Sandstone. 45. Conglomerate of the Isle of Ascension. 46. Drifted Sands. 47. Sand-Flood and Recent Limestones of Cornwall. 4S. Siliceous Deposits. 49. The Geysers. 50. Hertfordshire Brccia. 51. Effects of High Tempcrature. 52. Volcanic Agency. 53. Temple of Serapis. 54. Elevation of the Coast of Clili. 55. Lifted Beach at Brighton. 56. Rise of Scandinavia. 57. Retrospect.

\section{Introductory Remarks.-Having for many} years made fossil comparative anatomy my principal relaxation from the toils of a laborious and 
extensive medical practice, the collection of organic remains which I had formed in the course of a considerable period, began to acquire an European celebrity through the writings of Cuvier, Brongniart, Humboldt, and other eminent savans, who had honoured my discoveries by their favourable notice. During the summer months, visitors to my collection became so numerous that I was compelled to limit the admission of strangers to certain days, when all were gratuitously admitted. This method was continued when I first took up my residence in Brighton; but a perseverance in this plan was soon found impracticable, from the impossibility of restricting visitors to the appointed hours : I was, therefore, obliged to close my collection to the public,-and hence the origin of the Sussex Royal Institution. As, prior to its establishment, I lrad, in compliance with the wishes of my friends, given several lectures on Geology, for charitable purposes, I was induced to undertake the delivery of discourses on the same subject, in the hope of promoting the interests of the infant Society. In conformity with this arrangement, I now enter upon the present course, which is designed to offer a familiar exposition of the philosophy of Geology. And permit me to observe, that my career as a lecturer will begin and end in Brighton; for at the termination of this session, should Providence allot me life and health, I shall remove to a less public, but not less important sphere of usefulness. 
2. Value of Scientific Pursuits.-It has been observed by a distinguished divine, that in order to obtain a proper sense of the importance of any science, and of the worth and beauty of the objects it embraces, nothing more is necessary than the intent and persevering study of them ; and that such is the consummate perfection of all the works of the Creator, that every inquirer discovers a surpassing worth, and grace, and dignity, in that special department to which he has peculiarly devoted his attention. Whatever the walk of philosophy on which he may enter, that will be the path, which of all others will appear to him the most enriched, by all that is fittcd to captivate the intellect, and excite the imagination. "Yet before we can attain that elevation from which we may look down upon and comprehend the mysteries of the natural world, our way must be steep and toilsome, and we must learn to rcad the records of creation in a strange language. But when this is once acquired it becomes a mighty instrument of thought ; enabling us to link together the phenomena of past and future times, and giving the mind a domination over many parts of the natural world, by teaching it to comprehend the laws, by which the Crcator las ordained that the actions of material things shall be governed."

3. Importance of Geology.-In the whole circle of the sciences, there is perhaps none that more strikingly illustrates the force and truth of these remarks, than geology; none whose language 
is more mysterious, yet which offers to its votaries rewards so rich, so wondrous, and inexhaustible. In the shapeless pebble that we tread upon, in the rude mass of rock or clay, the uninstructed eye would in vain seek for novelty or beauty; like the adventurer in Arabian story, the inquirer finds the cavern closed to his entrance, and the rock refusing to give up the treasures entombed within its stony sepulchre, till the talisman is obtained that can dissolve the enchantment, and unfold the wondrous secrets which have so long lain hidden.

4. Nature of Geology.-Geology may be termed the physical history of our globe,-it investigates the structure of the planet on which we live, and explains the characters and causes of the various changes in the organic and inorganic kingdoms of nature. It has been emphatically called, by the most eminent philosopher of our time, the sister science of Astronomy. But, relating as it does to the history of the past, and carrying us back, by the careful examination of the relics of former ages, to periods so remote as to startle all our preconceived opinions of the age of our globe, the fate of its early cultivators has resembled that of the immortal Galileo and the astronomers of his time; and for a similar reason, namely, the supposer discrepancy between the discoveries and inferences of science, and the Mosaic cosmogony.

.5. Harnony between Revelation and GeoLoGY.-There was a time when every geologist was 
called upon to defend himself against imputations of this kind; but a more enlightened era has arrived, and it is unnecessary to allude to the circumstance, except to assure those who for the first time are called upon to follow the researches of the astronomer and the geologist, that in proportion as their minds become acquainted with the principles of scientific investigation, their apprehensions of any collision between the discoveries in the natural world, and the inspired record, will disappear. With regard to geology, I will content myself, on this occasion, with the following extract from the sermons of an eminent prelate, the Bishop of London: "As we are not called upon by Scripture to admit, so neither are we required to deny the supposition, that the matter without form, and void, out of which this globe of earth was framed, may hare consisted of the wrecks and relics of more ancient worlds, created and destroyed by the same Almighty Power, which called our world into being, and will one day cause it to pass away." *

Thus, while the Bible reveals to us the moral history and destiny of our race, and teaches us that man and other living things have been placed but a few thousand years upon the earth, the physical monuments of our globe bear witness to the same truth; and as astronomy unfolds to us myriads of worlds, not spoken of in the sacred records, geology

* Sermons, by Dr. Charles James Blomfield, Bishop of London. 8vo. 1829 . 
in like manner proves, not by arguments drawn from analogy, but by the incontrovertible evidence of physical phenomena, that there were former conditions of our planet, separated from each other by vast intervals of time, during which this world was teeming with life, ere man and the animals which are his cotemporaries, had been called into being.

6. Extensive Duration of Geological PeRIODs.-At the first step we take in geological inquiry, we are struck with the immense periods of time which the phenomena presented to our view must have required for their production, and the incessant changes which appear to have been going on in the natural world: but we must remember that time and change are great only with reference to the faculties of the being which notes them. The insect of an hour, contrasting its own ephemeral existence with the flowers on which it rests, would attribute an unchanging durability to the most evanescent of vegetable forms; while the flowers, the trees, and the forests would ascribe an endless duration to the soil on which they grow: and thus, uninstructed man, comparing his own brief earthly existence with the solid framework of the world he inhabits, deems the hills and mountains around him coeval with the globe itself. But, with the enlargement and cultivation of his mental powers, he takes a more just, comprehensive, and enlightened view of the wonderful scheme of creation; and while in his ignorance he imagined that the duration of the globe 
was to be measured by his own brief span, and arrogantly deemed himself alone the object of the Almighty's care, and that all things were ereated for his pleasure or his neeessities; he now feels his own dependenee, entertains more eorreet ideas of the mercy, wisdom, and goodness of the Creator; and, while exercising his high privilege of being alone capable of eontemplating and understanding the wonders of the natural world, he learns that most important of all lessons, - to doubt the evidence of his senses until confirmed by cautious and patient investigation.

7. Object of the present Course of LecTURES. - With these introductory remarks I proceed to the consideration of the subjects selected for the present lecture. And here I would observe, that, from the magnitude and diversity of the objects embraced by Geology, it is scarcely possible to offer, in the brief space assigned to a course of popular lectures, even an epitome of the wonders which modern Geology has brought to light. Let this consideration therefore be my apology for the hasty or imperfect manner in which many interesting phenomena may perhaps be noticed; and let me also beg of you to consider that lectures of this kind are intended to excite, rather than to satisfy, a rational curiosity; that they are designed to promote a taste for philosophical pursuits, but cannot supersede the necessity of study and of personal investigation. 
8. Physical Geography of the Earth.The globe we inhabit may be described as a planetary orb of a few thousand miles in circumference, and of a spheroidal shape; its figure being such as a body in a fluid state, and made to rotate on its axis, would assume. Its mean density is five times greater than that of water, its interior being double that of the solid superficial crust: the internal part of the earth, if cavernous, must therefore be composed of very dense materials. Its surface is computed to contain 190 millions of square miles, of which threefiftlis are covered by seas; another large proportion by vast bodies of fresh water, and by polar ice and eternal snows; so that taking into consideration sterile tracts, morasses, $\mathcal{E}$ c., scarcely more than onefifth of the surface of the globe is fit for the habitation of man and terrestrial animals.* The area of the Pacific Ocean alone is estimated as equal to the entire surface of the dry land. The distribution of the land is exceedingly irregular, the greater portion being situated in the northern hemisphere, as a reference to a map of the earth will clearly demonstrate. In a geological point of view, dry land can only be considered as so much of the crust of the eartl as is above the level of the water, beneath which it may again disappear. From accurate cal. culations it is inferred that the present land might be distributed over the bed of the ocean, in such manner

* Bakewell's Geology. 
that the surface of the globe would present an uninterrupted sheet of water. We perceive, then, that every imaginable distribution of land and water may take place; and consequently, every variety of organic life may find at different periods suitable abodes.

9. Geographical Distribution of AniMALS.-An investigation of the laws which govern the distribution of animals and vegetables is an inquiry of deep interest; but my limits compel me to be brief, and as Mr. Lyell has treated the subject in his accustomed lucid and masterly manner, I beg to refer you to the third volume of his "Principles of Geology," for more ample details. It will be sufficient for my present purpose, to state that although it might have been expected that, all other circumstances being equal, the same animals and plants would have been found in places of like climate and temperature; yet this identity of distribution does not exist. When America was first discovered, the indigenous quadrupeds were all dissimilar to those of the old world. The elephant, rhinoceros, hippopotamus, giraffe, camel, horse, buffalo, lion, tiger, \&c. were not met with on the new continent; while the American species of mammalia, as the llama, jaguar, paca, coati, sloth, \&c. were unknown in the old. New Holland contains, as is well known, a most singular assemblage of mammalia, consisting of more than forty species of marsupial animals, of which the kangaroo is a familiar example. The islands of the Pacific Ocean 
contain no quadrupeds except hogs, dogs, rats, and a few bats.

10. Geographical Distribution of VegeTABLES.-The distribution of vegetable life, although perhaps more arbitrarily fixed by temperature and by local influences than that of animals, presents many anomalies. From numerous observations it appears that vegetable creation took place in different centres, each being the focus of a peculiar species; for many plants have a local existence, and vegetate spontaneously in one district alone. The cedar of Lebanon is indigenous to that mountain, and does not grow spontaneously in any other part of the world. But it will be sufficient in this place to observe, that certain great divisions of the vegetable kingdom are distributed in certain regions; we shall have occasion to refer to this subject in the lecture devoted to the consideration of Fossil Botany.

11. Temperature of time Earth.-The temperature of the globe is materially influenced by solar light and lieat; and hence the difference of the seasons and of the climates of various latitudes. But there are also local causes, which occasion great variations in its superficial temperature; yet under equal circumstances the temperature decreases from the tropics to the pole. There is also an internal source of heat, the cause of which lias not yet been ascertained, but is probably dependant on the original constitution of our planet. 
12. Nature of the Crust of tine Eartir.The greatest thickness of the superficial crust of the globe, that is, of the mass of solid materials which the ingenuity of man has been able to examine, is estimated at about ten miles; this calculation extending from the highest mountain peaks to the greatest natural or artificial depths. As the earth is nearly eight thousand miles in diameter, the entire series of strata hitherto explored, is but very insignificant compared with the magnitude of the globe; bearing about the same relative proportion as the thickness of the paper which covers an artificial sphere, a foot in diameter. The inequalities and crevices in the varnish of such an instrument, would be equal in proportionate size to the highest mountains and deepest valleys in the world. In this diagram* (copied from Mr. De la Beche's admirable work) the proportions are well displayed : thus a line of an inch in breadth in the circle before you, represents a thickness of the external crust of the earth equal to 100 miles; and these fine lines in the margin, the altitude of the Alps, the Andes, and the Himalayeh Mountains, the highest in the world. As a thickness of 100 miles exceeds by ten times that of the whole of the strata that are accessible to human observation, we can understand how disturbances of the earth's surface, even to ten

* To preserve as far as possible the language and spirit of the original discourses, the references to diagrams and specimens are retained.-G. F. R. 
times the depth of any of those which come within the reach of our examination, may take place, without in any sensible degree affecting the entire mass of the globe. If these facts be duly considered, the mind will be prepared to receive one of the most startling propositions in modern geology-namely, that the highest mountains have once been at the bottom of the sea, and have been raised to their present situations by subterranean agency,-some gradually, others suddenly, but all, geologically speaking, at a comparatively recent period.

13. Composition of the Rocks and Strata. - The materials which compose the superficial crust of the earth, consist of numerous layers and masses of earthy substances; of which combinations of iron, lime, and silex (or the earth of flint), constitute a large proportion, the latter forming forty-five per cent. of the whole. Those which have been deposited the latest bear evident marks of mechanical origin, and are the water-worn ruins of older rocks; as we descend, strata of a denser character appear, which also exhibit proofs of having been deposited by water; but when we arrive at the lowest in the scale, a crystalline structure uniformly prevails; and while in the former strata trees, plants, shells, bones, and other remains of animals and vegetables are found in profusion, in the lowermost rocks all traces of organic life are absent.

14. Classification of Rocks.-In the infancy of the science these remarkable phenonena gave 
rise to an ingenious theory, which however, like all theories founded on insufficient data, has proved untenable. Still it may be convenient to notice the hypothesis, since the terms employed are still retained in the nomenclature of Geology. Agreeably to this theory, the mineral masses of which the crust of the earth is formed, are separated into three groups.

1st. The Primitive (now called Primary) Rocks; such as granite, sienite, porphyry, \&c.: these are of crystalline structure, and evidently owe their present state to igneous agency. They are the lowermost rocks, and constitute the foundation, as it were, on which all the newer strata have been deposited; they also rise to the highest elevations on the surface of the globe. They were called primitive, because it was inferred, from the entire ab. sence of organic remains, that they had been formed before the creation of animals and vegetables; but it is now clearly ascertained that granite and its associated rocks are, in fact, lavas of various ages.

2d. The Transition Rocks. These are superimposed on the primitive, and are more or less distinctly stratified-that is, are separable into layers, and contain the fossilized remains of animals, corals, plants, and shells. They were called transition, because it was assumed that they had been formed at the period when the surface of the earth and the seas were passing into a state fit for the reception of 
organized beings. Modern researches have however proved that they are strata altered by the effects of heat under high pressure.

3d. The Secondary. These have clearly originated from the destruction of the more ancient rocks, and have been deposited in hollows and depressions, by the action of rivers and seas. They abound in the mineralized remains of animals and plants; the most ancient enclosing zoophytes and shells; the next in antiquity containing, in addition, vegetable remains and fishes; those which succeed enveloping not only fishes, shells, zoophytes, and plants, but also bones of enormous reptiles. The chalk is the uppermost, or most recent of this class of strata. As the secondary rocks have manifestly been formed by the agency of water, it is clear that they were originally deposited in horizontal, or nearly horizontal layers or strata, although by far the greater portion lave been broken up, and now lie in directions more or less inclined to the horizon.

For the convenience of study, this subdivision of the deposits is still retained, as will be hereafter shown. To the above groups modern geologists have added a fourth class.

4th. The Tertiary.* These lie in hollows or basins of the clialk, and other secondary rocks, and are formed of the detritus of the ancient beds. They abound in shells, plants, zoophytes, crustacea,

* See Plate VI. Fig. 3. 
fishes, \&c.; and in them, with but one exception, the bones of mammalia first appear.

Of a later formation than the tertiary strata, are those accumulations of water-worn materials, which the surface of every country presents more or less abundantly. These are termed diluvial deposits; and in them arc found the remains of existing species of animals, associated with those of others that are no longer. to be met with on the face of the eartl.

Even this slight examination of the strata affords convincing proofs of a former condition of aninated nature, widely different from the present. We have evidence of a succession of periods of unknown duration, in which both the land and the sea teemed with forms of existence that have successively disappeared and given place to others; and these again to new races, approaching gradually more and more nearly to those which now inhabit the earth, till at length existing species make their appearance.

15. Geological Mutations.-From this view of the physical structure of our planet we learn, at least so far as the limited powers of man can penetrate into the history of the past, that the distribution of land and water on its surface has been undergoing perpetual mutation; yet, that through countless ages the physical condition of the earth has not materially differed from the present; that the dry land has been clothed with vegetation, and tenanted by appropriate inhabitants; and that the sea and the bodies of fresh water have swarmed with living 
forms; that at a remote epoch, though animal and vegetable life existed, the species were wholly different from any that now abound, and of a nature fitted to live in a temperature much higher, and more equally distributed, than could occur in the present state of the earth; and lastly, that in the inferior, or most ancient beds, all traces of mechanical action, and of animal and vegetable organization, are absent; or in other words, have either never existed, or have been altogether obliterated. Before entering upon the division of these discourses to which the term Geology is commonly restricted, it will facilitate our comprehension of many of the phenomena which the strata present to our notice, if in this place we endeavour to penetrate the mystery that veils the earliest condition of the earth; and which we shail in vain attempt, if our observations are confined to our own planet.

16. Connexion of Geology with Astronomy. - Here Geology conducts us to Astronomy, and teaches us to look to the kindred spheres around us, for the elucidation of the early history of our globe; and to consider our planet but as an attendant satellite on a vast central luminary. The solar system consists of the sun, whose mass is made up of matter like our earth, surrounded by a luminous atmosphere; and of eleven small planets, which revolve around it in various periods; our earth being the third in distance from the sun, and in bulk, as compared with that body, of the size of a pea to 
that of a globe two feet in diameter: and with a satellite, the moon, revolving round it. Upon examining the moon with powerful telescopes, we are enabled to ascertain that its surface is diversified by hill and valley; that it is a congeries of mountains, many of which are manifestly volcanic, some of the lava currents being distinctly visible. We have in fact a torn, crateriform, and disturbed surface, like that which we may conceive to have been presented by our earth, ere the pinnacles of the granite mountains were abraded, and the valleys neither smoothed nor filled up by the agency of water.* In Venus and Mercury the mountains appear to be enormous; while in Jupiter and Saturn there are but slight traces of any considerable elevations.

17. Nebular Theory of the Universe.Modern Astronomy instructs us that in the original condition of the solar system, the sun was the nucleus of a nebulosity or atmosphere, which revolved on its axis, and extended far beyond the orbits of all the planets; the planets as yet having no existence. Its temperature gradually diminished, and becoming contracted by cooling, the rotation increased in rapidity, and zones of vapour or nebulosity were successively thrown off, the centrifugal force overpowering the central attraction; the condensation of these separated masses constituting the planets and satellites. But this view of the conversion of gaseous matter

* See Appendix A. 
into planetary bodies is not limited to our own system; it extends to the formation of the countless myriads of suns and worlds which are distributed throughout the universe! The sublime discoveries of Sir Wm. Herschel have shown us that the realms of space abound in nebulous bodies in every varied condition, from that of a diffused nebulosity to suns and worlds like our own. It must be admitted that this assertion appears astounding,-and that it may fairly be asked if man, the ephemeron of the material world, can measure the mighty epochs which mark the progressive development of suns and systems? The genius of Herschel has effected this wonderful achievement, and has explained the successive clianges by which, through the agency of the eternal and unerring laws of the Almighty, suns and worlds are called into existence. By laborious and unremitting observations, that distinguished astronomer, and his no less gifted son, have demonstrated the progress of nebular condensation,- - not indeed from the phenomena presented by a single nebula, (for the process can only become sensible through the lapse of hundreds, perhaps thousands, of years;) but by observations on the almost countless series of related, contemporaneous objects in every varied state of progression, from that of a cloud of luminous vapour, to the most dense and mighty orbs that appear in the firmament. As the naturalist in the midst of a forest would be unable by a glance to discover that the trees around him were in a state 
of progressive change; yet, by perceiving that there were plants in different states of growth, from the acorn just bursting from the soil to the lofty oak that stood the monarch of the woods, could readily, from the succession of changes thus at once presented to his view, ascertain the progression of vegetable life, although extending over a period far beyond his own brief existence: in like manner, the astronomer looks into the wonders of the heavens, and by a survey of the sidereal world is able, by careful induction from the varied condition of the heavenly bodies around him, to discover the succession of changes, which, as regards a single nebula, even the duration of our solar system might possibly be insufficient to solve. Thus it is that Herschel has traced, from nebular masses of absolute vagueness to others which present form and structure, the effects of the mysterious law which governs the stupendous stellular changes that are constantly taking place.

Some of these bodies appear as mere clouds of attenuated light—others as if curdling into separate masses - while many seem assuming a spheroidal figure. Others again present a dense central nucleus of light surrounded by a luminous halo; and a series unay thus be traced, from clusters of round bodies with increased central illumination, to separate nebulæ with single nuclei-to a central disk constituting a nebular star-and finally to an orb of light with a halo like our sun ? 
In the comets, those nebular bodies which belong to our own and other systems, we have evidence that even in the most diffused state of the luminous matter, the masses which it forms are subservient to the laws of orbicular motion: of which an interesting proof is afforded by Eucke's comet, that mere wisp of vapour, which in a period but little exceeding three years revolves around the central luminary of our own system. This beautiful theory of Herschel and La Place is followed out by an casy and evident process, through the formation of planets and satellites, and explains the uniform direction of their revolutions. Yet not only is it believed that such are the laws which the Creator has established for the maintenance and government of the universe, but it is satisfactorily shown, upon mechanical principles, that such nebulæ must of necessity produce planetary bodies.

18. Formation of the Solar System.-In our own system the formation of the planets and satellites is thus explained. The sun is a planetary body with a nebulous atmosphere, the central nucleus of a once extensive nebulosity. During the condensation of this nebula the planets were successively thrown off; the most distant, as Herschel, being the first or most ancient, followed by Saturn, Jupiter, the four asteroids, Mars, the Earth, Venus, and Mercury; the satellites, as distinct worlds, being the most recent of the whole. In explaining their formation, it is inferred that in any given state of 
the rotating solar mass, the outer portion or ring might have its centrifugal force exactly balanced by gravity; but increased rotation would throw off that ring, which might sometimes retain its figure, of which we have a beautiful example in Saturu. This result, however, would not take place unless the annular band were of uniform composition, which would rarely be the case; hence the ring would most generally divide into several portions: these might sonetimes be of nearly equal bulk, as in the asteroids; while in others they would coalesce into one mass. The solar nebulæ, thus thrown off at various periods, and constituting planets in a gaseous state, would each necessarily liave a rotatory motion, and revolve in varying orbits around the central nucleus; and as refrigeration and consolidation proceeded, each might throw off entire annuli, or rings, or satellites, in like manner as the planets themselves had been projected from the sun.-But I must not pursue this most interesting subject farther; those who feel desirous of more ample information may consult a highly popular abstract of the discoveries of modern astronomy, recently published, under the title of "Views of the Architecture of the Heavens." *

You will at once perceive that this theory can in no wise affect the inference that the universe is the work of an all-wise and omnipotent Creator. "Let

* By Dr. Nichol, Professor of Practical Astronomy in the University of Glasgow. 
it be assumed that the point to which this hypothesis guides us, is the ultimate boundary of physical science-that the nearest glimpse we can attain of the material universe, displays it to us occupied by a boundless abyss of brilliant matter; still we are left to inquire how space became thus occupiedwhence matter thus luminous? And if we are able to establish by physical proofs, that the first fact which the human mind can trace in the history of the heavens is, that 'there was light,' we are irresistibly led to the conclusion, that ere this could take place 'God said, Let there be light.' "

This theory of the condensation of nebular matter into suns and worlds, marvellous as it may appear, will be found on due reflection to offer the only rational explanation of the phenomena observable in the sidereal heavens, and in our own globe; and its beautiful simplicity is in correspondence with the unity of design so manifest throughout the works of the Eternal.

19. Gaseous State of the Earth.-Though the mind unaccustomed to philosophical inquiries, may find it difficult to comprehend the idea that this planet once existed in a gaseous state, this difficulty will vanish upon considering the nature of the changes that all the materials of which it is composed must constantly undergo. Water offers a familiar example of a substance existing on the surface of the globe, in the separate states of rock, fluid, and vapour; for water consolidated into ice 
is as much a rock as granite or the adamant, and, as we shall hereafter have occasion to remark, has the power of preserving for ages the animals and vegetables that may be therein imbedded. Yet, upon an increase of temperature, the glaciers of the Alps, and the icy pinnacles of the Arctic circles, disappear; and, by a degree of heat still higher, might be resolved into vapour; and by other agencies might be separated into two invisible gases-oxygen and hydrogen. Metals may in like manner be converted into gases; and in the laboratory of the chemist, all kinds of matter easily pass through every grade of transmutation, from the most dense and compact to an aeriform state. We cannot, tlierefore, refuse our assent to the conclusion, that the entire mass of our globe might be resolved into a permanently gaseous form, merely by the dissolution of the existing combinations of matter.

From the light thus shed by modern Astronomy upon many of the dark and mysterious pages of the earth's physical history, we learn that the dynamical changes which have taken place in our globe-all the wonderful transmutations of its surface revealed to us by geological investigations - may be referable to the operation of the one, simple, universal law, by which the condensation of nebular masses into worlds, through periods of time so immense as to be beyond the power of human comprehension, is governed. 
The internal heat of our globe-the evidence afforded by fossil organic remains of a more equally diffused and higher temperature of the surface in the earlier state of the earth-and the elevatory process that has taken place and is still in active operation-all refer to such an origin, and such a constitution of our planet, as that contemplated by the nebular theory. This elevatory process is not peculiar to our own planet; for, as we have elsewhere remarked, Venus, Mercury, the Moon, and perhaps the Sun itself, exhibit evidence of a similar action.* In a philosophical point of view, the present physical epoch of the earth "is that of the fluidity of water, which is the nebulous bed or stratum last condensed, and which exerts mechanical and chemical action upon the previously consolidated materials." $\dagger$

20. Meteorites. - Intimately connected with this division of our subject, is the remarkable phenomenon of the fall of foreign bodies, called meteorites or meteoric stones, on our earth. The specimen before me, for which I am indebted to my kind and distinguished friend, Professor Silliman, of Yale College, Connecticut, is the fragment of a mass which was seen to fall at Nanjenoy, in Maryland, North America, a few years since. The

* This subject is treated at large in the interesting work of M. De la Beche, entitled "Researches in Theoretical Geology."

$\uparrow$ Dr. Nichol. 
following description by an eye-witness of the descent of this body, will serve to illustrate the ordinary phenomena which attend the appearance of these mysterious visitors.*

"On the loth of February, between the hours of twelve and one o'clock, I heard an explosion, as I supposed of a cannon, but somewhat sharper. I inımediately advanced with a quick step about twenty paces, when my attention was arrested by a buzzing noise, as if something was rushing over my head, and in a few seconds I heard something fall. The time which elapsed from my first hearing the explosion to the falling, might have been fifteen seconds. I then went with some of my servants to find where it had fallen, but did not at first succeed; however, in a short time the place was found by my cook, who dug down to it; and a stone was discovered about two feet below the surface. It was sensibly warm, and had a sulphurous smell: was of an oblong shape, and weighed sixteen pounds and seven ounces. It lias a hard vitreous surface. I have conversed with many persons, living over an extent of perhaps fifty miles square: some lieard the explosion, while others heard only the subsequent whizzing noise in the air; all agree in stating that the noise appeared directly over their heads. The day was perfectly fine and clear. There was but one report heard, and but one stone fell, to $\mathrm{my}$ 
knowledge; there was no peculiar smell in the air : it fell within 250 yards of my house."*

That ornament and pride of her sex, Mrs. Somerville, has the following interesting remarks on this subject:- "So numerous are the objects which meet our view in the heavens, that we cannot imagine a part of space where some light would not strike the eye: innumerable stars-thousands of double and multiple systems-clusters in one blaze with their ten thousands of stars-and the nebulæ amazing us by the strangeness of their forms; till at last, from the imperfection of our senses, even these thin and airy phantoms vanish in the distance. If such remote bodies shone by reflected light, we should be unconscious of their existence; each star must then be a sun, and may be presumed to have its system of planets, satellites, and comets, like our own; and for aught we know, myriads of bodies may be wandering in space, unseen by us, of whose nature we can form no idea, and still less of the part they perform in the economy of the universe. Nor is this an unwarranted presumption: many such do come within the sphere of the earth's attraction, are ignited by the velocity with which they

* An analysis of this aerolite gave the following results :-

Oxide of Iron . . . . 24.

Nickel . . 1.25

Silica with earthy matter 3.46

Sulphur, a trace. 
pass through the atmosphere, and are precipitated with great violence to the earth. The fall of meteoric stones is much more frequent than is generally believed: hardly a year passes without some instances occurring; and if it bc considered that only a small part of the earth is inhabited, it may be presumed that numbers fall into the occan, or on the uninhabited parts of the land, unsecn by man. They are sometimes of great magnitude : the volume of several has exceeded that of the planet Ceres, which is about seventy miles in diameter. One which passed within twenty-five miles of us was estimated to weigh about six hundred thousand tons, and to move with a velocity of about twenty miles in a second-a fragment of it alone rcached the earth. The obliquity of the descent of meteorites, the peculiar substances of which they arc composed, and the explosion attending their fall, show that they are foreign to our planet. Luminous spots, altogether independent of the phases, have been seen on the dark parts of the moon; these appear to be the light arising from the eruption of volcanoes; whence it has been supposed that meteorites have been projected from the moon by the impetus of volcanic eruption. If a stone were projccted from the moon in a vertical line with an initial velocity of 10,992 feet in a second-a velocity but four times that of a ball when first discharged from a cannon-instead of falling back to the moon by the attraction of gravity, it would come within the 
sphere of the earth's attraction, and revolve around it like a satellite. These bodies, impelled either by the direction of the primitive impulse, or by the disturbing action of the sun, might ultimately penetrate the earth's atmosphere and arrive at its surface. But from whatever source meteoric stones may come, it is highly probable that they have a common origin, from the uniformity, we may almost say identity, of their chemical composition."*

Von Hoff, in an admirable essay on the origin of meteoric stones, $\downarrow$ observes, that although it is demonstrated mathematically, that aerolites and masses of native iron which fall from the air, may be derived from the moon, yet the weight of evidence is in favour of their being nebulous matter suddenly condensed, and which descends to this planet's surface when this mysterious process takes place within the sphere of the earth's attraction. These masses present a general correspondence in their structure and appearance, liaving (with the exception of native iron) a crystalline character internally, and a black slaggy crust externally, as is seen in this specimen from Nanjenoy.

Assuming then that our planet, when first called into being by the fiat of the Creator, was a gaseous mass "without form and void," and destined through countless ages to undergo mutations which were

* Connexion of the Physical Sciences, p. 423. 4th Edition.

$\uparrow$ A Translation of this Memoir appeared in Jameson's Edinburgh New Philosophical Journal, July 1 \$37. 
designed ultimately to prepare it for the abode of the human race, we proceed to investigate the causes and effects of those agencies by which its surface is still modified. The consideration of what Sir John Herschel so emphatically terms "that mystery of mysteries" - the first appearance of organic life on our globe, will be reserved for the concluding lecture.

21. Existing Geological Changes.-In this division of the subject, it will be my object to explain in a clear and familiar manner some of those physical changes which, unheeded or unappreciated, are taking place around us; and which, operating on a large scale, and through a long period of time, are capable of producing effects that materially modify the earth's surface, and give rise to phenomena which, when viewed in the aggregate, fill the uninformed mind with astonishment, and cause it to call up imaginary convulsions and catastrophes to explain the result of some of the most simple operations of nature. As the mere lines that compose the alphabet constitute, when placed in combination, the mighty engine by which the master spirits of our race enlighten and benefit mankind; so natural causes, in themselves apparently inadequate to produce any important effects, become, by their combined and continued operation, an irresistible power, converting the dry land into the bed of the ocean, and the bed of the ocean into dry land; thus fulfilling that universal law of the 
Creator, which subjects every particle of matter to alternate decay and renovation.

Before proceeding farther in this inquiry, I would notice an opinion, so generally prevalent that it may possibly be entertained by some present; namely, that the phenomena which will come under our consideration, have been produced by that miraculous event, the deluge recorded in Scripture. Now whatever may have been the modifications of the earth's surface produced by that catastrophe, they must on the present occasion be wholly excluded from our consideration; for, as we shall hereafter perceive, the changes to which geological inquiries relate are of a totally different character.

I have now to direct your attention to those natural operations which, when properly investigated, will afford an easy explanation of facts of the highest interest and importance; will teach us how this limestone has been formed of brittle shells, and this marble filled with the coral to which it owes its beautiful markings-how wood has been changed into stone; and plants and fishes have become enclosed in the solid rock. I wish to explain to you that the ground on which we stand was not always dry land, but once formed the bottom of a sea or an estuary-that the lills, now so smooth and rounded, and clothed with beautiful verdure, have been formed in the profound depths of the ocean, and may be regarded as vast tumuli, in which the remains of beings that lived and died in the early 
ages of the globe are entombed;-and that the weald of Kent and Sussex, that rich and cultivated district which fills up the area between the chalk hills of Sussex, Surrey, Kent, and Hampshire, was once the delta of a mighty river, that flowed through a country which is now swept from the face of the earth-a country more marvellous than any that even romance or poetry has ventured to pourtray.

22. Effects of Streams and Rivers.-In pursuance of this object I shall first take into consideration the action of running water-of streams, and rivers. I need not dwell on those meteorological causes by which the descent of moisture on the surface of the earth is regulated; but shall content myself with observing, that rivers are the great natural outlets which convey the superfluous moisture of the land, into the grand reservoir, the ocean. And so exactly is the balance of expenditure and supply maintained, that all the rivers on the face of the earth, though constantly pouring their mighty floods into the ocean, do not affect its level in the slightest perceptible degree. Hence we may assume that the quantity of moisture evaporated from the surface of the sea, is exactly equal to the sum of all the water, in all the rivers in the world. But although the body of fresl-water poured by the rivers into the basin of the sea is again displaced by evaporation, yet there is an operation silently and constantly going on, which becomes an agent of 
universal change. The rivulets issuing from the mountains are more or less charged with earthy particles, worn from the rocks and strata over which they flow: their united streams in their progress towards the rivers become more and more loaded with adventitious matter; and as the power of abrasion becomes greater, by the increase in the quantity and density of the mass of water, a large proportion of materials is mechanically or chemically suspended in the fluid, and carried into the bed of the ocean. If the current be feeble, much of the mud, and the larger pebbles, will be thrown down in the bed of the river-hence the formation of the alluvial plains in the valleys of the Arun, the Adur, the Ouse, and Cuckmere, in this county. But the greater portion will be transported to the mouths of the rivers, and there form those accumulations of the fluviatile spoils of the land which constitute deltas and estuaries; the finest particles, however, will be carried far into the sea, and, transported by currents and agitated by the waves, will at length be precipitated into the profound and tranquil depths of the ocean. But the waters convey not only the mud and water-worn materials of the country over which they flow: leaves, branches of trees, and other vegetable matter-and the remains of the animals that fall into the streams, with shells and other exuriæ-human remains, and works of art-are also constantly transported and imbedded in the mud, and silt, and sand of the 
delta; some of these remains being occasionally drifted out to sea, and deposited in its berl.

23. Deltas of the Ganges, and Mississippi. -The changes here contemplated, as they are going on in our own island, may appcar insignificant, and incapable of producing any material effect on the earth's surface; but if wc tracc the results in countries where these agents operate on a larger scale, we shall at once pcrccive their importance, and that time only is wanting, to form accumulations of strata, equal in extent, and of precisely the same characters with many of those ancicut deposites, which will hercafter come under our observation.

Mr. Lyell states, that from experiments made with great care, it has been ascertaincl that the quantity of solid matter brought down by the Ganges and carried into the sea annually, is cqual to $6,368,077,440$ tons : in other words, to a mass of solid materials, equal in weight to sixty of the great pyramids of Egypt; the base of the grcat pyramid being eleven acres, and the perpendicular height 500 fect. The Burrampooter, another river in India, conveys annually as much earthy matter into the sea as thc Ganges. The waters of the Indus, as the celebrated traveller, Captain Burns, informcd me, are alikc loaded with earthy materials.

In the mighty rivers of America, the same effects are observable; the immense quantities of trees brought down by the Mississippi and imbedded in 
its deposites are almost incredible, and the basin of the sea around the embouchure of that river, is becoming shallower every day, by the sole agency of the operation now under our consideration. In the sediments of these rivers, the animals as well as the plants of the respective countries are continually enveloped. It is therefore evident, that should these deltas become dry land, the naturalist could, on examination of the animal and vegetable remains imbedded in the fluviatile sediments, readily determine the characters of the fauna, and flora of the countries through which the rivers had flowed. We may here observe, that in tropical regions, where animal life is profusely developed, and but little under the control of man, the animal remains buried in deltas, are far more abundant than in those of European countries, which are thickly peopled, and in a high state of civilization. The enterprising, but unfortunate Lander informed me, just before he embarked on his last fatal expedition to Africa, that in many parts of the Quorra, or Niger, the bed of that river, so far as the eye could reach, teemed with crocodiles and hippopotami; and that so great was their number, that he was oftentimes obliged to drag his boat on shore lest it should be swamped by these animals. But it is unnecessary for me to dwell longer on these operations, which are so admirably elucidated in the work of my friend Mr. Lyell: it will suffice to have shown, that by the simple operation of running water, great destruction and 
modification of the surface of the land are everywhere taking place; and that at the same time, accumulations of fluviatile deposits are forming on an extensive scale, and enveloping animal and vegetable remains. Thus, in the deltas of the rivers of this country, we find the bones and antlers of the deer, horse, and other domesticated animals, with the trunks and branches of trees and plants, of our island, and river and land shells, and bones of man, and fragments of pottery, and other works of art: while in those of the Ganges, and the Nile, the remains of the animals and vegetables of India, and of Egypt, are respectively entombed.

There is one circumstance connected with these phenomena which it will be necessary here to consider. You well know that the quantity of water in streams and rivers, varies considerably at different periods of the year; that in the rainy season the bed of the river is overflowing, and the waters remarkably turbid: the depositions, therefore, must be much greater at those periods than in the summer months, when the streams are feeble, and the rivers shallow. We must also remember, that in that part of the rivers affected by the tides, there is a constant flux and reflux of the waters, and from these causes the depositions must, in a certain degree, be periodical. Accordingly we find them disposed in strata or layers, from the partial consolidation of the surface of one layer of mud, before the superincumbent layer was precipitated upon 
it.* Where a river terminates in an extensire estuary, the sea throws over the layer of mud brought down by the river, a covering of sand: and frequently these alternate with the greatest regularity, the receding of the tide allowing the fresh water to deposit its mud, and the advance of the sea discharging sand over the surface.

24. Rippled Sand.-And here we may notice another phenomenon. Every one must have observed, when walking by the banks of a river at low water, or on the sands of the sea-shore; that when the water has been agitated by the wind, the surface of the mud, or sand, is undulated, or furrowed over by the rippling of the waves; the ripple marks presenting various appearances, according to the force and direction of the currents. Frequently, too, the vcrmes, and molluscous animals, mark the surface with meandering lines, and ridges ; and these varied markings on the sand are preserved, if a thin pellicle of mud be deposited over them before the next advance

* An American gentleman, who risited Egypt in 1834, remarks, in a letter to my distinguished friend Professor Silliman, that wherever a fresh break takes place in a bank of consolidated mud, in the delta of the Nile, it is easy to trace the deposites of each successive year, hy means of the lighter earth on the top of each. When a portion is taken into the hand, it separates at those lines into layers; and on closely examining the edges of these, very delicate thin lines are perceptible, showing a laminated structure, like those observable in the coal-shales. Judging from these layers, the annual deposites appear to vary considerably, but the average thickness is little more than a quarter of an inch. 
of the waves. I shall have occasion to refer to these appearances hereafter. We must also remark that there are certain kinds of mollusca, or shell-fish, that can only live in fresh water; others that are confined to the sea; while a third class is restricted to the brackish waters of estuaries. Accordingly, in the deposites under our consideration, the river and estuary species are abundant, while the marine only occur as stragglers, and are comparatively rare. Land plants, and those which affect a marshy soil, as the equiseta or mare's-tails, reeds, and rushes, are likewise often accumulated in such quantities as to form beds of peat.

25. Lewes Levels. - It will serve to impress the subject more forcibly upon our minds if we refer to some local example of fluviatile deposites: and from its immediate vicinity to Brighton, I select the valley of the Ouse, between Newhaven and Lewes, which is one of several estuaries from whence the sea has retired within the last eight or ten centuries. This valley is bounded by an amplitheatre of chalk hills, the river enters it through a gorge of the Downs on the north, and, pursuing a tortuous course through the valley, discharges its waters at Newhaven. This alluvial plain is called Lewes Levels; and here and there is flanked by lieadlands, and ancient cliffs, while a few insular mounds of chalk rise up through the fluviatile depositions, which have been accumulating during a long period of time. The following diagram represents 
a section of the valley of the Ouse, from east to west.

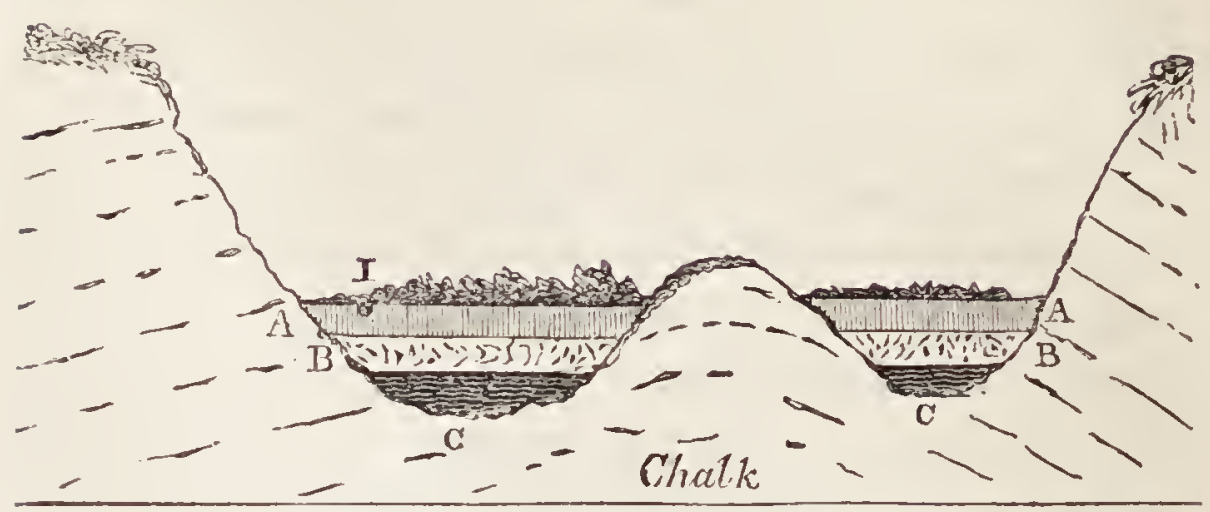

TAB. 1. Section of Lewes Letels.

Here we have a depression (or basin, as it is termed by geologists) of the chalk, partially filled up by layers of indurated mud or silt; the surface being clothed with verdure, and the bed of the river (I). situated near the eastern chalk cliffs. The deposits which repose on the chalk are as follows:-

A bed of peat about five feet in thickness: formed of decayed twigs and leaves of the hazel, oak, birch, \&c. enclosing trunks of large trees.

A.A.-Blue clay, or indurated mud, containing several species of fresh-water shells, like those which now inhabit the river or ditches; with numerous indusice, or cases of the larve of Phryganea, or caddis-wrorms. Bones of the horse, and deer, also occur in the lower part of this bed.

B. B.-Clay, containing fresh-water shells, with an intermixture of existing marine species, as the common cockle, (Cardium edule, ) tellina, \&c. 
C. C.-Blue clay, inclosing marine shells, viz. cockles, muscles, \&c. without any intermixture of fluviatile species. In this bed a skull of the narwal, or sea-unicorn (Monodon monoceros,) and porpoise have been discovered.

From the nature of these deposites we learn that this valley was once an arm of the sea, and that the following is the sequence of the physical changes which have taken place :-

First, There was a salt-water estuary, inhabited by marine shell-fish of the same species as those now existing in the British Channel; and into this estuary Cetacea occasionally entered.

Secondly, The inlet grew shallower, the water brackish, and marine and fresh-water shells were mingled in its blue argillaceous sediment.

Thirdly, The shoaling continued until fresh-water so much predominated, that fluviatile shells, and aquatic insects, could alone exist.

Fourthly, A peaty swamp, or morass was formed, by the drifting of trees, and plants, from the forest of Andreadswald, which formerly occupied the weald of Sussex; and terrestrial quadrupeds were occasionally imbedded.

Lastly, The soil, being inundated by the land floods only at distant intervals, became a verdant marshy plain.*

* See Mr. Lyell's Principles of Geology, fifth edition, vol. III. p. 265. Geology of the South-east of England, p. 16. 
26. Remains of Man in Modern Allu. viuM.-But the fluviatile deposites in the river valleys of the South Downs often contain not only the bones of the deer, horse, boar, and other terrestrial animals, but also human skeletons, sometimes in coffins of exceedingly rude workmanship; and canoes, * and other remains of the early inhabitants

* Ancient British Canoe. In 1835 a canoe was discovered at the depth of several feet in a bed of silt, occupying an ancient branch of the river Arun, at North Stoke, near Arundel. It has been presented, by my noble friend the Earl of Egremont, to the British Museum; and is placed on the right hand of the entrance of the court. This canoe is nearly thirty-five feet in length, four and a half wide in the centre, three feet three inches broad at one extremity, and two feet ten inches at the other; and is about two feet deep. It is formed of the single trunk of an oak, which has been hollowed out and brought to its present shape with great labour; it is evidently the workmanship of a very early period, and in all probability was constructed by some of the earliest inhabitants of our island, before the use of iron or even brass was known: the original tree must have been fifteen or sixteen feet in circumference. Three projections, left in the interior of the boat, appear to have been designed for seats; it is manifest therefore that the persons who constructed this vessel were unacquainted with the art of forming boards. This canoe is so similar to some of those which were fabricated by the aborigines of North America, when first visited by Europeans, that we can have no hesitation in concluding that it was constructed in a similar manner; namely, by charring such portions of the tree as were to be removed, and scooping them out with stone instruments: no doubt this canoe belongs to the same period as the flint and stone instruments called celts, which are found in the tumuli on the South Downs; it is now in the state of peat or bog-wood. 
of our island. This human skull, for which I am indebted to my intelligent friend, Warren Lee, Esq. of Lewes, was dug up at a great depth in the blue silt of Beeding Levels; it was inclosed, together with the other bones of the skeleton, in a coffin of oak, which was evidently of high antiquity, being formed of four planks, or rather squared trunks of trees, held together by oaken pegs. This skull is of a dark bluish-brown colour, like the bones of the deer and horse of similar dcposites. This appearance is owing to an impregnation of iron; when first dug up, blue phosphate of iron filled up the interstices of the bones. "The state of the teeth is remarkable; they are worn down almost smooth, although the individual must have been in the prime of life; a fact which seems to indicate that grain, or some other hard substances, constituted a large proportion of his customary food.

27. Peat Bogs.-Before proceeding to the next subject, I will advert to those extensive accumulations of vegetable matter called Peat Bogs; which are morasses, covered with successive layer's or beds of mosses, reeds, equiseta, rushes, and other plants that affect a marshy soil; and in particular of a kind of moss, the Sphagnum palustre, which generally constitutes a large proportion of the entire mass. The beds of peat are annually augmented by the peculiar mode of increase of the peat-moss, which throws up a succession of shoots to the surface, while the parent plants decay and form a new 
layer of the soil; a process analogous, as we shall explain hereafter, to the mode of increase of the coral reefs.

The peat bogs of Ireland are of great extent: one of the mosses on the banks of the Shannon, in breadth two or three miles, is filty miles in length. Mr. Lyell (to whose admirable work I must again refer you for more ample information on the effects of modern causes) observes, that the peat mosses of the North of Europe occupy the scite of the ancient forests of oak, and pine; and that the fall of trees from the effect of storms, or natural decay, by obstructing the draining of a district, and thus giving rise to a marsh, occasions the origin of most of the peat bogs. Mosses, and other marsh plants spring up, and soon overwhelm, and bury the prostrate forests. Hence the occurrence of trunks and branches of enormous oaks, firs, \&c. with their fruits.

De Luc states, that the scite of many of the aboriginal forests on the Continent, is now covered by mosses and fens, and that many of these changes are attributable to the destruction of the forests by the Romans. A remarkable fact relating to peat bogs must not be omitted; namely, the occasional occurrence of the bodies of men and animals, in a high state of preservation, at a great depth. In some instances the bodies are converted into a fatty substance, resembling spermaceti, called adipocire.

28. Subterranean Forests.-Independently 
of the trees immersed in peat bogs and morasses, there are also found entire forests buried deeply in the soil; the trees having their roots, trunks, branches, fruits, and even leaves, more or less perfectly preserved. Several accumulations of this kind have been discovered on the coast of Sussex, occupying low alluvial tracts, that are still subject to periodical inundations. * The trees are chiefly of the oak, hazel, fir, birch, yew, willow, and ash ; in short, almost every kind that is indigenous to this island occasionally occurs. The trunks, branches, \&c. are dyed throughout of a deep ebony colour by iron; the wood is firm and heavy, and sometimes sufficiently sound for domestic use. In Yorkshire it is employed in the construction of houses. The specimens which I now place before you, (and for which I am indebted to my distinguished friend Professor Babbage) exhibit the usual character of such remains; they are portions of the trunks of large trees of the yew, oak, and fir.

29. Geological Effects of the Sea.While the mountains, valleys, and plains of the interior of a country, are undergoing slow but perpetual change by the combined effects of atmospheric agency, and of running water, the coasts, and shores, are exposed to destruction from the action of the waves, and the encroachments of the sea. When the land presents a high and rocky coast, the waves

* See the Fossils of the South Downs. 
by their incessant action undermine the cliffs, which at length fall down, and cover the shore with their ruins. The softer parts of the strata, as the chalk, marl, clay, \&c. are rapidly disintegrated and washed away: while the more solid materials are broken, and rounded, by the continual agitation of the water, and form those accumulations of beach and sand which line our shores, and serve, in some situations, to protect the land from further encroachments. But when the cliffs are entirely composed of soft substances, their destruction is very rapid, unless artificial means are employed for their protection; and these in many instances are wholly ineffectual.

The encroachments of the ocean upon the land effected by this operation, often give rise to sudden and extensive inundations, and the destruction of whole tracts of country. Along the Sussex coast the inroads of the sea have been noticed in the earliest historical records; and you are doubtless aware, that the scite of the ancient town of Brighton, is entirely swept away, the sands, and the waves, now occupying the tract where the first settlers on this coast fixed their habitation.* On low and sandy coasts, the waves drive the loose and lighter materials towards the shore; and the drifted sand, becoming dry at the reflux of the tide, is carried by the wind inland; and in some situations is accumulated in such quantities as to form ranges of hills, which in

* See Geology of the South-East of England, p. 23. 
their progress overwhelm fertilc tracts, and engulf churches, and even entire villages. These sandbanks or downs, loose and fluctuating as they are in their first stage of advancement, become under certain circumstances, fixed, and converted into solid stone-a process to which we shall presently advert.

30. Bed of the OCEan.-But the production of beach, and gravel, and sand, on the shores, and the drifting of sand inland, are effects far less important than those which are going on in the profound depths of the ocean. In the tranquil bed of the sea, the finer materials, held in mechanical or chemical suspension by the waters, are precipitated and deposited, enveloping and imbedding the inhabitants of its waters, together with the remains of such animals, and vegetables of the land, as may be floated down by the streams and rivers. But, in the beautiful language of Mrs. Hemans,-

"The depths have more! What wealth untold

Far down and shining through their stillness lies!

They have the starry gems, the burning gold,

Won from a thousand royal argosies!

"Yet more-the depths have more! Their waves have roll'd

Above the cities of a world gone by-

Sand hath filled up the palaces of old,

Sea-weed o'ergrown the halls of revelry.

"To them the love of woman hath gone down,-

Dark flow their tides o'er manhood's noble head,

O'er youth's bright locks, and beauty's flowery crown." - 
Yes! in these modern depositions, the remains of man, and of his works, must of necessity be continually engulfed, together with those of the animals which are his contemporaries.

Of the nature of the bed of the ocean, we can of course know but little from actual observation. Soundings, however, have thrown light upon the deposites now forming in those depths, which are accessible to this mode of investigation; and thus we learn, that in many parts immense accumulations of the wreck of testaceous animals, intermixed with sand, gravel, and mud, are going on. Donati ascertained the existence of a compact bed of shells, 100 feet in thickness, at the bottom of the Adriatic, which in some parts was converted into marble. In the British Channel, extensive deposites of sand, imbedding the remains of shells, crustacea, $\mathcal{s}$ c. are in the progress of formation. This specimen, which was dredged up at a few miles from land, is an aggregation of sand with recent marine shells, oysters, muscles, limpets, cockles, \&c. with minute corallines; and this example, from off the Isle of Sheppey, consists entirely of cockles (Curdium cdule), held together by conglomerated sand. In bays and creeks, bounded by granitic rocks, the bed is found to be composed of micaceous and quartzose sand, consolidated into what may be termed regenerated granite. Off Cape Frio, solid masses of this kind were formed in a few months, and in them were imbedded dollars, and other treasures from the wreck of a ressel, to 
recover which an exploration by the diving-bell was undertaken.

31. Currents, and their effects.-The distribution, over the bottom of the sea, of the detritus brought down by rivers and streams, and of the materials worn away by the action of the waves on the shores, is principally effected by the action of currents, which, from their regularity, permanency, and extent, may be considered as the rivers of the ocean. To this agency I can but bricfly allude, and will only instance the Gulf-stream, which is the great current that transports the waters, and the temperature of the tropical regions, into the climates of the north. From the mouth of the Red Sea a current about 50 leagues in breadth sets continually towards the south west; doubling the Cape of Good Hope, it assumes a north-west direction, and in the parallel of St. Helena its breadth exceeds 1000 miles; then taking a direction nearly east, it meets in the parallel of $3^{\circ}$ north, along the northern coast of A frica, with a current from the north; entering the Gulf of Florida, they are reflected and form the Gulf-stream, which, passing along the coast of North America, stretches across the Atlantic to the British Isles. At the parallel of $38^{\circ}$, nearly 1000 miles from the Straits of Bahama, the water of the stream is ten degrees warmer than the air. The course of the Gulf-stream is so fixed and regular, that nuts and plants from the West Indies are annually thrown ashore on the western islands of Scotland. The mast of a man-of- 
war, burnt at Jamaica, was driven ashore several months afterwards on the Hebrides, "after performing a voyage of more than 4000 miles under the direction of a current which, in the midst of the ocean, maintains its course as steadily as a river upon the land."* The transportation of detritus, resulting from the action of such a current, is obvious; and we therefore need not wonder at finding the productions of one country, so frequently included among the fossils of another.

32. Tufa, Incrusting Springs, \&c.-The phenomena' hitherto considered, are referable to the mechanical action of water; and the process has been one of disintegration, and clestruction, in the first instance ; and in the second, of accumulations of sediments in water-channels, and in the bed of the sea. We must now refer to an operation of a totally different character-the power possessed by streams, as clear and sparkling as poet ever feigned, or sung, of consolidating loose materials, of converting porous strata into solid stone, and of filling up their own channels by the deposition of calcareous matter.

That most fresh-water holds a greater or less proportion of carbonate of lime in solution, is well known; and also that change of temperature, as well as many other causes, will occasion the calcareous earth to be in part or wholly precipitated. The fur, as it is called, that lines a boiler which has been long

* Playfair's Works, edition 1822 ; vol. i. p. 414. 
in use, affords a familiar illustration of this agency. At the temperature of $60^{\circ}$, lime is fusible in 700 times its weight of watcr; and if to this solution a small portion of carbonic acid be added, a carbonate of lime is formed, and precipitated in an insoluble state. If, however, the carbonic acid be in such quantity as to supersaturate the lime, it is again rendered soluble in water; and it is thus that carbonate of lime, held in solution by an excess of fixed air, not in actual combination with the lime, but contained in the water and acting as a menstruum, is commonly found in all waters. An absorption of carbonic acid, or a loss of that portion which exists in excess, will therefore occasion the calcareous earth to be set free, and precipitated on any substance in the water, such as stones, sprigs and leaves of trees, \&c. Some springs contain so large a proportion of calcareous earth when they first issue from the rocks, and so speedily throw it down in thcir course, that advantage has been taken of this circumstance to obtain incrustations of various objects, as leaves, branches, baskets, nests with eggs, and even old wigs. The incrusting springs in Derbyshire are celebrated for such productions. These depositions are termed tufa, or travcrtinc; and in Italy, and many other countries, they constitute extensive beds of concretionary limestone, which is often of a crystalline structure. Even the Cyclopean walls and temples of Prestum, are formed of this aqueous deposite. At the baths of San Filippo, in 
Tuscany, where the waters are highly charged with tufa, this property is applied to a very ingenious purpose. The stream is directed against moulds of medallions, and other bas-reliefs, and very beautiful casts are thus obtained; of which we have an example in this medallion, which bears the head of Napoleon, and was presented to me by the Marquis of Northampton.

33. Incrustations not Petrifactions.-As incrustations of this kind are commonly, but erroneously, termed petrifactions, I will briefly explain their real nature. We have before us several incrustations from various places : baskets of shells, and nests with eggs, from Derbyshire, for which I am indebted to the kindness of Sir George Sitwell, Bart.; a bird, from Knaresborough, Yorkshire, presented by Mr. Thorby; and a branch, partially incrusted, from Ireland, by Miss Ellen Mahony.

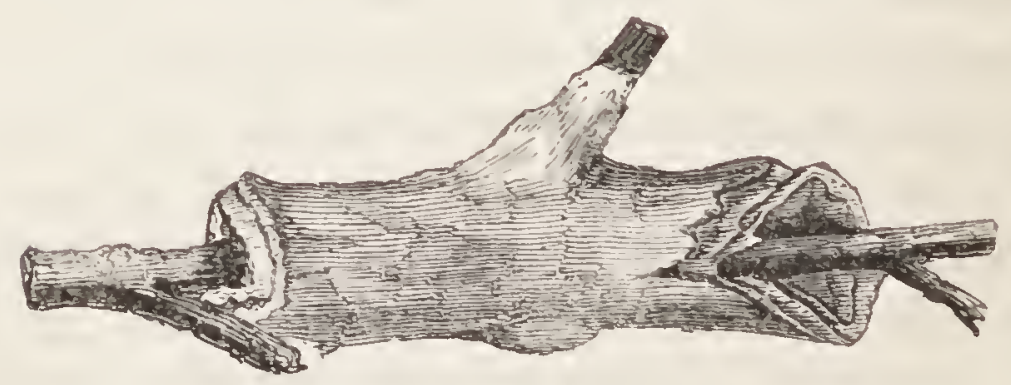

TAB. 2. INCRUSTATION.

I need scarcely observe, that on breaking such specimens, we find the substances enclosed to have undergone no change but that of decay, in a greater or less degree. In this incrusted bird's nest, the 
twigs of which it is composed, like the branch above mentioned, are exposed in several places, and, as you perceive, are not permeated by stony matter, but are dry, and brittle. Now, a true petrifaction is altogether of a different nature: the substance being saturated throughout with mineral matter; if we break it, we find that every part of its structure lias undergone a change; sometimes flint has filled up every interstice, and upon slicing and polishing it, the most delicate texture of the original may be detected. Wood, for instance, which is so commonly petrified by flint or chalcedony, may be cut so thin, that with a powerful lens the ramifications of the vessels and the structure of their tissues may be seen, and from their form, and disposition, we may determine the particular kind of tree to which the specimen belonged, although it may, during countless ages, have been cased up in stone. When bone is petrified, the same phenomena are observable; the most delicate parts of the internal structure are preserved, and all the cells filled up with stone or spar, oftentimes of a different colour from that of the walls of the cells, thus forming a natural, anatomical preparation, of great beauty, and interest.

34. Lake of the Solfatara.-This celebrated lake lies in the Campagna between Rome and Tivoli, and is fed by a stream of thermal water which flows into it from a neighbouring pool. The water is of a high temperature, and is saturated with carbonic acid gas, which, as the water cools, is constantly 
escaping, and keeping up an ebullition on the surface. The formation of travertine is so rapid, that not only the vegetables, and shell-fish, are surrounded and destroyed by the calcareous deposition, but insects also are frequently incrusted. In these beautiful specimens of travertine from Solfatara, for which I am indebted to Dr. Jenks, vegetable impressions are distinctly seen; and the cavities in the mass, have evidently been occasioned by the decomposition of the vegetable matter.* The stream that flows out of the lake fills a canal, which is conspicuous at a distance, from the line of vapour emanating from the water.

A considerable number of the edifices of both ancient and modern Rome, are built of travertine, derived from the quarries of Ponte Luccano, which have clearly originated from a lake of the same kind. Prestum is also built of calcareous tufa, derived from similar deposites formed by lakes. "The waters of these lakes," says Sir Humphry Davy, "have their rise at the foot of the Appennines, and hold in solution carbonic acid, which has dissolved a portion of the calcareous rocks through which it has passed; the carbonic acid is dissipated by the atmosphere, and the marble, slowly precipitated, assumes a crystalline form, and produces coherent stones. The acid originates in the action of volcanic fires on the calcareous rocks of which the Appennines are com-

* See Appendix B. 
posed; and carbonic acid being thus evolved, rises to the source of the springs derived from the action of the atmosphere, gives them thcir impregnation, and enables them to dissolve calcareous matter."

35. Marble of Tabreez.-In Persia, a beautiful transparcnt limestone, called Tabreez marble, is formed by deposition from a celebrated spring near Maragha, where the whole process of its formation may be seen. In one part the water is clcar, in another dark, muddy, and stagnant; in a third it is very thick, and almost black; while in the last stage it is of a snowy whiteness. The petrifying pools look like frozen watcr: a stone thrown on them breaks the crust, and the watcr exudes through the opening. In some states the petrifying process lias proceeded so far as to admit of being walked upon. A section of the stony mass resembles an accumulation of shects of paper, being finely laminated. Such is the tendency of the water to solidify, that the very bubbles on its surface become hard, as if they had been suddenly arrested, and metamorphosed into stone.**

36. Stalactites, and Stalagmites.-By the infiltration of water through limestone rocks, into fissures and cavities, sparry concretions are produced on the roofs, sides, and floors of caverns. The concretionary masses which arc dependant from the roof, resembling icicles, are called stalactites; and

* Morier's Travels. 
those which form on the floor, from the droppings of the water, are termed stalagmites; and when, as frequently happens, the two unite, a singularly picturesque effect is produced,- - the caves appearing as if supported by pillars of the most extraordinary variety and beauty.* Sometimes a linear fissure in the roof, by the direction it gives to the dropping of the lapidifying water, forms a transparent curtain or partition. A remarkable instance of this kind occurs in a celebrated cavern in North America, called Weyer's Cave, which is situated in the limestone range of the Blue Mountains. $\dagger$ There are many caverns in England, celebrated for the rariety and beauty of their sparry ornaments: those in Derbyshire are well known.

37. Grotto of Antiparos.--The Grotto of Antiparos in the Grecian Archipelago, not far from Paros, is justly admired. The sides and roofs of its principal cavity are covered with immense incrustations of calcareous matter, which form either stalactites, depending from above, or irregular pillars rising from the floor. Several perfect columns reaching to the ceiling have been formed, and others are still in the course of formation, by the union of the stalactite from above, with the stalagmite below. These being composed of matter slowly deposited, have assumed the most fantastic shapes; while the pure, white, and glittering spar, beautifully catches 
and reflects the light of the torches of the visitors to this subterranean palace, in a manner which causes all astonishment to cease at the romantic tales told of the place - of its caves of diamonds, and its ruby walls; the real truth, when deprived of all exaggeration. being sufficient to excite admiration, and awe. Some of these concretions form a thin curtain, which is perfectly transparent.*

The specimens which I have selected from my collection, to illustrate these remarks, exhibit the usual character of stalactitical concretions; these long stony icicles are from Portland; and thesc minute straws of spar, from an archway near the Chain Pier, have been formed by the infiltration of rain through the superincumbent bed of calcareous rock. This specimen of pebbles, held together by calc spar, is from the cliffs at Kemp Town; and affords a proof that in periods very remote, the same process was in action along our shores. These beautiful slabs of marble are portions of stalagmite, from St. Michael's Cave, Gibraltar; and this large conical mass, which has been cut through and polished to show its structure, was dug up on the summit of Alfriston Hill, in this county, and must have been formed in some chalk cavern, of which no traces now remain.

38. Consolidation of Sand, and Loose

* See an interesting Essay on Grottoes, in the Saturday Magazine. 
Materials by Infiltration.-The changes effected in loose strata by this process are, however, of still greater importance; for by an infiltration of crystallized carbonate of lime, sand is converted into sand-stone,-fragments of soft chalk are transmuted into a solid rock, as in the Coombe rock of Brighton,--and accumulations of beach, and gravel, into a hard conglomerate, as in this example of the ancient shingle bed of the cliffs, at Rottingdean, shells, into a building stone, as in this mass from Florida,-and broken corals, into limestone, as in these specimens from Bermuda. By this agency, the bones of animals become permeated with calcareous spar, and the medullary cavities lined with crystals of carbonate of lime: and clay, which has cracked by drying, has its fissures filled up, and becomes consolidated into those curious masses, called Septaria, which when polished, form the beautiful slabs for which Weymouth is so celebrated.

39. Destruction of Rocks by Carbonic Acid Gas.-Although, in the instances cited above, water by its combination with carbonic acid, occasions the solidification of loose and porous beds of detritus, yet the effect of this gas on certain rocks is that of disintegration; for by its solvent influence on the felspar, granite itself is reduced to a friable state; the quartz and mica, which with felspar constitute granite, being set at liberty. Mr. Lyell mentions, that the disintegration of granite, is a striking feature in large districts in Auvergne, 
especially in the neighbourhood of Clermont. In the ancient bed of shingle in the cliffs at Kemp Town, blocks of granite occur; and here is an example, which may be crumbled to pieces between the fingers. I have already slown you masses of pebbles held together by calcareous spar, from the same beach; we have, therefore, examples in that ancient beach both of the conservative, and disin. tegrating effects of carbonic acid-ccmenting the loose beach into solid blocks by incrustation; and, when in a gaseous state, or combined with water, dissolving the granite by its action on the felspar.

40. Carbonic Acid Gas in Caves and Wellos. - The escape of carbonic acid through fissures, into wells, and caverns, is of frequent occurrence; and as the specific gravity of this gas is greater than that of atmospheric air, it occupies the bottom of these cavities, and its presence is seldom suspected till shown by its deleterious effects.

A melancholy accident that recently occurred at Petworth, the particulars of which were communicated to me by the Earl of Egremont, arose from the sudden escape of carbonic acid into a well, by which two men, cmployed in the excavation, were almost instantly suffocated.

The Grotto del Cane, near Puzzuoli, four leagues from Naples, has for centuries been celebrated on account of the carbonic acid gas, which rises from fissures in the rock. The gas being spread over the floor of the cave, like a pool of water, its effects are 
not perceptible to a creature whose organs of respiration are placed above the level of this invisible mephitic lake; but if a dog, or other small animal, enter the cave, it instantly falls senseless, and would expire if not speedily removed; the name of the cave is obviously derived from the experiment being often made on dogs, for the amusement of visitors.*

41. Consolidation by Iron. - Water charged with a large proportion of iron, acts an important part in the consolidation of loose materials, converting sand into iron-stone, and beach or shingle into ferruginous conglomerates. In this example of a horse-shoe firmly impacted in a mass of pebbles and sand, presented by Davies Gilbert, Esq., the cement which binds the mass, is derived from the iron. Nails are frequently found in the centre of a nodule of hard sandstone formed by this process; the nail supplying the water with the materials by which the surrounding sand is clianged into stone. In this very interesting niass of breccia, $\uparrow$ which has been produced by a like process, are two

* See Sandy's' Travels.

$\uparrow$ The specimen was dug up ten feet below the bed of the river Dove, in Derbyshire; and the coins are presumed to be part of the treasures contained in the military chest of the Earl of Lancaster, which was lost in crossing the river in the dark; the guards being alarmed by a sudden panic, and the chest with all its contents thrown into the Dove. The Earl of Lancaster was beheaded in March 1322: the specimen before you was discovered about six years since, more than five centuries after its submersion. - See the Iignette of the Title-page. 
silver pennies of Edward I. ; and this curious specimen, for which I am indebted to G. Grantham, Esq. of Lewes, was procured from a Dutch vessel, stranded off Hastings a century ago, and is a conglomerate of glass beads, knives, and sand; the cementing material having been derived from the oxidation of the blades.

42. Iron from a Morass.- These masses of oxide of iron were dug up in a marshy soil, near Bohney, in Sussex, and are of the same nature as the substance called bog-iron ore, which occurs in peat. The ebony colour of the woods from Ireland, which we have already examined, has been occasioned by an impregnation of iron. Specimens of bog-iron are not uncommon in the superficial loam and gravel of this part of England.

The consolidation of sand and other loose materials by these agencies, is taking place everywhere; on the shores of the Mediterranean; on the coasts of the West India Islands; of the Isle of Ascension; and on the borders of the United States; and thus the remains of man, at Guadaloupe-of turtles, in the Isle of Ascension-of recent shells, and bones of ruminants, at Nice-of ancient pottery, in Greeceand of vegretables, and other substances, in our own country, have become imbedded and preserved.

I now proceed to notice a few instances of these most interesting and important operations, by which much of the solid crust of the globe is perpetually being renewed. 
43. Recent formation of Marine Limestone in the Bermudas.-The valuable series of specimens before me (presented by W. D. Saull, Esq.) is from the Bermuda Islands, and affords examples of this class of deposites in different states of forma. tion. On the shores of the Bermudas a most interesting deposition of limestone is taking place which is principally composed of calcareous materials thrown up by the sea. 'The ocean which surrounds the Bermudas abounds in corals and shells, and from the action of the waves on the coral reefs, and on the dead shells, the waters become loaded with calcareous matter. Much of this detritus, no doubt, is carried down to the profound depths of the ocean, and there envelopes the remains of animals and vegetables, thus forming new strata for the use of future ages; but a great proportion is wafted by the waves towards the shores, and is deposited in the state of fine sand. This sand is drifted inland by the winds, and becomes more or less consolidated by the percolation of water, and the infiltration of crystallized carbonate of lime; and a fine white calcareous stone is thus formed, which in some localities is sufficiently compact for building. Imbedded in this limestone are numerous shells, and corals, of the species which inhabit the neighbouring seas: in some instances the large mottled trochus, so well known to collectors both in its natural and polished state, with all its colours preserved, is im. bedded in a pure, white, limestone; in many, the 
colours are faded, and the shell very much in the state of the fossils found in the tertiary strata at Grignon-in others the shell is wanting, but the hard limestone retains its form and markings. The corals are imbedded in a similar manner; and masses are seen in the limestone so like the fossil corals of the oolite of this country, that it requires an expcrienced eye to detect their real character.

These specimens, as you perceive, show the transition from loose sand to a solid rock. We liave-

1. Broken shells and corals, retaining their colours.

2. Similar materials, more comminuted and completely blanched.

3. An aggregation of fine sand, broken shells, and corals.

4. Coarse friable limestone, resembling soft chalk, and composed of comminuted corals, \& c.

5. Hard limestone, of similar materials.

6. Compact limestone, enclosing shells, and pebbles.

7. A fine indurated limestone, so hard as to be with difficulty broken by the liammer, enclosing a few sliells, and corals : this stone is employed for building.

Mr. Lyell, some years since, in a valuable paper in the Transactions of the Geological Socicty, showed that in the lakes of Scotland a fresh-water limestone, imbedding the remains of recent shells, and aquatic plants, was in a state of formation. In this interesting series of specimens from Forfarshire, 
for which I am indebted to the liberality of $\mathrm{my}$ distinguished friend, there are various species of fresh-water sliells, and masses of that common lacustrine plant, the Chara medicaginula, beautifully preserved; even the minute seed-vessels of the chara are found converted into stone, in precisely the same manner as is observable in the ancient fresh-water tertiary limestones. And in the formations at Bermuda, we have an instance, that the sea is, at this time, producing effects analogous to those which have given rise to many of the secondary rocks of Europe.

44. Fossil Human Skeleton of Guadaloufe. - Similar formations are in progress along the shores of the whole West Indian Archipelago; and in St. Domingo they have greatly extended the plain of Cayes, where accumulations of conglomerates occur, and in which, at the depth of 20 feet, fragments of ancient pottery have been discovered. On the north-east coast of the main land of Guadaloupe, a bed of recent limestone forms a sloping bank, or glacis, from the steep cliffs of the island to the sea, and is nearly all submerged at high tides. This modern rock is composed of consolidated sand and comminuted shells and corals, of species now inhabiting the adjacent seas. Land shells, fragments of pottery, stone arrow-heads, carred stone and wooden ornaments, and human skeletons, are found therein enveloped. This being the only known undoubted instance of the occurrence of human bones in solid limestone, has excited great attention; and the fact, 
simple and self-evident as is its history, has been made the foundation of many vague, and absurd hypotheses.

In most instances the bones are dispersed; but a large slab of rock, in which a considerable portion of the skeleton of a female is imbedded, is preserved in the British Museum, and has been described by Mr. König, in a highly interesting memoir in the Philosophical Transactions, of 1814.

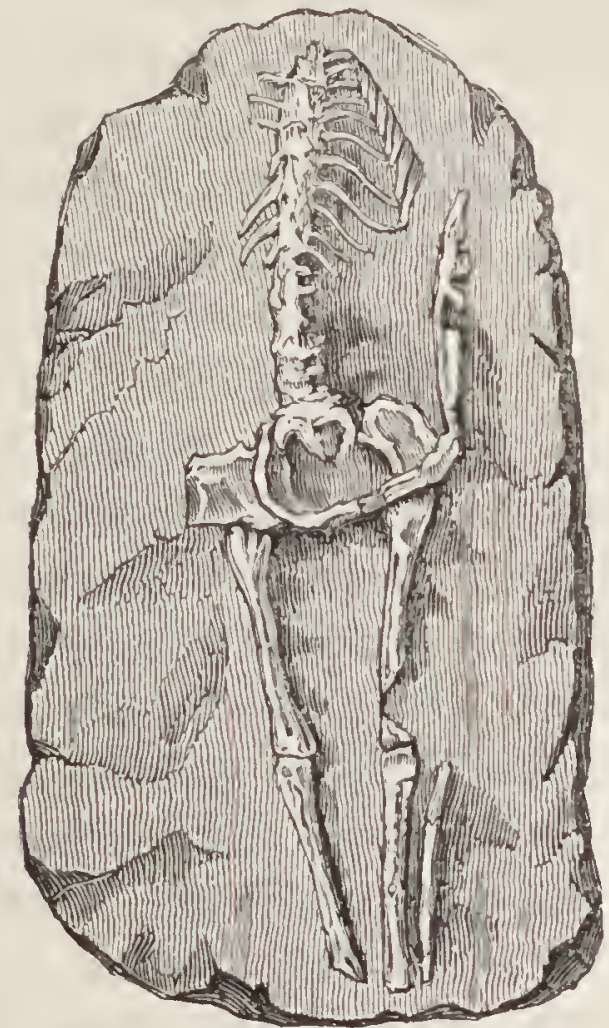

Tab. 3. Fossil Human Skeleton, From Guadloupe.

The annexed representation will serve to convey an idea of this celebrated relic, which was detached from the rock at the Mole, near Point-a-Pitre. 
In this specimen the skull is wanting, but the spinal column, many of the ribs, the bones of the left arm and hand, of the pelvis, and of the thighs and legs, remain. The bones still contain some animal matter, and the whole of their phosphate of lime. It is not a little curious, that the fragments of the skull of this very specimen have, during the present year, been described by Professor Moultrie, of the Medical College of South Carolina; having been purchased for the Museum of that State, of a French naturalist, who brought them from Guadaloupe. These relics consist of portions of the temporal, parietal, frontal, sphenoidal, and inferior maxillary bones, of the right side of the skull. An entire skeleton was also discovered in the usual position of burial; another, which was in a softer sandstone, was in a sitting posture. The bodies, thus differently interred, may have belonged to distinct tribes. General Emouf, who carefully investigated this interesting deposite, conjectured that the occurrence of the scattered bones might be explained by the tradition of a battle, and massacre of a tribe of Gallibis, by the Caribs, on this spot, about 120 years ago; the skeletons being covered by sanddrift from the sea, which became converted into stone. Dr. Moultrie, however, from a rigorous examination, and comparison of the bones of the skull in his possession, is of opinion, that the specimen in the British Museum did not belong to an individual of the Carib, but to one of the Peruvian race, or 
of a tribe possessing a similar craniological development. In another fossil human skeleton from Guadaloupe, now in the museum of the Jardin des Plantes, and represented in the last edition of Cuvier's Théorie de la Terre, the figure is bent, the spine forms an arc, and the thigh is drawn up as if the individual were in a sitting posture; a portion of the upper jaw, and the left half of the lower, with several teeth, nearly the whole of one side of the trunk and pelvis, and a considerable portion of the upper and lower left extremities, are preserved. The stone is a travertine, and encloses terrestrial, and marine shells; it is evident that the former have been drifted by the streams from the interior, and the latter deposited by the ocean. In the bed from which the block was extracted have been found teeth of the caiman (crocodile), stone hatchets, and a piece of wood, having rudely sculptured on one side a mask, and on the other the figure of an enormous frog: it is of guaiacum wood, but has become extremely hard, and as black as jet.

45. Impressions of Human Feet in SandSTONE.- - In connexion with the occurrence of human bones in limestone, I will here notice a discovery of the highest interest, but which has not, as yet, excitcd among scientific observers the attention which its importance demands. I allude to the fact announced in the American Journal of Science, vol. v. for 1822, of impressions of human feet in sandstone, observed many years ago in a quarry at $\$$ t. 
Louis, on the western bank of the Mississippi. The

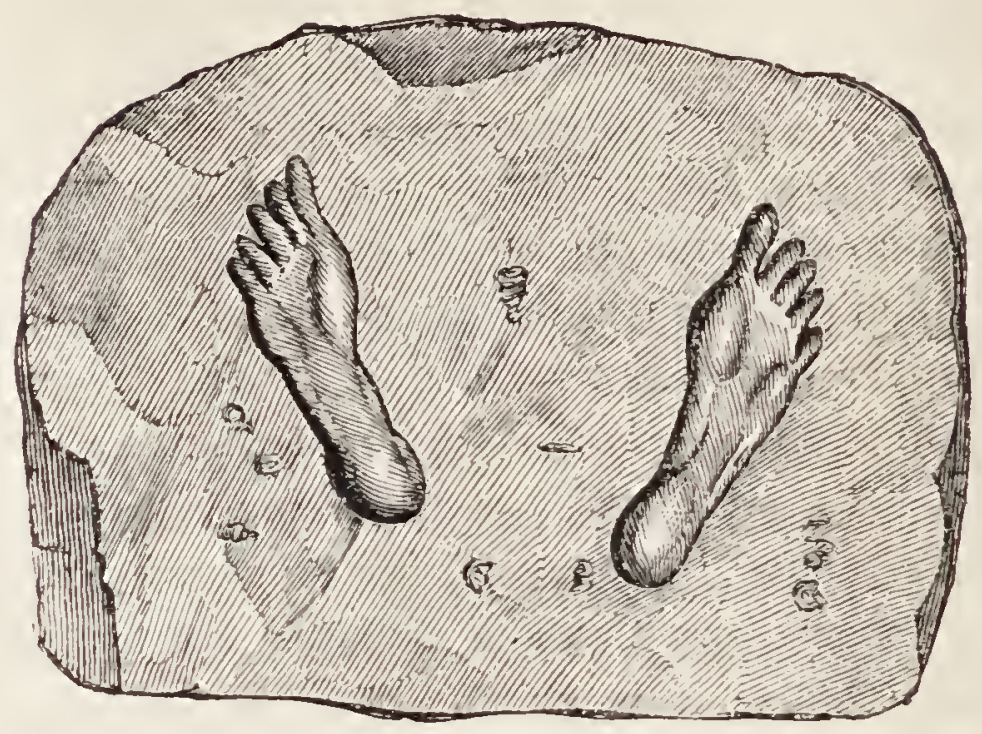

Tab. 4. Prints of Humax Feet in Sandstone.

above figure is an exact copy of the original drawing, and exhibits the impression of the soles of two corresponding human feet, placed at a short distance from each other, as of an individual standing upright, in an easy position. The prints are described as presenting the perfect impress of the feet, and toes ; exhibiting the form of the muscles, and the flexures of the skin, as if an accurate cast had been taken in a soft substancc. They were at first supposed to have bcen cut in the stonc by the native Indians, but a little reflection sufficed to show that they were beyond the efforts of these rude children of nature; since they evinced a skill, and fidelity of execution, which even my distinguished friend, Sir Francis Chantrey, could not have surpassed. No doubt exists in my 
mind, that these are the actual prints of human feet in soft sand, which was quickly converted into solid rock by the infiltration of calcareous matter, in the manner already described. The length of each foot is ten inches and a half, the spread of the toes four inches, indicating the usual stature; and the nature of the impression shows that the feet were unconfined by shoes, or sandals. This phenomenon, unique of its kind, is fraught with so much importance, that I have requested Professor Silliman to ascertain the nature of the sandstone, and the period of its formation. Hereafter I shall have to direct your attention to impressions of another kind, in rocks of immense geological antiquity.

46. Is Le of Ascension.- This island, a volcanic cone in the midst of the Atlantic, which appears to have been a dome of trachytic rocks, subsequently affording vent to lava currents, has its shores bounded by a conglomerate of sand with comminuted shells, corals, echini, and fragments of lava. In the suite of specimens before you, presented me by Mr. Lyell, are portions of this conglomerate in various states of consolidation. The specimens are composed of corals, which still retain their colour; shells, more or less broken; sand formed of similar materials ; and pebbles of trachytic and glassy lavas. The shores of this island are a favourite resort of turtles, which repair thither in immense numbers, and deposit their eggs in the loose sand: the rapid conversion of the coarse, calcareous banks into solid stone, occasions 
the frequent imbedding, and preservation of the eggs; and there are specimens in the cabinet of the Geological Society, in which the bones of young turtles, just on the point of being hatched, are well preserved.* The conglomerate of the Isle of Ascension is, as you may observe, principally composed of corals. Here we have another example of a rock formed of the calcareous skeletons of those wonderful forms of organic existence. It is not my intention in this place to dwell on the geological changes produced by recent zoophytes, in the formation of coral reefs, \&c.; as the examination of the recent, and fossil corals, will form the subject of a distinct lecture.

47. Drifted Sand.-We have already briefly alluded to the encroachments on the land by the drifting of sand-banks, thrown up beyond the reach of the tide, and borne by the winds inland; thus effecting the desolation of whole regions by their slow, but certain progress. Egypt instantly presents herself to the imagination, with her stupendous pyramids, the sepulchres of a mighty race of monarchs, and the wonder of the world-her temples, and palaces, once so splendid and massive, as to bid defiance to the ravages of time-her plains, and valleys, once teeming with abundance, and supporting a numerous population-now stripped of her ancient glories, her fairest regions depopulated, and converted into arid wastes,-her cities overwhelmed, and prostrate in the dust-and the colossal monuments

- See Lyell's Principles of Geology, 5th edit. rol. iii. p. 269. 
of her kings, and the temples of her gods, half buried beneath the sands of the desert! And this melancholy instance of the vanity of human power, and magnificence, is the result of that simple agency, which this affecting desolation serves so strikingly to illustrate. The drifting of the sands of the Lybian desert by the westerly winds, has left no lands capable of cultivation on any part of the western bank of the Nile not sheltered by mountains; and in Upper Egypt, whole districts are covered by moveable sands, and here and there may be seen the summits of temples, and the ruins of cities which they have overwhelmed. "Nothing can be more melancholy," says Denon, "than to walk over villages swallowed up by the sand of the Desert, to trample under foot their roofs, and minarets, and to reflect that yonder were cultivated fields-that there grew trees-that here were the dwellings of men, and that all have now vanished." The sands of the Desert were in ancient times remote from Egypt; and the Oases which still appear in the midst of this sterile region, are the remains of fertile soils which formerly extended to the Nile.*

48. Sand-Flood, and recent Limestone of CoRNWALL. - On many parts of the shores of Scotland, sand-floods have converted tracts of great fertility into barren wastes; and on the northern coast of Cornwall an extensive district has been covered

- See an Essay on the Moving Sands of Africa, in Professor Jameson's Cuvier's Theory of the Earth, p. 375. 
by drifted sand, which in some places forms ranges of low mounds, or hills, forty feet high, and has become consolidated by the percolation of water holding iron in solution. This sandstone offers a striking and most interesting example of recent formation, and lias been described by Dr. Paris, in a memoir which I do not hesitate to characterize as one of the most graphic, and instructive geological essays on modern deposites, that has appeared in this country.* The sand has clearly been originally drifted from the sea by hurricanes, probably at a remote period, and is first seen in a slight, but increasing state of aggregation, on several parts of the shore in the Bay of St. Ives. Around the promontory of New Kaye, the sandstone occurs in various states of induration, from that of a friable aggregate, to a stone so compact, as to be broken with difficulty by the hammer; and which is used in the construction of churches, and houses. Upon examining the stone with a lens, it appears to be principally made up of comminuted shells; and it is worthy of remark, that the shelly particles are frequently found to be spherical, from the previous operation of water, and much resemble the ancient limestone called oolite, which will hereafter come under our notice. The rocks upon which the sandstone reposes are clay, slate, and slaty limestone; and the water effecting their decomposition may have thus obtained the iron, alumina, and

- Appendix E. 
other mineral matters by which the loose sand has been converted into sandstone.

The infiltration of water thus impregnated, Dr. Paris observes, is a common and extensive cause of lapidification: at Pendean cove, granitic sand is gradually hardening into breccia, by this process; and in the island of St. Mary, Dr. Boase has noticed granitic sand becoming indurated by the slow action of water impregnated with iron.

49. Siliceous Defositrons.-Siliceous earth, or the earth of flint, is another abundant mineral, and constitutes so large a proportion of the rocks and strata, that it is computed to form, either in a pure or combined state, nearly one-half of the solid crust of the globe. The flints from our cliffs, the boulders and gravel on our shores, and the pebbles of agate, quartz, and chalcedony, are well-known examples of the usual varieties of silex.**

* Here I would digress for a few moments, to notice an opinion which is so generally prevalent, that I may bc permittcd to assume, that even some of my auditors may not be prepared at once to answer the question,-Do stones grow? The farmer who annually ploughs the same land, and every year observes a fresh crop of stones, would probably answer in the affirmative; and the general observer, who had for successive years noticed his gardens and plantations strewed with stones, notwithstanding their almost daily removal, might entertain the same opinion. A moment's reflection, however, will serve to show, that it is impossible stones can be said to grow, in the proper acceptation of the tcrm. Organic bodies grow, because they are provided with vessels by which they are capable of taking up and assimilating particles of matter, and converting them into their own substance; but an inorganic body can only increase in bulk by 
I scarcely need observe, that this nodule of flint, derived from a neighbouring chalk quarry, has once been in a soft or fluid state; for here we perceive impressions of shells, and of the spines of an echinus deeply imprinted on its surface.* We have already seen that water impregnated with carbonic acid gas is capable of holding lime in solution; and that beds of travertine, of limestone, and other calcareous deposites, have originated from this agency; and although, even in the present advanced state of chemical knowledge, we are unacquainted with the process by which any large proportion of silex can be held in solution by water, yet we have unquestionable proofs, that the solution of siliceous earth has been effected by natural processes, on a very extensive scale. At the present moment, Nature, in her secret laboratories, is still carrying on a modification of the same process; and of this fact we have a remarkable instance in the springs of the Geysers, in Iceland, and of Carlsbad, in Bohemia. Professor Silliman remarks, that "the sulphuret of silicon, which is the base of silex, is very soluble, and that siliceous earth itself is taken up by fixed alkalies, and by fluoric acid; and these agencies, like most of those which are chemical, are rendered more active by heat." A high temperature therefore

the addition of extraneous matter to its outer surface; hence stones may be incrusted, or they may become conglomerated together, but they cannot grow.

"Vide "Thoughts on a Pebble." 
appears necessary to enable water to dissolve a large proportion of silex, \&c.; hence, we find that the thermal springs of volcanic regions are the principal agents by which siliceous depositions and incrustations, are at present effected. Thc Geysers, or boiling fountains, of Iccland, have long been celebrated for possessing this property in an extraordinary degree; holding silex in solution in a large proportion, and depositing it, when cooling, on vegetables and other substances, in a manner similar to that in which carbonate of lime is precipitated by the incrusting springs of which we have already spoken.

50. The Geysers.-Iceland may be considered as a mass of volcanic matter; the only substances not of volcanic origin in the whole island, being beds of surturbrand or bituminous wood, in which occur leaves, trunks, and branches of trces, with clay and ferruginous carth. These strata support an alternation of basalt, tufa, and lava, forming the summit of the hill in which these vegetable remains occur. The Geysers, of which there are a considcrable number, ale springs, or rather intermittent fountains of hot water, which issue from crevices in a bed of lava. A fountain of boiling water first appears, and is ejected to a considerable hcight, accompanied with a great evolution of vapour; a volume of steam succeeds, and is thrown up with great force, and a terrific noise like that produced by the escape of steam from the boiler of an engine, 
and this operation continues sometimes for more than an hour; an interval of repose of uncertain duration succeeds, after which the same phenomena are repeated. If stones are thrown into the mouth of the cavity, from which the fountain has issued, the stones, after a short interval, are ejected with violence; and again a jet of boiling water, vapour, and steam, appear in succession. Sir G. S. Mackenzie, in his interesting work, "Travels in Iceland," has proposed an ingenious theory, also adopted by Mr. Lyell, to explain these plienomena; and which the following diagram will serve to illustrate.

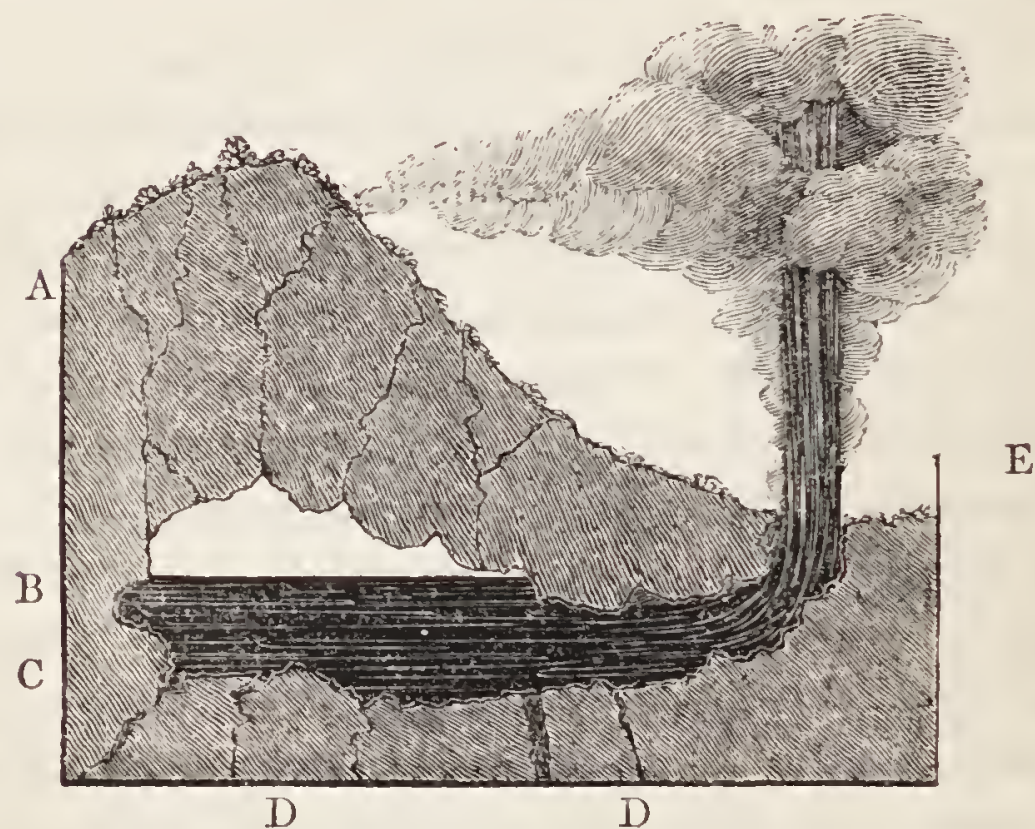

TAB. 5. Plan of the Gersers.

The water from the surface percolates through crevices (A) into a cavity in the rock (B), and heated steam, produced by volcanic agency, rises 
through the fissures in the lava (D D). The steam becomes in part condensed, and the water filling the lower part of the cavity (C) is raised to a boiling temperature, while steam under high pressure occupies the upper part of the chasn. The expansive force of the steam becomes gradually augmented, till at length the water is driven up the fissure or pipe (E), and a boiling fountain with an escape of vapour is produced, and continues playing till all the water in the reservoir is expended, and the steam itself escapes with great violence till the supply is exhausted.

The siliceous concretions formed by these springs cover an extent of four leagues; these are speciniens of the more friable varieties, presented me by Professor Babbage. M. Eugene Robert, who has recently visited Iceland, states that this curious siliceous formation may be seen, passing by insensible gradations, from a loose friable state, the result of a rapid deposition, to the most compact and transparent marbles, in which impressions of the leaves of the birch-tree, and portions of the stem are distinctly perceptible, and present the appearance of the agatized woods of the West Indies. Stems and leaves of Equiseta, and different mosses, also occur, but none of these plants now exist in the island, the species appearing to have been wholly destroyed by the siliceous deposites. Numerous thermal springs, in the midst of which the Geysers are situated, occupy the valley in the interior of the island. It is evident 
that these waters arise from deep crevices in which they have been heated by volcanic fires. 'The rivers proceeding from the springs often resemble milk in appearance, owing to the argillaceous bole which they take up in their passage among the siliceous concretions: such are the white rivers of Olassai. Mount Hecla, like all the mountains of Iceland, is entirely covered with snow, and no smoke appears on its summit. Accumulations of rolled masses of obsidian and pumice-stone form a layer on the flanks of the mountain, thirty feet thick; fragments of branches of the birch-tree occur in the midst of this bed; they are the remains of the ancient forests of the island, which the volcanic eruptions have entirely extirpated.*

This extensive modern formation of siliceous deposites, is a fact of great interest and importance. It tells us in language that cannot be mistaken, that the most solid and refractory substances may be reduced into a liquid state, and assume other modifications, merely by the agency of thermal waters; hence the envelopment of the delicate corals, shells, and spines, in flint nodules, is readily explained.

51. Hertaordshire Breccia, or PudingSTONE.-We have before us a collection of conglomerates formed by carbonate of lime; in other words, an aggregation of pebbles, sand, shells, and corals, cemented together by calcareous spar and by ferruginous solutions: but this specimen is an example

* Bulletin de la Société Géologique de France. 
of a mass of rounded flint pebbles imbedded in a siliceous paste, forming the well-known substance called Hertfordshire puddingstone, which was formerly in great request, for the siliceous cement, being as hard and solid as the pebbles themsclves; the stones may be cut and polished by the lapidary into a great diversity of ornaments. The formation of this breccia must have been effected by a stream of siliceous matter injected into a bed of gravel, converting some masses of the loose pebbles into a solid rock, while those parts, which the melted flint did not reach, remained a layer of loose water-worn materials. It is not $m y$ intention in this lecture to dwell on the silicification* of the remains of animals and plants; I will only remark, that in the deposites of the Geysers, delicate vegetable substances are beautifully preserved; and that in these silicified woods from the West Indies the most minute structure may be detected, although the specimens will strike fire with steel.

52. Effects of High Temperature.-The phenomena presented to our notice in this investigation of the Geysers of Iceland, lead to the consideration of another agent in the transmutations that take place in the crust of the globe. It must be obvious to any intelligent mind, that beds of unconnected and porous materials can have acquired hardness and solidity only by one of the following processes,

* Petrifaction by flint. 
namely :- - 1st, by matter dissolved in a fluid, and subsequently deposited among the porous mass in the manner just described; or, 2dly, by their reduction by heat into a state of softness or fusion, and afterwards cooling into a solid mass.* Fire-or to speak more correctly, high temperature, however induced, whether by electro-magnetic influence, or from central or medial source of heat-and water, are therefore the great agents by which the condition of the surface of our planet is modified. We have already seen how vast are the changes which result from the effects of the latter; we must now take a rapid survey of the influence which the former is capable of exerting; an influence far more universal, and varied, than we may at first be prepared to expect. The expansive power of heat on most substances, its conversion of the most solid and durable bodies, first into a fluid, and lastly into a gaseous state, are phenomena so familiar as to require no lengthened comment. But the effects of heat are found to vary according to the circumstances under which bodies are submitted to its operation, and hence the changes induced by high temperature under great pressure, are totally different from those effected by fire on the surface, under the ordinary weight of the atmosphere. A familiar example will best illustrate my meaning. Chalk consists of lime combined with carbonic acid; and as for agricultural, and other economical purposes, it is desirable 
to have the lime in its pure state, the chalk, or limestone, is exposed to a great heat, in kilns erected in the open air, until all the carbonic acid is dissipated, and the chalk is said to be burnt into quicklime. In these specimens, you see the same substances in the state both of chalk and lime. Now it may readily be conceived, that if this operation were conducted under such a degree of pressure that the gas could not escape, the formation of quick-lime would not take place; the chalk would be fused; the carbonic acid, released from its present relation with the calcareous particles, would enter into other combinations, and the mass when cooled would be wholly different from the product of the lime-kilns, formed by the same agency in the open air. Experiments have proved that this opinion is correct. Sir James Hall exposed pounded chalk to intense heat, under great pressure, and it was fused, not into lime, but crystalline marble: and shells enclosed in the chalk underwent the same transmutation, yet preserved their forms. That analogous changes have been effected by a similar operation in nature, we have abundant proof; but in this stage of our inquiry it is only necessary to remark, that where ancient streams of lava have traversed chalk, the latter invariably possesses a crystalline structure. We shall hereafter find, in accordance with the beautiful and philosophical theory of Dr. Hutton, that all the strata have been more or less modified by heat, acting under great pressure 
and at various depths; and that the present position and direction of the materials composing the crust of the globe, have been produced by the same agency. * The Huttonian theory, indeed, offers a most satisfactory explanation of a great proportion of geological phenomena, enabling us to solve many of the most difficult problems in the science; and it is but an act of justice to the memory of an illustrious philosopher, and of his able illustrator, Professor Playfair, to state that this theory, corrected and elucidated by the light which modern discoveries have shed upon the physical history of our planet, is now embraced by the most distinguished geologists.

53. Volcanic Agency.-Of the activity and power of the agent to which these remarks more immediately refer, the streams of lava ejected through crevices and fissures of the earth, accompanied with evolutions of heat, and smoke, and vapour, afford the most striking proofs; and the volcano, with its frequent concomitant the earthquake, lias in all ages excited the curiosity of mankind. It would be foreign to the design of this discourse, to enter at large upon the nature and causes of volcanic action. Dr. Daubeny,t Mr. Scrope, + and others, have published highly interesting treatises

* See Playfair's Illustrations of the Huttonian Theory, vol. i. p. 33, et seq. Edin. $1 \$ 22$.

$\uparrow$ Daubeny's Lectures on Volcanoes, 1826.

¥ Scrope's Considerations on Voleances, 1825. 
on the subject; and Mr. Lyell has given an admirable sketch of volcanic phenomena.* I will only advert to the increased temperature of the earth in proportion as we penetrate the interior, and the profound depths from which thermal waters take their rise, as tending to support the opinion, that volcanic eruptions are occasioned by electrochemical changes, which are constantly going on in the interior of our globe. We shall hereafter have occasion to demonstrate that dislocation of the strata, and elevation of the bottom of the ocean, and eruptions of melted mineral matter, have taken place from the earliest geological periods within the scope of our enquiries.

The expansive power of heat, even in ordinary circumstances, is very considerable, as is shown by the instrument called a Pyrometer, which illustrates a phenomenon continually presented to our notice, namely, the expansion of a bar of metal by heat, and its contraction, by cooling, into its original dimensions. The thermometrical expansion of solid bodies when effected on an enlarged scale, gives rise to many interesting phenomena; and experiments made with great care by Colonel Totten, on the expansion of granite, marble, and other rocks, by variations of temperature, have shown that the mere expansion, or contraction, of extensive beds of these materials, would account for the elevation and subsidence of considerable

* Principles of Geology. 
tracts of country, and explain many analogous phenomena.*

54. Temple of Jupiter Serapis.-One of the most interesting examples of local elevation and subsidence, apparently resulting from this cause, is afforded by the celebrated remains of the temple of

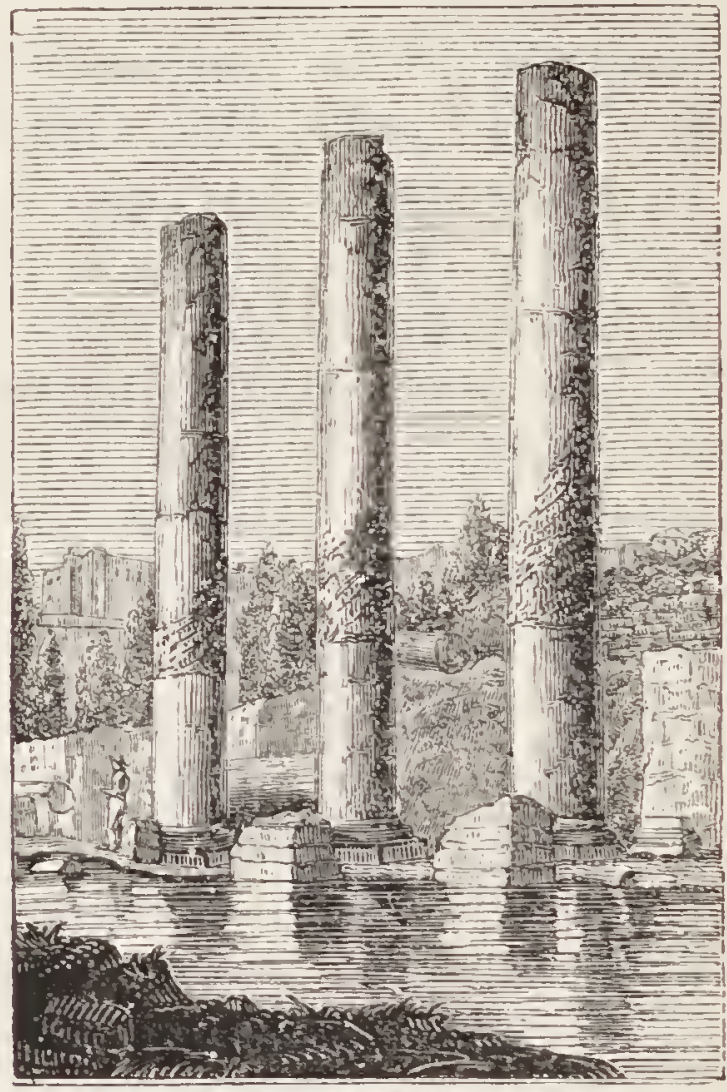

TAB. 6.-TEMPLE OF JUPITER SERAPIS.

(From Mr. Lyell's Principles of Geology.)

Jupiter Serapis, at Puzzuoli; and which my distinguished friend Mr. Lyell, by selecting as the subject of the frontispiece of his invaluable work, has for ever associated with the Principles of Geology.

* American Journal of Science, vol. xxii. 
These ruins are situated on the shore of the Bay of Baiæ, and consist of the remains of a large building of a quadrangular form, seventy feet in diameter; the roof of which was supported by twenty-four granite columns, and twenty-two of marble, each formed of a single stone. Many of the pillars are broken and strewed about the pavement, but three remain standing nearly erect, and on these are inscriptions, not traced by Greek or Roman, but by some of the simplest forms of animal existence, which have here left enduring records of the pliysical changes that have taken place on these shores, since man erected the temple in honour of his gods. The tallest column is forty-two feet in height; its surface is smooth and uninjured to an elevation of about twelve feet from the pedestal, where a row of perforations made by a species of marine boring muscle (Modiola lithophaga) com. mences, and extends to the height of nine feet; above which all traces of their ravages disappear.** The perforations, many of which still contain shells, are of a pear sliape, and are so numerous and deep as to prove unquestionably that the pillars were inmersed in sea-water, at the very time when the base and lower portions were protected by rubbish and tufa, and that the upper parts projected above the waters, and consequently were placed beyond the reach of the lithodomi. The platform of the temple is now about one foot below high-water

* See Appendix F.

$$
\text { G } 2
$$


mark ; and the sea, which is only forty yards distant, penetrates the intervening soil. The upper part of the band of perforations is, therefore, now at least twenty-three feet above the level of the sea; and yet it is evident that these columns were once plunged in salt water for a long period. It is equally clear that they have since been elevated to a height of twenty-three feet, still maintaining their erect position, amid the extraordinary changes which they have undergone, and incontrovertibly proving that the relative level of the land and sea, on that part of the coast, has changed more than once since the christian era; each movement, both of subsidence and elevation, having exceeded twenty feet.* Yet there stand those marrellous columns at the present moment, -

"Flinging their shadows from on high, Like dials, which the wizard Time Hath raised to count his ages by!'

Professor Babbage, in a valuable paper on these phenomena, attributes the tranquil elevation and depression of the temple, to the contraction and expansion of the strata on which it is built. The sources of volcanic action in the surrounding country are, as you know, very numerous; and a hot spring still exists on the land-side of the ruins. The change of level is therefore easily accounted for, by supposing the temple to have been built on

* Pinciples of Geology, vol. ii. p. 268. 
the surface of rocks, of a high temperature, which subsequently contracted by slow refrigeration. When this contraction had reached a ccrtain point, a fresh accession of heat from the neighbouring volcano increased the temperature of the strata; which again expanded and raised the ruins to their present level.*

Professor Babbage, in the interesting Essay to which I have alluded, carries out the views embodied in these brief remarks, to explain the elevation of continents and mountain ranges; assuming as the basis of his theory the following facts:-

1st. As we descend below the surface of the earth, the temperature increases.

2dly. Solid rocks expand by being heated, but clay and some other substances contract.

3dly. Rocks and strata of dissimilar characters present a corresponding difference as conductors of caloric.

4thly. The radiation of heat from the earth varies in different parts of its surface; according as it is covered by forests, mountains, deserts, or water.

5thly. Existing atmospheric agents, and other causes, are constantly changing the condition of the surface of the globe.

Thus wherever a sea or lake is filled up by the wearing down of the adjacent lands, new beds are formed, conducting heat much less quickly than the water; while the radiation from the surface of the

* Appendix G. 
new land will also be different. Hence, any source of heat, whether partial or central, which previously existed below that sea, must heat the strata underneath, because they are now protected by a bad conductor.* They must therefore raise, by their expansion, the newly-formed deposites above their former level; - and thus the bottom of an ocean may become a continent. The whole expansion, however, resulting from the altered circumstances, may not take place until long after the filling up of the sea; in which case its conversion into dry land will result partly from the accumulation of detritus, and partly from the elevation of the bottom. As the heat now penetrates the newly-formed strata, a different action may be induced; the beds of clay or sand may become consolidated, and instead of expanding, may contract. In this case, either large depressions will occur within the limits of the new continent, or after another interval, the new land may again subside, and form a shallow sea. This sea may be again filled up by a repetition of the same processes as before; - and thus alternations of marine and fresh-water deposites may occur, having interposed between them the productions of the dry land. $\dagger$

* Sir John Herschel observes, that this process is precisely similar to that by which a great coat, in a wintry day, increases the feeling of warmth; the flow of heat outwards being obstructed, and the surface of congelation remored to a distance from the body, by the heat thereby accumulated beneath the new covering.

$\uparrow$ Proceedings of the Geological Society, March 1834. 
To review the physical changes which are still taking place around the Bay of Naples would prove highly interesting, and I much regret that time will only permit me to remark, that whole mountains have been elevated on the one hand, and temples and palaces are seen beneath the sea on the other. In our sister island we have also evidence of former changes of a like nature; and which are alluded to by our inimitable lyric poet, in the following beantiful lines:-

On Lough Neagh's bank as the fisherman strays,

When the clear cold eve's declining, He sees the round towers of other days,

In the wave beneath him shining!

Thus shall memory often, in dreams sublime,

Catch a glimpse of the days that are over;

Thus, sighing, look through the waves of time

For the long faded glories they cover!

55. Elevation of the Coast of Chili.-One of the most remarkable modern instances of the elevation of an extensive tract of country, is that recorded by Mrs. Calcott, as having been produced by the memorable earthquake which visited Chili in 1822, and continued at short intervals till the end of 1823. The shocks were felt through a space of 1,200 miles, from north to south. At Valparaiso, on the morning of the 20th of November, it appeared that the whole line of coast had been raised above its level; an old wreck of a ship, which could not previously be approached, was now accessible from the land; and beds of scallops were brought 
to light, which were not before known to exist. "When I went to examine the coast," says Mrs. Calcott, "although it was high-water, I found the ancient bed of the sea laid bare and dry; with oysters, muscles, and other shells, adhering to the rocks on which they grew: the fish being all dead, and exhaling the most offensive effluvia. It appeared to me, that there was every reason to believe the coast had been raised by earthquakes at former periods, in a similar manner; for there were several lines of beach, consisting of shingle mixed with shells, extending in parallel lines to the shore, to the height of fifty feet above the sea." Part of the coast thus elevated consists of granite; and subsequent observations have proved that the whole of the country was raised, from the foot of the Andes to far out at sea: the supposed area over which the elevatory movements extended, being about 100,000 square miles; a space equal in extent to half the kingdom of France. Mrs. Somerville mentions, that a further elevation to a considerable extent has also taken place along the Chilian coast, in consequence of the violent earthquake of 1835 .

56. Lifted Sea Beach at Brighton.-Examples of such changes occur in almost every part of the world; and there is perhaps no considerable tract of country which does not afford some proof that similar physical mutations have taken place in modern times. And although I cannot point out to you a temple of Serapis on our 
shores, yet within a few hundred yards of this place, there is unquestionable evidence that the relative level of land and sea, has undergone great changes within, to speak geologically, a comparatively recent period. The upper part of the cliffs, extending from the commencement of the low range by Shoreham, to Rottingdean, is composed of chalk with rubble, flints slightly rolled, and clay and loam; the whole being clearly an accumulation of water-worn materials, deposited in an estuary or bay of the sea. The base of the cliffs, to the height of a few feet, is composed of the solid chalk strata, which may be seen at low-water extending far out to sea, and covered here and there by shingle and sand. Upon the upper surface of the chalk, and interposed between it and the superincumbent mass just described, is a bed of shingle, composed of rolled chalk, flints, pebbles, and sand, with boulders of granite, porphyry, and other rocks, not now met with on our shores; in fact, an ancient sea beach, which has evidently been formed at some remote epoch, on the Sussex coast, in like manner as the present bed of shingle, which skirts the base of the cliffs, is in the course of formation. Among the pebbles of this ancient beach, are rolled masses of chalk and limestone, which are full of perforations made by boring shells; here are several specimens, which, as you perceive, are similar to those made in the chalkrock by the recent pholades and mytili. As I shall have occasion to revert to these cliffs in my next 
lecture, this brief description will be sufficient for our present purpose.

The following diagram represents a vertical section of the cliffs, as seen in those parts where the inroads of the sea have extended to the chalk strata, and the face of the ancient chalk cliff is exposed, the new deposites being shown in profile.

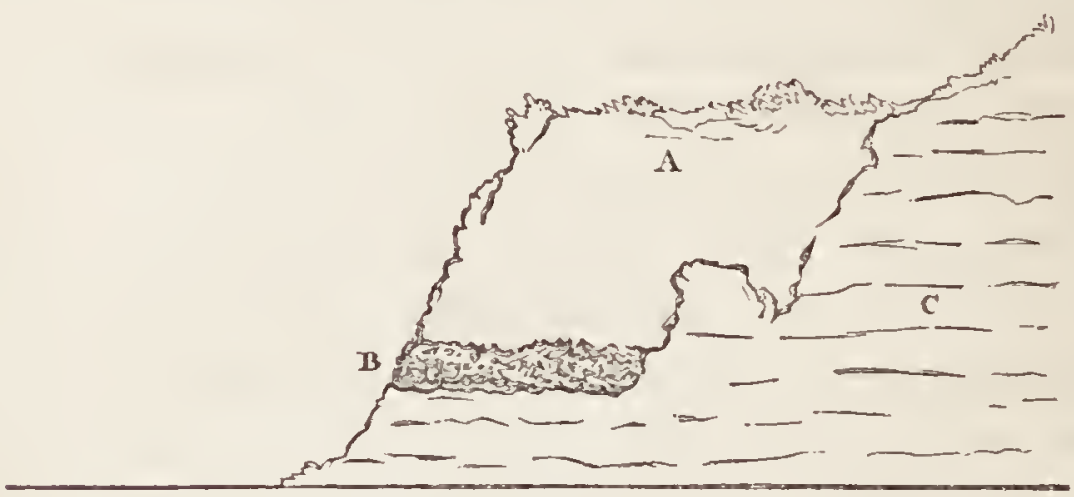

Tab. 7.-Elevated Beach at Brightox.

(A) Chalk, rubble, loam, \&c., obscurely stratified; and called the Elephant-Bed, from its containing teeth and bones of elephants. This constitutes the upper three-fourths of the cliffs.

(B) Shingle, or sea beach and sand, many feet above high-water mark. This ancient shingle, though, from the inroads of the sea, it extends in the cliffs beyond Kemp Town but a short distance inland, is constantly found beneath the loam and clay, several hundred yards from the shore in the western part of Brighton. In a well lately dug in the Western road, the shingle bed occurs at the depth of fifty-four feet. 
(C) The undisturbed chalk, which forms a sloping cliff, inland, or behind the beds (A) and (B), passing under the ancient sea beach, and appearing as a terrace at the foot of the present cliffs.**

These appearances demonstrate the following sequence of changes in the relative level of the land and sea on the Sussex shores:-

First. The chalk terrace on which the ancient shingle rests, was on a level with the sea for a long period, and the beach was formed, like the modern beach, by the action of the waves on the then existing cliffs. The rolled condition of the materials, and the borings of the lithodomi, prove a change of level as decidedly as do the perforations in the columns of the temple of Serapis.

Secondly. The whole line of coast, with the shingle (B), was submerged to such a deptl, as to admit the deposition of the strata (A) above them.

Lastly. The cliffs were raised to their present elevation, and this period was the commencement of the existing sea beach.

The elevation of the sea shore with beds of marine shells, already alluded to as having been produced by earthquakes on the Chilian coast, has here then a parallel ; and, should the correctness of these inferences be questioned, I would beg of you to visit Castle Hill, near Newhaven (about eight miles east of Brighton), and there you will find, immediately

* See Geology of the South-East of England, p. 30 ; and Fossils of the South Downs, p. 277. 
beneath the turf, a regular sea beach and beds of oyster-shells, many feet in thickness, lying on the summit of chalk cliffs, 150 feet above the level of the sea. Near Bromley, in Kent, and at Reading, in Berkshire, similar accumulations of beach and oyster-shells are to be found: specimens from each of these localities are placed on the table before us. Elevated shingles, of comparatively recent epochs, occur on the shores of the Frith of Forth, and also along the western coasts of England; as my distinguished friend, Mr. Murchison, has satisfactorily demonstrated.

57. Elevation of Scandinavia. - Having thus adduced a few striking proofs of the mutations which the land has undergone in past times, we are led to enquire-Is this change still going on? Is the alternate subsidence and elevation of the land the effect of a law of nature, established from the existence of the present condition of our planet, and destined to continue in action while its physical constitution remains the same? We shall hereafter find, that this law has been in constant action from the earliest periods of the earth's history, of which her physical monuments afford any indications; and I now proceed to adduce an instance in which the elevation of a country, with the whole burthen of its people and its cities, is actually taking place, unheeded by the busy multitude, and known only by the researches of the natural philosopher. I allude to Scandinavia, where it is ascertained, that the 
whole country, from Frederickshall, in Sweden, to Abo, in Finland, and even, perhaps, as far as St. Petersburgh, is slowly and visibly rising; while the adjacent coast of Greenland is suffering a gradual depression. The state, therefore, is one of oscillation, the waters appearing to sink at Torneo, and to retain their former level at Copenhagen. The opinion that Swerlen is in this state of change is no new idca; it was long since noticed by Celsius,* and other Swedish philosophers. Mr. Lyell has twice visited Scandinavia within the last few years, with the view of determining this interesting question, and has fully convinced himself that certain parts of Sweden are undergoing a gradual rise, to the amount of two or three feet in a century; while other parts, farther to the soutl, appcar to have experienced no movement. $\dagger$ He visited some parts of the shores of the Bothnian Gulf, between Stockholm and Gefle, and of the western coasts of Sweden, districts particularly alluded to by Celsius. He examined the marks cut by the Swedish pilots, under the direction of the Swedish Academy of Sciences, in 1820, and found the level of the Baltic, in calm weather, to be several inches lower than the marks, and several feet below those made seventy or a hundred years ago. Similar results were obtained on the side of the ocean, and in both districts the

* Illustrations of the Huttonian Theory, p. 436, edit. 1 S22.

+ Philosophical Transactions. Principles of Geology, Fifth Edition, vol. ii. p. 286. 
testimony of the inhabitants agreed with that of their ancestors, recorded by Celsius. Mr. Lyell discovered on the shores of the Northern Sea, elevated banks of recent shells, at various heights, from 10 to 200 feet, and deposites on the side of the Bothnian Gulf, between Stockholm and Gefle, containing fossil shells of the same species which now characterize the brackish waters of that sea. These occur at various elevations, from one to a hundred feet, and sometimes reach fifty miles inland. The shells are partly marine and partly fluviatile; the marine species are identical with those now living in the ocean, but are dwarfish in size, and never attain the average dimensions of those which live in water sufficiently salt, to enable them to reach their full development. The specimens before you were collected by my valued friend at Uddevalla, in Sweden, from cliffs twenty feet above the level of the sea; they consist of recent marine species, such as inhabit the neighbouring waters.

Of the reality of these changes in the relative level of the land and the Northern ocean, there cannot exist a doubt; but the mind is so accustomed to associate the idea of stability with the land, and of mutability with the sea, that it may be necessary to offer a few additional remarks on these highly interesting phenomena. As it is the property of all fluids to find their own level, it is obvious that if the level of the sea be elevated or depressed in any one part, that elevation or depression must extend 
over the whole surface of the ocean, and the level therefore cannot be affected by local causes. But movements of the land may take place, and the effect extend over whole countries, as in South America,-or along lines of coast, as in Sussex, or be confined to a single island, - or even to the broken columns of a temple, as at Puzzuoli.* But while the land is rising in the more northern latitudes, it appears to be sinking on the shores of the Mediterranean. Breislak mentions $\$$ that numerous remains of buildings are to be seen in the gulf of Baiæ; ten columns of granite, at the foot of Monte Nuovo, are nearly covered by the sea, as are the ruins of a palace built by Tiberius in the island of Caprea. Thus, while the level of the sea is sinking in the north, it is rising in the Mediterranean; and as all the parts of the ocean communicate, the level of the sea cannot permanently rise in one part and sink in another, but must rise and fall equally to maintain its level. We must therefore consider it as demonstrated, that the relative change of level has proceeded from the elevation or depression of the land, and that these phenomena are produced by the expansive force of heat, or of electro-chemical agency. If we bear in mind the insignificance of the masses affected by these operations, as contrasted with the earth itself, recollecting that the varnish of a small artificial sphere is equal in

* See Playfair's admirable comments on this geological problem.-Illustrations, p. 433.

$\uparrow$ Playfair. 
proportionate thickness to the entire series of strata which the ingenuity of man has been able to explore, we can readily conceive that as fissures and inequalities are produced in that varnish by heat or cold, in like manner the elevation of mountain chains, the rending of countries, and the subsidence of whole continents, may be occasioned by the thermometrical expansion or contraction of the materials of which our planet is constructed.

58. RETROSPECT.-In this imperfect review of the geological phenomena, which even a superficial examination of the surface of the globe presents to our notice, I have doubtless dwelt on several subjects which are familiar to many of my auditors. But as one of our most accomplished philosophers has remarked - "The teacher of Geology must suppose himself called on to answer questions both concerning the facts of the science and the inferences to be deduced therefrom; and his instruction will be so much the more successful as he takes these questions in the most natural order of their occurrence, and answers them most completely and satisfactorily. In doing this he is not at liberty to neglect even elementary truths, for if these were passed over in compliment to such as have made progress in the science; those for whose advantage he is especially interested, would be called to the unreasonable task of labouring without instruments, and theorizing without intelligible data."*

* Phillips, Guide to Geology. 
From the vast field of inquiry over which our observations have extended, it may be useful to offer a brief summary of the leading principles that have been enunciated, and the phenomena on which they are founded. By the most profound and sublime investigations of which the human mind is capable, we learn that our earth is one of countless myriads of spherical bodies, revolving round central luminaries; and that these bodies occur in every variety of condition, from that of diffuse luminous vapour, to opaque solid globes like our own. All the materials of which the earth is composed may exist either in a solid, fluid, or gaseous state; and simply by a change of temperature, or by electro-chemical agency, every substance may undergo a transition from one state to the other. Water existing as ice, fluid, or vapour, and separable into two invisible gases, offers a familiar example of a body constantly exhibiting these changes; and mercury, of a metal which, although generally fluid, or melted, becomes, when exposed to a very low temperature, a solid mass like silver. The relative position of land and water, and the inequalities on the surface of the earth, are subject to constant changes, which are regulated by certain fixed laws. The principal causes of the degradation of the land are atmospheric agencies, changes of temperature, and the action of rumning water, by which the disintegrated materials of the land are carried into the bed of the ocean. The mud, sand, 
and other detritus thus produced, are reconsolidated by certain chemical changes which are in constant activity, both on the land and in the depths of the ocean, and new rocks are thus in the progress of formation. But the conjoint effect of these disintegrating agencies is unremitting destruction of the lands, and were there no conservative process, the whole of the dry land would disappear, and the earth be covered by one vast sheet of water. The interior of the globe, however, possesses a source of heat,-and whether this heat exists as a central nucleus of high temperature, or as medial foci, - whether dependent on its assumed nebulous state, or produced by electro-magnetic forces acting on the mineral substances contained in the interior of our planet,-does not affect the present inquiry. This internal heat, however produced, occasions constant changes in the relative level of the land and water; elevating whole continents, converting the bed of the sea into dry land,-and submerging the dry land into the abyss of the ocean. The volcano and the earthquake are the effects of its paroxysmal energies, - the quiet and insensible elevation of the land, of its slow but certain operation. By this antagonist power the accumulation of the spoils of the land, which the livers, and waves, and currents have carried into the bed of the ocean, are again brought to the surface, and form the elements of new islands and continents; and by the organic remains discovered 
in these strata, we trace the naturc of the countries from whence these spoils were derived. In the deltas and estuaries of modern times, - in the detritus accumulating in the beds of the ocean,-in the recent tracts of limestone forming on the seashores,-in the cooled lava currents erupted from existing volcanoes, - the remains of man and of his works, and of the animals and plants which are his contemporaries, are found imbcdded.

Such are the deductions derived from the phenomena which have been submitted to our examination.

To the mind previously uninstructed in geological science, I am ready to acknowledge that to attribute mutability to the rocks and the mountains, must appear as startling and incredible, as did the astronomical doctrines of Galileo to the people of his times. But the intelligent observer, whose attention has been directed to the facts laid before him, even in this brief survey, cannot, I conceive, refuse his assent to the inferences thus cautiously obtained. As we proceed in our investigation, we shall find that from the earliest period of the earth's physical history, its surface has been subject to inccssant fluctuation; and as the land has been the theatre of perpetual mutation, that element, which has hitherto been considered as the type of mutability, can alone be regarded as having undergone no change. This idea is finely embodied by Lord Byron in the following sublime apostrophe to the 
Ocean, with which I will conclude this discourse.

"Thy shores are empires changed in all save thee: Assyria, Greece, Rome, Carthage, what are they? Thy waters wasted them while they were free, And many a tyrant since-thy shores obey The stranger, slave, or savage; - their decay Has dried up realms to deserts; - not so thou! Unchangeable, save to thy wild waves' play; Time writes no wrinkle on thine azure browSuch as Creation's dawn beheld, thou rollest now!" 


\section{LECTURE II.}

1. Introductory Observations. 2. Extinction of Animals. 3. Animals extirpated by Human Agency. 4. The Aptcryx Australis. 5. The Dodo. 6. The Cervus megaceros, or Irish Elk. 7. Epoch of Terrestrial Mammalia. 8. Cliaracter of the Ancient Alluvial Deposites. 9. Classification of Organic Remains. 10. Comparative Anatomy. 11. Adaptation of Structure. 12. Osteological Characters of the Carnivora. 13. Structurc of the Herbivora. 14. The Rodentia. 15. Fossil Bones. 16. Fossil Elephants and Mammoths. 17. Mammotli, and Rhinoceros, imbedded in Ice. 18. Tectli of Recent, and Fossil Elcphants. 19. The Mastodon. 20. Mastodons found in the Burmese Empire. 21. The Sivatherium. 22. The Megathcrium. 23. The Megalonyx. 24. The Sloths. 25. Fossil Hippopotamus, and Rhinoceros. 26. The Dinotherium. 27. Bones of Carnivora in Caverns. 28. Cave of Gaylenreuth. 29. Forster's IIöhle. 30. Bones found in Caverns, in Great Britain.-Kirkdalc Cavc. 31. Fossil Diseased Bones of the Carnivora. 32. Human Bones, \&ic. in the Bone Caverns. 33. Osseous Breccia in Fissures. 34. Caves in Australia. 35. Retrospect.

1. Introductory Observations. - In the previous lecture we took a comprehensive view of the actual physical condition of the surface of our planet, and the nature and results of the principal agents by which the land is disintegrated and renewed. We found in the modern fluviatile and marine deposites, that the remains of man, of works of art, and of the existing races of animals, were preserved. In every step of our progress, the grand law of nature, alternate decay and renovation, was exemplified in striking characters-whether in the 
regions of eternal snow, or in torrid climes-in the rocks and mountains, or on the verdant plains-by the agcncy of heat, or by the effect of cold-of drought, or of moisture- of steam, or of vapourby the abrasion of torrents and rivers-by inundations of the ocean-or by volcanic eruptions-still the work of destruction, in every varying character, was apparent. And on the other hand we perceived that amidst all thesc processes of decay, and desolation, perpetual renovation was at the same time going on,--and that Nature was repairing her ruins, and accumulating fresl materials for new islands, and continents; and that countless myriads of living instruments were employed to consolidate, and build up the rocky fabric of the earth; and that even the most terrific of physical phenomena, the carthquake, and the volcano, were but salutary provisions of the Supreme Cause, by which the harmony and integrity of the earth werc maintained and perpetuated. The occurrence of human skeletons in modern limestone-of coins and works of art in recent brcccia-and the preservation of the bones of existing species of animals, and of the leaves and branches of vegetables, in the various deposites that are in progress, incontestibly prove that enduring mcmorials of the present state of animated nature on our globe, will be transmitted to future ages. When the beds of the existing seas shall be clevated above the waters, and covered with woods and forests - when the deltas of our rivers shall be 
converted into fertile tracts, and become the scites of towns and cities-we cannot doubt that in the materials, extracted for their edifices, the then $\mathrm{ex}$ isting races of mankind will discover indelible records of the physical history of our times, long after all traces of those stupendous works, upon which we vainly attempt to confer immortality, have disappeared. But we must now proceed, and pass from the ephemeral productions of man, to the enduring monuments of nature-from the coins of brass and silver, to the imperishable medals on which the past events of the globe are inscribedfrom the mouldering ruins of temples and palaces, to the examination of the mighty relics, which the ancient revolutions of the earth have entombed.

2. Extinction of Animals.-Before entering upon the examination of the geological phenomena, which belong to the period immediately antecedent to the present, it will be necessary to notice one of the most remarkable facts which geological investigations have established,-namely, the entire obliteration of certain forms of animals and plants. The fluctuating state of the earth's surface, with which our previous inquiries have made us familiar, will have prepared us for the disappearance of some species of animals;-and here another law of the Creator is manifest. Certain races of living beings, suitable to peculiar conditions of the earth, appear to have been created; and when those states became no longer favourable for the continuance of such 
types of organization, according to the natural laws by which the conditions of their existence were determined, the races disappeared, and were probably succeeded by new varieties of life.

The extinction of whole genera of animals and plants has no doubt depended on many causes. In the earlier ages, the changes of temperature, and the rapid mutations of land and water, were probably the principal agents of destruction; but since man has become the lord of the creation, his necessities and caprice have occasioned the extirpation of whole tribes of animals, whose relics are found in the superficial strata, with those of species concerning which both history and tradition are silent.

In this country the beaver, wolf, hyena, bear, \&c. are examples of species which still exist elsewhere; while the Irish elk and the mammoth, whose remains occur in our alluvial deposites, are both extinct; and the former was unquestionably extirpated by the early inhabitants of these islands. The obliteration of certain forms of organization, is therefore clearly dependent on a law in the economy of nature which is still in active operation; and I shall now proceed to notice the connecting links between the actually existing species, and those which are blotted out from the face of the earth.

3. Animals Extinct by Human Agency.That the extinction of many of the existing races of animals must soon take place, from the immense destruction occasioned by man, cannot admit of 
doubt. In those which supply fur, a remarkable proof of this inference is cited in a late number of the American Journal of Science. "Immediately after South Georgia was explored by Captain Cook, in 1771, the Americans commenced carrying sealskins from thence to China, where they obtained most exorbitant prices. One million two hundred thousand skins have been taken from that island alone, since that period; and nearly an equal number from the island of Desolation! The numbers of the fur-seals killed in the South Shetland Isles (S. lat. $63^{\circ}$,) in 1821 and 1822 , amounted to three hundred and twenty thousand. This valuable animal is now almost extinct in all these islands." From the most authentic statements it appears certain that the fur trade must henceforward decline, since the advanced state of geographical science shows that no new countries remain to be explored. In North America the animals are slowly decreasing from the persevering efforts, and the indiscriminate slaughter, practised by the hunters, and by the appropriation to the use of man, of those forests and rivers which have once afforded them food and protection. They recede with the aborigines before the tide of civilization.

4. Apteryx Australis. - An extraordinary bird, a native of New Zealand, of which no living individual is known, and but one stuffed specimen exists in Europe, appears to be on the point of extinction, if, indeed, it be not already obliterated. 
It is the Apteryx represented below, and which derives its name from being destitute of wings. The only specimen known to naturalists, was figured and described by Dr. Shaw, and is now in the collection

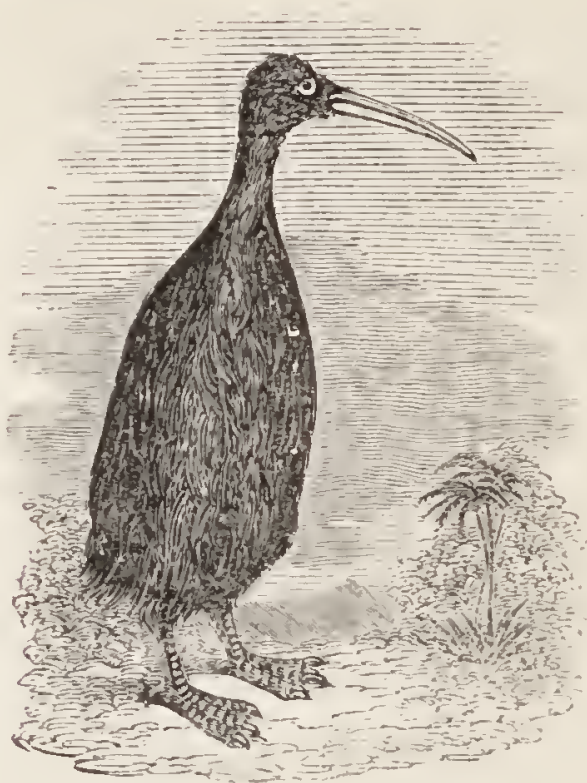

TAB. S.-APteryx AÚstralis.

of Lord Stanley. It has lately been examined by Mr. Yarrell, so that the characters of the skeleton are correctly ascertained. The creature is of a greyish brown colour, and has neither wings nor tail. The beak is slightly curved, and the nasal apertures, instead of opening at the base, as in birds in general, and especially in those of a similar conformation of beak, which is adapted for respiration while immersed in mud or water, is placed at the apex. The eyes are very small. The feathers are long and loose, like those of the emu, but each plume 
has a single shaft. The most active inquiries have not succeeded in obtaining either a living or dead specimen of this bird, although a missionary informed me that skins of the creature were still worn as ornaments by the New Zealand chiefs. There can be no doubt, however, that this wonderful creature either is extinct, or will shortly cease to exist.

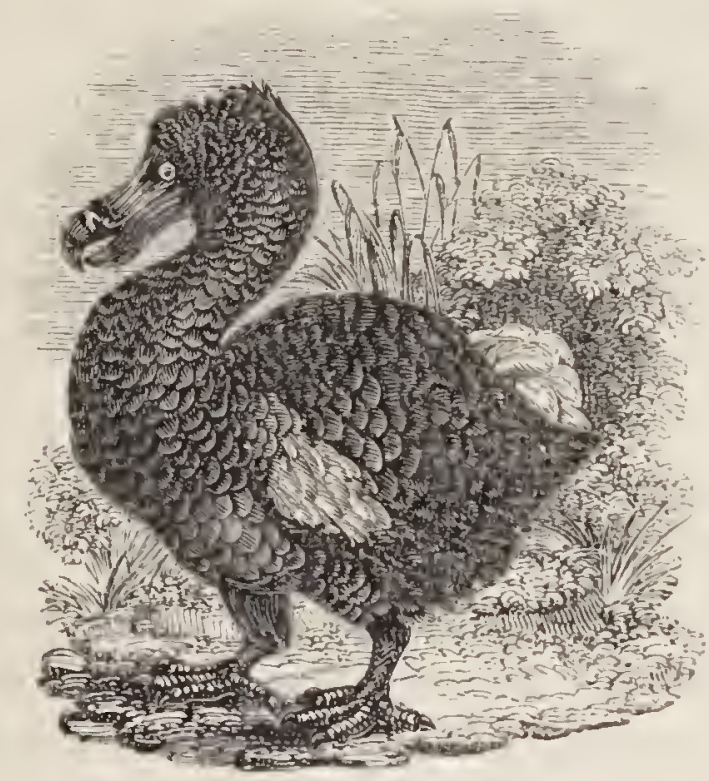

TAB. 9.-TIE Dodo.

5. The Dodo (Didus ineptus).-But lest this alleged extirpation of a peculiar type of organization be considered questionable, let me call your attention to a remarkable instance afforded by the Dodo, which has been annihilated, and become a denizen of the fossil kingdom, almost before our eyes. The Dodo was a bird of the gallinaceous tribe, larger than a turkey, which existed in great 
numbers in the Mauritius and adjacent islands, when those parts were first colonized by the Dutcl, about two centuries ago. This bird formed the principal food of the inhabitants, but it was found to be incapable of domestication, and its numbers soon became sensibly diminished. Stuffed specimens were preserved in the museums of Europe, and paintings of the living animal were executed, and are still extant in the Ashmolean Museum at Oxford, and in the British Museum. But the Dodo is now extinct -it is 110 longer to be found in the isles where it once flourished; and even all the stuffed specimens are destroyed. The only relics that remain, are the head and foot of one individual in the Ashmolean, and the leg of another in the British Museum. To render this illustration complete, the bones of the Dodo have been found in a tufaceous deposit, beneath a bed of lava, in the Isle of France; so that if the remains of the recent bird already alluded to, had not been preserved, these fossil relics would liave constituted the only record that such a creature had ever existed on our planet.

6. The Irish Elk, or Cervus megaceros. (Elk with great antlers.) - The shell marls of Ireland also afford evidence of the existence of a creature, which, like the Dodo, was once cotemporaneous with the human species, but is now altogether extinct, the last individual of the race having, in all probability, been destroyed by man. These remains commonly occur in the beds of marl 
beneath the peat-bogs, which are probably, like those of Scotland, the scites of ancient lakes. In Curragh, immense quantities of the bones of the Elk lie within a small space, as if the animals had assembled in a herd: the skeletons appear to be entire, and the nose is elevated, and the antlers thrown back on the shoulders, seeming to denote that the creatures had sunk in a morass, and been suffocated. Remains of the Elk occur also in beds of marl and gravel, in many parts of England, France, Germany, and Italy. This enormous ruminant very far exceeded in magnitude any living species. The skeleton is upwards of ten feet high from the ground to the highest point of the horns; and the antlers, which are palmated, are from ten to fourteen feet from one extremity to the other. The museum of the late eminent anatomist, Josluua Brookes, which, to the disgrace of the government of this country, was suffered to be dispersed, contained a magnificent pair, measuring eleven feet in expanse, which are now in my collection. Skulls liave been found without horns, and these probably belonged to females. The average weight of the head and horns is computed at three-quarters of a hundred weight. The horns are generally in a fine state of preservation, coloured of a dark brown, with here and there a bluish incrustation of phosphate of iron, like those of the deer from Lewes Levels. The Elk shed its horns, and probably, like existing species, annually. Professor Jameson, Mr. Weaver, and 
others, have clearly proved that this majestic creature was coeval with man. A skull was discovered in Germany, associated with urns and stone hatchets ; and in the county of Cork, a human body was exhumed from a wet and marshy soil, beneath a bed of peat eleven feet thick; the body was in good preservation, and enveloped in a deer skin, covered with hair, which there is every probability to conclude was that of the Elk. A rib of the Elk has also been found, in which there is a perforation, evidently formed by a pointed instrument while the animal was alive, for there has been an effusion of callus or new bony matter, which could only result from something remaining fixed in the wound for some time; such an effect, indeed, as would be produced by the head of an arrow, after the shaft was broken off.* There is, therefore, presumptive evidence that the race was extirpated by the hunter-tribes who first took possession of these islands. $t$

In the rcmarkable examples just cited, we have an interesting transition from the recent to the lost types of animal existence. 1st. Species extinct in these islands, but which are still living in other countries. 2dly. Animals whose absolute extinction is doubtful, but probable. 3dly. Species which have been entirely destroyed within the last few centuries. Lastly, Animals that were blotted out from the face of the earth by the early races of mankind.

* Jameson's Cuvier. $\quad+$ Appendix H. 
7. Epoch of Terrestrial Mammalia.-We must now advance another step in the history of the past, and procecd from the considcration of what is known, to that which is unknown; and I shall restrict the subsequent divisions of this discourse, to the geological phenomena of the pcriod immediately anteccdent to the present; a period in which the earth appears to have teemed with enormous mammalia, and with which but few of the existing races were associated. Thus while the present may be termed the Modern or Human Epoch, that which forms the immediate subject of our investigation may be designated the Epoch of gigantic Mammalia.

8. Character of the Ancient Alluvial Deposites. - "When the travcller," says Cuvier, "passes over those fcrtile plains, where the pcaceful waters preserve, by their regular courses, an abundant vegetation, and the soil of which is crowded by an extensive population, and enriched by flourishing cities, which are never disturbed but by the ravages of 'war, or the oppression of despotism, he is not inclined to believe that nature has also had her intestine wars, and that the surface of the globe has bcen overthrown by various revolutions and catastrophes. But his opinions change as he penetrates into that soil at present so peaceful; or as he ascends the hills which bound the plains. His ideas expand, as it were, with the prospect, and so soon as he ascends the more elevated chains, or follows the beds of 
those torrents which descend from their summits, he begins to comprehend the extent and grandeur of those physical events of ages long past. Or if he examines the quarries on the sides of the hills, or the cliffs which form the boundaries of the ocean, he there sees, in the displacement and contortion of the strata, and in the layers of water-worn materials, teeming with the remains of animals and plants, proofs that these tranquil plains, these smooth unbroken downs, have once been at the bottom of the deep, and have been lifted up from the bosom of the waters; and every where he will find evidence that the sea and the land have continually changed their place."

In almost every part of the world, beneath the modern alluvial detritus, the nature and character of which were described in the former lecture, extensive superficial beds of gravel, clay, and loam, are found spread over the plains, or on the flanks of the mountain chains, or on the crests of ranges of low elevation; and in these accumulations of waterworn materials, are found immense quantities of the bones of large mammalia.* These remains belong principally to enormous animals related to the elephant, as the mammoth, mastodon, \&c., and the hippopotamus, rhinoceros, horse, ox, deer, and many extinct genera and species; while in caverns and

* The term diluvium is commonly applied to these ancient alluvial beds; they are the newer pliocene in the classification of Mr. Lyell, as we shall hereafter explain. 
fissures of rocks filled with calcareous breccia, the skeletons of tigers, boars, hyenas, and other carnivorous tribes, are imbedded. Remains of this kind exist, in such abundance, all over Europe, Asia, and Anerica, that it is impossible to enumerate the localities; they are found alike in the tropical plains of India, and in the frozen regions of Siberia; while there is no considerable district of Great Britain in which some traces of these fossil bones do not occur.

9. Classification of the Organic Remains. -Dr. Buckland, in his Bridgewater Essay, considers these remains as referrible to four divisions.

First. Land animals, drifted into estuaries or seas, and associated with marine shells, such as the Subappennine formations; the beds of gravel, sand, \&c. provincially termed Crag, in Norfolk and Suffolk; loam and clialk conglomerate of Brighton cliffs; clay off IIarwich and Herne Bay, and on the coast of Western Sussex.

Secondly. Terrestrial quadrupeds, imbedded with fresh-water shells; these strata have been formed during the same epoch as the above, at the bottom of fresh-water lakes; such are the lacustrine marls of the Val d'Arno.

Thirdly. Similar remains found in superficial detritus, spread over the surface of rocks of all ages. In beds of gravel near London; Petteridge Common, Surrey; and near Eastbourn, Sussex.

Fourthly. Osseous remains of carnivorous and 
herbivorous animals in caverns and fissures of rocks which formed part of the dry land, during the later period of the same epoch. The caverns of Gaylenreuth, Kirkdale, \&c. are examples.

Lastly. The relics in the osseous breccia, found in the fissures of limestone on the shores of the Mediterranean, in the Ionian Isles, in the rock of Gibraltar, at Plymouth, and in the Mendip hills.*

Before I direct your attention to the fossils collected from those alluvial deposites, which are on the table, and which comprise specimens from almost every part of the world, it will be necessary to review the leading principles of that science which explains the structure of animal existence. Thus while in our preceding investigations we referred to Astronomy to dissipate the obscurity which shrouded the earliest history of our planet, we are now led to that most important department of natural knowledge, Comparative Anatomy, to enable us to restore the lost forms of animal existence. I shall therefore point out to you the mode of induction, employed by the scientific observer, in his investigation of the fossil remains of animals, and by which he is enabled to ascertain the structure and habits of those creatures which have long since disappeared from the face of the earth.

10. Comparative: Anatomy. - To a person uninstructed in this science, the specimens before

* Dr. Buckland’s Bridgwater Essay, p. 94. 
us would appear a confused medley of bones and osseous fragments, impacted in the solid stone; and the only knowledge he could derive from their examination would be the fact, that the stone was once in the state of sand or mud, in which, while soft, the bones became imbedded. But in vain would he seek for farther information from these precious historical monuments of Nature; to him they would appear as unintelligible as were the hieroglyphics of Egypt, before Young and Champollion explained their mysterious import. It is only by an acquaintance with the structure of the living forms around us, and by acquiring an intimate knowledge of their osseous frame-work or skeletons, that we can hope to decipher the landwriting on the rock, obtain a clue that will guide us through the labyrinth of fossil anatomy, and conduct to those interesting results, which the genius of the immortal Cuvier first taught us how to acquire. And here it will be necessary to enter upon the consideration of those beautiful principles of the relation of structure in organized beings, which were first announced by that illustrious philosopher.

11. Adaptation of Structure in Anmals. - The organs of every animal are parts of a machine, all mutually dependent and admirably adapted for the functions they are destined to perform; and such is the relation of the several parts of the machine with each other, that any variation in 
one part, is constantly accompanied by some corresponding modification in another. This mutual adaptation of the several parts of the animal fabric is a law of organic structure, which, like every other induction of physical truth, has only been established by patient and laborious investigation. It is by the knowledge of this law that we are enabled to re-assemble, as it were, the scattered organs of the beings of a former state of the globe, - to determine their place in the scale of animated nature,-and to reason on their structure, habits, and economy, with as much clearness and certainty, as if they were still living and before us. I will demonstrate this proposition by a few examples. Of all the solid parts of the frame the most obviously mechanical are the jaws and teeth; and as we know in each instance the operations they are intended to perform, this part of the animal structure affords the most simple yet striking illustration of the principles I have just enunciated.

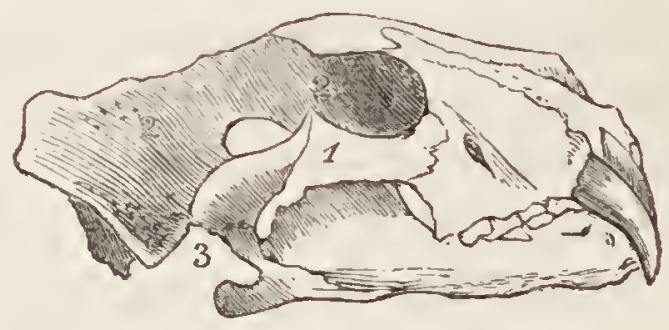

Tab. 10.-Shutl of the Bengat Tiger.

12. Osteological Character of the CarNIVoRA. - Let us examine the jaws of the skull 
before us, that of a Bengal tiger. We pcrceive that there arc cutting teeth in front,-sharp fangs on the sides, - and molar, or bruising, or crushing tecth, in the back part. The molar rise into sharp lanciform points, and ovcr-lap each other in the upper and lower jaw, like the edges of a pair of shears; and the tceth are extcrnally covered with a thick crust of enamel. This is cvidently an apparatus for tearing and cutting flesh, or for cracking bones; but is not suited for grinding the stalks or seeds of vegetables. The jaws fit together by a transverse process, which moves in a corresponding depression in the skull, likc a hinge. (Tab. 10. 3.) They open and shut like shcars, but admit of no grinding motion; this, then, is such an articulation as is adapted for a carnivorous animal; and every part of this instrument is admirably fitted for its office. But all these nice adjustments would be lost, werc therc not levers and muscles to work the jaws, - were not each part of the animal framc adapted to all the other parts,and were not the instincts and appetites of the animal such as are calculated to give to this apparatus its appropriate movements. Let us reversc the order of our argument,-let us assume that the stomach of an animal be so organized as to be fitted for the digestion of flesh only, and that flesh recent,-we should find that its jaws would be so constructed as to fit them for devouring live prey, - the claws for seizing and tearing it,-the teeth 
for cutting and dividing it,- - the whole system of its powers of motion for pursuing and overtaking it, the organs of sense for discovering it at a distance,-and the brain endowed with the instinct necessary for teaching the animal how to conceal itself, and lay snares for its victims. Such are the general relations of the structure of carnivorous animals, and which every being of this class must indispensably combine in its constitution, or its race cannot exist. But subordinate to these principles, are others connected with the nature and habits of the prey upon which the animal is intended to subsist, and thence result modifications of details in the forms which arise from the general conditions. Thus, in order that the animal may have the power requisite to carry off its prey, there must be a certain degree of vigour in the muscles which elevate the head; and thence results a determinate form in the vertebræ or bones from which these muscles originate; and in the back of the head in which they are inserted. That the paws may be able to seize their prey, there must be a certain degree of mobility in the toes, and of strength in the claws, and a corresponding form in all the bones and muscles of the foot. It is unnecessary to extend these remarks, for it will easily be seen that similar conclusions may be drawn with regard to all the other parts of the animal. In the tiger we have a familiar illustration of what has been advanced. 
13. Structure of the Herbivora. - In animals which are destined to live on vegetables we have the same mutual relations; the sharp fangs of the teeth are wanting, the enamel is not all placed on the top of the teeth as in the carnivora, but is arranged in deep vertical layers, alternating with bony matter; and this arrangement, in all states of the teeth, secures a rough grinding surface, as in the horse and the elephant. This fossil tooth of a

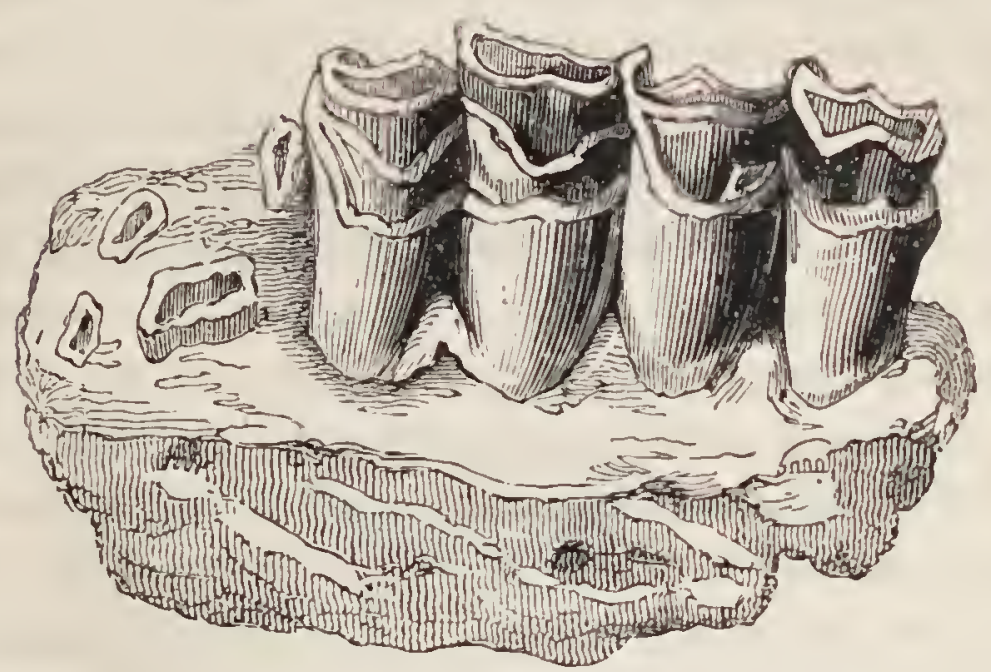

Tab. 11.-Tooth of a Ruminant in osseous Breccia.

ruminant from Cerigo will serve as an illustration. The flat molar teeth are not formed for cutting, but for mastication, and the jaws are loosely articulated together so as to allow of a grinding movement: had the socket and corresponding part of the jaw been the same as in the tiger, the tooth could not have performed its office. Again, I might proceed in the argument, and show the adaptation 
of the muscles of the head to the apparatus here described; and beginning with the jaw review the whole animal frame, and demonstrate how all its parts are alike wonderfully constructed and fitted together, to perform the functions necessary for the being to whom it belongs.

14. Structure of the Rodentia, or GnawERS.-If we now examine the jaw of some intermediate order, we shall perceive new adaptations of the same apparatus.
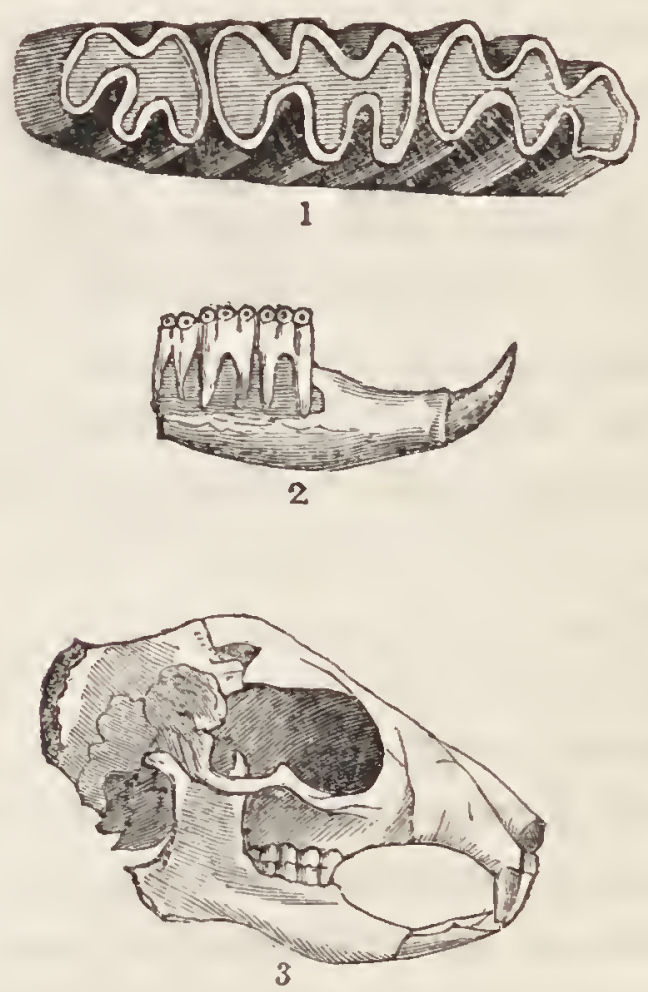

Tab. 12.-SKull and TeEth of Rodentia.

Fig. 1. Molar Teeth of the Upper Jaw of a Florida Rat (Arricols Floridana) magnified; seen obliquely. FIG. 2. Left side of the Lower Jaw, of the natural size. FIG. 3. Skull of the Squirrel. 
15. Skull and Teeth of Rodentia.-Thus the animals called rodentia or gnawers, have long sharp cutting teeth, like pincers; hence the rat can very speedily gnaw a hole through a board, and the squirrel in a nut, in consequence of the exquisite adaptation of their teeth for these operations. In this skull of the squirrel (Tab. 12, Fig. 3) you may perceive that the front teeth are of enormous size, as compared with the molar, and that they lock together in such a manner as to render a grinding movement impossible; a new adjustment has, therefore, been supplied,- - the lower jaw is so adapted as to work in the skull neither in a transverse nor in a rotatory direction, but lengthwise, like the action of a carpenter using his plane. And if you watch a rabbit while eating, you will perceive that its teeth move backward and forward precisely as I have described. The enamel of the molar teeth (see Tab.12, Fig. 1) is placed vertically and transverse to the jaw, so as to form an admirable grinding surface. But this is not the only variation of structure observable in the teeth of these animals. The incisors being implements of continual use, are renewed by perpetual growth, and there is a special provision for their support in a bent socket. The enamel is unequally distributed round the tooth, being very thin behind and thick in front, by which means the cutting edges are always preserved. By the very act of gnawing, the hinder part of the incisor wears away quicker than the fore part, and 
thus it is that a sharp inclined edge is maintained, like that of an adze or chisel, and which is the very form required in the economy of the animal. The skull of the common rabbit or hare will exemplify these remarks. These are but a few of those admirable adaptations of means to ends which are observable throughout the various classes of organized beings: but the brief space of a single lecture will not allow me to be more diffuse, and I trust it is unnecessary to offer further remarks, to show that the conclusions of geologists, as to the ancient inhabitants of our globe, are not vague assumptions, as those unacquainted with the science they attempt to impugn assert, but the legitimate deductions of laborious and patient investigation. A few teeth and bones - sometimes but a single relic of this kind - are the elements by which the comparative anatomist is enabled, not only to restore the forms of creatures now banished from the face of the earth, but also to ascertain their habits and economy, and even arrive at positive conclusions respecting the nature of the country of which they were once the inhabitants. For if we find the remains of animals which lived on vegetables, it follows that there must have been vegetables for their subsistence, and a condition of nature calculated for the growth of vegetable productions; a soil fitted for their existence, and a country diversified by hills, and valleys, and plains, with streams and rivers to carry off its superfluous waters. The same laws, 
under certain modifications, apply to other classes of beings. Thus in birds, the form of the feet is modified according to the habits of the different orders. In the parrot, the claws are adapted to climb trees and perch on the branches; but in the eagle they are widely different, for its talons are constructed to lacerate and tear its prey. The feet of aquatic birds are formed like a paddle or oar, to enable them to make their way through the water; those of birds that frequent marshes, have a great expansion, like a tripod, that they may move over the unstable surface of the morass; while in species destined to inhabit sandy deserts, as the ostrich, the feet present a corresponding change.

Thus we find that every vertebrated animal has a solid and durable skeleton, or osseous support, formed upon one general plan, but modified in almost endless variety, in the relative magnitude, situation, and aspect of the different parts, so as to adapt itself to the various habits and functions of the diversified forms of animal life. In short, that the Author of nature has by these changes varied the same general fabric in innumerable ways; bestowed upon it a thousand different instincts and passions; adapted it to every element and climate; and to every possible variety of food and mode of existence.

From a knowledge of these principles of the corelation of the different parts of every organized being, which I have thus attempted to elucidate, 
we may understand how the scientific observer can reconstruct the entire animal fabric: and we are now prepared to enter upon that department of Geology called Palæontology, or the science which relates to the fossil remains of the beings which were the inhabitants of our planet in former ages.

16. Fossil Bones. - As the bones are the least perishable parts of the animal structure, they become the most frequent, and often the only indications of the zoological character of the more ancient epochs. Occasionally very delicate parts, such as the tunic of the eye, the membranes of the stomach, and the wings of insects, are preserved in a fossil state, examples of which we shall hereafter adduce. In the more ancient deposites, the bones are generally mineralized, and no longer possess the white and glossy appearance of the recent skeleton; but those which occur in the superficial gravel, and in caverns, are commonly of a porous and earthy character, like bones that have lost a portion of their animal matter by being buried in a dry and loose soil.

The animals whose fossil remains I now proceed to describe, may be separated into two classesthe Herbivora, whose bones occur in the gravel and marl, - and the CARnivorA, which are found in fissures and caverns.

17. Fossil Elephants, or Mammoths.*-

* From the Arabic behemoth, signifying elephant. 
I will first notice the fossil remains of the animals of the elephantine family. These occur in great abundance, and are very generally distributed. In the earlier ages, their colossal bones were supposed to belong to gigantic races of mankind, and hence the tradition of giants possessed by every country in Europe: nor need we smile at the ignorance and credulity of our ancestors, for, not many years since, a fossil tooth of an elephant, which was discovered in digging a well in this town, was supposed to be a petrified cauliflower!-In Russia, particularly in Siberia, the bones of fossil elephants are found throughout all the low lands, and in the sardy plains, (but not in the elevated primary chain of hills,) stretching from the borders of Europe to the nearest extreme point of America, and south and north from the base of the nountains of central Asia, to the shores of the Arctic sea. Within this space, which is scarcely inferior in extent to the whole of Europe, fossil ivory is every where to be found; and the tusks are so numerous, and so well preserved, especially in Northern Russia, that thousands are annually collected, and form a lucrative article of commerce, being exported as ivory for turning. In Siberia alone, the remains of a greater number of elephants have been discovered, than are supposed to exist at the present time all over the world. In a low island in the Frozen Sea ( $72^{\circ}$ north latitude) bones of mammoths are seen imbediled; and they also abound in an iceber. on 
the north-west angle of the American continent, close to Behring's Straits.

18. Mammoth and Rhinoceros imbedded in ICE.-But the most remarkable fact relating to these remains, is the preservation, not merely of the bones, but of the flesh and skin, in short, of entire animals, in ice-bergs and in frozen gravel! In 1774, near Vilhoui, the carcase of a rhinoceros was taken from the frozen sand, where it must have been concealed for ages, the soil of that region being always frozen to within a few inches of the surface. The carcase was a complete natural mummy, part of the skin being still covered with long hairs, and forming, a warmer covering than that of the African rhinoceros. The discovery of a manmoth, under similar circumstances, is still more interesting. It appears, that towards the close of the last century, a Tungusian fisherman observed in a cliff' of ice and gravel, on the banks of the river Lena, a shapeless mass, the nature of which he was unable to determine. In the course of the next year it was more visible, and on the third a large tusk was seen projecting from the ice-cliff, and at length became detached. On the fifth year, an early thaw set in, and the entire carcase of a mammoth was exposed, and at length fell upon the ground. It was nine feet high, and about sixteen feet in length; the tusks were nine feet long. The flesh was in such a state of preservation, that it was devoured as it lay by wolves and bears, and the 
hunters fed their dogs with the remains. The skin was covered with hair, consisting of black bristles, thicker than horsehair, and fifteen inches in length ; wool of a reddish brown, and hair of a fawn colour ; and with a mane on the neck. Upwards of $30 \mathrm{lbs}$. of hair were collected, and specimens of it are preserved in the Hunterian Museum. The ear remained dry and shrivelled; the brain and even the capsule of the eye were preserved! the bones and part of the integuments, and a considerable quantity of the hair, are in the Museum of Natural History at St. Petersburgh. The accompanying sketch represents the skeleton in its present state.

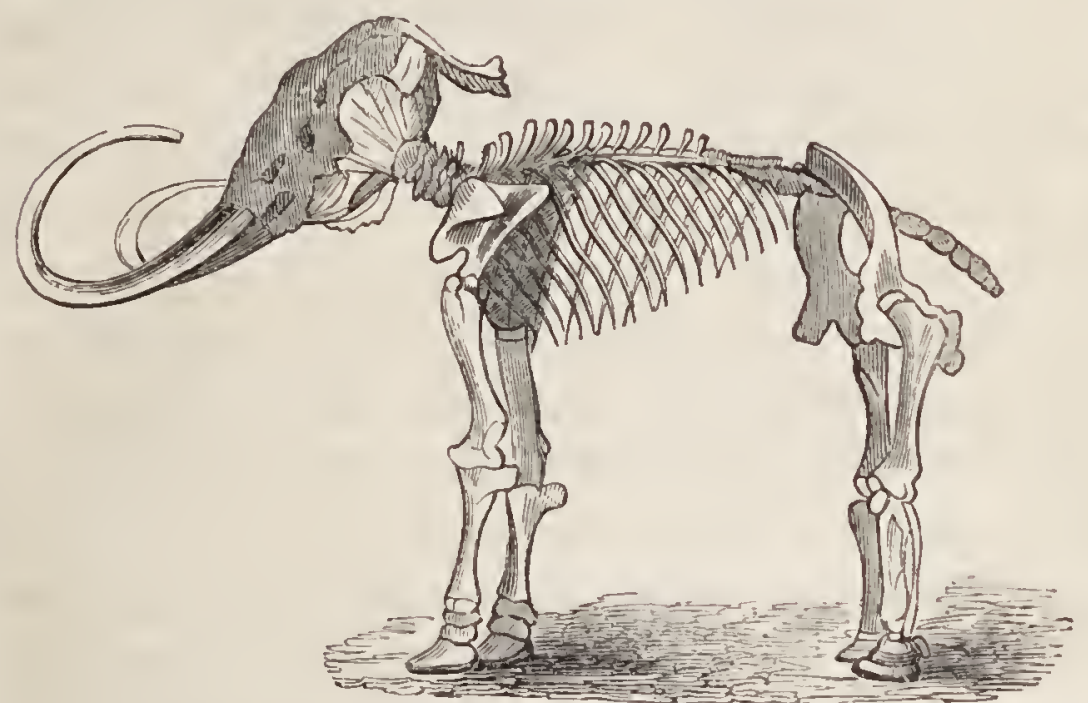

TAB. 13.-MAMMOTH IMBEDDED IN FROZEN GRAVEL IN SIBERIA.

The occurrence of large mammalia, in latitudes where but few forms of animal life can now possibly find the means of subsistence, is a fact of so much interest, that I must indulge in a few additional remarks. You are aware that the existing elephants 
belong to two species, the African, which occurs as far south as the Cape of Good Hope; and the Asiatic, which is limited to $31^{\circ}$ north latitude. They are distinguished by certain characters; but those which more especially relate to our present inquiry, are the peculiarities of the teetl.

19. Teeth of Recent and Fossil ElePHANTS.-The teeth of animals are formed of three distinct substances, which are variously disposed in different orders, according to the habits and economy of the species; a fact to which I alluded when treating of the distinguishing character of the rodentia, \&c. The nucleus of the tooth is formed of a bony matter, consisting almost entirely of phosphate of lime, with albumen, and gluten; it is called ivory. This central portion of the tooth is covered by the enamel, a substance still more dense, and which is of a fibrous structure, and so hard as to strike fire with steel. In the teeth of man, the enamel cover's the whole external surface, and the ivory forms the internal part. In herbivorous animals the cnamel and ivory are intermixed; and there is in some genera, a third substance called crusta petrosa, which is a kind of yellowish, opaque ivory. These three substances enter into the composition of the teeth of the elephant, and in the masticating surfaces their intermixture is apparent; they are differently disposed in the two species. In the African elephant (Tab. 14, fig. 2,) the worn surface of the molar 
teeth presents a series of lozenge-shaped lines of enamel, having the ivory on the inner margin of the ridges, and being surrounded by the crusta, petrosa.

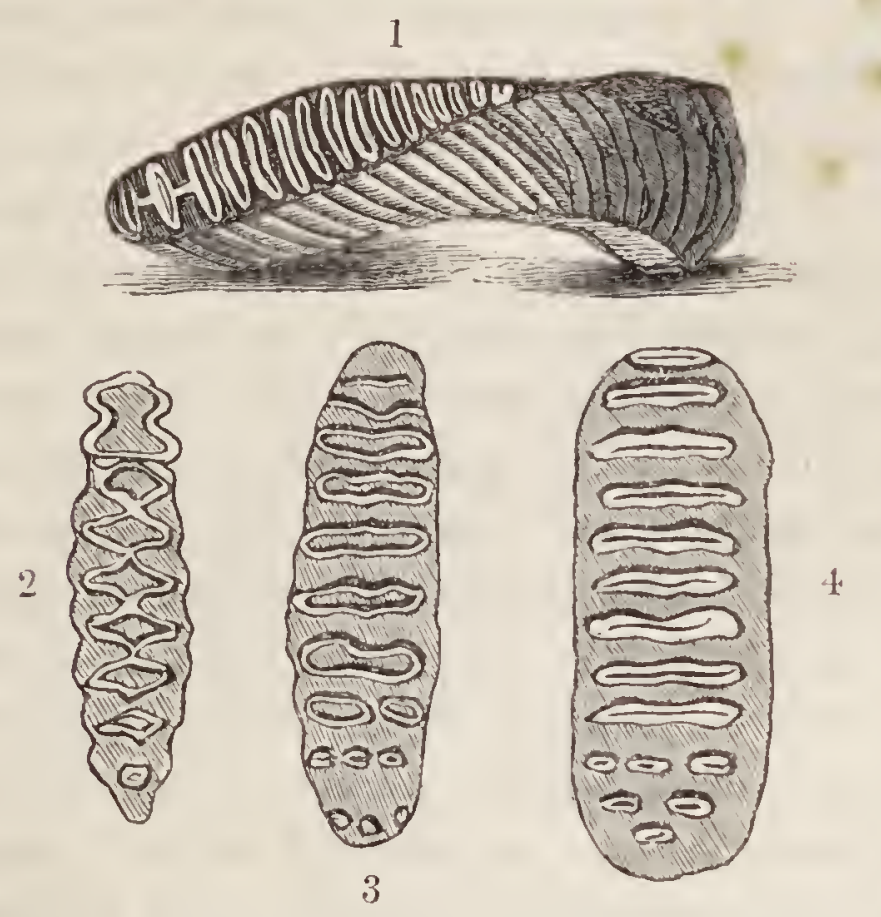

Tab. 14.-Teeth of Recent and Fossic Elerinants.

Fig. 1. Fossil Tooth of an Elephant from Brighton Cliff. Fig. 2. Crown of a Tootl of the African Elephant. Fig. 3. Grinding surface of a Tootl of the Mrammoth. Fig. 4. Grinding surface of the Asiatic Elephant.

In the Asiatic species (fig. 4) the enamel forms narrow transverse bands; and the tooth of the mammoth, or fossil elephant, (Figs. 1 and 3,) has an analogous, but somewhat different distribution. It is obvious that the structure here exhibited, is fitted for the grinding of vegetables; for the three substances, being of different degrees of hardness produce by their unequal wearing, a constant rough 
surface for trituration.* The elephant has but four teeth in each jaw; the deficiency of prehensile teeth being supplied by that wonderful organ, the trunk. The teeth found in a fossil state, appear to be distinct from either of the recent species; but they are more nearly related to the Indian or Asiatic, than to the African species, as you may observe by these specimens from Siberia, India, North America, and from the cliffs on the Sussex coast. In some examples the teeth are water-worn, but most commonly are very perfect, and exhibit no marks of attrition. From a careful review of all the characters of the fossil elephant, or mammoth of Siberia, Cuvier determined that the species was now extinct; that the structure of the teeth, configuration of the skull, and its hairy and woolly skin, proved that it was adapted to live in a colder climate than that in which the Asiatic species could exist; and he infers that the animals originally inhabited the countries where their remains are now found imbedded; and that the preservation of the carcases in ice, proves that the change in the temperature of the climate was sudden, and has since remained unaltered. Mr. Lyell offers an ingenious solution of this curious problem. He supposes that a large region of central Asia, perhaps the southern half of Siberia, may lave enjoyed a climate mild enough to have admitted of the existence of the

* See Dr. Roget's Bridgwater Treatise, for a lucid and most interesting Essay on the teeth of animals. 
extinct elephants; for vegetation may be found in lat. $40^{\circ}$ and $50^{\circ}$ north: and he infers from the physical geography of the country, that the whole tract from the mountains to the sea may have been upraised like Sweden; and that the refrigeration of the north-east of Asia, and its present physical condition, have been the result.

Time will not permit me to dwell at length on other discoveries of fossil elephants, but I will briefly mention a few instances in our own country. On the coasts of Norfolk and Suffolk, so many teeth of fossil elephants have been collected, that Mr. Woodward (the author of "The Geology of Norfolk") has calculated that they must have belonged to above 500 individuals. At Walton, in Essex, and at Herne Bay, bones and tusks have been found. But by far the most extraordinary collection of the remains of British fossil elephants that I ever beheld, is in the possession of Mr. Gibson, of Bow, near London; it contains skulls, tusks, and teeth, from the sucking animal to the adult, and in a marvellous state of preservation; the whole of which were discovered in Essex. In the highly interesting museum of W. D. Saull, Esq. of London, many fine elephantine remains are also preserved. On the western coast of Sussex, and in the neighbourhood of Arundel, and at Patcham, and in this town, teeth and bones of elephants have at different times been exhumed. At Brighton the teeth are found in a deposit of water-worn materials, 
consisting of loam, chalk, and broken flints, resting on a bed of shingle which covers the chalk.* In the conglomerate, of which I lave already spoken, (Tab. 7. p. 90,) as well as in the superincumbent deposit, the teeth of elephants, with bones and teeth of a species of deer, and horse, and bones of Cetacea, occur, and are associated with marine shells. When these remains were imbedded, this part of the English coast, as well as the opposite shores of France, must have formed part of the boundary of a bay or estuary, of a country inhabited by large Mammalia; for similar fossils are found in a deposit of a like character, along the French coast.

20. The Mastodox.-In various parts of North America, there are marshy tracts abounding in salt or brackish waters, which are frequented by deer, and other animals; a circumstance from which they have acquired the American name of Lick. In these morasses vast quantities of bones of gigantic terrestrial Mammalia have been discovered. The spot most celebrated for these remains in Kentucky, is called Big-bone Lick, and is situated to the south-east of the Ohio, in the midst of a group of low hills, and is traversed by a small stream of brackish water. The bottom consists of a black fetid nud, intermingled with sand, and traces of vegetable matter. In this bog, bones of great magnitude occur in profusion. Some of them are

* See Geology of the South-East of England, p. 32. 
referrible to the fossil elephant, but others, as you may observe from the specimen before us, must have belonged to a creature not less gigantic, but with very different characters.

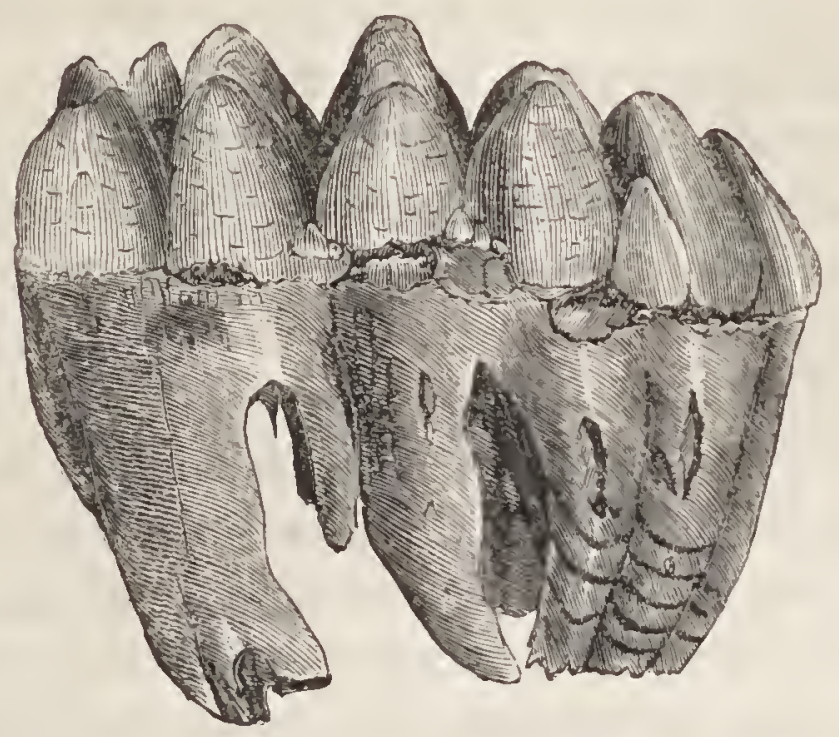

TAB. 15.-Tooth of the Great Mastodon.

(From Professor Silliman of Yale College.)

These teeth, you will in an instant observe, are very dissimilar to those of the elephant; they are composed of ivory and enamel only, and the enamel, which is very thick, is spread over the crown of the tooth, which, when unworn, is divided into several transverse tubercles, $\mathrm{or}^{\circ}$ processes, each of which is subdivided into two obtuse points; from this character of the teeth the name of MAstodon (from two Greek words, signifying mammillary teeth,) has been given to the creature from whom they are derived. These teeth have no relation to those of the carnivora; for although they have an 
external investment of enamel like those of the tiger, yet they are destitute of the longitudinal, serrated, cutting edge; and in those which are worn, the protuberances become truncated into a lozenge form. The structure is similar to that of the hog and the hippopotamus, and is fitted for the bruising and masticating of crude vegetables, roots, and aquatic plants. The remains of the Mastodon have been found throughout the plains of North America, from north of Lake Erie to as far south as Charleston, in South Carolina; they have been also discovered on the Continent, and in the Crag of Norfolk, in England. Here are examples from the banks of the Ohio, of the Hudson, and from Big-bone Lick, presented to me by Professor Silliman; this is an example of a young perfect tooth, and this of a very old animal, for the surface is almost worn flat by use. The remains of the Mastodon are found at moderate depths, with no marks of detrition, and therefore the animals must have lived and died in the country where their relics are entombed. The skeletons of the great Mastodon found in bogs in Louisiana are in a vertical position, as if they had sunk in the mire; and one discovered in New Jersey, forty miles to the south of New York, was found in black earth, in the same position, the head being on a level with the surface of the soil. There is an entire skeleton of the Mastodon in the museum of Mr. Peale, in Philadelphia: it is fifteen feet long and eleven feet 
high; and by this specimen it has been ascertained that the Great Mastodon, or animal of the Ohio, as it has been called, was not unlike the elephant, but somewhat longer and thicker. It had a trunk or proboscis, tusks, and four molar teeth in each jaw, and no incisors. From the nature of its food, as shown by the structure of the teeth, it must have frequented marshy tracks, but it was undoubtedly a terrestrial animal. In the midst of a collection of these bones imbedded in mud, was found a mass of little branches, grass, and leares, in a half bruised state, and among these was a species of reed, common in Virginia; the whole appeared to have been enveloped in a sack, probably the stomach of the animal. In another instance, traces of the trunk or proboscis were observed. The tusks are composed of ivory, and vary in their curvature like those of the elephant. The bones of this colossal quadruped are found remarkably fresh and well preserved; but they are generally impregnated with iron, and have evidently been buried in the earth for ages. No living instance of this creature is on record, and no doubt can exist that its race is totally extinct. The Indians believe that men of similar proportions were coeval with the Mastodon, and that the Great Spirit destroyed both with his thunder.* There are several species of the Mastodon, some of which have been found in North America only, and

* Cuvier. See an admirable English Epitome of Cuvier's Fossil Animals, by Edward Pidgeon, Esq. 1 vol. 8vo. 1833. 
others in Europe. That eminent philosopher Baron Humboldt discovered a tooth of the Mastodon near the rolcano of Imbaburra, at an elevation of 1,200 fathoms. The turquoises of Simone are composed of mammoth bones, impregnated with some metallic oxide. In conclusion I will mention, that a very fine skull, witl teetl, of the Great Mastodon, from Big-bone Lick, has lately been placed in the British Museum, and is well worthy rour notice when risiting that now magnificent collection. This specimen, which was purchased for 150 guineas, consists of the cranium with two perfect grinder's, and the sockets of the other two. The length of the skull, from the occiput to the socket for the tusks, is 36 inches.

21. Mastodons found in the Burmese EmPIRE.-I now request your attention to the remains of a species of Mastodon which, from the structure of the teeth, fills up, as it were, the interral that separates the Mastodon from the Elephant, and which has been named by Mr. Clift, the Mastodon elephantoides. The teeth, which, together with the collection of fossil bones and wood before us, I owe to the liberality of $\mathrm{Mr}$. Craufurd, present characters very peculrar; for while their structure is similar to that of the Great Mastodon, the form of the ridges in which the crown of the teeth is disposed, resembles those of the elephant; and the grinding surface of the tooth, when worn, would bear an analogy with that of the African elephant. 
These teeth, together with bones and tecth of the hippopotamus, rhinoceros, horse, tapir, ox, antelope, hog, gavial, fresh-water turtle, \&c. and silicified wood, are part of an extensive collection formed about ten years since by Mr. Craufurd, on his mission to Ava. Descending the river Irawaddi, his steamboat, owing to the shallowness of the water, ran aground, between Prome and Ava, about $20^{\circ}$ north latitude, near some Petroleum wells, where the bank of the river presents a cliff 80 feet high; and on the strand were observed masses of petrified wood, and vast quantities of bones. The adjacent country is formed of low, sterile sand-hills, intersected by ravines, with beds of gravel, which are here and there cemented into a breccia by iron and carbonate of lime, by the process which was explained in the former lecture. Scattered over the surface, and in some instances lying loose in the sand, in others half buried, were masses of silicified wood, and fragments of bones, which had become exposed, by the removal of the sand by winds or rains. The bones, as you may perceive, in these incrusted specimens, were more or less invested with a hard calcareous, siliceous conglomerate, which appears to be a mere local concretion, from the consolidation of the loose sand by ferruginous and calcareous infiltrations. The natives who assisted Mr. Craufurd's party in collecting these remains, believed that they were the bones of giants who had warred against Vishnu, by whom they had 
been destroyed. On these important discoveries of Mr. Craufurd, Dr. Buckland* calls attention to the remarkable fact, that in the twelve chests full of osseous remains, not a fragment belongs to the elephant, tiger, and byena, which abound in India; while of the extinct Mastodon, evidence is afforded that it must once have swarmed in the districts bordering on the Irawaddi.

22. The Sivatherium. $†$ - The flanks of a range of hills belonging to the Sub-Himalaya Mountains, between the river Sutlej and the Ganges, are covered by beds of concretionary sandstone, conglomerate, and loam, bearing a close analogy to those of Ava we have just examined. These hills, which are called the Sivalik, (from Siva, an Indian deity,) rise to an altitude of from one to three thousand feet above the level of the sea. In these deposites occur immense quantities of the fossil teeth, and bones of the elephant, mastodon, hippopotamus, rhinoceros, elk, ox, horse, deer; and of several carnivorous animals, crocodiles, gavials, and fresh-water turtles; with fluviatile shells, and remains of fishes. Extinct species of monkey and camel have also been found. These interesting discoveries were made by Captain Proby Cautley, of the Bengal artillery, and Dr. Falconer, who, with an energy and perseverance beyond all praise, have

* See an interesting Memoir on the Bones from Ava, by Dr. Buckland. Geol. Trans. vol. ii. New Series.

† From Seva, an Indian deity, and therium, wild animal. 
followed out their researches, and transmitted magnificent collections of these remains to England. The valuable specimens before us were, with great liberality, sent to me by Captain Cautley, to whom I am an utter stranger; among them you may observe the same species of mastodon as that of Ava; with bones of the horse, rhinoceros, hippopotamus, gavial, and a fine skull of the fossil elephant, with all the four teeth perfect. But the labours of these naturalists have been yet more richly rewarded by the discovery of the skull, and other parts of the skeleton, of a creature hitherto unknown; one that forms, as it were, a link between the ruminants and the large pachydermata. From the skull, which is remarkably well preserved, it is ascertained that the animal had four horns, and was furnished with a proboscis; that it was larger than a rhinoceros, and combined the horns of a ruminant, with the characters of the pachydermata. The discoverers have named it the Sivatherium. This animal, when living, must have resembled an immense antelope, or Gnu; with a short and thick head, an elevated cranium, crested with two pairs of horns; the front pair were small, and the hinder large, and set quite behind, as in the aurochs. With the face and figure of the rhinoceros, it must have had small lateral eyes, great lips, and a nasal proboscis; these inferences have been deduced from certain anatomical characters exhibited by the fossil bones, but upon which I must not now enlarge. 
23. The Megatherium. (Megas, great, and Therium, wild beast.) — The Pampas, those immense plains of South America, on the south bank of the river Saladillo, which present a sea of waving grass for 900 miles, are principally composed of alluvial loam and sand, containing fresh-water with marine shells, and were once, like Lewes Levels, a gulf, or arm of the sea. In these alluvial deposites, enormous bones have been frequently discovered. Towards the close of the last century, an almost entire skeleton of a gigantic animal was dug up, at the depth of 100 feet, in a bed of clay, on the banks of the river Luxor, about four leagues W.S.W. of Buenos Ayres. This skeleton was sent to the museum at Madrid, in 1789, where it now remains. It is described and figured by Cuvier, under the name of the Megatherium. In 1832, my friend, Sir Woodbine Parish, with considerable labour and expense, collected many parts of a skeleton of a similar creature from the Salado, actually diverting for a time the river from its course, that he might disinter these precious relics, which he has since deposited in the Hunterian Museurin of the Royal College of Surgeons. But, before I enter upon a description of these fossils, it will be requisite to notice the remains of an animal of analogous structure, which has been discovered in the saltpetre caves in Virginia and Kentucky, and which, from the size of the unguical or claw-bones, has been named the Megalonyx. 
24. The Megalonyx.*-I have placed upon the table, models of all the bones which are now preserved in the museum of Philadelphia, and for which I am indebted to an eminent physician and geologist of that city, Dr. S. G. Morton, the author of the most valuable treatise that has appeared on the Fossils of the United States. $†$ The late American President, Jefferson, who first described the remains of this animal, inferred, from the form and magnitude of the claw-bone, that the creature was a carnivorous animal of colossal proportions. But Cuvier, by his profound knowledge of the principles of anatomy, determined, from certain characters of the articulating surfaces, that the animal was related to the Bradypus, or sloth. I will endeavour briefly to explain to you the mode by which this induction was obtained. The paws or feet, both of the canine and feline tribes, are armed with claws; in the former, the nails are thick and coarse as in the dog, wolf, \&c. and fitted to bear the friction and pressure incident to a long chase; while in the cat tribe, on the contrary, they are curved and sharp, which qualities are preserved by a peculiar mechanism. The last bone which supports the claw is placed

* Megas, great; onyx, claw. See a "Description of the Fossil Bones of the Megalonyx," in Dr. Harlan's Medical and Physical Researches.

$\uparrow$ Synopsis of the Fossils of the Cretaceous Group.

+ That surface of the bone which forms a joint with another corresponding bone.-G. F. R. 
laterally to the penultimate bone, and is so joined to it that an elastic ligament draws it back, and raises the sharp extremity of the claw upwards; and the nearer extremity of the farthest bone presses the ground in the ordinary running of the animal, while the claw is retracted into a sheath: but when the creature makes a spring and strikes, the claws are uncased by the action of the flexors or bending tendons. In the Bengal tiger, the claws are so sharp and strong, and the arms so powerful, that they have been known to fracture the skull of a man, by a single touch in the act of leaping over him.* A cat affords a familiar illustration of this peculiarity of structure; when pleased, its claws are retracted, and when angry they are thrown out. In the claw of the Megalonyx there is no such lateral provision, which is necessary for its retraction, and the point could not have been raised rertically, as in the cat, so as to have permitted it to touch the ground without injury. The articulating surface is double, that is, there is a ridge or spine in the middle, and it must, therefore, have moved like a hinge.

25. The Sloth.-There is among recent animals an order called Tardigrada, from their feeble power of progression-these are the Paresseux or Sloths; which have large toes, and long nails, of a construction similar to those of the fossil. Their nails are folded up, but in a very different manner from those of the cat; they just enable the animal

* Sir C. Bell. 
to walk, in the same way as if our fingers were folded under the palms of the hands. This is a specimen of the Bradypus (slow-footed) tridactylus (three-toed) from South America, and which is called the $A i$, from its peculiar cry. The arms, you perceive, are double the length of the legs, and, from the construction of the limbs, the animal, when it walks, or rather crawls on the ground, is obliged to drag itself along on its elbows. But these creatures are destined to inhabit trees; their proper element is on the branches, and they can pass from bough to bough, and from tree to tree, with a rapidity which soon enables them to lose themselves in the depths of the forests. They live on the leaves and the young shoots, and, unless disturbed, never quit a tree till they have stripped off every leaf. To avoid the trouble of a descent, they drop to the ground, previously coiling themselves into a round ball, in which state, while attached to the branch, they may be taken alive. This brief notice of the habits and economy of the Sloth, points out the necessity for a peculiarity of structure in its nails. The monkey leaps and swings himself from tree to tree, and catches at will the branches or the trunk. But the sloths do not grasp; their claws are mere hooks to hang by, and their great strength is in their arms. They never unfix one set of hooks until they have caught a secure hold with the other, thus hanging by their arms and legrs, while their bodies are pendant; and they sleep in the same position. 
In the bones of the arm of the Megalonyx, we find a corresponding analogy with those of the Sloths. The humerus, or arm-bone, has a long internal condyle for the origin of very large muscles to move the enormous claws; and there is a foramen or opening for the passage of nerves and blood-vessels, to protect them from the pressure to which they would be exposed from the powerful muscular action; while the radius is so constructed as to allow of a rotatory motion of the arm. With the bones of this animal were found masses of osseous polygonal scales, like mosaic work; and it is supposed that the original was covered with an armour resembling that of the armadillo.

I now proceed to the consideration of the Megatherium. This creature was about seven feet high, and nine long, and therefore larger than the largest rhinoceros; but this comparison by no means conveys a proper idea of its bulk, since its proportions are perfectly colossal, the thigh-bone bcing three times as large as that of the elephant, and the pelvis or haunch-bone, twice the breadtl. It possessed no incisor teeth, and the molars or grinders are seven inches long, of a prismatic form, and, like those of the elephant, composed of ivory, enamel, and crusta petrosa, or cement. They are so formed, that the crown of the teeth always presents two cutting, wedge-shaped, salient angles. As in an adze, a plate of steel is placed between two of iron, so as to project in a line, in like manner these teeth have in the 
centre, a cylinder of ivory, which is protected by a plate of enamel, and has an external coating of crusta petrosa; these teeth are, therefore, admirably adapted for cutting and bruising vegetable matter. The entire fore-foot is about a yard in length, and the claws are set obliquely to the ground, like those of the mole; a position which would render them dig. ging instruments of great power. The pelvis measures five feet in width, and the sacral aperture of the spinal marrow is one foot in circumference! This enormous size was suitable to the habits of an animal requiring to maintain an upright posture for a considerable time, and to employ its fore-feet in digging. As Dr. Buckland has so admirably elucidated the structure and habits of this enormous being of the ancient world, and as his work is, or ought to be in every library, I will not dwell on other important peculiarities in its osteology, but content myself with stating, that the Megalonyx and Megatherium were intermediate between the sloths, armadillos, and ant-eaters. The Megatherium, with the head and shoulders of the sloth, combined in its legs and feet an admixture of the characters of the armadillo and ant-eater. Both the megalonyx and megatherium were herbivorous, but they were not capable of climbing, even had there been trees that could have supported their enormous weight: their food, like that of the armadillos, must have consisted of roots and stems of succulent vegetables, which the peculiar structure of their feet enabled them to dig up with 
facility. Like their recent types, they are limited in their geographical distribution to nearly the same regions of the new world.*

26. Fossil Hippopotamus, Rhinoceros, Horse, sc. - With the fossil remains of the Mammoth, Elephant, and other large mammalia, the teeth and bones of the Hippopotamus, Horse, Elk, Ox, and Auroch, are very commonly associated. In the Vale of Arno, in Italy, immense quantities of the teeth and bones of Hippopotami are found. On the table before us are specimens from that locality; as well as molars and incisors of a young animal from Huntingdonshire, presented by W. D. Saull, Esq. F.G.S.; and tusks and bones, dug up a few months since at Southbourn, in Sussex. Bones of this animal also occur in alluvial deposites near Rome; and here are examples, collected by the Marquis of Nolthmpton. Among the objects sent me by Captain Cautley, from India, are several fine portions of jaws, with teeth, belonging to a Hippopotamus (H. Sicaliensis.) Several extinct species of Hippopotamus have been determined by Baron Cuvier, one of which was not more than half the size of the common species. The bones and teeth of the Rhinoceros are constantly associated with those of the fossil Elephant; and in this country they occur in superficial gravel and loam: these examples of teeth were discovered in Surrey.

Sce D: Buckland's Bridgewater Essay. 
But the most extraordinary and interesting fact, relating to the fossil Rhinoceros, is the discovery of the entire carcass, with the skin, in frozen sand, on the banks of the Wilaji, in Siberia. The head was extremely large, and sustained two very long horns; it had no incisors; the body was covered with brown hair, particularly on the limbs; and the general form of the animal was lower and more compact than the living species.

The teeth and bones of one or morc species of Horse, occur very constantly with those of the larger and extinct Pachydermata; in these examples of the conglomerated shingle from Brighton cliffs, the coffin, pastern, and cannon bones, as they are termed, are imbedded; in some instances the cavities of the long bones are filled with crystallized carbonate of lime.

In addition to the animals we have already noticed, the deposites now under our examination contain many lost species of ruminants and other orders of Mammalia. The fossil remains of an animal resembling the musk-ox are found with elephant's bones in Siberia; an extinct species of fallow-deer in Scania; of roe-buck and reindeer in France; and gigantic oxen, aurochs, $*$ deer, \&c. in our own country. As Dr. Buckland has given

* Auroch, a recent species of wild bull or buffalo, distinct from the common ox. The horns of the fossil ox are sometimes of enormous size: Mr. Parkinson had a pair in which the length of the horn was 2 feet 7 inches. 
a list of the different animals that have been discovered in these beds, I will content myself with the remark, that while the fossil pachydermata, such as the elephant, rhinoceros, \&c. belong to senera which inhabit torrid climes, the ruminants arc of genera which at the present time are natives of northern latitudes.

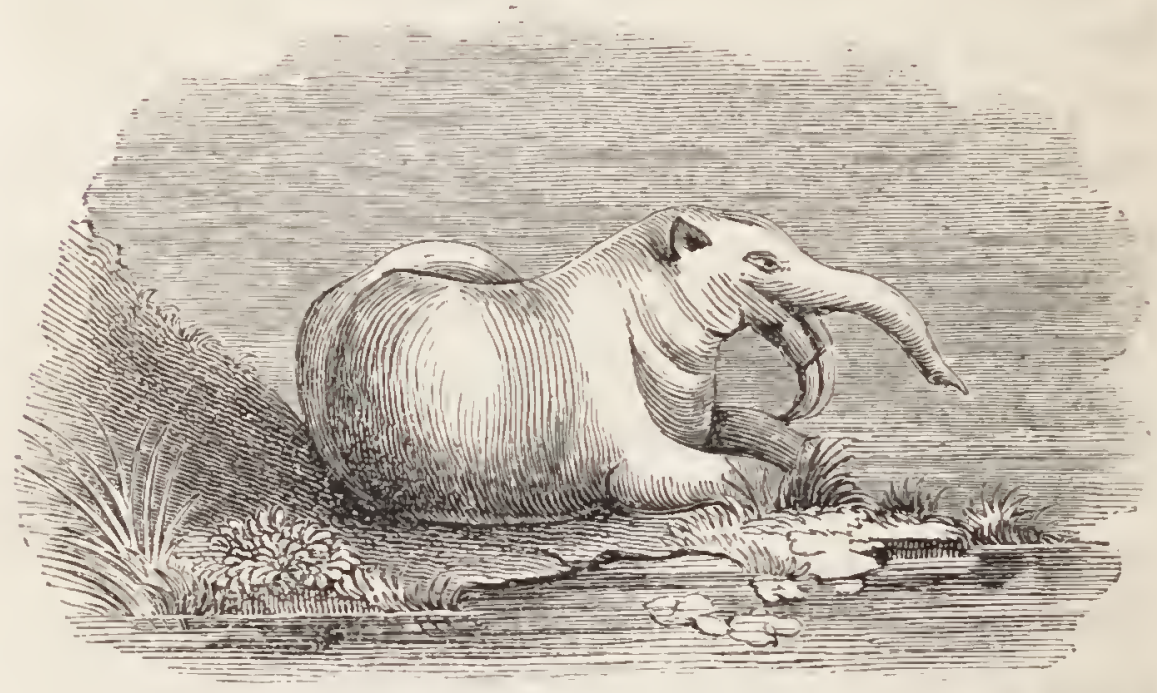

Ta B. 16.-The Disotherium.

27. The Dinotherium.*-I shall conclude my remarks on the large Mammalia by a description of a gigantic creature of a very peculiar character, whose bones occur with those of the Mastodon, Elcphant, and other animals which we have already examined; as wcll as with the remains found in more ancient deposites. In various parts of the south of France large molar teeth, resembling in their form and structure the teeth of Tapirs, have been

* Dinos, terrible ; therium, a wild beast. 
occasionally found; and they are described by Baron Cuvier under the name of the "Gigantic Tapir." These are models of the principal specimens deposited in the Museum at Paris, presented to me by Baron Cuvier, together with others which I shall place before you on a future occasion. Subsequent discoveries in Bavaria, Austria, and particularly at Eppelsheim, about twelve leagues south of Mayence, have made us acquainted with the form and structure of the original, which appears to have been one of the largest of lacustrine animals, the skeletons showing that some individuals were eighteen feet in length! The scapula, or shoulder-blade, was like that of the mole, and the fore-leg must therefore have been adapted for digging up the earth. The most extraordinary deviation from ordinary types consists, however, in the curved tusks, which are fixed in the lower jaw in a downward direction, as those of the Walrus are in the upper; the lower jaw is four feet in length. It is certain that the creature had a proboscis, because it possesses no incisor teeth with which to seize its food, and the jaws do not even close together in front; and from the structure of the anterior portion of the cranium, and the disposition of the nasal fossæ; the tusks were probably weapons of defence, like those of the elephant. The above drawing, (Tab. 16,) from a restoration by M. Kaup, an eminent German naturalist, represents the supposed form of the original creature. It would appear that the 
Dinotherium was nearly related to the Hippopotamus, forming a link between the Cetacea and Pachydermata, or large terrestrial Mammalia; and that it was an herbivorous aquatic animal, and inhabited lakes and marshes.

28. Fossil Carnivora in Caverns. - We have passed in review the extinct population of a remote period of our globe,- - those enormous pachydermata, the mastodons and mammoths, that lie buried in the alluvial and superficial strata. We now arrive at the consideration of phenomena not less interesting-the occurrence of the skeletons of immense numbers of carnivorous animals in fissures and caverns. In the former discourse I alluded to the cavities which abound in certain rocks of limestone, and described the process by which their roofs, floors, and walls were coated with sparry incrustations, and ornamented with stalactites and stalagmites. Some of these caverns appear to have been occasioned by the destruction of the softer portions of the rock by subterranean streams; others are so extensive, and present such decided marks of angular fracture, as to leave no doubt that they have been produced by the shocks of earthquakes. The occasional occurrence of the bones of animals in such cavities might reasonably be expected. Those that admitted of easy access from without, might be frequented by those animals whose habits lead them to retire into dark and secret recesses; while other species, as kids, deer, \&c. might fall 
into open fissures, and their bones thus become enveloped and preserved in calcareous incrustations. But the immense quantities of only one or two species of carnivora that are found in some caverns, show that these have been for a long period the dens of extinct species of bears, wolves, tigers, hyenas, and other carnivorous tribes.

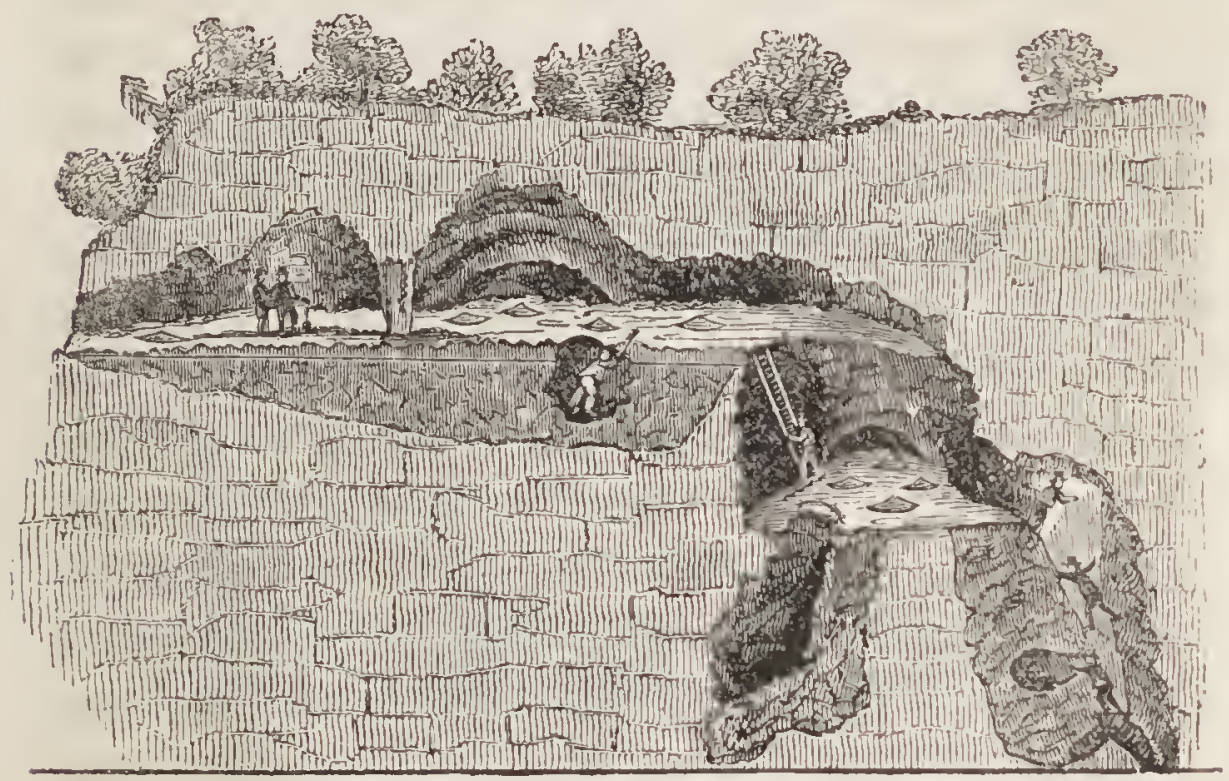

Tab. 17.-The Caves of Gaylenrfuth.

29. Caves of Gaylenreuth.-For many centuries, certain caverns in Germany have been celebrated for their osseous treasures, particularly those in Franconia: the most remarkable is that of Gaylenreuth, which lies to the north-west of the village, on the left bank of the river Wiesent. The entrance, which is about seven feet high, is in the 
face of a perpendicular rock, and leads to a series of chambers from fifteen to twenty feet high, and several hundred feet in extent, terminated by a deep chasm, which, however, has not escaped the ravages of visitors. This cavern is perfectly dark, and the icicles, or pillars of stalactite, reflected by the torches which it is necessary to use, present a highly picturesque and striking effect. The floor is literally paved with bones and fossil teeth; and the pillars and corbels of stalactite also contain osseous remains. Loose animal earth abounding in bones, forms in some parts a layer ten feet in thickness. A highly graphic description of this cave was published by M. Esper, more than sixty years ago; at that period, some of the innermost recesses of the cave contained waggon loads of bones and teeth; some imbedded in the rock, and others in the loose earth. The bones in general are scattered and broken, not rolled; they are lighter and less solid than recent bones, and are often cemented with stalactite. Through the kindness of Lord Cole, and Sir Philip Egerton, I am able to illustrate these remarks by a very extensive suite of osseous remains, exhumed from the deepest recess in the cavern; and which were collected a short time since by these distinguished geologists. But the most interesting specimen in my possession is this remarkably perfect skull of a Bear, which belonged to my friend the late Mr. Parkinson, the author of that delightful work, The Organic Remains of a 
Former World. A comparison of this relic with the skull of the Polar bear, shows that it must have belonged to a species of that aninal.* Cuvier, who enjoyed the opportunity of examining a very large collection of bones from Gaylenreuth, was enabled to determine that at least three-fourths of the osseous contents of the caverns belonged to some species of bear; and the remaining portion to hyenas, tigers, wolves, foxes, gluttons, weasels, and other small carnivora. By the bones which were referrible to the bear, he established three extinct species; the largest of these has a more prominent forehead than any living species, and is called the Ursus speleus, or bear of the caverns, and it is to this species the skull I have just exhibited belongs; the other has a flatter forehead, and has been named Ursus arctoidcus. The hyena was allied to the spotted hyena of the Capes, but differed in the form of its teeth and head. Bones of the elephant and rhinoceros are also said to have been discovered; togetler with those of existing animals, and fragments of sepulchral urns of high antiquity.

30. Forster's Hönle.-Another cavern in this part of Germany is mentioned by Dr. Buckland, as one of the most remarkable for the beauty of its

* Their Royal Highnesses the Princes George of Cumberland and Cambridge, when inspecting my collection a few years since, at Lewes, pointed out this skull to me as resembling some fossil remains that had been exhumed from a fissure in limestone, in the kingdom of Hanover. 
incrustations. Its height varies from ten to thirty feet, and its greatest width is about ten yards; in the side vaults, or recesses, which descend, at an angle of about forty.five degrees, into the main chamber, the stalagmite has formed the appearance of cascades of pure alabaster, the waves of which seen to be rushing out at the bottom, to pour themselves into the stagnant lake of the same substance which covers the floor. The rocky roof has been corroded into deep cavities, which are separated by partitions of every conceivable form and tenuity, giving it the appearance of the richly fretted Gothic roof of a chapel, with pendent corbels. Beautiful stalactites depending from these projections, reach almost to the floor, and contribute by their delicacy and transparency to give additional richness to the scene.

It is certainly, as M. Cuvier remarks, a most extraordinary fact, that caves, spread over an extent of two hundred leagues, should have the same osseous contents. The relative proportions of the different species are computed to be as follow:three-fourths of bears-two-thirds of the remainder of hyenas-and a small number of the tiger or lion, and of the wolf or dog; rolled pebbles of a greyish blue marble are the only extraneous materials found with the bones. Let me here call your attention to the singular association of species which some of these caves present; their recent types being widely separated. Thus in one cavern, animals allied to 
the spotted hyena of the Cape of Good Hope, are collocated with the remains of others related to the glutton, which inhabits Lapland; and in another, bones of the rhinoceros are associated with those of the rein-deer. Numerous caves containing similar remains are scattered over the continents of Europe and America; and even in Australia, bones are found in caverns.

31. Bone Caverns in England-Kirkdale CAvE.-Several caverns containing bones of bears, and other carnivora, in every respect analogous to those of Germany which we have just described, have been discovered and explored. Dr. Buckland, in his valuable work, the Reliquice Dilurianc, has noticed several of the most interesting assemblages of this kind. The eave of Kirkdale, now so well known in consequence of the highly interesting disquisition on its contents by my distinguished friend, is one of the most celebrated; and it is highly gratifying to me, that I can illustrate these remarks by an extensive series of bones, \&c. from that cavern. In tlie summer of 1821, a cave was discovered near Kirkdale, about twenty-five miles NN.E. of York, in a bank about sixty feet above the level of a small valley, and near a public road. Some workmen who were quarrying stone, cut across the narrow mouth of a cliasm, which had been choked up with rubbisl, and overgrown with grass and bushes; and which from this cause, as well as from its inaccessible situation, had hitherto 
escaped observation, the entrance being so small that it was only possible for a person to enter in a. bent position. The passage is exceedingly irregular in its dimensions, varying from two to seven feet in breadth, and from two to fourteen feet in height; its greatest length is 245 feet. It divides into several smaller passages, which have not yet been explored, as they are nearly closed by stalactital concretions; these cavities occur where the roof is intersected by fissures, which are continued for a few feet, but are gradually lost in the superincumbent limestone, and are thickly lined with stalactites. The true floor of the cave is only seen near the entrance; for in the interior the whole has been covered with a bed of hardened mud or clay, about a foot in average thickness; the surface of which was perfectly smooth and level when the cave was first opened, except where stalagnites had formed upon it by infiltration from the roof. Where stalactitic matter incrusted the sicles, it also extended over the bottom like a thin coat of ice; and therefore must lave been formed since the mud was introduced. This mud or clay was filled with fragments of bones belonging to a great variety of animals; and some of the bones exhibited marks of having been gnawed. From many corroborative circumstances these appearances are, with much probability, supposed to have been occasioned by hyenas. The bones thus preyed upon belong to the tiger, bear, wolf, fox, weasel, elephant, rhino- 
ceros, hippopotamus, horse, ox, and deer. Bones of a species of hare or rabbit, water-rat, and mouse, with fragments of the skeletons of ravens, pigeons, larks, and ducks, were also discovered with these remains.

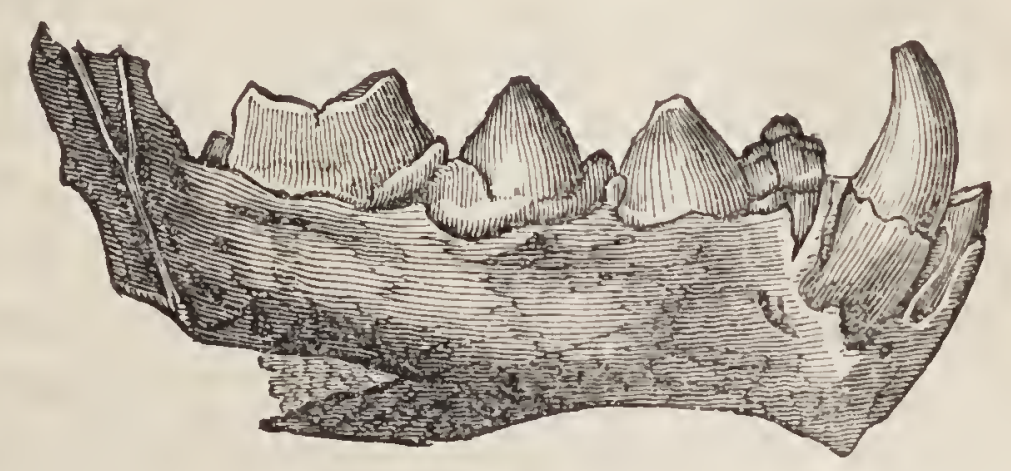

TAB. 18. JAW OF A HENA, FROM KIRKDALE CAVE.*

From these facts Dr. Buckland infers that the cave at Kirkdale was inhabited by hyenas for a considerable period, and that many of the remains found there were of species which had been carried in, and devoured by those animals; and that in some instances the hyenas preyed upon each other. Portions of elephants' bones seem to show that occasionally the large Mammalia also served as food; but it seems probable that many of the smaller animals may have been drifted in by currents, $O{ }^{\prime}$ have fallen into the chasm, through fissures now closed up by stalactite.

Kent's Cave, near Torquay, which is nearly

* This figure is from Dr. Buckland's representation of a portion of the lower jaw of a hyena, from Kirkdale Cave. 
600 feet in length, has yielded immense quantities of bones of carnivora; and in the Isle of Portland, at Plymouth, and in the Mendip Hills, similar accumulations have been found. In the south-east of England but one instance is known; a fissure in the sand-rock at Boughton Quarries, near Maidstone, contained the jaw and bones of a hyena, which are now in Dr. Buckland's Museum, at Oxford. This fact is highly interesting to us, for it proves the existence of the same condition of animated nature in this part of our island, as in the districts previously mentioned; and I cannot doubt that sooner or later bone caverns will be found in the south-east of England. Very recently a cavern has been discovered near Plymouth, in which hyenas' bones were in abundance associated with those of the elephant, rhinoceros, horse, \&c.

From what has been stated, we learn that our wastes and forests were once inhabited by carnivorous animals of extinct species and genera, which are now confined to southern climates; - that these lived and died for successive generations, and were the prey or the devourers of each other; - that the hyenas, according to their peculiar habits, dragged into their dens the creatures which they killed or found dead, and devoured them at their leisure; - that subsequently the races were amnihilated, and have been succeeded by animals altogether of a different character.

32. Diseased Bones of Carnivora found in 
Caves.-Among the bones found in the caves of Germany are many in a condition which must have resulted from accident or disease. In some there has been a formation of new bony matter to repair fractures; in others there is anchylosis, or adhesion of the joints from inflammation: while in some the effects of caries, or decay of the bones, the result of tedious and painful diseases, are apparent. Others have a light and spongy character, and are very fragile, which must have arisen from a want of energy in the nutritive system, in conscquence of a scrofulous affection.*

33. Human Bones, anil Works of Art, in CA VERns.-Bones of man, and fragments of ancient pottery, have been found in caves, both in France and Germany; a circumstance perfectly natural, since we are well aware that mankind, in a rnde state, have been in the habit of living in caves, and traces of their having inliabited recesses, which had previously been the retreat of wild animals, were therefore to be expected. But as bones of extinct animals occurred with them, it was rashly assumed that they were coeval with each other; more accurate obserrations have, however, shown that the human remains were introduced at a subscquent period. We have historical proof that the early inhabitants of Europe often resided, or sought shelter

* Professor Walther, on the Antiquities of Diseases of Bones; see Professor Jameson's Cuvier's Theory of the Earth, Edin. 1827. 
in natural caves. Thus Florus relates, that Cæsar ordered the inhabitants of Aquitania to be enclosed in the caverns to which they had retired. Many tribes of the Celtic race occupied these subterranean retreats, not only as a refuge in time of war, but also for shelter from cold; as magazines for their corn, and for the produce of the chase; and as places of concealment for the animals which they had domesticated. The bones of such of these people as perished, or were buried in these caverns, would become blended with the mud, gravel, and debris of the animals already entombed; and a stalagmitical paste would in some places be formed by the infiltration of water, as at Bize, and would thus cement the whole into solid aggregates. We should therefore expect to find masses of stone, containing bones of the bear, and other extinct. species, with human bones, fragments of pottery, and terrestrial shells, and bones of animals of modern times. Such are the contents of numerous caves, and the above explanation points out the mode in which these accumulations have taken place.*

34. Osseous Breccias, or Bone ConglomeRATES.-The phenomena we liave next to examine are even more extraordinary than those which have already been described; for the osseous remains which now claim our attention are not imbedded in gravel $o^{n}$ clay, or collected together in cares, but

* Memoir by M. Desnoyer. 
are found in fissures of limestone, which extend over an area of many hundred leagues, and occur in detached rocks and islands, very remote from each other. The limestone presents but little variety, and the substance in which the bones are enveloped is every where the same; the fossil remains belonging, with but few local exceptions, to similar species of animals. The rocks are split in erery direction, and the fissures filled with what geologists term an osseous or bone breccia; that is, bones, and fragments of bones, held together by a calcareous cement or paste; in the same manner as the conglomerated shingle of Kemp Town; or, to exemplify its nature by a still more familiar illustration, the mixture of mortar, pebbles, \&c. employed in masonry, and called concrete. This cement is of a reddish-brown, very much resembling common brick; and the bones are beautifully white, having in many instances their cavities lined with spar, as in these specimens from Gibraltar. In some examples the bones have undergone but little change; in others, the cells in the cancellated structure, are filled with calcareous matter; as you may observe in this specimen from Cerigo, (presented to me by Lady Mantell,) which is cut and polished, to show the internal structure of the bones. This tooth of a species of ruminant (Tab. 11, p. 119,) from Gibraltar, resembles in its general appearance the teeth found in the Coombe-rock of the Brighton cliffs. But the stone to which it is 
attached is more compact, and partakes of the character of marble; it is of a dull red colour, mottled with white, and is susceptible of a good polish. This osseous breccia occurs on the northern shores of the Mediterranean; in the rock of Gibraltar; at Cette, Nice, and Antibes; in Dalmatia, and in the isles of Cerigo, Corsica, \&c.; and in Sicily, and Sardinia, and many parts of Germany. Each of these localities present highly interesting examples of the immediate subject of our inquiry.

35. The Rock of Gibraltar. - The rock of Gibraltar, so well known from its historical and political importance, affords an admirable illustration of the phenomena under review; and, for the sake of brevity, I shall chiefly confine my observations to that celebrated spot. Gibraltar is situated, as you well know, on the Spanish side of the Mediterranean, and is united to the main land by a narrow isthmus, which is about three-fourths of a mile broad, eight or ten feet above the level of the sea, and formed of consolidated sand. The rock stands on the western extremity of the area in which the osseous breccias occur, and its greatest altitude is about 1,350 feet. It consists principally of a compact, bluish-grey marble, which, like most limestone masses, is cavernous. The principal carern is called St. Michael's, and contains stalagmites and stalactites, some of which when polished are of great beauty. In the fissures with which the rock 
is intersected, as well as in some of the caves, a calcareous concretion, of a reddish-brown colour, occurs, which in some parts is a mere earthy mass, but in others is highly indurated. The bones are commonly in a broken state, and but seldom waterworn; and the fragments of limestone, with which the fissures abound, are also angular, and have evidently, like the bones, fallen into the crevices at different periods, and been gradually incrusted and conglomerated by calcareous infiltrations. Snails and other land shells are often found impacted in the solid breccia; they belong to the existing species of the country. As the concretion is still in progress of formation, masses may be found in which terrestrial shells occur, unmixed with bones. The cementing material is very similar in the different localities where the breccia has been observed; namely, at Cette, Nice, Antibes; in Dalmatia and Sardinia. The animal remains of the breccia are referrible to several species, some recent and others extinct, of deer, antelope, rabbit, rat, mouse, \&c. Bones of birds and of lizards have been found at Cette; and of lenmings, * and of the Lagomys, $\uparrow$ which now only exists in Siberia: it is but rarely that traces of carnivora are observed. No one can fail to be struck with surprise at the occurrence of these isolated, yet analogous phenomena, which

* Lemming, or Lapland marnot.

+ Signifying rat-hare. A genus of animals which forms a link between the hare and the rat. 
surround the great basin of the Mediterraneanrocks of a uniform character, fissured and broken, their rents filled up with similar materials, and with the remains of the same species of animals. The occurrence of species, either extinct, or no longer inhabiting the same latitudes (as the Lagomys), refers the period of the existence of these animals to the epoch of the mammoths and mastodons; and the absence of marine remains, and of the usual abrading effects of water, show that the breccia was formed on dry land, and not beneath the waters of the ocean.

The rational explanation of these phenomena appears to be that which assumes the original union of these distant rocks and islands into a continent, or large island, which, like Calabria, was subject to repeated visitations of earthquakes; and that the animals which inhabited the country fell into the fissures thus produced, and were preserved by the calcareous infiltrations that were constantly in progress. Subsequent convulsions severed the country into rocks and insular masses, of which catastrophe the osseous conglomerates are the plysical and only record.

36. Osseous Breccia in Australia.-Caves and fissures, filled with osseous breccia, in the same manner with those I have described, have been discovered also in New Holland, to the westward of Sydney, near the banks of the Macquarrie river; and it is not a little remarkable, that even the red 
ochreous colour of the European conglomerate prevails; the bones, however, belong to animals wholly distinct from any hitherto noticed in the preceding examples. Some of them are of living, others of extinct species, but all of them are referrible to marsupial animals, as the Kangaroo, Wombat, Dasyurus, \&c. A portion of a large bone, found in a cave, is said to resemble the leg-bone of the hippopotamus, but this requires confirmation; it is, however, a subject worthy of attention, since the kangaroo is the largest animal now known in those regions. The fact that all the fossil animals of Australia are marsupial, that is, belong to the creatures which carry their young in a pouch-a type of organization which is the peculiar feature of the existing races of the country-is also of great interest; for it proves the marsupial cliaracter of the zoology of those regions from a very remote period.

37. Retrospect.-I must now bring to a close this examination of the ancient superficial deposites -those accumulations of alluvial matter, which, taken as a whole, are referrible to a more early period than those which strictly belong to the modern or human epoch. And as in the former discourse I found it necessary to dwell on the discoveries of astronomy, to elucidate some of the physical changes of our planet; in the present I have summoned comparative anatomy to our aid, and have endeavoured to point out the mode of 
induction pursued by the palæontologist, in his inquiries into the fossil remains of animal organization, by which he is enabled to call forth from their rocky sepulchre the beings of past ages, and, like the fabled sorcerer, give life and animation to the inhabitants of the tomb. From the facts that have been presented to us in the course of this lecture, we arrive at the following important inferences:-

First, That the extinction of certain forms of animal existence is a law, which is not only in operation at the present moment, but has extended throughout the period comprehended in our present researches; and we have traced its influence from the partial extirpation of certain existing species, to the entire annihilation of species and genera that once were cotemporary with man; as well as to those which are known to have lived, and become extinct, long prior to the creation of our race.

Secondly, That while in the modern marine and fluviatile accumulations, the remains of existing species of animals, and of man and his works, are entombed, in the ancient deposites of water-worn materials, those of large mammalia alone are imbedded.

Thirdly, That the animal remains principally belong to extinct Pachydermata, related to the elephant, hippopotamus, and sloth; with horses, deer, and other ruminants; and that these had for 
their contemporaries bears, hyenas, tigers, and other carnivora belonging to extinct species.

Fourthly, That there was therefore a period immediately preceding the existence of man, when the earth teemed with large herbivorous animals, which roamed through the primeval forests unmolested, save by beasts of prey. Numerous species and entire genera have been swept away from the face of the earth, - some by sudden revolutions, others by a gradual extinction, - while many have been exterminated by man.

Lastly, That these various deposites, whether formed in the beds of lakes or rivers, or in the estuaries and basins of the ocean, have been elevated above the levels of the waters, and now constitute fertile countries, supporting the busy population of the human race.

I have thus endeavoured to interpret one page of the ancient physical listory of our planet, and to explain the records of one epoch in geological chronology. We have entered upon the confines of the past, and already we find ourselves surrounded by an innumerable population of unknown types of being - not as dim and shadowy phantoms of the imagination, - but in all the reality of form and structure, and bearing the impress of the mighty changes of which they constitute the imperishable memorials. We have again witnessed the effects of the continual mutations of the land and water,- 
have seen that our present plains and valleys were submerged beneath the ocean, at a period when large mammalia, apparently unrestricted by existing limits of climate, were inhabitants of regions which are now no more-and we have obtained additional proof that-

New worlds are still emerging from the deep,

The old descending in their turn to rise!

Even in this early stage of our progress, we have conclusive evidence of the extinction of whole tribes of animals, equally admirable in their adaptation to the condition in which they were placed, as the races which still survive. And delightful it is to the geologist, to find that this fact, which but a few years since was received with hesitation by most, and condemned and rejected by many, is now ad.. duced by the moralist and the divine, as affording fresh proofs of the wisdom and overruling providence of the Eternal. Reflecting on these phenomena, the mind recalls the impressive exclamation of the poet-

My heart is awed within me, when I think

Of the great miracle which still goes on

In silence round me-the perpetual work

Of THy creation, finished, yet renewed

For ever! 


\section{LECTURE III.}

1. Introduction. 2. Mineral Composition of Rocks. 3. Crystallization. 4. Stratification. 5. Inclined and Vertical Strata. 6. Veins and Faults. 7. Chronological Arrangement of the Formations. 8. Tertiary Deposites. 9. Mr. Lyell's Classification. 10. Fossil Shells. 11. Mineralogical Character of the Tertiary Rocks. 12. Newcr Tertiary or Pliocene. 13. The Crag. 14. The Sub-Appenines. 15. Medial Tertiary or Miocene. 16. Ancicnt Tertiary or Eocene. 17. Paris Basin. 18. London Basin. 19. Isle of Sheppey. 20. Fossil Fruits of Sheppey. 21. Upper Marine Sand. 22. Artcsian Wells. 23. Hampshire or Isle of Wight Basin. 24. Alum Bay. 25. London Clay of Hants. 26. Fresh-Water Strata of the Isle of Wight. 27. Organic Rcmains of the English and Paris Basins. 28. Tertiary Fossil Plants. 29. Tertiary Shells. 30. Tertiary Ceplialopoda. 31. Crustacca and Fishcs. 32. Fossil Birds. 33. Cuvierian Pachydermata. 34. Palæotheria and Anoplotheria. 35. Fossil Monkey. 36. Tertiary Deposites of Aix in Provence. 37. Fossil Insects. 38. Lacustrinc Formation of Eningen. 39. Fossil Fislies of Monte Bolca. 40. Tertiary Volcanocs. 41. Crater of Puy de Come. 42. Mont Dor. 43. Fresli-Water Limestone. 44. Summary of geological Phenomena of Auvergne. 45. Erosion of Rocks by Torrents. 46. Extinct Volcanoes of the Rhine. 47. Brown Coal or Lignite. 48. Tertiary Deposites of North America. 49. Tertiary Strata of the Andes. 50. Salt Mines of Gallicia. 51. Retrospect.

1. Introductory Remarks. - It is my object in these Lectures to present a general view of the philosophy of Geology, rather than enter at length on the nature and distribution of the materials of which the crust of our globe is composed, - and to render the details of geological phenomena subservient to an explanation of the laws which the Divine Author of all things has established for the production, maintenance, and government of 
the organic and inorganic kingdoms of Nature. Based as Geology is upon observations of the various physical changes which are now taking place, and on inquiries into the natural records of those changes, in periods antecedent to all human history and tradition, the rocks and mountains are the alphabet-the book of Nature the volume-by which the student of this interesting department of science can best learn its important lessons. But to those who cannot examine Nature in her secret recesses, or accompany an experienced teacher to the valleys, or to the mountain-tops, lectures, illustrated by specimens and drawings, afford, perhaps, the best substitute for the more efficient and delightful mode of instruction.

That we may obtain a clear and comprehensive view of the vast field of inquiry that lies open before us, artificial classifications are necessary, in this as in other departments of science; and without assuming that the arrangcment, in which the various deposites are grouped by geologists, will not, in the progress of discovery, require considerable modification, I purpose, as an introduction to the subjects hereafter to be discussed, to place before you a tabular view of the rocks and strata in their presumed chronological order. At the same time it is necessary to bear in mind, that all classifications of this kind must necessarily involve arbitrary distinctions, and that very possibly it will hereafter be found that we may in some instances have classed as general, 
what may prove to be merely local phenomena; and grouped together rocks and deposites, which farther investigations may show to be distinct, and separated from each other by vast periods of time. But this consideration will not effect those leading principles of modern Geology, which it is my present endeavour to render familiar to the intelligent but unscientific inquirer.

We will now take a general view of the nature of the mineral substances which enter into the composition of the crust of our globe; and briefly notice the laws which regulate the deposition of detritus in the beds of the lakes and rivers, and in the depths of the ocean. But as I have already remarked, it is not my intention to enter on these departments of Geology in detail; the works of Mr. Bakewell, * Lyell, $\uparrow$ Phillips, + + Delabeche, $\S$ and

* Introduction to Gcology, by Robcrt Bakewell, Esq. 1 rol. 8vo. This excellent volume should bc the first book in the library of the young geologist.

† The Principles of Geology, by Charles Lyell, Esq. F.R.S. 4 vols. $12 \mathrm{mo}$. One of the most intercsting works in the English language. I have reason to believe that an elementary work will shortly be published by my distinguished friend, that will supply what has long been a desideratum-a popularview of the "Elements of Geology."

$\ddagger$ A Guide to Geology, by John Phillips, Esq. F.R.S. 1 vol. 12mo. The article on Geology, in the Encyclopedia Metropolitana, by the same excellent writcr, is in my opinion the best scientific epitome of modern Geology that has yct appeared.

§ A Gcological Manual, by H. T. De la Beche, Esq. F.R.S. An admirable work of reference. 
others, afford every information on these subjects which the student can require.

2. Substances composing the Crust of the Groвe.-Every substance is composed of atoms of inconceivable minuteness, held together by a principle which is termed attraction or cohesion, and is probably a modification of that influence, which, as it exists under other conditions, in inorganic substances, is called electricity, galvanism, or magnetism; and in organized beings, nervous influence. As the different states of solidity, fluidity, or vapour in which every material body may exist, have been exemplified in the former lectures,"we now need only remark, that there are about sixteen substances, which in the present state of chemical knowledge are considered simple in themselves, and that these constitute by their various combinations, if not entirely, by far the largest amount of the matter, either gaseous, liquid, solid, organic, and inorganic, of the earth. Of these, eight are non-metallic substances; viz. oxygen, hydrogen, nitrogen, carbon, sulphur, chlorine, fuorine, and phosphorus. There are also six metallic bases of alkalies and earths, namely, silicium, alumine, potassium, sodium, magnesium, and calcium; and two, the oxides of which are neither earths nor alkalies, namely, iron and manganese. The remaining metallic substances, copper, lead, zinc, arsenic, silver, gold, \&c. are comparatively unimportant in a geological point of view.*

* De la Beche. 
The common sedimentary rocks are in a great degree composed of lime, silex, or argillaceous earth. These substances have, what in mineralogical language is calied, a cleavage, or peculiar fracture, which is distinct in each. Thus, if I take a flint and break it at random, you perceive that it still preserves a glassy or conchoidal fracture, a sharp cutting edge; and subdivide it as I may, it still retains the same character: but if I break a piece of chalk, the edge is not sharp or cutting, but blunt and dull, exhibiting what is called in mineralogy an earthy fracture. Again, if I shiver to pieces with my hammer this calcareous spar, every fragment presents, more or less distinctly, a rhomboidal form; so true is the remark, that we cannot break a stone but in one of nature's joinings.

3. Crystallization. - Crystallization may be defined a methodical arrangement of the particles of matter according to fixed laws. For instance, there are nearly 500 varieties of crystallized carbonate of lime, each crystal being made up of millions of atoms of the same compound substances, and having one invariable primary form-that of a rhomboid. Mechanical division is incapable of altering this arrangement; break them as we may, we can only separate them into a rhomboidal figure; nor can this condition be altered except by chemical decomposition. If we pursue our investigations yet farther, analysis shows that every atom of these crystals is composed of quicklime and carbonic 
acid, which are each made up of countless molecules. "Lime and carbonic acid are also themselves compounds, lime being composed of a metal called calcium and oxygen; and carbonic acid, of carbon and oxygen. Thus these ultimate particles of calcium, carbon, and oxygen, form the indivisible atoms into which all the secondary crystals of lime may be reduced."*

4. Stratification.-As our previous investigations have shown that the disintegration and solution of the most refractory, and apparently indestructible substances, by the conjoined effects of mechanical and chemical agency, are constantly in progress, we can at once proceed to the consideration of the manner in which the spoils of the ancient land have been accumulated, and converted into the rocks and strata of existing islands and continents. We have already adverted to the formation of beach and sand, and the deposition of mud and clay in layers or strata, and their subsequent consolidation into rocks. And here let me remind you, that strata, are the successive layers or accumulations of detritus, spread over each other, in such manner as to allow of the partial consolidation of one bed, before it is covered by a deposition of the materials of another; and a rock is said to be stratified, when it presents the appearance of such divisions. The chalk cliffs, and the sandstone quarries

* See Dr. Buckland's Bridgwater Essay. 
in the South-east of England, afford excellent illustrations of this structure. The original direction of these layers must have been more or less horizontal, for this obvious reason, that from their fluid, or semi-fluid state, they would find their own level, and spread over the surface of the basin into which they flowed; and although they might partake of the inequalities of the depression in which they were deposited, yet this cause would not affect their general distribution. The strata when accumulated in very thin layers, resembling the seams formed by the leaves of a closed book, are termed laminc; and this character very commonly prevails in fluviatile or river deposites: thus the shells, aud clays, and sandstones, in 'Tilgate Forest are laminated, and often bear the impress of the waters which have meandered over them. (See page 36.) The contemporaneous deposites formed in the same oceanic basin, however they may maintain a general character over very extensive areas, must nevertheless vary considerably. At the present moment, the rivers flowing from different latitudes into our existing seas, must necessarily be producing in the same marine basin accumulations of a very dissimilar character; and the geographical distribution of the detritus, must be still more affected by the agency of those mighty currents, to which allusion has already been made (page 47). Bearing in mind these elements of variation in the depositions that may contemporaneously take place within 
the same hydrographical basin, we shall be prepared to find similar discrepancies in the contents of the beds of the ancient oceans.

5. Inclined and Vertical Strata.-But although the strata, whether accumulated in banks or ridges, or deposited in basins or depressions, have originally been consolidated in horizontal layers, yet this arrangement has frequently been disturbed by expansive forces from below, and the strata have been broken up, and thrown into every direction, from a slight degree of inclination, to a vertical position. The sections before us, (Plates $5,6$,$) to which I shall hereafter have occasion$ to refer, exhibit strata in various states of displacement.

Although it is my wish to abstain as much as possible from technical language, yet in some instances its use cannot be avoided without much circumlocution; I will therefore explain a few convenient terms:-Thus, when a series of strata present the same direction, like books piled horizontally upon each other, (Plate 5, No. II. Section near Devizes,) they are said to be conformable; but when beds are superimposed on others that lie in a different direction, (Plate 5, No. III. The fresh-water limestone, $\&$. on the Lias,) as if a set of horizontal volumes were placed flat on the inclined edges of another series of books, they are, in geological language, in an unconformable position.

6. Veins and Faults.-But not only have the 
strata suffered change of position from the disturbing causes which we have seen are in continual action; they have also been rent and broken up, and exhibit cracks or fissures, which in rocks near the surface are sometimes filled, as we have already noticed, with bones, pebbles, and stalactitical concretions (page 160); and in those of ancient epochs, with eruptions of melted matter, and metalliferous ores. The term fault is applied to those fractures and displacements of the strata which are accompanied with the subsidence of one part of a mass and the elevation of another. This is exemplified in this section of the carboniferous strata, (plate 3, fig. 7,) where three curved layers, or seams of coal, have shifted to a lower level, although both sides of the rock remain in apposition. In short, stratification may be compared with the operations of man in erecting various buildings; strata of clay being comparable to beds of mortar, those of harder rocks to layers of brick; while the fissures, veins, and faults are analogous to the cracks, sinkings, and displacements produced by the settling of various portions of the whole erection.

7. Chronological Arrangement of Strata. -In the ancient alluvial gravel, sand, and marl, containing the remains of gigantic mammalia, which formed the principal subject of the last lecture, but few indications of stratification occur; these deposites, for the most part, bearing the character of materials transported by river currents, or accumu- 
lated in estuaries, and thrown up in bays and creeks by the waves, rather than of tranquil depositions. In the formations which succeed, we shall find whole countries composed of regularly stratified rocks, interspersed here and there with diluvial debris. The plan of the strata before you (plate 3 ) is intended to present a general view of the various systems of rocks, from the modern to the most ancient, as classified by modern geologists. For more detailed explanations and sections, I refer you to the works already noticed, and particularly to the admirable systematic diagram of that veteran geologist, Mr. Webster, which forms the frontispiece of Dr. Buckland's Bridgwater Essay.

\section{Cinonological Arrangement of the Strata.}

Commencing with the uppermost or newest Deposites.

Fossiliferous Strata.

1. Modern and Ancient Alluvium.-Comprising the modern and ancient superficial deposites, described in the previous lectures. The modern are characterized by the remains of man and contemporaneous animals and plants; the ancient, by an immense proportion of large mammalia and carnivora, of species and genera, both recent and extinct.

II. The Tertiary Strata.-An extensive series, comprising groups of marine and lacustrine deposites, characterized by the remains of animals and regetables, the greater portion of which are extinct. Volcanoes of great extent were in activity during this epoch. 


\section{Secondary Formations.}

IIT. The Chalk, or Cretaceous System.-A marine formation, comprising beds of limestone, sandstone, marl, and clays, abounding in remains of zoophytes, mollusea, eephalopoda, eehinodermata, fishes, Sc.; drifted wood, and marine plants, with eroeodiles, turtles, and extinct reptiles.

IV. The Wealden.-Comprising the Weald elay, the strata of Tilgate Forest, and the limestones and elays of Purbeek. A freshwater formation, evidently the delta of some aneient river; charaeterized by an abundanee of the remains of enormous and peculiar reptiles, the Iguanodon, Hylæosaurns, Megalosaurus, Plesiosaurus, Crocodile, Sc., of terrestrial plants, freshwater mollusea, and Birds.

V. THE Oolite.-A marine formation of vast extent, eonsisting of limestones and elays, abounding in marine shells, corals, fishes, and reptiles, both terrestrial and marine. Land plants of peculiar species, and the remains of one genus of MAMMalia.

VI. The Lias. - A series of elays, shales, and limestones, with marine shells, cephalopoda, crinoidea, and fishes. Reptiles, particularly of two extinet genera, the Plesiosaurus and Ichthyosaurus, in immense quantities. Drifted wood, and plants.

VII. The Saliferous Strata.-Comprising marls, sandstones, and conglomerates, frequently of a red colour, with shclls, corals, and plants; fishes and reptiles. This series forms the grand depository of rock-salt.

VIII. The Carboniferous System, or Coal.-Shales, ironstones, millstone grit, freshwater limestone, and immense beds of coal. The lower part of the series eonsists of red sandstone and conglomerates. This system is eharaeterized hy innumerable remains of land and aquatic plants of lost species and genera, and of a tropieal character ; fishes and reptiles; inseets.

IX. The Silurian Systea.-Composed of marine limestone, 
shales, sandstones, and calcareous flags; abounding in shells, many of new forms; and swarming with corals, crinoidca and trilobites.

X. The Cumbrian, or Grauwacke System.-Consists principally of a largely developed series of slate rocks, and conglomerates, with shells, and corals.

\section{Metamorphic Rocks.}

Destitute of Organic Remains.

\section{Stratified.}

XI. Tile Mica Schist.--Sedimentary rocks, altered by high temperature; mica slate, quartz rock, crystalline limestone, gneiss, and hornblende schist, \&c., exhibiting no traces of organic remains.

XII. The Gneiss System.-Formed of gneiss, sienite, and quartz rock, alternating with clay, slate, mica, schist, \&c.

\section{Unstratified.}

AIII. Granite. In amorphous masses and veins; porphyry; serpentine, trap, \&c.

I have represented in this diagram (plate 3) intrusions of the ancient melted rocks, as serpentine, porphyry, trap, and granite, into the sedimentary strata; and metalliferous and granitic veins in the granite, to which I shall hereafter have occasion to refer. At present it will only be necessary to mention, that the leading features of this arrangement may be recognised in every considerable extent of country throughout the world; but the lesser divisions are more local, and cannot be generally maintained, for reasons which must be sufficiently obvious, after what has already been advanced. 
From this general view of the physical records of the mutations which the surface of our globe has undergone, we learn how numerous and important are the phenomena comprised within the sphere of geological inquiry, and how vain is the attempt to offer more than an epitome of its wonders in the brief space allotted to a popular course of lectures. We will now enter upon the consideration of the Tertiary Formations, those deposites of the seas, and rivers, and lakes, which are referrible to the period immediately antecedent to the existence of the mammoth and mastodon, and subsequent to the deposition and consolidation of the chalk.

8. Tertiary Formations. - The important discoveries of MM. Cuvier and Brongniart, about twenty years since, in the immediate vicinity of Paris, first directed the attention of geologists to the important series of deposites which are now distinguished by the name of tertiary (see p. 1t). The fossil bones which abound in the gypsum quarries of Montmartre, and belong to extinct genera of mammalia, were by the genius of Cuvier, again called into existence, and the philosophers of Europe saw with astonishment, whole genera of unknown and extraordinary types of being, disinterred from rocks and mountains, which had hitherto been considered as possessing no scientific interest. The existence of analogous strata, some marine, others of a lacustrine and fluviatile character, has since been discovered throughout the continents of Europe 
and America, forming series so vast and extensive, and requiring such a lapse of time for their production, that the chalk, hitherto considered as comparatively modern, is carried back to a period of immense geological antiquity. The tertiary system may be said to constitute a series of formations which link together the present and the past; for while the most ancient contain organic remains related to the secondary formations, the most recent insensibly glide into the modern deposites, and contain many existing species of animals and plants, associated with forms that are now blotted out for ever. Mr. Lyell has formed a classification of the tertiary strata, founded on the proportion of recent species of animals which they contain; and as shells occur in many of the strata in great abundance, and in an excellent state of preservation, he has selected those types of animal organization for the distinctive characters of the subdivisions into which, for the convenience of study, he proposes separating these deposites. In the present state of our knowledge, this arrangement is of great utility, but it appears probable that it may require considerable modification, or, perhaps, hereafter be altogether abandoned with the progress of geological researches; for it cannot be concealed, that strata in which no recent species have yet been found, may yield them to more accurate and extended observations.

9. Classification of the Tertiary Sirata. 
-Mr. Lyell has arranged the tertiary system into four principal groups, each characterized by the relative proportion of recent and extinct species of shells which they contain, and he has adopted a nomenclature denoting the characters upon which this arrangement is founded. They are as follow :-

The Pliocene (signifying more new or recent). - Tertiary strata, in which the shells are for the most part recent, with about ten per cent of extinct species; these beds are again subdivided into the newer and older pliocene.

The Mrocene (denoting less recent).-Containing a small proportion, about twenty per ccnt., of recent species.

Eocene (signifying the dawn of recent, in allusion to the first appearance of recent species).Containing very few recent species, perliaps not more than three or four per cent.

The marine formations are associated with a like number of freshwater deposites, and the general characters of the tertiary system are alternations of marine and lacustrine strata. The districts occupied by these deposites in Europe, are exceedingly variable in extent, as Mr. Lyell has shown in a very ingenious map of the tertiary seas ;* and it appears certain, that during the epoch of their formation, there were areas which werc alternately the sites of freshwater lakes and inland seas, and that these

* Mr. Lyell's Principles of Geology, vol. i. p. 214. 
changes were dependent on oscillations of the relative level of the land and water.

10. Fossil Shells.-The geological evidence afforded by the remains of animals and plants has already been fully exemplified; but our remarks have hitherto in a great measure been confined to the fossilized skeletons of terrestrial quadrupeds; shells, however, from their durability, often escape obliteration under circumstances in which all traces of the higher orders of animals are lust. In loose sandy strata, they occur in a high degree of perfection; in mud and clay, in a fragile state; in some instances they are silicified; and many limestones are wholly composed of these remains, cemented together by calcareous matter. Molluscous animals* are divided into Mollusca, properly so called, which are covered with a shell, as snails, periwinkles, \&c.; and Conchifera, $\uparrow$ having a shell with two valves, as the oyster, scallop, \&c. The former are of a higher organization than the latter, having eyes, and consequently a distinct nervous system; the latter have neither eyes nor head, and are therefore called Acephala. ${ }_{+}^{+}$Like terrestrial animals, some genera of mollusca are lierbivorous, living exclusively on vegetables; and others are carnivorous, having commonly a retractile proboscis, by which they can perforate wood, shells, and other substances. This instrument is protected by a canal, and the

* Soft bodied animals.

$\uparrow$ Shell-bearing animals.

$\ddagger$ Having no head. 
shells of the carnivorous testacea are, therefore, generally provided with a channel or groove for the passage of that organ (as in Tab. 22, Fig. 3, 4, 5); while the herbivorous, being destitute of that appendage, have the opening of the shell entire ('Tab. 23, Fig. 3, 5, 6, 7). Some tribes are exclusively marine, others live only in fresliwater, while many are restricted to the brackish waters of estuaries. Their geographical distribution is alike various: certain forms (the Cephalopoda) inhabit deep waters only, and are provided with an apparatus by which they can rise to the surface; while others are littoral, that is, live only in the shallows along the sea shores; many exist in quiet, others in turbulent waters; some are gregarious, like the oyster, while others live in small groups. All these varieties of condition are more or less strongly impressed on their shelly coverings, which may be considered as their external skeletons, ${ }^{*}$ and the experienced conchologist is enabled at once, by the peculiar characters of the shell, to determine the economy and habits of the animal, and consequently the pliysical condition in which it was placed. In this point of view, fossil shells become objects of the highest importance to the geologist, since they are frequently the only records of the early condition of our planet. But I must return from this

* See an interesting paper on Shells, by Mr. Gray, of the British Museum. Philosophical Transactions. 
digression, and review the phenomena presented by the several groups of the tertiary formations.

11. Mineralogical Characters of the Tertaria System.- The predominating characters of the tertiary system, as I have already mentioned, are alternations of marine strata with those of lacustrine and freshwater origin. A large proportion are arenaceous, with intervening beds of clays and marls. Shingles, the remains of ancient seabeaches, abound in some localities, and form a conglomerate or puddingstone, as that of Hertfordshire (page 76); or a ferruginous breccia, as at Castle Hill, near Newhaven, on the Sussex coast. The ruins of the chalk are everywhere recognisable in the beds of chalk-flints, which contain shells and zoophytes peculiar to the cretaceous system. Large boulders are of frequent occurrence, and may, perhaps, be referred to the newest beds of the series. In the vicinity of Brighton, blocks of ferruginous breccia lie near the old church, and on the race-course; and large masses of quartzose sandstone, of a saccharine structure, are seen at Falmer and in Stanmer Park: a remarkable rock of this kind formerly existed in Goldstone Bottom, but is now destroyed. In many of the gravel beds around London, are blocks of siliceous breccia, and I have noticed specimens of considerable magnitude in the grounds of John Allnutt, Esq. of Clapham Common. In some of the tertiary formations, limestone predominates, and alternates with sands and marls of 
great variety and brilliancy of colour; with beds of gypsum, and siliceous nodules closely resembling the flints of the chalk. Such are the general features of this system of deposites, which I will now examine more in detail.

The distribution of the tertiary deposites over Europe, appears to be in areas more or less well defined; in our own island, there are the basins of London and Hampshire, and the remains of others in Yorkshire, and in Norfolk and Suffolk. In France, the metropolis is situated within the confines of a tertiary basin; and in the south and north of France, extensive tracts are formed of these deposites; in Auvergne, where they are associated with ancient volcanic eruptions, they constitute a district of unrivalled geological interest. In the Sub-appennines, they are largely developed, and in other parts of Sicily and Italy insensibly pass into vast deposites, which are still in progress of formation.

12. Newer Tertiary, or Pliocene Deposites.-From the large proportion of recent species of shells which occur in some of the Pliocene strata, the beds have the appearance of a modern aggregate, as the extensive and beautiful collection from Palermo, before us (for which I am indebted to the kindness of the Marquis of Northampton,) well displays. A low range of hills, rising to an elevation of about 200 feet above the level of the Mediterranean, immediately belind Palermo, is in a great 
measure constituted of coarse limestone, formed of friable shells, which, as you may perceive, are frequently in an admirable state of preservation; white and friable in general, but in some examples preserving their markings and natural polish. The elegant and picturesque manner in which they are occasionally grouped together, as in many of these specimens, renders them objects of great beauty and interest. The shells, with but very few exceptions, belong to species still living in the adjacent seas; a proof that when this limestone was formed, the same condition of the basin of the Mediterranean existed as at present, and continued uninfluenced by the elevation of this portion of its ancient bed. In other parts of Sicily, limestone, blue marls, with shelly calcareous breccia, and gypseous clay, intermingled with volcanic products, occur. The Val di Noto is particularly mentioned by Mr. Lyell, as presenting a remarkable assemblage of deposites; $*$ and I will quote his lucid and highly graphic description. "The rising grounds of the Val di Noto are separated from the cone of Etna, and the marine strata on which it rests, by the plain of Catania, which is elevated above the level of the sea, and watered by the Simeto. The traveller passing from Catania to Syracuse, by way of Sortina and the valley of Pentalica, may observe many deep sections of these 
modern formations, which rise into hills from one to two thousand feet in height, entirely composed of sedimentary strata, with recent shells; these are associated with volcanic rocks. The whole series of strata, exclusively of the volcanic products, is divisible into three principal groups. 1. The uppermost, compact limestone in laminated strata, with recent shells; total thickness from 700 to 800 feet. 2. Calcareous sandstone, witl schistose limestone. 3. Laminated marls and blue clays." The whole of the above groups contain shells and zooplyytes of the same species as those from Palermo which I have just noticed. The large scallop or Pecten, which you perceive is here so beautifully preserved, and at the present day is profusely strewn on the Sicilian shores, is also abundant in the compact limestone. Leaves of plants and stems of reeds, are of common occurrence.

13. Crag of Norfolk and Suffolk.-On the eastern coasts of Essex, Norfolk, and Suffolk, berls of sand and gravel, abounding in shells and corals, which are superposed on the blue clay lying on the chalk, are distinguished by the name of Crag, a provincial term signifying gravel. My late friend, Mr. Parkinson, first noticed these deposites, and in the "Organic Remains of a Former World,"* has figured a shell, which was formerly in much request among collectors the Essex reversed whelk,

* Vol. iii. pl. 6. fig. 5 . 
(Fusus contrarius), in which the spiral convolutions pass from right to left, instead of in the opposite and ordinary direction. Here are several beautiful examples of this fossil shell, collected by my friend Sir Woodbine Parish; they all have the deep ferruginous colour which so commonly prevails in the fossils of the Crag. The Crag first appears at Walton Nase in Essex, and forms the summits of the cliffs on both sides of Hanwell, from a few feet to thirty or forty in thickness. It extends inland along the Suffolk and Norfolk coast, forming a tract of at least forty miles in length; near Ipswich it is spread over a considerable area, and abounds in shells and other marine exuviæ. The series which I now place before you is from collections made by the late Mrs. E. Cobbold, of Holywell Park, near Ipswich ; Sir Woodbine Parish; Samuel Woodward,* and Edward Charlesworth, $\uparrow$ Esqrs. whose recent investigations have thrown much light on the zoological characters of these deposites. Mr. Charlesworth divides the Crag into two groups; the lowermost series, or Coralline Crag, which is composed of loose sand, and abounds in corals, sponges, and shells, in so perfect a state as to indicate that they lived and died on the spot where their remains are entombed. This series is upwards of fifty feet in thickness, and

* Author of "Outlines of the Geologr of Norfolk."

$\uparrow$ The present Editor of the Maga ine of Natural History. 
rests upon a bed of blue clay which will hereafter be noticed. The uppermost, or Red Crag, so called from its deep ferruginous colour, consists of sand with shells, which are generally broken and waterworn; the Norfolk Crag appears to be principally composed of these upper deposites. The fossils of the Crag are extremely numerous, they consist of several hundred species of marine shells, some extinct, but the greater part of species now existing in the German Ocean ; corals, sponges, and more than a hundred species of microscopic foraminifera; with teeth and scales of fishes. The collection of Crag shells on the table was exanined by Mr. Lyell, and M. Deshayes, a distinguished French naturalist, by whom more than half the species were considered to be of extinct forms; and the remainder identical with species which now inhabit the German Ocean.*

14. The Sub-appennines.-The Appennines, that chain of hills which extends through the Italian peninsula, are flanked both on the side of the Adriatic and the Mediterranean, by the Subappennines, a low range composed of tertiary marls, sands, and conglomerates, abounding in marine shells of genera and species, which prove that some of the deposites were contemporaneous with the Crag, and that others are referrible to a more ancient epoch. These beds have resulted from the

* Principles of Geology, vol. iv. p 71. 
waste of the secondary rocks which form the Appennines and were dry land before these strata were deposited.*

15. Middle Tertiary, or Miocene DepoSites.-In the classification of Mr. Lyell, the term Miocene designates those tertiary beds in which recent species of shells occur, but in a much less proportion than in the preceding division; seldom amounting to one-fifth of the whole. As there are no good types of this group in Great Britain, I shall merely observe, that marine and fresh-water deposites possessing the characters here defined occur near Bourdeaux and Montpellier; in Fiedmont, Styria, Hungary, and other parts of the European continent; but in many instances cited by Mr. Lyell, the strata seem to merge into one or other term of the series. I proceed therefore to the consideration of the Eocene, or those tertiary strata which are of the highest antiquity, and deposited in basins or depressions of the chalk, where that formation constitutes the fundamental rock of the country. Every step of our progress will now be replete with the deepest interest, and new and singular forms of being will appear before us. I shall pass rapidly over the stratigraphical character of these deposites, that our attention may be more fully directed to the extraordinary organic remains which they inclose.

* Lyell's Principles of Geology, vol. iv. Brocchi, an eminent Italian naturalist, published many years since a raluable work on the fossil shells of the Sulb-appemines. 
LOWER TERTIARY, OR EOCENE DEPOSITES. 193

16. Lower Tertiary, or Eocene Deposites. -I propose, in the first place, to describe the geographical distribution and general characters of a few principal groups of the older tertiary strata; secondly, to investigate the nature of the more remarkable fossil animals and plants; and lastly, to survey those regions of central France, of the Rhine, and South Anerica, which have been the scenes of active volcanoes during the tertiary epoch.

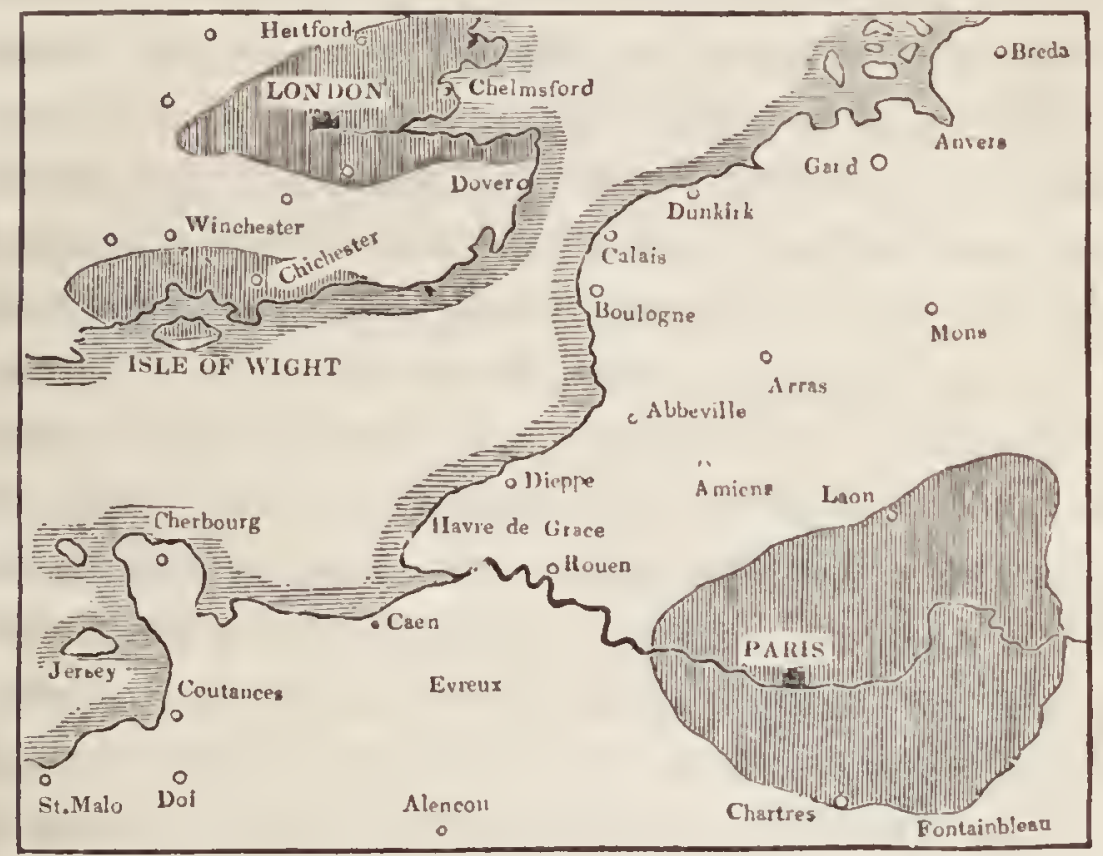

Tab. 19.-Tertiart Basixs of Paris, London, ayd Haxts.*

It may be regarded as a singular coincidence, that the capitals of Great Britain and France are located on strata of the same geological epoch. Paris is

* From Mr. Webster's Map in the Geological Transactions. 
situated on a vast alternation of marine and freshwater deposites, lying in a depression of the chalk; the latter forming the boundary of the area in which the city is placed. London is built on clays, sands, and shingles, also filling up a basin of the chalk, which skirts the area of the tertiary strata on the south, but is open to the sea on the east. In Hampshire, a series of contemporaneous deposites, but with intercalations of lacustrine beds, in like manner occupy a depression in the chalk, and constitute the basin of the Isle of Wight. The relation, situation, and comparative extent of these three systems of tertiary beds, are shown in the preceding map, reduced from that which accompanied $\mathrm{Mr}$. Webster's first announcement of the character's of the British tertiary formations.

17. Tine Paris Basin.-The formation here delineated is in extent from east to west about 100 miles, and 180 from north-east to south-west; the total thickness of the deposites, or, to use other terms, the depths passed through to reach the chalk, varying from one to several hundred feet.

The strata, commencing with the lowermost, or most ancient, present the following characters :-

1. The louermost. Chalk flints, broken and partially rolled, sometimes conglomerated into ferruginous breccia. A layer of this kind is rery common on the South Downs, immediately below the turf.

2. Plastic clay, and sand. Clay and sand, with fresh-water shells, drifted wood, lignite, leaves, and 
fruits; intercalated with limestone containing marine shells.

3. Siliceous limestone, with fresh-water and terrestrial shells and plants; and marine limestone, or Calcaire grossier; a coarse compact limestone, passing into calcareous sand, and abounding in marine shells.-These beds often alternate, and are considered by M. Constant Prevost to be contemporaneous formations; the marine strata having been formed in those parts of the basin which were open to the sea; and the siliceous limestone, by mineral waters pouredinto the bay from the south; the continent being situated then, as now, to the south, and the ocean to the north. Partial deposites of milliolite limestone, ${ }^{*}$ almost entirely composed of microscopic chambered shells, occur in this part of the basin.

4. Gypseous marls, and limestones, with bones of animals, and fresh-water shells of fluviatile origin. These are supposed to have been discliarged by a river which flowed into the gulf; the gypsum being precipitated from water holding sulphate of lime in solution, in the same manner as travertine or carbonate of lime, of which we have already spoken. (page 48.)

5. Upper marine formation, consisting of marls, micaceous and quartzose sand, with beds of sandstone abounding in marine shells.

6. Upper fresh-water marls, with interstratified

* So called from its inclosing immense quantities of a minute shell, called Milliolite. 
beds of flint, containing seed-vessels of aquatic plants (Chare), and animal and vegetable remains. These beds are attributed to lakes or marshes, which existed after the marine sands had filled up the basin.

From this rapid sketch, we perceive that the strata which fill up the Paris basin, have been produced by a succession of changes, that readily admits of explanation by the principles so ably enforced by Hutton, Playfair, and Lyell, and explained in the previous lecture. Here we have an ancient gulf of the chalk, which was open to the sea on one side, while on the other it was supplied by rivers charged with the spoils of the country through which they flowed, and carrying down the remains of animals and plants, with land and river shells; and there were occasional introductions of mineral waters. Oscillations of the level of the land and sea took place, and thus admitted of new accumulations upon the older previous deposites; and lastly, the country rose to its present elevation. Changes of this kind, we have already scen, are in actual progress at the present moment, and afford a satisfactory elucidation of these interesting phenomena. I reserve my remarks on the organic remains of the Paris basin to the next section of this discourse, and pass to the examination of the analogous deposites in our own island.

18. The London Basin.- The tertiary strata on which the metropolis of England is situated are 
spread over a considerable area, which is bounded on the south by the North Downs; extends on the west beyond High-elm Hill, in Berkshire; and on the north-west is flanked by the chalk hills of Wiltshire, Berkshire, Oxfordshire, Buckinghamshire, and Hertfordshire. On the east it is open to the sea; the Isle of Sheppey, situated in the mouth of the Thames, being an outlier of the same deposit.* It spreads over Essex, a considerable part of Suffolk, Fpping and Hainault forests, the whole of Middlesex, and a portion of Bucks. In the immediate vicinity of the metropolis, a stiff clay of a bluish-black colour, abounding in marine remains, constitutes the great mass of the materials which fill up this ancient gulf of the ocean. Immediately upon the chalk, however, there occur thick beds of sand and clay, called Plastic clay (from its ana$\operatorname{logy}$ to the Argile Plastique of the Paris basin), in which fresh-water shells, plants, and drifted wood, have been found in some localities. In other instances, layers of green sand lie upon the chalk, which at Reading contain immense quantities of oyster-shells: a similar accumulation of shells has been observed in Surrey, at Headley, a few miles from Reigate, by Mr. Peter Martin, jun. of that town. At Bromley in Kent, there is a bed of oyster shells with pebbles of chalk-flints, which are cemented together by a calcareous deposit into a

* See Mr. Webster's paper in the Geological Transactions; and Conybeare and Phillips' Geology of England and Wales. 
remarkable conglomerate, which is used for ornamental grottoes. The London clay is found immediately beneath the gravel which so generally forms the sub-soil of the metropolis; it is of great extent, and varies from 300 to 600 feet in thickness. This clay forms a dark, tough soil, and has occasional intermixtures of green and ferruginous sand, and variegated clays. It abounds in spheroidal nodules of indurated argillaceous limestone, internally filled by veins of calcareous spar, or sulphate of barytes, disposed in a radiating manner from the centre of the nodule to the circumference. From the appearance of partitions which this character confers, these concretions are commonly known by the name of Septaria : shells and other organic remains frequently form the nucleus of these nodules, which are used in prodigious quantities for cement. The specimens on the table are from Highgate and Bognor ; two from the latter locality, presented to me by my friend Dr. Hall, contain beautiful examples of an extinct species of Nautilus. The septaria are commonly disposed in horizontal lines, and lie at unequal distances from each other. Brilliant sulphuret of iron abounds in the clay, and is seen in this septarium, as well as in many of the organic remains. Crystallized sulphate of lime, or selenite, is also common in these as in other argillaceous strata. 'The cuttings through Highgate Hill, to form the arcliway; the excavations in the Regent's Park; and more recently the tunnels carried 
through a part of the same ridge of elay at Primrose Hill, in the line of the Birmingham railroad; and the explorations, by wells, over the whole area around London, have brought to light such prodigious quantities of organie remains, that the fossils of this deposit are almost universally known. The admirable work of my late friend Mr. Sowerby, ealled early attention to these testaeeous remains, the first plate in his Mineral Conehology being devoted to the "Nautili of the London Basin." Immense numbers of marine shells of extinct speeies; crabs, lobsters, and other crustacea; teeth of sharks, and remains of other genera of fishes; bones of erocodiles and turtles; leaves, fruits, stems of plants, and rolled trunks of trees, perforated by boring shells,-oceur throughout these deposites, but are located in greater abundanee in some spots than in others. The elay and gravel pits at Woolwieh, on the banks of the Thames, abound in univalve marine shells; and at Plumstead, Bexley, and other places, shells occur in clay, and indurated argillaceous limestone.

19. The Isle of Sheppey.-The Isle of Sheppey is entirely eomposed of the London elay, and the depth of the beds is upwards of 550 feet. It has long been eelebrated for its organie remains; and I may observe, that the diseovery of seed-vessels and stems of plants in pyritous clay, in a visit which I made to Queenborough, when a boy, tended to confirm my early taste for geological researches. 
The cliffs on the north of the island, are about 200 feet high, and consist of clay, abounding in septaria, which are washed out of the cliffs by the action of the sea, and are collected for cement. The organic remains are, however, unfortunately so strongly impregnated with pyrites, that the collector often finds the choicest fossil fruits in his cabinet, like the fabled apples of the Dead Sea, one moment perfect and brilliant, and the next decomposed and changed to dust; leaving only an efflorescent sulphate of iron. The animal and vegetable remains that occur in the blue clay of the metropolis, abound in profusion in the Isle of Sheppey.

20. Fossil Fruits. - Seed-vessels, and stems and branches of trees, of a tropical character, probably drifted by currents into the gulf of the London basin, are in such abundance and variety, that the existence of a group of spice islands seems necessary to account for so vast an accumulation of vegetable productions. The seed-ressels
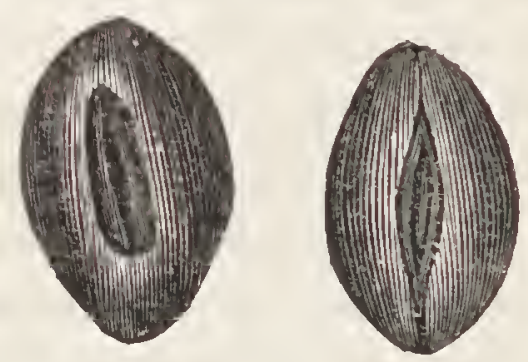

Tab. 20.-Fossil Fruits, from Sirepper.

found at Sheppey are referrible to several hundred species; some are related to the cardamom, date, 
areca, cocoa, (Cocos Parkinsonis): and one berry bears much resemblance to the coffee. (Tab. 20). The wood found in the Sheppey clay is generally of a dark colour, with the ligneous fibres and circles of growth well developed; it is often veined with brilliant pyrites, and the fissures and cavities are frequently filled with this miner al.It is rarely that any considerable mass of wood is found free from the ravages of a species of teledo, resembling the recent Teredo navalis, or borer, which inhabits the seas of the West India islands. The tubular shells sometimes remain, but their cavities, as well as the perforations in the wood, are filled with pyrites, indurated clay, argillaceous limestone, or calcareous spar; and specimens, when cut and polished, exhibit interesting sections of the meandering grooves of the Teredines. In this specimen, which I picked up on the banks of the canal in the Regent's Park, the grain of the wood, with the shells, and their excavations, are beautifully displayed.

21. Upper Marine, or Bagshot Sand.-At Highgate and Hampstead, Purbright and Frimley Heaths, in Surrey, and on Bagshot Heath, extensive beds of sand occur, with but few traces of organic remains; those hitherto observed are marine shells. The boulders and masses of saccharine sandstone, which are abundant in some of the chalk valleys and on the flanks of tle Downs, are called Sarsden-stone, or Druid sandstone, from being the principal material employed in the construction of Stonehenge, and 
other Druidical monuments, are supposed to have been derived from the sand-beds, which overlie the London clay in the places above named: they may, however, have belonged to the sands which lie between the clay and chalk. The wastes and unproductive heaths around the metropolis, are sites of these arenaceous deposites, which also form the sub-soil of that charming and picturesque spot, Hampstead Heath. The gravel and shingle, associated with the sands, have unquestionably been derived from the ruins of the chalk formation.

22. Artesian Wells.-As from the alternation of porous, arenaceous strata, with stiff or impervious beds of clay, the artificial perennial fountains, called Artesian wells, are of frequent occurrence in the vicinity of the metropolis, I will offer a few remarks on the phenomena of springs. The descent of moisture from the atmosphere upon the earth, and its escape into the basin of the ocean, by the agency of streams and rivers, were noticed in the first lecture. The rain descending on a gravelly or porous soil must, of course, descend through it, till its progress is arrested by a clayey or impervious stratum, which thus forms a natural tank or reservoir, collects the water, and a subterranean pool or canal is produced, according to the direction and configuration of the upper surface of the clay. This state of things will continue, till, by an increased supply, the waters rise above the level of the basin, or 
channel, and overflowing, escape, either through the porous strata, or by fissures in the solid deposites, to another level. If the course of the waters be subterranean, the softer portions of the rock are worn away, and chasms or caverns are formed. Subterranean rivers and streams, of great extent, occur in many of our mines; but if the water finds its way to the surface, a spring is said to burst forth. This is the nature of all springs, except those which arise from great depths, and are probably dependent on the condensation of steam, evolved through fissures by volcanic agency; such are the thermal waters of many countries. Streams impregnated with the mineral substances contained in the strata through which they flow, are called mineral waters. Those in the tertiary strata near Epsom, contain sulphate of magnesia, whence the name of Ejsom Salts, given to this substance wherever it occurs. But it may happen, that strata which are pervious, alternate with others which are not so; or may form a basin, the area of which is partially filled with clay, through which water cannot pass: in such a case, it is obvious that the bed of sand beneath the clay, fed by the rain which descends on the uncovered margin of the basin, must form a reservoir, and the water gradually accumulate beneath the central plateau of clay, through which it cannot escape. If this bed of clay be penetrated, either by natural or artificial means, the water must necessarily rise to the surface, and may even be thrown up in a jet, 
to an altitude which will depend on the level of the fluid in the subterranean reservoir; such is the phenomenon observable in the Artesian wells around London. The blue clay confines the water contained in the sands beneath, and the engineer perforates this bed, introduces tubes, and taps the natural tank; by this method, the perennial fountains of Tooting, Hammersmith, Fulham, \&c. have been obtained.* Of the practical utility of geological knowledge, even in the common operation of sinking a well, I once had a striking proof. A gentlemanr residing in Sussex, on the borders of the Forest Ridge, who had seen with admiration the perpetual springs in the environs of the metropolis, determined to form one in his grounds at - Park. Accordingly, a person conversant with the construction of certain wells around London was employed, and the necessary apparatus obtained: but the engineer, being wholly ignorant of the nature of the strata, carried his operations to a great depth, 'through the beds of the Wealden sand, of which the district is composed, and, of course, without success, as the least geological knowledge of the strata of the country would have foretold. The undertaking, after considerable labour and expense, was abandoned.

23. The Hamfshire, or Isle of Wight Ba-

* Consult Dr. Buckland's Bridgwater Essay, p. 561; and an admirable Essay on Artesian Wells, in that excellent scientific periodical, the Mining Journal, conducted by H. English, Esq., F.G.S. 
Sin.- The London basin has presented us with but little analogy to the series of alternate marine and freshwater deposites of that of Paris; but in Hampshire and the Isle of Wight, there is an extensive suite of tertiary strata, which, like that of France, is made up of clays, sands, and limestones, containing marine, with intercalations of freshwater remains. This series of tertiary beds extends over a considerable district. On the east, a small outlier of the lower beds appears at Castle Hill, near Newhaven; but proceeding to the westward of Brighton, the London clay rises to the surface beyond Worthing, and forms the tract between the Downs and the sea-shore. The inland boundary stretches by Chichester, Emsworth, and Southampton, to Dorchester; and the clay is spread over the whole area of the New Forest and the Trough of Poole, being flanked by the chalk on the north, north-east, and north-west, and open to the sea on the south. The Isle of Wight, although now separated from the main land, is a disrupted mass of the formations of the south-east of England, as I shall explain in a future lecture. My observations on the present occasion are confined to the tertiary strata; and I will only observe, that the chalk basin has been broken up, and that in some instances, both the chalk and the superimposed sands, clays, and gravel, are thrown into a vertical position. A remarkable and well-known instance of this phenomenon occurs at Alum Bay, so called from the 
alum, formerly extracted from the decomposing pyrites, with which the clay abounds.

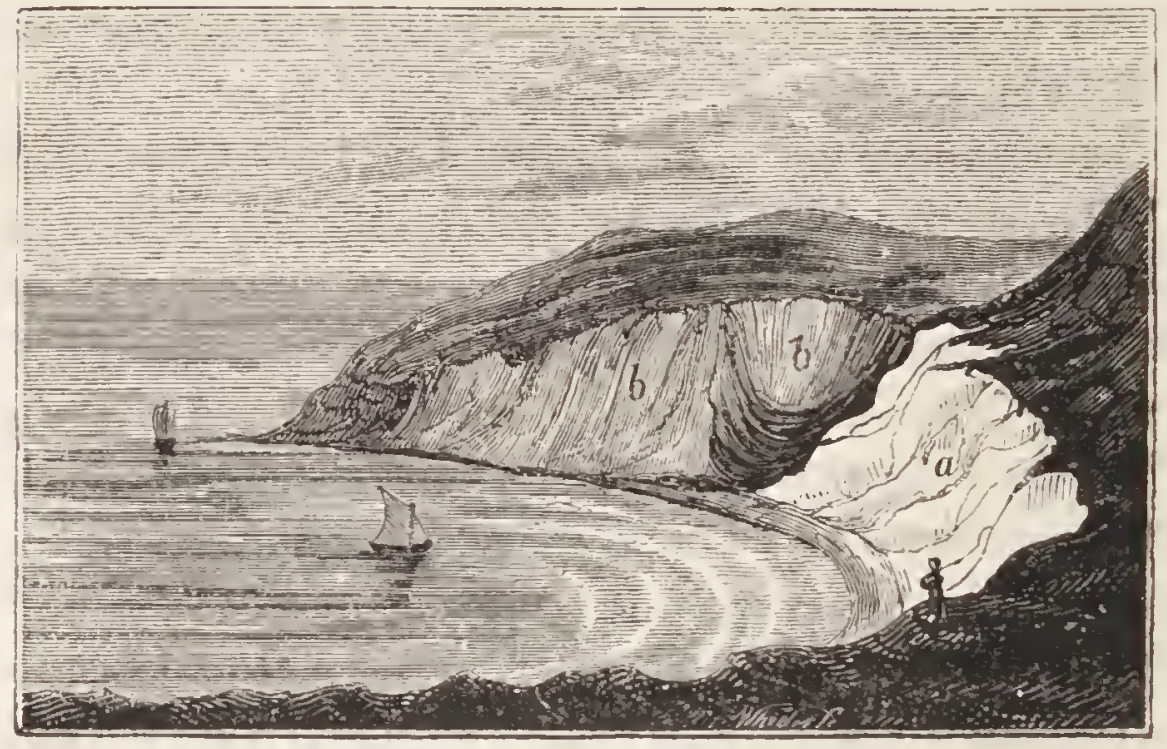

TA13. 21.-Alum Bay, Isle of Wight.

(Drau'n by Miss Susan Chassereau.)

24. Alum Bay.-This view conveys a general outline of the bay; $(a)$ represents the vertical chalk, and $(b \quad b)$ the corresponding marine tertiary strata, consisting of sands and clays of an infinite variety of colour, and containing abundance of shells; advantage is taken of the diversified tints of the sand to imitate the drawings of landscapes, Sc. in glass vessels, which are sold to visitors. The appearance of Alum Bay is thus graphically described by Mr. Webster, whose able memoir on the strata above the English chalk, formed a new era in British Geology, and raised uur tertiary 
series to an importance equal to that of the Paris basin. "The clays and sands of Alum Bay afford one of the most interesting natural sections that can well be imagined. They exhibit the actual state of the strata immediately above the chalk, before any change took place in the position of the latter. For, although the beds of which they are composed are quite vertical, yet, from the nature and variety of their composition, and the regularity and number of their alternations, no one who views them can doubt that they have suffered no change, except that of having been moved with the chalk from a horizontal to a vertical position. The colour of these sands and clays embraces every variety of green, yellow, red, crimson, ferruginous, white, black and brown." Beds of pipe-clay also occur; some of these contain layers of wood-coal, with branches and leaves of vegetables. This coal burns with difficulty, and emits a strong sulphureous smell; masses are constantly drifted by the sea and thrown on the sea-shores near Brighton, where this substance was formerly used as fuel by the poorer inhabitants.*

25. London Clay of the Hampshire Basin. - The London clay extends over the greater portion of the area of the Hampshire basin, its peculiar fossils abounding in many localities. Castle Hill, near Newhaven, which has been already mentioned, is a series of sands, marls, and clays, with beds of

See Geology of the South Downs, p. 261. 
oyster-shells and of shingle that occupy the upper part of the liill, and rest upon the chalk which forms the lower fifty feet of the cliff. The sub-sulphate of alumine,* a mineral substance peculiar to this locality, occurs in the ochraceous clay which is in immediate contact with the chalk. Selenite abounds in the gypseous marls; a layer of wood-coal, a few inclies thick, contains impressions of plants; and the argillaceous beds contain marine shells in such abundance, that some of them are mere masses of compressed shells, held together by argillaceous earth. The oysters are consolidated into coarse stone, and where pebbles enter into the composition of this concrete, a close resemblance is presented to the Bromley oyster-breccia. Teeth of sharks and a few fresh-water shells have been collected in these strata. At Chimting Castle, near Seaford, on the eastern escarpment of the valley of the Ouse, olive-green sand, and a ferruginous conglomerate of chalk-flints, lie upon the chalk, thus determining the original extension of the tertiary beds along the Sussex coast.f Proceeding westward from Brighton, the London clay is perceived near Worthing, emerging from beneath those newer deposites which, as we lave already seen, contain remains of elephants. At Bognor, an arenaceous

* British Mineralogy, Tab.499. Geology of the SouthEast of England, p. 56.

+ Fossils of the South Downs, Pl. viii. figs. 1, 2, 3, 4 .

+ Geology of the South-East of England, p. 62. 
limestone, full of the usual shells of the Calcaire yrossier and London clay, ${ }^{*}$ constitutes a group of low rocks, which in another century will have entirely disappeared. The beauty and variety of the shells, particularly of the Nautili, and of the perforated fossil wood, render these organic remains objects of great attraction. The series on the table contains almost every species that has been discovcred in these rocks; and Sir Woodbine Parish, Dr. Hall, R. Skynner, Esq. Mr. Parker of Shorehanı, and $\mathrm{Mr}$. Baxter of Lcwes, liave contributed interesting examples to my collection. In the blue clay at Bracklesham Bay, on the western coast of Sussex, and at Stubbington, fossil shells may be obtained at low-water in profusion; and Hordwell Cliff, in Hampshire, has so long been celebrated for similar productions, that its elegant shells are seen in every collection of organic remains. In all these localities the shells are of the same genera and species with those of the contemporaneous deposites of France.

26. Fresh-water Strata of the Isle of WIGHT.-The great peculiarity and interest of the Isle of Wight basin, as compared with that of London, consists in the existence of strata containing almost exclusively fresh-water shells, and affording in a few instances remains of the animals that occur in the vicinity of Paris. Mr. Webster has arranged the various tertiary beds of

* Fossils of the South Downs, p. 271. 
Hampshire, in the following sub-divisions:-1st. lowermost; Plastic clay and sand. 2d. London clay. 3d. Fresh-water deposites,-sandy calcareous marls, with immense quantities of fresh-water shells. 4.th. Clay and nuarl, abounding in marine shells; very generally of different species from those in the London clay. 5th. Upper fresh-water deposit; yellowish white marl, and calcareous limestone, employed for building; nearly sixty feet in thickness, and almost one entire mass of fresh-water shells.

The above series is well developed at Headon Hill, where the fresh-water strata, which succeed the marine beds of Alum Bay, lie in a nearly horizontal direction. At Binstead, near Calbourne, and Morley, quarries have been opened in the fiesh-water limestone; and bones of Anoplotheria, and of a species of Moschus, have been discovered.

27. Organic Remains of the Paris, London, And Hants Basins.-I can attempt but a brief description of the fossils of the strata which we have now surveyed, so numerous are the relics of the inhabitants of the aucient land and water which they inclose. To condense my remarks as much as possible, I shall select the fossils of the Paris basin as the types of the zoological characters of the older tertiary epoch, and include notices of such species as occurring in British and other localities, may be requisite for the illustration of the subject. 
28. Plants. - Fossil wood occurs in vast abundance, particularly in large trunks and branches, which appear to have been drifted, and are full of perforations inclosing shells of boring inollusca. Bognor rocks, the clay around Londion, Isle of Sheppey, \&c. abound in specimens of this kind. The wood is dicotyledonous, that is, like the oak, ash, \&c. its mode of increase was by annular circles of growtl, as will be explained in the Lccture on Fossil Botany. Leaves and stems of palms have been found in the Paris basin, and in the Isle of Sheppey, \&c.; and a trunk of a tree allied to the palm, nearly four fect in diameter, at Soissons. Fruits belonging to trees allied to the areca, pine, fir, cocoa-tree, Scc. have been discovered in several localities. Accumulations of vegetable matter, in the state of lignite or brown coal, occur' at Bovcy 'Tracey in Devonshire, and in various parts of France. Amber, and a sub. stance which has been calied Highgate resin, are occasionally imbedded in these deposites.

Zoophytes. - Polyparia occur in some parts of the marine strata, but they are not numerous; several species of turbinolia, caryophillia, fungia, and other corals, are figured and described by authors. I have a few specimens from Grignon: the modern tertiary, (those of Palermo,) abound in flustra and spongia.

29. Shells of the Tertiary Sirata.-So numerous are the shells of the tertiary epoch, already determined by naturalists, that they esceed one-half 
of the known living species, amounting to nearly three thousand. We have already seen that some of the strata are almost entirely composed of these remains

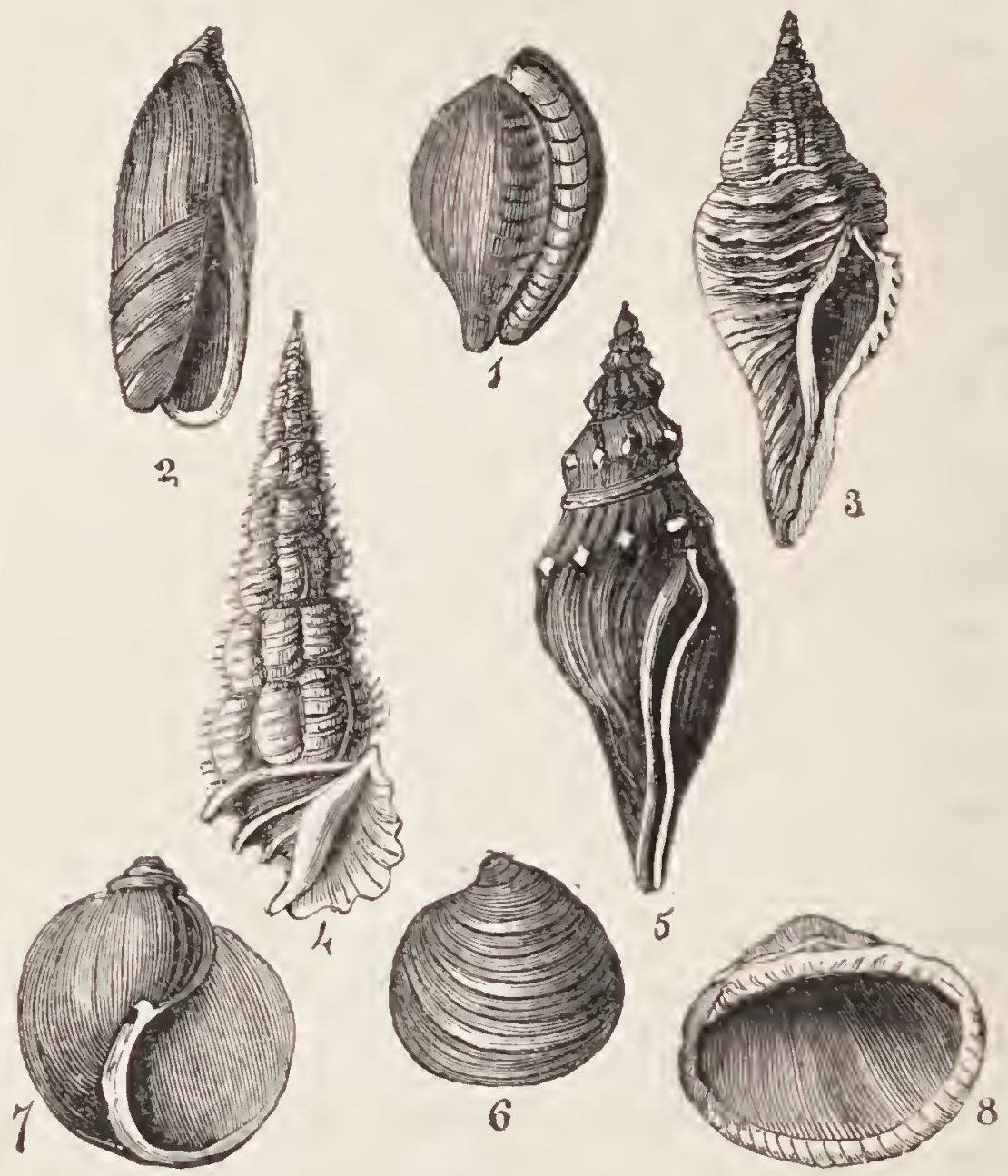

Tar. 22.-Marixe Sufilg of the Paris Basix.

Fig. 1. Cyprea inflata. 2. Ancilla canalifcra. 3. Fusus uniplicatus.

4. Cerithium lamellosum. 5. Pleurotoma dentata. 6. Lucina sulcata, 7. Ampullaria sigaretina. S. Peclunculus angusti-costatus.

in a broken and compressed state: at Newhaven, many seams in the argillaceous beds wholly consist of shell-dust. In other localities the shells occur in 
the most perfect state; and Grignon, a few leagues from Paris, has long been celebrated for its beautiful productions of this kind, many hundred species of shells peculiar to the older tertiary strata having been collected in one spot alone: these shells belong to the Calcaire grossier, and many of the species occur in the London and Hampshire basins, and Bognor rocks. I have selected a few specimens, from the many hundreds in my possession, to convey an idea of their usual characters and appearance. (Tab. 22.)

Although, in mentioning the names of these shells, I do not expect that any but the scientific inquirer will endeavour to fix them on the memory, yet it is useful to point out to you the characters which prevail in these tertiary beds; for, as I have already stated, certain fossils are peculiar to certain strata, and the experienced geologist can often, at a glance, determine the relative antiquity of a deposit by an examination of a few species of shells. The whole of these forms must be familiar to you, because they belong to genera which have species that still live in our present seas. The Cyprea, or cowry, fig. 1, and the Ancilla, or olive, fig. 2, are wellknown types. The Cerithium, fig. 4 , belongs to a genus which is most abundant in the sands of the Paris basin; and is remarkable for the elegance, number, and variety of the species, which exceed by three times that of their living analogues. The Cerithium giganteum attains a considerable magni- 
tude. Some masses of the Bognor rock are almost wholly composed of a species of Pectunculus. The Ampullaria, (Tab. 22, fig. 7,) abourds at Grignon, and is commonly in a beautiful state of freshness. You will recollect that the channel in the aperture of the shells (Tab.22, figs. 2, 3, 4, 5, ) indicates that the animals belonged to the carnivorous tribes.

1
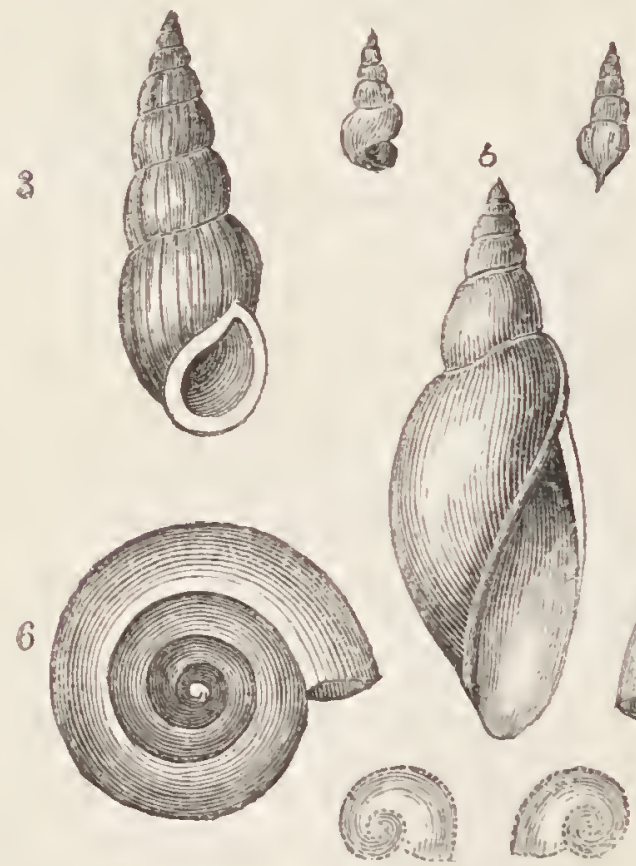

3

2

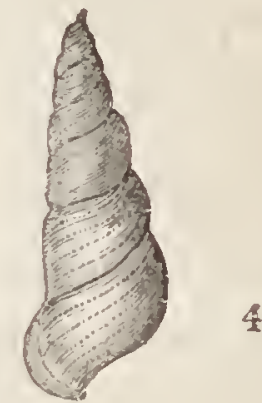

4

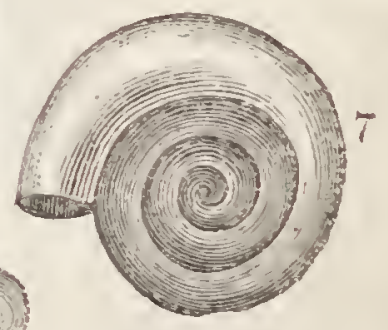

Tab. 23. Fresh-water Shells of the Paris Basis.

Figs. 1, 2. Bulimus conicus. 3, 4. Cyclostomamumia. 5. Lymners efflea. 6, z, 8. Planortis.

Tertiary Fresh-water Shells.-It has already been observed, that the shells of the mollusca which inhabit fresh water, possess characters by which they may be readily distinguished from the 
marine species. This small selection from the freshwater beds of Paris will serve to clucidate iny observations.

The general appearance of these shells will bring to your recollection the species which inhabit our ponds and rivers; particularly the large thin snail, fig. 5, and the discoidal shells, $6,7,8$; while figs. 3 and 4 resemble a shell often found on the banks of lakes. At Headon Hill, and at Binstead in the Isle of Wight, the clay and limestone are filled with the remains of several species of Planorbis and Lymnea.

30. Nautili, and other Cephalopoda.There are several species of Nautilus which abound in the tertiary strata; those inclosed in the septaria, or indurated argillaceous nodules, of the London clay at Highgate, Sheppey, and Bognor, possess considerable beauty, and admit of being cut in sections, which admirably display the internal structure of the shell. I shall, however, defer an explanation of their mechanism to the subsequent lecture, when analogous fossil genera will come under our notice. My observations will now be restricted to an interesting division of the Cepha. lopoda (as those mollusca are termed whose head is surrounded by the organs of motion, or feet), called Foraminifera, which comprehends many genera, and several hundred species, the greater part being microscopic, and analogous to the recent forms which inhabit the Mediterranean. These 
bodies are entirely different from the testaceous habitations of snails, periwinkles, \&c. : they are, in truth, not an external but an internal apparatus; and it is supposed, that, in addition to their serving as a point of attachment and support to the soft body of the animal, they acted as a buoy, which could be made heavier or lighter at pleasure, and by which the animal was enabled either to sink or swim. The fossil called Nummulite (from its resemblance to a coin) affords a familiar example

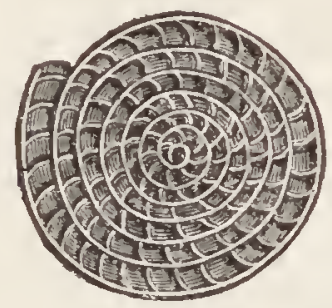

1

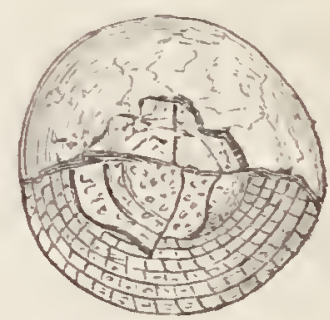

2

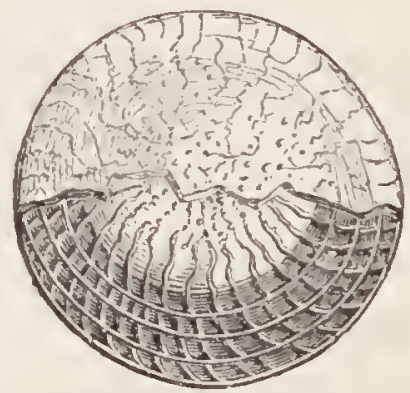

3

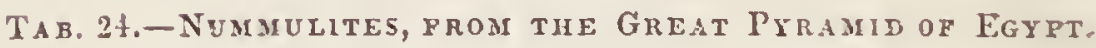

(Collected by Dr. George IIall, of Brighton.)

Fig. 1. Transverse Seclion of a Nummulite. Figs. 2, 3. Nummulites, wits the external plate partially removed.

of the structure of these bodies. The nummulite is of a lenticular, discoidal form, and varies in size 
from a mere point to all inch and a half in diameter. 'The outer surface is generally smooth, and marked with fine undulating lines. On splitting the shell transversely, it is found to be composed of several coils, which are divided into a great many cells or chambers by oblique partitions (Tab. 24, fig. 1), apparently having no communication with each other, but which, it is probable, the animal had the power of filling with fluid, or air, through foramina or pores; whence the name of the order. To my valued friend, Dr. Hall (plysician to the Sussex Hospital), I am indebted for the specimens exhibiting this structure, which I now place before you. They are from the limcstone formed of nummulites (Tab. 24, ) held together by calcareous cement, which constitutes the foundation rock of the Great Pyramid of Egypt, and of which it is in part constructed. Strabo alludes to the nummulites of the pyramids, under the supposition that they are lentils which had been scattered about by the workmen, and bccome converted into stone. This polished, silicious pebble, prescnted me by Lord Northampton, is also from Egypt; the mark. ings on the surface are sections of the inclosed shells. The nummulite is one of the most widcly diffused of fossil shells, its remains forming whole chains of calcareous hills : it is not confined to the tertiary, but occurs also in the secondary formations, constituting immense beds in the Alps and Pyrenees. The blue clay at Bracklesham 
and at Stubbington, and the calcareous sandstone of Emsworth and Bognor, in Sussex, abound in nummulites. In North America limestone occurs near Suggsville, constituting a range of hills about 300 feet in height, which is entirely composed of one species of nummulite. The limestone is porous, and contains spheroilal cavities formed by the decomposition of the organic remains.*

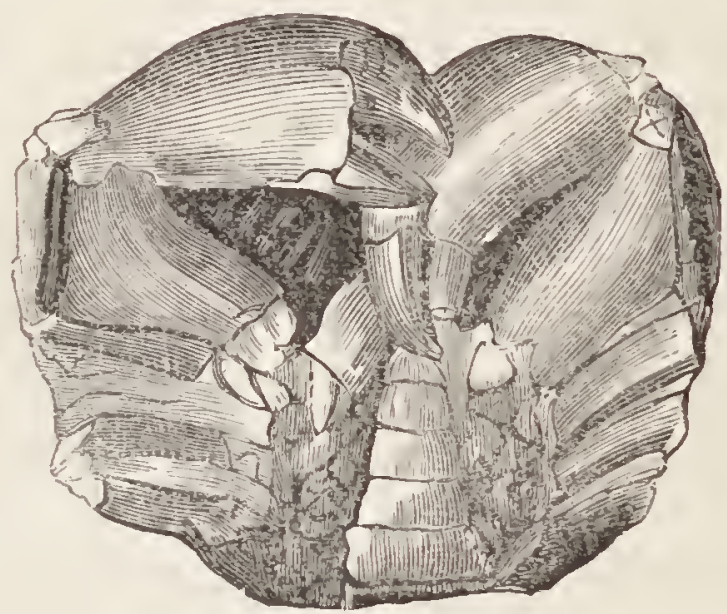

TAB 25.-Fossil Crab, Froy MaIt.

(Cuncer Macrochelus.)

31. Crustacea and Fisines.-Crabs and lobsters, of species related to the recent, several of which are described by MM. Brongniart and Desmarest, in their beautiful work on Fossil Crustacea, have been found in the clay of Highgate, and in the Isle of Sheppey. The external configuration of the shell or crustaceous covering of these animals,

- Dr. Martin's Synopsis of the Organic Remains of the Cretaceous Gromp of North America. Sro. Philadelphia. 
being in conformity to the viscera which they inclose and are intended to protect, the naturalist is able, by an accurate acquaintance with the characters of the living species, to point out the relation or difference of the fossil, even though the carapace or buckler alone remains; and the size and situation of the heart, stomach, \&c. may thus be readily de. termined. 'This remarkably fine crab ('Tab. 25,) is from Malta; it shows the state of perfection in which fossil crustacea are sometimes discovered.

In the cream-coloured limestone of Papjenheim, crustacea, allied to the shrimp, lobster, and cray-fish,

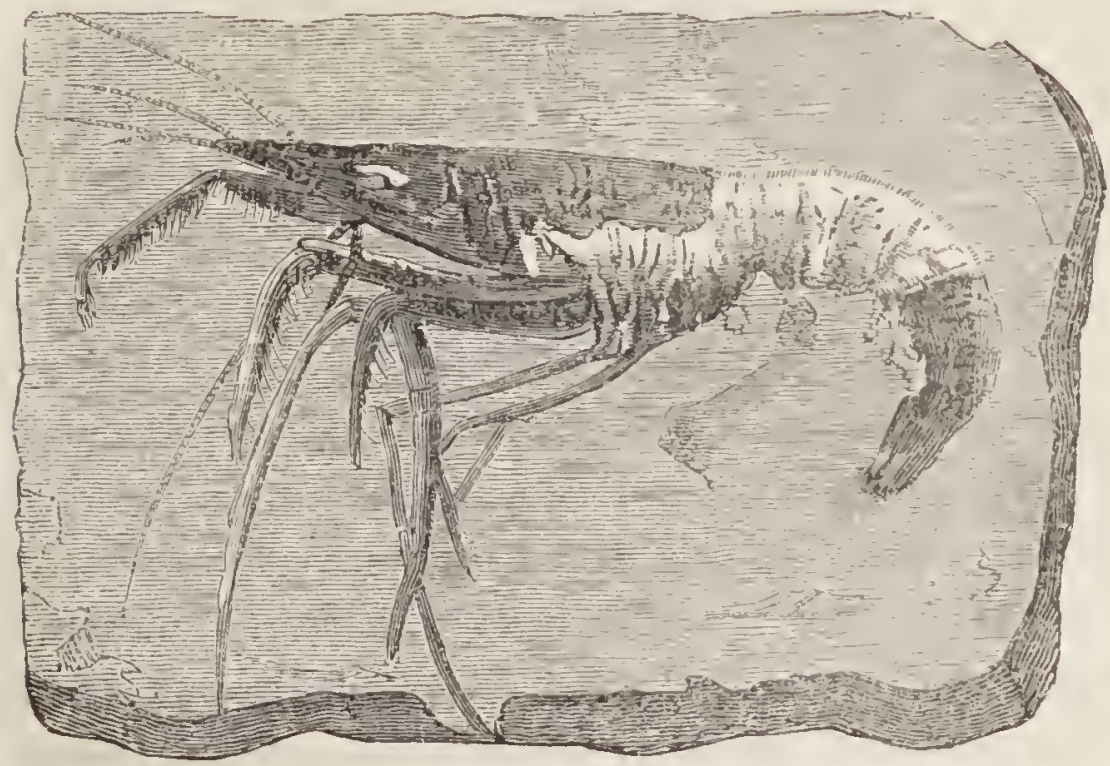

Tab. 26.-Fossit Prawn, from Pappenileim.

(Palcmon Spinipes.)

are often met with; and many beautiful specimens are figured by foreign authors. Knorr's splendid 
work, "Monumens des Catastrophes que le Globe terrestre a essuiées," in particular, has coloured representations of crabs, astacidæ, \&c. : the specimen here figured (Tab. 26, ) exhibits the extraordinary state of preservation of these remains.

In the Paris basin alone, there have been discovered seven or eight species of fishes, of extinct genera. The teeth of several kinds of sharks (Lamna) occur every where, and are known by the name of "Birds' bills." In the clay of Sheppey and London, beautiful fossil fishes have been found, the scales possessing a metallic lustre, from an impregnation of sulphuret of iron. But I must pass cursorily over these remains, as well as those of crocodiles, turtles, and tortoises, which are imbedded in these deposites, or I shall far exceed my limits.

32. Fossil Birds, - In the gypseous buildingstone of Montmartre, M. Cuvier found many bones which possessed characters peculiar to the skeletons of birds; and after much research he was enabled to determine several fossil species, belonging to the genera Pelican, Sea-lark, Curlew, Woodcock, Buzzard, Owl, and Quail. In some examples there are indications of the feathers, and even of the airtubes. Sometimes the skeleton is wanting, but a peilicle of a dark brown substance points out the configuration of the original. (Tab. 27.)

Not only are the skeletons and feathers of birds found in the tertiary strata, but even the eggs of 
aquatic birds occur in the lacustrine limestone of Auvergne. We have already noticed that eggs

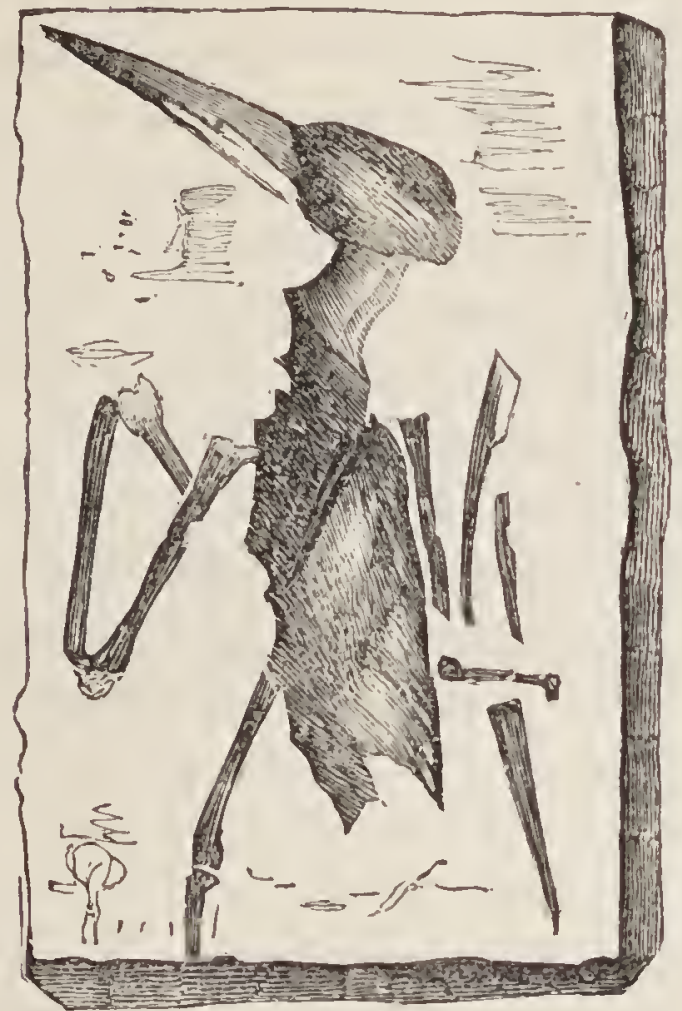

TAB. 27.-Fossil Bird, From Moxtmartre.

of turtles are daily in the course of fossilization on the shores of the Isle of Ascension.

33. Cuvierian Pachymermata. - We have next to consider the fossil remains of the Mammalia whose skeletons were entombed in the mud of the waters which formerly occupied the area of Paris, and which the genius of Cuvier has again, as it were, called into existence. The forms of these extinct creatures are now as familiar to us as our domestia animals, and even the names of Palæotheria and 
Anoplotheria arc almost become household words. The gypsum quarries whieh are spread over the flanks of Montmartre have long been known to afford fossil bones; but, although specimens occasionally attracted the notiee of the naturalists of Paris, and collections were formed, yet no one appears to have suspected the mine of wonders which the rocks contained, till the curiosity of Curier was awakened by the inspection of a large collection of these bones, after he had successfully applied the laws of eomparative anatomy to the investigation of the fossil Elephants and Mammoths. He had previously paid little or no attention to the partial accounts of fossil bones found in the vieinity of Paris, although in 1768 Guettãrd had figured and described many bones and teeth. Cuvier now, however, perceived that a new world was open to his researches, and he soon, by zeal and energy, obtained an extensive eollection, and found hinself (to use his own expression) in a charnel-house, surrounded by a confused mass of broken skelctons of a great variety of animals. To arrange eaeh fragment in its proper place, and to restorc order to these heaps of ruins, seemed at first a hopeless task; but a knowledge of the inmutable laws by which the organization of animal existence is governed, soon enabled hin to assign to each bone, and even fragment of bone, its proper place in the skeleten; and the forms of beings hitherto unsecn by mortal eye arose before him. "I camnot," says this illustrious philosopher, in all 
the enthusiasm of successful genius, "express $11 y$ delight on finding how the application of one principle was instantly followed by the most triumphant results. The essential character of a tooth, and its relation to the skull, being determined, immediately all the other elements of the fabric fell into their places; and the vertebra, ribs, bones of the legs, thighs, and feet, seemed to arrange themselves even without my bidding, and precisely in the manner which I had predicted." The principles of comparative anatomy enumerated in the second lecture will have prepared you for this result; and I now need not dwell on the application of the laws of co-relation of structure by which the animals of the Paris basin have been restored.
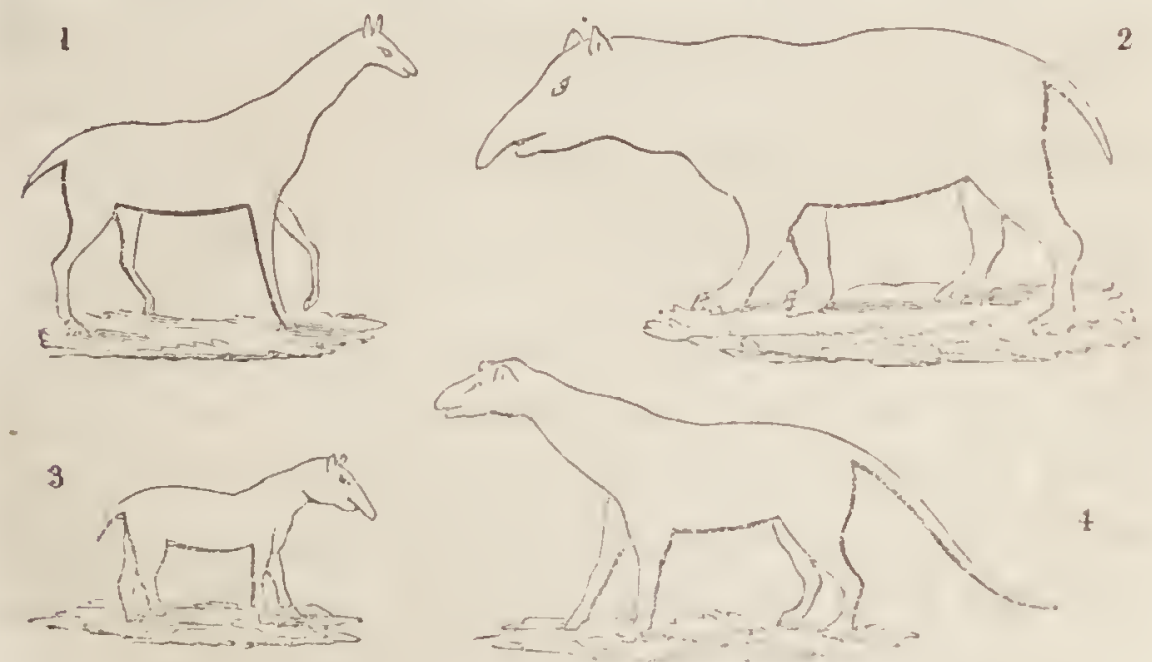

TAB. 28.-ANimals of THE Tertiany Epoch.

Fig. 1. Anoplolherium gracile. 2. Paleolherium magnum. 3. P. minns. 4. Anoplotherium commune.

This group of figures, from Cuvicr's restorations, is indeed a splendid triumph of Palæontology. 
The examination of the fossil teeth at once showed that the animals were herbivorous, the enamel and ivory being disposed in the manner already explained (page 119); and the crown of the tooth composed of two or three simple crescents, as in certain pachydermata; thus differing from the ruminants, which have double crescents, and each four lines of enamel. Following out the inquiry, Cuvier at length established that the great proportion of bones and teeth belonged to two extinct genera of pachydermata, bearing an affinity to the Tapir, Rhinoceros, and Hippopotamus. Almost every one is familiar with the form and labits of the two last animals; but the Tapir is not so well known. Of this genus there are several living species, all natives of tropical climes. The Malay Tapir (a stuffed specimen of which is placed on the lobby of the British Museum, sometimes attains eight feet in length, and six in circumference. It las a flexible proboscis, a few inches long; its general appearance is heavy and massive, resembling that of the Hog. The eyes are small, the ears roundish; the skin is thick and firm, and covered with stout hair; the tail short. It inhabits the banks of lakes and rivers, and has been observed to walk under water, but never to swim.*

34. Paleotheria, and Anoplotheria. The fossil animals are divided into the genera

* Griffiths' Animal Kingdom, vol. iii. p. 434. 
Palæotherium (ancient wild beast); and Anoplotherium (unarmed wild bcast), so named from the absence of canine teeth. I will now describe the species here figured.

Palmotherium magnum, fig. 2. This animal was of the size of a horse, but more thick and clumsy; it had a massive head, and short extremities. It was like a large tapir, but with differences in the teeth, and a toe less on the fore feet. It must have been from four to five feet in height, which is about equal to that of the rhinoceros of Java. From the conformation of the nasal bones, no doubt can exist of its having been furnished with a short proboscis, or trunk.

Paleotherium minus, fig. 3 . Of the size of the roebuck. This creature had light and slender limbs, with the general configuration of the tapir.

Anoplotierium gracile, fig. 1. This animal, to which Cuvier gave the name of gracile, from its elegant proportions, was of the size and form of a gazelle, and must have lived after the manner of the deer and antelopes.

Anoplotherium commune, fig.4; was of the height of a wild boar, but of a more elongated form, and had a long and thick tail like a kangaroo, the feet having two large toes like the ruminants. It seems probable that it could swim with facility, and frequented the lakes, in the beds of which its bones were deposited.

More than fifty extinct mammalia have been 
discovered in the older tertiary, and their characters determined by Baron Cuvier. Some are related to the animals we have just described; as the Anthracotherium, (so named from the discovery of its remains in the Anthracite, or lignite of Cadibona,) which held an intermediate place between the hog and hippopotamus. Six or seven species of carnivora, an opossum, a squirrel, dormouse, \&c. have also been found in the Paris basin.

In the miocene strata of Touraine and of Darmstadt, there is an intermixture of the remains of the above extinct mammalia with those of the Mastodon, and of genera which still exist. Mr. Murchison has discovered in Bavaria, bones of the Palæotherium, Anoplotherium, Anthracotherium, Mastorlon, Rhinoceros, Hippopotamus, Ox, Horse, Bear, \&c. in lacustrine deposites, associated with fresh-water and land shells.

35. Fossil Quadrumana or Monkeys.-At Sausan, in the department of Gers, are tertiary deposites, abounding in remains of the rhinoceros, horse, palæotherium, anoplotherium, and other mammalia. M. Lastel has discovered a jaw of a Monkey, which, from its proportions, must have belonged to an animal about three feet in height. The molar teeth in the specimen are worn, and very closely resemble those of a man of middle age, reduced to half their natural size. Another fossil monkey has been found in the lills near the Sutlej, associated with remains of mastodons, elephants, 
crocodiles, turtles, $\mathcal{E}$ c. The specimen is the right half of the upper jaw, to which a portion of the orbit of the eye remains attached, and this alone is sufficient to enable an anatomist to determine the nature of the original, the orbits of the Quadrumana being peculiar. Without entering upon details uninteresting to the general inquirer, it may be stated that evidence is thus afforded of the existence of a gigantic species of monkey, contemporaneously with the pachydermata, whose fossil remains occur in the Sub-Himalayas. The important fact is therefore now established, that animals of that type of organization which most nearly resembles the human, existed in the ancient tertiary epochs.*

* The Quadrumana.-These animals come nearest to man in the form and proportion of their skeleton, and of their separate bones; in the general disposition of their muscular system, and its adaptation for a semi-erect position of the body; in their great cerebral organization, the perfection and equable development of their senses; their intellectual capacity, and complicated instincts. These most elcvated of all inferior animals are fitted to select, obtain, and digest the succulent ripe fruits of trees, and are destined to inhabit the rich and shady forests of tropical climates. They leave to the squirrels and the sloths the buds and leaves; to the ponderous elepliant and rhinoceros the branches and the stems; and to the beavers, and other rodentia, the dry bark of the trees. Their delicate organization is adapted only for the richest products of the vegetable kingdom; and the soft and nutritious quality of their food is suitable to the broad enamelled crowns of their molar teeth, which are studded witl rounded tubercles: their stomach, is simple. With a high cercbral and muscular devclopment, corresponding with their elevated rank in the scale of beings, and the 
36. Tertiary Strata of Aix, in Provence, - A group of tertiary strata, remarkable as well for their mineralogical character as for the organic remains which they contain, occurs near Aix, a town in Provence, which is situated upon a thick deposit of tertiary conglomerate. The series on the northern side of the valley consists of - 1. Tertiary breccia, (see Pl.V. fig. 3,) lying unconformably on the secondary rocks of oolite, and green sand, which are nearly vertical. 2. Marl, with fishes and insects. 3. Gypsum and gypseous marls, with fishes and insects; leaves of palms, and other plants; fresh-water univalve and bivalve shells, particularly a species of Cyclas in great abuudance. The cyclas inhabits lakes and marshes, and therefore positively denotes the lacustrine character of the deposites. 4. Freshwater limestone. To the south, extending towards Toulon, are lacustrine strata of red marl, with compact limestone inclosing shells, gyrogonites, \&c. Still farther to the south, beds of grey fresh-water limestone appear; and at Fuveau, (see the section, Pl. V. fig.3,) a series of blue limestone, shale, and coal, which is extensively worked. Fresh-water shells, seed-vessels of Charx, and other vegetable remains, occur in abundance in the coal-beds and position of their food, they are the most agile and sportive of all Mammalia; and they are provided with prehensile organs at every point; their teeth, tail, feet, and hands assist in their agile movements, and in their boundings from branch to branch, and from tree to tree. - Dr. Grant's Leciures on Comparative Anatomy. 
intermediate layers of shale. The section employed to illustrate this description is copied from a rough sketch made by Mr. Lyell on the spot, when he first visited this interesting locality; and which I greatly value on that account. (The term Lias in the lithograph, Pl. V. fig. 3, is an error'; the beds of limestone thus denominated are fresh-water tertiary deposites.)

The marls, as you may perceive, in this extensive suite of specimens, collected by my friends Messrs. Lyell and Murchison, (whose admirable Memoir* on these strata is of high interest,) are very finely laminated, and contain insects and fishes in a remarkable state of preservation. The fishes are very numerous; one small species in particular (Smerdis minutus) is found grouped together in every variety of form and position.

37. Fossil Insects.-But the insects are the most extraordinary fossil remains, appearing as fresh as if enveloped but yesterday. This beautiful example, presented to me by that highly-gifted lady Mrs. Murchison, shows the exquisite preservation of these delicate objects. A few of the most interesting forms are here delineated on a slightly enlarged scale, from the plate accompanying the paper to which I have referred. $\downarrow$

* On the Fresh-water Formation of Aix, in Provence, by C. Lyell, and R. I. Murchison, Esqrs. Edinburgh Philos. Journal, 1829.

† Jameson's Edinburgh Journal, for 1829. Pl. VI. 
Mr. Lyell states, that all the insects are referrible to existing genera, and that only one species is aquatic. The anterior tarsi* are generally obscure,

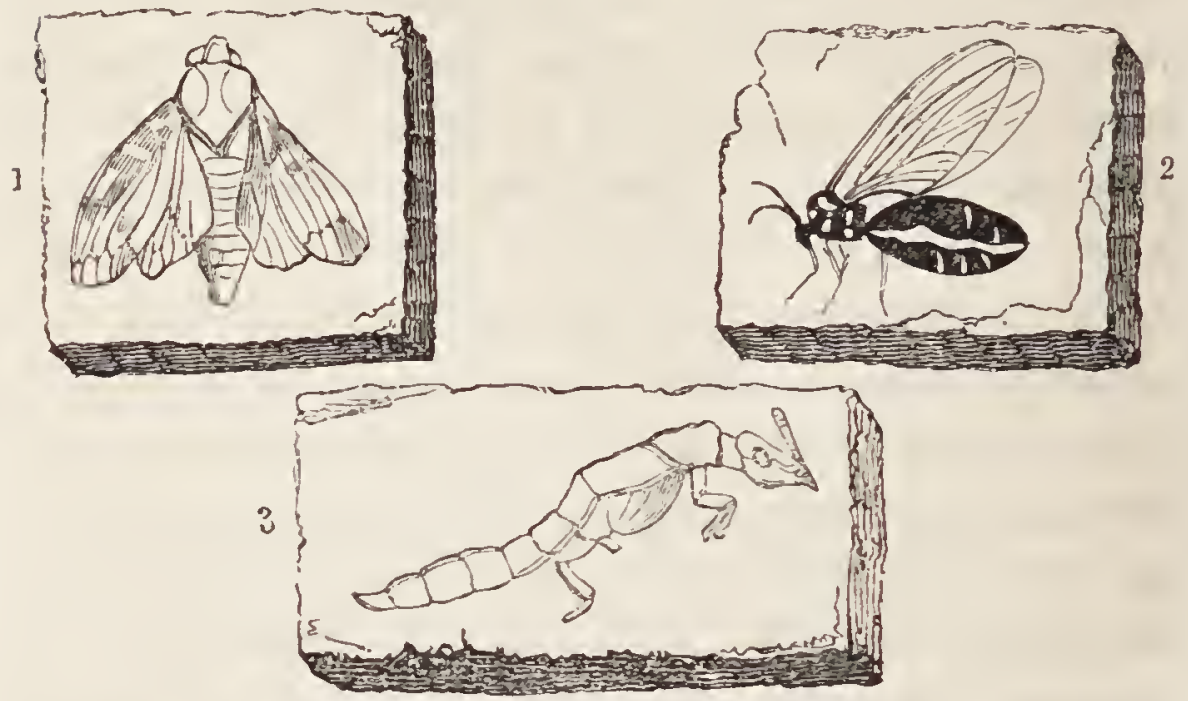

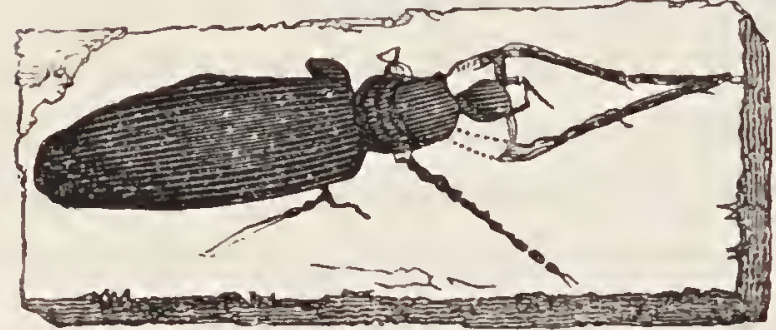

4

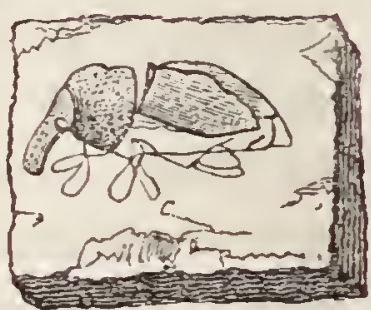

5

Tab. 29. -Fossil INsfocts prom Aix, ix Provence.

Fig. 1. Tettigonia spumaria. 2. Mycetophila, imbedded while in the act of walking; the articulations of the body distended by pressure. 3. Lathrobium. 4. Allied to Penthetria holosericea. The hinder legs are broken off, and one of them is reversed, so that the tarsi nearly touch the thigh; the palpi are long and perfect; the antenna remarkably distinct. 5. J.iparus, resembling L. punctatus.

or distorted; but in some specimens the claws are visible, and the sculpture, and even a degree of local colouring are preserved. The nerves of the

* Principles of Geology, rol. iii. p. 211. 
wings in the diptera, and even the pubescence on the head, are distinctly seen. Several of the beetles have the wings extended beyond the elytra, as if they had fallen into the water while on the wing, and had made an effort to escape by flight. M. Marcel de Serres has enumerated nearly seventy genera of insects, and a few Arachnides, or spider's. The most curious fact is, that some of the insects are identical with species which now inhabit Provence. It seems probable that these insects were brought together from different localities by floods, and mountain streams; yet, as Mr. Curtis observes, all of them might lave inhabited moist and shady forests. The laminated marls contain also the coverings of a fresl-water crustacea, called Cypris, which swarns in our pools and stagnant waters, and must be familiar to all who have seen the exhibition of the oxy-hydrogen microscope; living specimens being commonly shown, and appearing somewhat like the head and feet of a flea protruding from an oval case or shield, and swimming by means of their fine cilia, which resemble pencils of hair. These crustacea shed their cases, some of which are siliceous and others calcareous, annually, and the surface of the mud spread over the bottoms of lakes is often strewed with their relics. The marls of Aix, as well as of many other fresh-water formations, abound in fossil Cyprides, which sometimes constitute entire seams or laminæ, that alternate with the marl. The seed-vessels of the Chara, a common 
plant in our ditches and ponds, also occur in profusion; they were formerly supposed to be shells, and from their peculiar structure received the name of Gyrogonites, which they still bear, although their real nature has long been ascertained.* In conclusion, Mr. Lyell observes, "that this series of tertiary deposites differs essentially from those of the London and Paris basins. The great development of regular beds of blue limestone and shale, the quality and appearance of the coal, the thickness of the compact grey, brown, and black argillaceous limestones and sandstones, give to these deposites the aspect of the most ancient of our secondary rocks; and it is only by the various peculiar species of fluviatile and lacustrine shells, the seed-vessels of the Chara, \&c. that the comparatively recent date of the whole group is demonstrated."

38. Lacustrine Formation of Ceningen.Among the tertiary lacustrine formations on the continent, there is one so much celebrated for its organic remains, that I will offer a few remarks on its peculiar characters. CEningen, near Constance, has for centuries been known to contain fossil remains of great beauty and interest. A short, but graphic, memoir by Mr. Murchison, $\nmid$ presents in a few pages the history of this ancient lake. The Rhine, in

* See an Essay on the Fresh-water Marls of Scotland, by Mr. Lyell.

† On a Fossil Fox found at Oningen, by R. I. Murchison, Esq., Pres. G.S. \&c. Geological Transactions. 1832. 
its course from Constance to Schaffhausen, flows through a depression of the tertiary marine formation, known by the name of Molasse, which forms hills on both sides of the river, of from 700 to 900 feet in height. In a basin of this molasse, is a series of strata composed of marls, and creamcoloured, fine-grained, fetid limestone, with laminated white marl-stones, forming a total thickness of thirty or forty feet. In the marl-stone, leaves and stems of plants, insects, shells, crustacea, fishes, turtles, a large aquatic salamander, birds, and a perfect skeleton of a fox, have been discovered. The fox was obtained by Mr. Murchison, for whom I developed it, and removed the stone so as to expose the entire skeleton: this extraordinary fossil, which does not differ in its osteology from the recent species, is figured and described in the Geological Transactions for 1832. A tortoise, three feet in length, with the head, neck, tail, and three of the paws, well preserved, has since been discovered. Mr. Murchison concludes that these fresh-water deposites are the contents of a lake, belonging to the newer pliocene epoch; yet the period of their formation must have long preceded the present condition of the country, the Rhine having subsequently worn a channel through them to the depth of several hundred feet.

39. Fossil Fishes of Monte Bolca.-I will here notice another interesting assemblage of tertiary strata-the celebrated ichthyolite quarries of Monte 
Bolca-and then proceed to the consideration of the effects of volcanic action during the geological epochs embraced in this discourse. Monte Bolca is situated on the borders of the Veronese territory, about fifty miles NN.W. of the lagunes of Venice, and forms part of a range of hills of moderate elevation; volcanic deposites abound in the neighbouring Vicentin; and the summit of the hill is capped with basalt.* It is principally composed of argillaceous and calcareous strata, with beds of a cream-coloured fissile limestone, which readily separates into laminæ of moderate thickness, and abounds in fishes in the most beautiful state of preservation. They are all compressed flat, but the scales, bones, and fins remain; their colour is a deep brown, thus admirably contrasting with the limestone in which they are imbedded. Several hundred distinct species are supposed to be contained in these quarries, and thousands of specimens have been collected; according to M. Agassiz, all the species, though related to the recent, are extinct. From the immense quantities which occur in so limited an area, it seems probable that the limestone in which they are imbedder, was erupted into the ocean in a fluid state by volcanic agency; and that the fishes were thus suffocated, and surrounded by the calcareous mass. Nor is this hypothesis without support, for on the appearance of a rolcanic island in the

* Organic Remains of a Former World, vol. iii. p. 247. 
Mediterranean, a few years since, hundreds of dead fishes were seen putrid and floating in the waters; and it cannot be doubted that shoals of fishes might at the same time have been enveloped in the volcanic matter at the bottom of the sea, and become compressed and preserved; when the mud which envelopes them is consolidated, and the bed of the Mediterranean elevated above the waters, these fishes may resemble the ichthyolites of Monte Bolca.

4.0. Tertiary Volcanoes.-In the former lecture I have briefly alluded to volcanic action as still existing, and as having taken place in more ancient periods; and we have abundant proof that during the immense lapse of time comprehended between the earliest and the latest of the tertiary formations, the internal fires of our globe were not dormant. I have already had occasion to observe, how rarely the former geographical relations of a country are preserved, and that although we may be able to pronounce with certainty that this spot was once dry land, - that there flowed a river, - that here is the bed of an ancient sea-yet seldom can we ascribe limits to the one, or trace the boundaries of the other. But there is one remarkable exception-a district, where the most important and striking geological mutations have taken place, and yet the area of these changes still preserves its ancient physical geography that district is Auvergne, a province in central France. 
Nearly a century since, two French academicians, MM. Guettard and Malesherbes, on their return from an exploration of Vesuvius, arrived at Montelimart, a small town on the left bank of the Rhone, where Faujas St. Fond, a distinguished naturalist, was sojourning. These savans were struck with the pavements of the streets, which were formed of short joints of basaltic columns, placed perpendicularly in the ground; and upon inquiry they found, that the stones were brought from the neighbouring mountains of the Vivarais. This information induced them to survey the country; and upon arriving at Clermont, a town with about 30,000 inhabitants, the capital of Auvergne, they were satisfied that the whole region was of volcanic origin; for in the vicinity of the town they discovered currents of lava, black and rugged as those of Italy, descending uninterruptedly from some conical hills of scoria, which still preserved the form of craters! "To those who now visit central France, and see on all sides the most unequivocal marks of volcanic agency - the numerous hills formed entirely of loose cinders, and porous and diversified as if just tlirown from a furnace, surrounded by plains of black rugged lava, on which even the lichen almost refuses to vegetate,-it appears scarcely credible, that previous to the last lialf century, no one had thought of attributing these marks of desolation to the only powers in nature capable of producing them. This, however, is perfectly natural, and 
not without examples. The inhabitants of Herculaneum and Pompeii built their houses with the lava of Vesuvius, ploughed up its scoriæ and ashes, and ascended its crater, without dreaming of their neighbourhood to a volcano which was to give the first proof of its energies by burying them beneath its eruptions. The Catanians regarded as a fable all mention of the former activity of Etna, when, in 1669, half their town was overwhelmed by its lava currents."*

The country which is the site of the extinct volcanoes to which I am about to call your attention, may be described as a vast plain, situated in the department of the Limagne d'Auvergne: it is so remarkable for its fertility, that it is called the Garden of France; a quality attributable to the detritus of volcanic rocks, which enters into the composition of the soil. It is inclosed on the east and west by two parallel ranges of gneiss and granite. Its average breadth is twenty miles, its length between forty and fifty, and its altitude about 1,200 feet above the level of the sea. The surface of this plain is formed of alluvial deposites, composed of granitic and basaltic pebbles, and boulders,

* Geology of Central France, by G. Poulett Scrope, Esq. F.R.S., 1827. Mr. Bakewell was the first English geologist who directed attention to this remarkable district; (Travels in the Tarentaise, by Robert Bakewell, Esq. 2 vols. Svo. 1823.); subsequently Dr. Daubeny, Messrs. Scrope, Lyell, and Murchison, have severally published highly interesting treatises on the subject. 
reposing on a substratum of limestone. Hills, of various elevations, composed of calcareous rocks, are scattered over the plain; and the river Allier flows through the district, over beds of limestone, except where it has excavated a channel to the foundation-rock of granite; or over siliceous sandstone, which also, in many places, prevails. The hills, composed of calcareous and alluvial deposites, are relics of a series of beds, which once constituted an ancient plain, at a higher elevation than the present. Many are surmounted by a crest or capping of basalt, to which their preservation is probably attributable; others have escaped destruction from being protected by horizontal layers of a durable limestone, which I shall presently describe. We have, then, as the ground plan of the district, an extensive plain, chequered with low hills of fresh-water limestone, which are capped witl compact lava (Plate IV. figs. III. Iv.) ; the boundaries of the plain being formed of ranges of primary rocks, 3,000 feet in altitude. To the westward the limestone disappears, and a plateau of granite rises to a height of about 1,600 feet above the valley of Clermont, being 3,000 feet above the level of the sea. This supports a chain of volcanic cones and domeshaped mountains, about seventy in number, varying in altitude from 500 to 1,000 feet from above their bases, and forming an irregular range nearly twenty miles in length, and two in breadth. The highest point of this range is the Puy de Dome, which is 
above 4,000 feet above the level of the sea (Pl. IV. fig. II. 4), and is composed entirely of volcanic matter; it possesses a regular crater, 300 feet deep, and nearly 1,000 feet in circumfercnce. Many of these cones retain the form of well-dcfined craters, and their lava currents may be traced as readily as those of Vesurius.

41. Crater of Puy de Come.-One of the most remarkable cones is the Puy de Come, which rises from the plain to the height of 900 fcet; its sides are covered with trees, and its summits present two distinct cratcrs, one of which is 250 feet in depth. A stream of lava may be scen to have issued out from the base of the hill, which at a short distance, from having becn obstructed by a mass of granite, has separated into two branches; these may be traced along the granitic platforms, and down the side of a hill into an adjacent valley, where they have dispossessed a river of its bed, and constraincd it to work out a fresh channel between the lava and the granitc of the oppositc bank. Another cone is described by Mr. Scrope as rising to the height of 1,000 feet above the plain, having a crater nearly 600 feet in vertical depth, and a lava current, which first falls down a steep declivity, and then rolls over the plain in hilly waves of black and scorified rocks. In one part of this volcanic group, is a circular system of cones, apparently the produce of several rapidly succeeding eruptions. "The extraordinary character of this scene inpresses it for ever on the 
memory ; for there is, perhaps, no spot, even among the Phlegræan fields of Italy, which more strikingly displays the characters of volcanic desolation: for although the cones are partially covered with wood and herbage, yet the sides of many are still naked; and the interior of their broken craters rugged, black, and scorified, as well as the rocky floods of lava with which they have loaded the plain, have a freshness of aspect, such as the products of fire alone could have so long preserved, and offer a striking picture of the operation of this element in all its most terrible energy." * A description of the accompanying sketches $\dagger$ will serve to illustrate these remarks. (Plate IV. fig. III.) The environs of Clermont. - The town is seen on the plain or basin, which has been excavated by diluvial agency, since the deposition of the surrounding hills. In front is a basaltic peak (coloured green), crowned by the Castle of Montrognon; and beyond are basaltic platforms (green), on hills of limestone. In the distance is the primitive escarpment, forming part of the boundary of the volcanic district.

Pl. IV. fig. II. Part of the southern volcanic chain of Puys, exhibiting the broken craters of Chaumont ; from the bases of several, lava currents (green) are seen to issue. No. 1, Montchal; 2, Puys de

* Scrope's Gcology of Central France. + The delineations are reduced sketches from the elaborate and beautiful drawings of Mr. Scrope. 
Montgy ; 3, Monjughat; 4, Mont Dome in the distance.

Pl. IV. fig. 4, represents hills of secondary Jura limestone, capped by basalt (coloured green); the terminations of lava currents, that are extended over the whole area, covering a platform of primary rocks, and flowing on to the secondary, which, in this part of Ardêche, constitute an elevated limestone district.

This region affords a striking illustration of the erosion of the surface of a country by alluvial action. The thickness of the volcanic mass is between 300 and 400 feet; it is composed of two distinct beds of basalt, separated by a layer of scoriæ and volcanic fragments. Many portions, both of the upper and lower beds, are made up of well-defined, vertical, polygonal columis. The streams of lava to which these plateaux belong, have been traced by Mr. Scrope for more than thirty miles; rising in a narrow ridge across the primitive heights, and then spreading over the secondary formations, and forming a parallelism with them. The limestone beneath the basalt is, in some places, covered with a vegetable soil, containing a common species of terrestrial shell (Cyclostoma elegans). The nearly horizontal disposition of the basalt, its columnar structure, and position on limestone, into which it has injected veins and dikes, render it, as Mr. Scrope observes, very analogous to the ancient volcanic rocks of Ireland, which I shall describe in a future lecture. 
42. Mont Dor.-Before entering upon the description of the organic remains found in the rocks and strata we have thus hastily surveyed, it will be necessary to notice another system of extinct volcanoes, situated in the same district, and connected with the Puy de Dome. While in the district I have just described, the primitive soil is only partially obscured by the volcanic products, in Mont Dor, the granitic foundation is covered over an area of many miles in extent, and the erupted masses attain a considerable elevation. Mont Dor is a mountainous tract, the highest portion of which is about 6,000 feet in altitude. It consists of seven or eight rocky summits, grouped together within a zone of a mile in diameter, the whole formed of a succession of beds of volcanic origin. It is deeply channelled by two principal valleys, and furrowed by many minor water-channels, all having their. sources near the central eminence, and diverging towards every point of the horizon. The beds "of which this group is composed, consist of scoria, pumice-stones, trachyte, and basalt; these rocks all dip off from the central axis, and lie parallel to the sloping flanks of the mountain, as is the case in Etna, the Peak of Teneriffe, and all other insulated volcanic mountains (see the section of a volcano, Pl. IV.fig. 1). There is no crater, ali traces having been destroyed since the extinction of its fires; but streams of lava may be traced in elevated peaks, over a gorge which occupies the 
very heart of the mountain. Some of these lava currents extend, as beforc stated, to a distance of many miles. A remarkable natural section, worn by a cascade, at a short distance from the baths of Mont Dor, exhibits the general structure of the beds (Pl. IV. fig. 5). They consist of -1. A bed of porphyritic trachyte; a volcanic rock, 160 feet in thickness. 2. Arenaceous tufa. 3. Columnar basalt. 4. Brcccia, made up of volcanic fragments, cemented together by tufa. 5. Thick beds of basalt. 6. White ferruginous tufa, enveloping fragments of granite, basalt, \&c. This bed is traversed by veins of the overlying basalt.

I will only remark, that the volcanic vents of central France are evidently of very different ages; some being of immense antiquity, while others must bc of comparatively recent origin, for they have exploded through the older beds of basalt.

43. Fresh-water Limestone, and Organic Remains of Auvergne. - The beds of the volcanic district of this province present alternations of limestonc, abounding in fresh-water shells and other animal remains; with basalt, scoriæ, and other igncous productions, based on a foundation of granite. These depositcs may be arranged in the following chronological order, beginning with the lowest or most ancient :-

1st. Clay, sand, and breccia, without organic remains.

2d. Limestone and calcareous marl, in strata nearly R 2 
horizontal; about 900 feet thick. These are entircly of fresh-water origin, containing shells of the genera (Potamides, Helix, Planorbis, and Lymnea) known to inhabit lakes and rivers. Some of the beds contain bitumen; others are entirely made up of the cases of the caddis-worm (Indusia tubulata), ccmented together by calcareo-silicious matter. This specimen, which was in the cabinet of Faujas St. Fond, displays the characters of this remarkable concrete: it consists of the tubes or cases of the larva of a species of Phryganea; similar remains have been mentioned as occurring in abundance in the alluvial silt of Lewes Levels (page 88). The tubes are formed by the adhesion of shells to the outer surface of the silken case secreted by the insect; these cases are abandoned by the animal when its metamorphosis is completed, and groups of them may be seen in ditches or lakes. In the fossil they have been cemented by calcareons infiltration into a stone, so liard as to be employed for building. The attached shells are so minute, that more than a hundred are affixed to one tube, and the space of a cubic inch often includes ten or twelve tubes. If, says Mr. Scrope, we consider that repeated strata, of five or six feet in thickness, almost entirely composed of these tubes, were extended over the whole plain of the Limagne, occupying a surface of many hundred square miles, we may have some idea of the countless myriads of minutc beings which lived and dicd within the 
bosom of this once extensive lake. In this limestone, associated with land and fresh-water shells, and remains of vegetables, are bones of the palæotherium, anoplotherium, lagomys, martin, dog, rat, tortoise, crocodile, serpent, and birds, and in which the lava current that has flowed over them has produced but little alteration. This series of strata comprises also beds of gypseous and laminated marls, with intercalations of silicious limestone, containing impressions of lake and river shells. In some localities, the fresh-water limestone has an intermixture of volcanic matter, presenting all the characters of a sediment slowly and tranquilly deposited in a lake, into which ashes, and fragments of rocks and scoriæ, were projected by a neighbouring volcano; while there are beds which appear to have been formed by a violent intrusion of volcanic matter.

$3 \mathrm{~d}$. Immense beds of volcanic production, consisting of basalt, scoriæ, \&c. now existing in sheets of lava; spread over the tabular masses of freshwater limestone, or as crests on the summits of the lower hills. (Pl. IV. fig. 3.)

4th. Beds of sand and diluvial gravel, containing bones of the mastodon, elephant, lippopotamus, rhinoceros, tapir, horse, boar, felis, liyena, bear, dog, castor, hare, \&c. ; with these are associated lignite, and other vegetable remains. Some of the beds of limestone abound in the seed-vessels of the Chara; and the laminated clays contain 
fishes, and leaves, stems, \&c. of reeds and other plants.

There are several incrusting springs in Auvergne, largely impregnated with carbonic acid, which pour out immense quantities of calcareous tufa; these burst through the primitive rocks, which form the base of the whole territory, and cover the volcanic focus whence these mineral waters, in all probability, originate. Thermal springs are also very numerous throughout this volcanic district.

44. Summary of the Geological PhenoMENA OF AUVERGNe. - In the calcareous and silicious limestones of Auvergne, and their associated laminated marls, gypsum, lignite, and conglomerate, we have a general analogy with the older freshwater tertiary formations of Paris and the Isle of Wight; the shells and plants being similar, and the quadrupeds of the same genera. And if we suppose the Paris basin to have been elevated during the active state of neighbouring volcanoes, and that successive streams of lava had poured over its sedimentary deposites, we should have a series of phenomena resembling those of Auvergne, with the exception that the presence of marine remains would denote that the basin had been filled with salt water. The facts submitted to our notice appear to establish the following sequence of physical events.

1st. The elevation, after the deposition of the secondary limestone, of the whole area of the 
primary roeks which form the foundation of central France.

2 dly. A period of tranquillity, during which freshwater lakes oceupied the irregular hollows of the distriet; the neighbouring country being inhabited by Palæotheria, Anoplotheria, and other extinct mammalia, whose bones, together with the then existing vegetation, and the shells of the laeustrine mollusca, were imbedded in the tranquil depositions going on in the lacustrine basins.

$3 \mathrm{dly}$. Another elevation of the district; a new system of lakes was established, the country became clothed with forests, and inhabited by large deer, oxen, rhinoeeroses, and hyenas; their remains being imbedded in the sediments of the waters.

4thly. The volcanoes became active; explosions took plaee through hundreds of vents; traehyte and basalt were ejeeted, piereing the fresh-water deposites in some places, and in others overspreading them with sheets of lavas. Vegetation still flourished, and remains of plants became entombed in the volcanie products.

5thly. A nother period of tranquillity - the rivers, and other water-courses, dammed up, or deranged by the lava currents, formed new channels, and accumulated beds of gravel, sand, and clay. Gigantie deer and oxen still inhabited the district, having for eontemporaries hyenas and other carnivora. Voleanic eruptions succeeded, and eontinued till a comparatively reeent period. 
Lastly. Floods and rivers of later date, which now constitute the drainage of the country, began to wear away channels through the beds of lava and limestone to the granite rock beneath, intersected the country with valleys and ravines, and spread over the ancient beds the modern alluvial soil.*

45. Erosion by WAter-CURREnts.-There is perhaps no district which exhibits in more striking characters the erosive power of running water, than Auvergne. In many places the basalt is columnar, like that of Staffa, and the Giants' Causeway; and one range, on the banks of the Ardêche, forms a majestic colonnade 150 feet in height, extending a mile and a half along the valley which has been channelied out by the stream that flows at its base. Mr. Scrope's description of this process is highly graphic. "The bed of the Ardêche is strewed with basaltic boulders, pebbles, and sand, originating from the destruction of the columnar ranges. In some of the volcanic cones the currents of basalt may be traced issuing from the water and following the inequalities of the valley, just as a stream of lava would flow down the same course at the present time. Yet these ancient currents liave

* This account of the rolcanic district of Auvergne, is an abstract of the interesting Essays of Messrs. Bakewell, Scrope, Lyell, Murchison, Dr. Daubeny, Dr. Hibbert, MM. Croiset, Jobert, Robert, and Bertrand-Roux. Mr. Scrope's work cannot be perused, even by the general reader, without deep interest. 
since been corroded by rivers, which have worn through a mass of 150 feet in height, and formed a channel even in the granite rocks beneath, since the lava first flowed into the valley. In another spot, a bed of basalt 160 feet high, has been cut through by a mountain stream, and very beautiful columnar masses are displayed. The vast excavations effected by the erosive power of currents along the valleys which feed the Ardêche, since their invasion by lava currents, prove that even the most recent of these volcanic eruptions belong to an era incalculably remote."

46. Extinct Volcanoes of the Rhine.I have dwelt so long on the Phlegræan fields of Auvergne, that but a brief space can be afforded to another group of tertiary volcanoes. Every one who has ascended the Rhine, will remember where

"The castled crag of Drachenfels

Frowns o'er the wide and winding Rhine,"

forming one of the Siebengebirge, or Seven Mountains, whose majestic and graceful forms suddenly burst on the sight, rising from the level plains on the right bank of the river, to an altitude of nearly 1,500 feet. These picturesque objects form part of a group of extinct volcanoes; while, on the opposite side of the river, the Eifel, with its crater covered with scoriæ and cinders, and lava currents, still distinctly visible, attest the wide area over which these ancient fires once extended. Unlike the district 
we have just noticed, the foundation-rock of the country is an ancient sedimentary deposit, called greywacke, consisting of coarse red sandstone and slate of a peculiar character, which we shall describe hereafter, thrown into a highly inclined position. Through these beds the volcanic eruptions, consisting of trachyte, basalt, and other modifications of trap rocks and scorix, have forced their way. The basalt is black, very compact, and breaks into sharp fragments; it is frequently columnar, and the separate hexagonal pillars are made use of for posts, and paving, in the adjacent towns. - Such, says Mr. Horner (whose admirable memoir* has furnished the materials for this iniperfect sketch), is the profusion of basaltic pillars, that the walls of the town of Linz are wholly built of these materials, placed on their sides, with the ends projecting outwards. The streets are paved with the smaller columns set on end, thus forming a miniature representation of the Giants' Causeway; and the same volcanic product forms a large proportion of the walls of Bonn and Cologne. The greywacke is covered by a series of tertiary deposites, consisting of beds of sand, sandstone, clay, and lignite, constituting what is termed a brown coal formation. On these strata an extensive layer of gravel is superposed, over which is spread a loosely coherent, sandy loam, provincially termed

* On the Geology of the Environs of Bonn, by Leonar Horner, Esq. F.R.S. Geological Transactions, vol, iv. 1836. 
Loess, containing recent species of terrestrial and fresh-water shells, and forming the subsoil of the vast plains in which Bonn and Coblentz are situated, extending as far as the falls of Schaffhausen.

47. Brown Coal Formation.-As the usual condition in which bituminized vegetable matter occurs in the tertiary formations, is well exemplified in the brown coal, or lignite, of the Rhine, it will be instructive to examine the characters of this deposit somewhat in detail; for we shall thereby obtain data which will prepare us for the investigation of the ancient carboniferous deposites. This formation, which is spread over a great extent of country on both sides of the Rhine, consists of layers of clay, sand, sandstone, conglomerates, clay and ironstone, and lignite, or bituminized wood of various qualities, disposed in distinct beds, and intermixed with argillaceous matter. The breadth of the ridge of low hills formed by this assemblage of deposites on the left bank of the Rhine, is from three to five miles, its elevation varying from 50 to 200 feet.

The lignite occurs in the following states:1. A black earthy and pulverulent substance. 2. Concretionary masses, with leaves and fragments of wood. 3. Wood in various degrees of bituminization, and of shades of colour, from a light-brown to jet-black. 4. Very finely laminated masses of bituminous matter and clay, of a dark chocolate colour, and separating into elastic flakes, as thin as 
paper, whence its name Papierkolle. These specimens, collected by Sir P. M. de Grey Egerton, Bart. exhibit the peculiar character of the substance, which is so highly bituminous as to burn with a bright flame. The wood is generally in inconsiderable fragments; but stems of large trees, somewhat compressed, occasionally occur; in some instances the trees are imbedded in an upright position, with the roots attached and the stems passing through several beds of lignite. In many examples the wood is so little changed, that, like the timber of our peat-bogs, it is employed in building; in others it is highly pyritous-in other words, is impregnated with sulphuret of iron, like the fossil vegetables of Sheppey. Mr. Horner states, as the result of his investigations, that there were extensive fresh-water lakes, in the sediments of which trees and plants, drifted by land-floods, were engulfed; and that volcanic eruptions were simultaneously going on, in the same manner as in the modern submarine volcanoes. There is a great fault, or dislocation, of the brown coal formation, which may be attributed to a powerful and sudden volcanic explosion, that probably occasioned the elevation of the Siebengebirge, and raised up that portion of the coal-beds which repose on the flanks of these peaks. The gravel covering the lignite, must have been strewed over the plain previous to this elevation, for it is found on both sides of the river at a great height, and not in the intermediate plain. 
These inductions are so evident as to require no comment.

The ancient alluvium called the Loess, very much resembles a bed of loam which occurs in some parts of Lewes Levels, and incloses fresh-water and land shells of many existing species. The Loess rarely contains bones of quadrupeds; but Mr. Lyell mentions that remains of the horse and mammoth have been discovered.* From the extensive distribution of this deposit, and its occurrence at various elevations, in some instances on the flanks of mountains 1,200 feet above the level of the sea, at others spread out over the gravel of the vast plain of the Rline, Mr. Lyell infers, that although the Loess has been deposited since the existing system of the hills and valleys of the country, yet that changes must have taken place in the physical geography of the district, subsequent to its original formation; and that there is reason to conclude, that since the deposition of this fluviatile loam all the land between Switzerland and Holland has suffered a subsidence, and a subsequent elevation, to the amount of many hundred feet. $\downarrow$

48. Other Tertiary Deposites of Europe, Nortu America, \&c. - It has already been mentioned that strata, referrible to the period compre-

* Principles of Geology, vol. iv. p. 33.

$\uparrow$ Ibid; read with particular attention, pp. 36 \& 37. 
hended between the newest secondary formations and the human epoch, occur throughout Europe, presenting in some instances well-defined groups, with marked boundaries; in others, vast areas, over which these deposites are irregularly spread. The geographical relations of the tertiary strata to the existing lands and seas, is an inquiry of deep interest, but one into which my limits forbid me to enter. I will only remark, that Europe must have possessed many of its most striking physical characters at the commencement of the Eocene period; and that its present configuration has been produced by the conjoint effect of successive mutations in the relative level of land and water, during the formation of the marine and fresh-water deposites, reviewed in this discourse. In India formations of like character have been observed in the Burmese empire, in the Sub-Himalaya mountains, and in the Caribari hills; and among the remains of various quadrupeds a new species of Anthracotherium, one of the genera discovered in the tertiary strata of France, has been found.

In North America the researches of Dr. Morton, Professor Vanuxem, and other observers, have shown that in the territories of the United States tertiary deposites extend over a great part of Maryland, along the coast of New York and New England, and occur in New Jersey, Delaware, Long Island, \&c. The tertiary beds of Maryland consist of limestone, clay, sand, and gravel, and 
abound in the usual types of European tertiary marine shells. I have placed before you an extensive collection from the United States, for which I ain indebted to the kindness of Dr. Morton, Mr. Conrad, Professor Silliman, Dr. Harlan, and other American savans; and you will observe how striking is the general analogy between these shells and those of the Paris and London basins. The Turritella, Venericardia, Fusus, Ancilla, \&c. are identical with the European species; but some of the types are altogether new.

49. Altered tertiary Strata of the Andes. -But striking as are the proofs already adduced of elevations, and other effects of rolcanic agency, during the tertiary period, these sink into comparative insignificance when contrasted with the enormous changes which have taken place in the great mountain chains of Soutl America during the same geological cycle. From the researches of an eminent naturalist and highly intelligent observer, Mr. Charles Darwin, we learn that an extensive tertiary system, analogous to those of Europe, skirts both flanks of the primary rocks which form the southern chain of the Andes, the latter having suffered a certain degree of elevation before the deposition of the former. The tertiary strata are of great thickness and extent, and separable into two groups; the lowermost beds, like those of Auvergne, repeatedly alternate with lavas, and thus denote the commencement of the 
eruptions of the ancient craters. Over these deposites are accumulations of porphyritic pebbles, covered, at elevations of many hundred feet, by beds of shells of recent species; and the sides of the mountains appear like a succession of lifted sea-beaches, which have been slowly and tranquilly lifted up during a long period of time. The altered character of the tertiary deposites within the influence of the igneous products, -the transmutation of accumulations of loose pebbles into solid, compact rocks, - and the occurrence of metalliferous veins in strata of comparatively modern formation-are facts so powerfully exemplifying the geological principles enunciated in the former lectures, that although this discourse has extended to a great length, I cannot omit Mr. Darwin's spirited and graphic description of these phenomena, as originally communicated in a letter to Professor Henslow, of Cambridge, dated Valparaiso, March 1835.

"You will have heard of the dreadful earthquake of the 20th February. I wish some of the geologists, who think the earthquakes of these timcs are trifling, could see how the solid rocks are shivered. In the town there is not one house habitable; the ruins remind me of the drawings of the desolated eastern cities. We werc at Valdivia at the time, and felt the shock very severely. The sensation was like that of skating over very thin ice, that is, distinct undulations were perceptible. ' The whole scene of Conception and Talesana is one of the most interesting spectacles we have beheld since we left England. I was much pleased at Chiloe by finding a thick bed of recent oyster-shells, S.c. capping the tertiary plain, out of which grew large forest trecs. 
I can now prove that both sides of the Andes have riscn in this recent perio? to a considerable height. Hcre the sliells were 350 feet above the sea. On the barc sides of the Cordilleras complicated dykes and wedges of variously coloured rocks are seen traversing, in every possible form and shape, the samc formation, and thus proving by their intersections a succession of violences. The stratification in all the mountains is beau'ifully distinct, and owing to a varicty of colouring can be scen at great distances. Porphyritic conglomerates, resting on granite, form the principal masses. I cannot imagine any part of the world presenting a more extraordinary scene of the brcaking up of the crust of the globe than these central peaks of the Andes. The strata in the highest pinnacles are almost universally inclined at an angle from $70^{\circ}$ to $80^{\circ}$. I cannot tell you how mucl I enjoycd some of the views; it is alone worth coming from England to feel at once such intense delight. At an clevation of from ten to twelve thousand feet there is a transparency in the air, and a confusion of distances, and a stillness, which give the sensation of being in another world. The most important and most developed formation in Chili is the porphyritic concretc. From a great number of sections I find it to be a truc coarse conglomerate or breccia, which passes by cvery step in slow gradation to a fine clay-stonc porphyry; the peblics and cement becoming porphyritic, till at last all is blendcd in one compact rock. The porphyries are excessively abundant in this chain, and at lcast four-fifths of then, I am sure, have been thus produccl from sedimentury beds in situ. The Uspellata range is geologically, although only six or seven thousand fect high, a continuation of the grand castern chain. It has its nucleus of granitc, consisting of beds of various crystalline rocks, (which I liave no doubt are subaqueous lavas,) alternating with sandstone, conglomerates, and white aluminous beds, like dccomposed felspar, with mary other curious varieties of sedimentary deposits. In an escarpment of compact greenish sandstone, I found a small wood of petrificd trces in a vertical position, or rather the strata were inclincd about $20^{\circ}$ or $30^{\circ}$ to one point of the trces, $70^{\circ}$ to the other; that is, before the tilt, thcy were truly rertical. The 
sandstone consists of many horizontal layers. Eleven of the trees are perfectly silicified, and resemble the dicotyledonous wood which I found at Chiloe and Conception; the others, from thirty to forty in number, I only know to be trees from the analogy of form and position; they consist of snow-white columus of coarsely crystallized carbonate of lime. The largest trunk is seven feet in circumference. They are all close together, within one hundred yards, and about the same level; no where else could I find any. It cannot be doubted that the layers of fine sandstone have quietly been deposited between a clump of trees, which were fixed by their roots. The sandstone rests on lava; is covered by a great bed, apparently about one thousand feet thick, of black augite lava; and over this there are at least five grand alternations of such rocks, and aqueous sedimentary deposits, amonnting in thickness to several thousand feet. According to my view of these phenomena, the granite, which forms peaks of a height probably of 14,000 feet, has been fluid in the tertiary epoch; strata of that period have been altered by its heat, and are traversed by dykes from the mass, and are now inclined at high angles, and form regular or complicated anticlinal lines. To complete the climax, these same sedimentary strata and lavas are traversed by very numerous true metallic veins of iron, copper, arsenic, silver, and gold, and these can be traced to the underlying granite. A gold mine has been worlied close to the clump of silicified trees!"

50. Tertiary Saliferous Deposit. - Not only coal, but even extensive deposites of rock salt occur in the tertiary system. The celebrated salt mines of Gallicia, of which my friend M. Boué* has given an intercsting description, are referrible to this epoch. The deposit is nearly 3000 yards long, 1066 broad, and 250 yards deep. The upper part

* Journal de Géologie, quoted by M. De la Beche. 
of the mine consists of green salt, with nodules of gypsum in marl. The salt contains in some places lignite, bituminous wood, and shells. In the lower division are beds of arenaceous marls, with lignite, impressions of plants, and veins of salt; coarse sandstone, with vegetable remains; aluminous and gypseous shale, and indurated calcareous marl, with sulphur, salt, and gypsum.

51. Retrospect.-So numerous and varied have been the phenomena presented to our notice in this general survey of the tertiary strata, that a comprehensive retrospect is necessary, in order that we may arrive at the important inferences which they offer.

In the pliocene, or newer tertiary, which also embraces the mammalian epoch of the last lecture, the fossil remains in the alluvial deposites afford incontestible proof that the mammoth, mastodon, hippopotamus, dinotherium, and other colossal animals of extinct genera or species, together with birds, reptiles, and enormous carnivora, inhabited such districts of our continents as were then dry land; while the older tertiary, or eocene, inclose the bones of land animals, principally of a lacustrine character, which approximate to certain races that now exist in the torrid zone, but belong to extinct genera, which preceded the mammoth and the mastodon. The seas and lakes of that remote epoch occupied areas which are now above the waters; and rocks and mountains, hills and valleys, streams and rivers, 
diversified the surface of countries which are now destroyed or entirely changed; and whose past existence is revealed by the spoils which the streams and rivers have accumulated in the ancient lakes and seas. The ocean abounded in mollusca, crustacea, and fishes, a large proportion of which is referrible to extinct species. Crocodiles, turtles, birds, and insects, were contemporary with the palæotherium, and anthracotherium; and animal organization, however varied in certain types, presented the same general outline as in modern times; the extinction of species and genera being then, as now, in constant activity. The regetable world also contained the same great divisions; there were forests of oak, elm, and beech; of firs, pines, and other coniferous trees; palms, tree-ferns, and the principal groups of modern floras; while the water, both salt and fresh, teemed with the few and simple forms of vegetable structure peculiar to that element. The state of the inorganic world is not less manifest: the abrasion of the land by streams and rivers, - the destruction of the sea-shores by the waves, and the formation of beach and shingle,-the desolation inflicted by volcanic eruptions,-all these operations were then, as now, in constant action. The bed of an ancient sea, containing myriads of the remains of fishes, crustacea, and shells, now forms the site of the capital of Great Britain; and the accumulation of tropical fruits and plants, drifted by ancient currents from 
other climes, constitute islands in the estuary of the Thanes; while the sediments of lakes and gulfs, teeming with the skeletons of beings which are blotted out from the face of the earth, make up the soil of the metropolis of France.

Although the changes in the relative level of the land and sea during this epoch were numerous and extensive, yet one region still preserves traces of its original physical geography, and although the earthquake has rent its mountains to their very centre-though hundreds of volcanoes have again and again spread desolation over the land-and inundations and mountain torrents have excavated valleys, and chequered the plains with ravines and water-courses-yet the grand primeval features of that country remain; and we can trace the boundaries of its ancient lakes, and the succession of changes it has undergone from the first outbreak of its volcanoes, to the commencement of the present state of repose. The lowermost lacustrine deposites in Auvergne, which are spread over the foundation rock of granite unmixed with igneous productions, mark the period antecedent to the volcanic era; while the intrusions of lava and scorix in the superincumbent strata, denote the first eruptions of Mont Dome. The succeeding period of tranquillity is recorded in characters alike intelligible. The slow deposition of calcareous mud-the incrustation of successive generations of aquatic insects, crustacea, and mollusca, and we may even add of infusoria 
- the imbedding of the bones of mammalia, birds, and reptiles - the accumulation of lignite and other vegetable matter-are data from which we may restore the ancient country of Central France. It was a region encircled by a chain of granite mountains, and watered by numerous streams and rivulets, and possessing lakes of vast extent. Its soil was covered with a luxuriant vegetation, and peopled by palæotheria, anoplotheria, and other terrestrial mammalia; the crocodile and turtle found shelter in its marshes and rivers; aquatic birds frequented its fens, and sported over the surface of its lakes; while myriads of insects swarmed in the air, and passed through their wonderful metamorphoses in the waters. In a neighbouring region, ${ }^{*}$ herds of ruminants and other herbivora, of species and genera now no more, with birds and reptiles, were the undisturbed occupants of a country abounding in palms and tree-ferns, and having its rivers and lakes, with gulfs which teemed with the inhabitants of the sea; and to this district the fiery torrents of the volcano did not extend. But to return to Auvergne-a change came over the scene-violent eruptions burst forth from craters long silent-the whole country was laid desolate-its living population swept away-all was one vast waste, and sterility succeeded to the former luxuriance of life and beauty. Ages rolled by - the mists of the mountains

* The Paris basin is about 220 miles from Auvergne. 
and the rains, produced new springs, torrents, and rivers-a fertile soil gradually accumulated over the cooled lava currents and the beds of scoriæ, to which the sediments of the ancient lakes, borne down by the streams, largely contributed. Another vegetation sprang up-the mammoth, mastodon, and enormous deer and oxen now quietly browsed in the verdant plains-other changes succeededthese colossal forms of life in their turn passed away, and at length the earlier races of mankind took possession of a country, which had once more become a region of fertility and repose.

To those who have favoured me with their attention through these discourses, it cannot be necessary to insist that the changes in organic and inanimate nature, which I have thus rapidly portrayed, are supported by proofs so incontrovertible, and traced in language so intelligible, as to constitute a body of evidence with which no human testimony can compete. It is true that the time required for this succession of events must have extended over an immense period; but, as I have before remarked, time and change are great only in relation to the beings which note them, and every step we take in geology, shows the folly and presumption of attempting to measure the operations of nature by our own brief span. "There are no minds," says Mr. Scrope, "that would for one moment doubt that the God of Nature has existed from all eternity; but there are many who would reject as preposterous, the 
idea of tracing back the history of His urorks a million of years. Yet what is a million, or a million of millions of years, when compared to eternity ?"*

Germany presents us with an interesting series of analogous changes, effected in a later era. The outburst of the now extinct volcanoes of the Rhine, the accumulation of fluviatile silt over the plains, and the subsequent elevation of the whole country, show that these physical mutations were not confined to a single region or period.

In the Andes, the enormous disruptions and elevations of the most ancient as well as modern deposites, teach us, that through a long lapse of ages, the volcanic fires of South America have acted with intense energy ; and yet more, that the melting and transmutation of loose materials into compact rocks, the conversion of incoherent strata into solid stone, and even the sublimation of gold and other metals into fissures and veins, are phenomena which have taken place since our seas were peopled by existing species of mollusca. The importance of thesc extraordinary and interesting facts, will be rendered more obvious in a subsequent lecture.

In conclusion; it will be useful to inquire, even though some repetition may be incurred, what are the legitimate inferences as to the condition of the earth and its inhabitants during the tertiary epoch, from the facts that have been placed before us?

* Geology of Central France. 
Was there, as some have supposed, an essential difference in the constitution of the earth?was its surface more covered with lakes and marshes than now? - and did animal life more abound in those types, which are suitable to a lacustrine condition?-or have these conclusions been drawn from a partial view of the phenomena, and do the facts only warrant the inference that certain regions which are now dry land were in ancient times occupied by vast lakes, and that there may have existed contemporaneously as great an extent of dry land as at present, in areas now buried beneath the ocean? In the fossilized remains of the tertiary population of the land and waters, we find all the grand types of the existing animal creation-terrestrial, lacustrine, and marine mammalia-lierbivora, carnivora, birds of every order, and of numerous species and genera-reptiles, fishes, crustacea, insects, zoophytes, and even those living atoms, the infusoria*-in short, all the leading divisions, and even sub-divisions of animal existence. In the vegetable world, as I have already remarked, the same general analogy is maintained. And as all these varied forms of being required physical conditions suitable to their respective organizations, we have at once conclusive evidence that the general constitution of the earth in the tertiary epoch,

* In tertiary strata the remains of beings of which millions would occupy but a cubic inch have been discovered. They will be described hereafter. 
could not essentially have differed from the present. Dry land and water, continents and islands, existed then as now-their geographical distribution may have varied-the temperature in certain latitudes may have been much higher-countries may have existed in areas now covered by the water, and marshes and fens have prevailed in regions now arid and waste; but the same agents of destruction and renovation were then, as now, in constant activity. It is true that immense numbers of large mammalia lie buried in regions where it is utterly impossible such creatures could now find subsistence, and in latitudes whose climates are unsuitable to such forms of organization. But some of these apparent anomalies may be explained by the fact, that the alluvial beds in which these remains occur, cannot have been the sites of the dry land on which these lost beings existed; they are the sediments of ancient lakes-the deltas of former rivers-the estuaries of seas-they are formed of the detritus of the land transported from a distance. If the Gulfstream annually strews the shores of the Hebrides with the fruits of torrid climes, the currents of the ancient seas must have produced analogous results; and in our attempt to interpret past changes, it must not be forgotten that they have most probably been produced by causes which are still in action. I do not question the assumption that the countries containing these fossil remains, may have enjoyed a milder climate in the tertiary epoch than 
at present; or that in still earlier periods there may not have prevailed all over the world a higher temperature than now. But it appears to me that the variation of climate which a change in the distribution of the land and water would occasion, as suggested by $\mathrm{Mr}$. Lyell,-or a difference in the radiation of heat from internal sources, as explained by Sir J. Herschel, and Mr. Babbage,-may account for these phenomena.

The occurrence of groups of animals of the same families, in certain districts, is in strict conformity with the distribution of living species, in regions not under the control of man; and thus when ancient France presented a system of lakes, animals fitted for such physical conditions found there the means of subsistence-when the vast plains and forests of America were adapted for colossal mam. malia, there the mastodons and the mammoths obtained food and shelter-and when the former continent of Europe swarmed with herbivora, the carnivorous tribes, as the lion and the tiger, the bear and the hyena, obtained the support which their habits and economy required.

One striking feature in the events that liave passed in review before us, is the inımense scale on which the extinction of species and genera has been effected: but it must be remembered that our observations have extended over a period of vast duration, and that we therefore have seen the aggregate effects of a law, which even before our 
eyes is producing great and important modifications in the system of animated nature.

Thus the tertiary epoch displays to us a state of the earth replete with life and happiness: the physical constitution of its surface being then, as now, admirably adapted to the habits and economy of the beings it was designed to support. In the most ancient periods, forms of life prevailed which gradually became extinct, and were succeeded by others which in their turn also passed away; and if we trace the varying types of being from the earliest ages, we perceive a gradual approach to the present condition of organic existence; the grand line of separation between the present and the past being the creation of the human race. From that period, in proportion as man has extended his dominion over the earth, many races of animals have been either exterminated, or modified by his caprices or necessities; and it camnot be doubted that in the lapse of a few thousand years, a total change will have been effected by human agency alone, in the relative numerical proportions of existing genera and species. 


\section{LECTURE IV.}

1. Introductory Remarks. 2. Secondary Formations. 3, The Chalk Formation. 4. Chalk and Flint. 5 Flint Nodules. 6. Sulphuret of Iron. 7. St. Petcr's Mountain. 8. The Mosæsaurus, or Fossil Animal of Maestricht. 9. Organic Remains of the Chalk. 10. Fossil Flora of the Chalk. 11. Corals, Sponges, \&c. 12. Radiaria - Crinoidea. 13. Echinitcs. 14. Shells of the Chalk. 15. Cephalopoda, and Chambered Shclls. 16. Bclemnite and Nautilus. 17. The Ammonite. 18. Spirolinites. 19. Infusoria in Flint. 20. Crustacea. 21. Fishes of the Chalk-Sharks. 22. Fossil Salmon, or Smelt. 23. Maeropoma and other Fishes. 24. Reptiles. 25. Review of the Characters of the Chalk Formation. 26. Geology of the Soutlı-cast of England. 27. Geologieal Phenomena between Loudon and Brighton. 28. The Wealden. 29. Wealden Strata on the Sussex Coast. 30. Pounceford. 31. Sub-divisions and Extent of the Wealden. 32. Quarries of Tilgate Forest. 33. Rippled Wealden Sandstone. 34. Wealden of the Isle of Wight. 35. Isle of Purbeek. 36. Isle of I'ortland. 37. Fossils of the Wealden. 38. Palms, Yuccas, and other Fossil Plants. 39. Shells of the Wealden. 40. Sussex Marble - Fossil Cypris. 41. Fishes of the Wcalden. 42. Fossil Reptiles of Tilgate Forcst. 43. Turtlcs. 44. Plesiosaurus. 45. Croeodiles. 46. Swanage Crocodile. 47. Megalosaurus. 48. Diseovery of the Iguanodon. 49. Maidstone Iguanodon. 50. Diseovery of the IIylaesaurus. 51. Flying Reptiles, or Pterodactyles. 52. Fossil Birds. 53. Country of the Iguanodon. 54. Sequence of Gcological Events. 55. Geological Epochs. 56. Retrospect.

1. Introductory Remarks. - The knowledge we have acquired from our investigation of the phenomena described in the previous lectures, will materially facilitate our geological progress, by enabling us to comprehend the former effects of those agencies, by which, through all time, the surface of the earth has been renovated and maintained. 
The elevation of the beds of seas and rivers, and their conversion into fertile countries-the submergence of islands and continents beneath the waters of the ocean - the rapid formation of conglomerates from shells and corals on the sea shore-the accumulation of beach and gravel, and the inhumation of animals and vegetables-the slow deposition of sediment by lakes, the imbedding of countless generations of insects, and the formation of limestone from their almost invisible skeletons-the construction of solid stone out of fragments of bones, and rocks, shivered by earthquakes-the engulfing, in estuaries and inland seas, of land animals, birds, and reptiles-the consolidation of both organic and inorganic substances into rock, by the infiltration of flint and lime by thermal watersthe transmutation of inmerged forests into coal and lignite-the destructive and conservative effects of volcanic eruptions - the conversion of sand, gravel, and clay into homogeneous masses by heat, and even the production of metalliferous veins of gold and silver-all these phenomena have passed in review before us, although our inquiries have extended but through periods which, however vast and remote in relation to the records of our race, are brief and modern in the physical history of the earth.

The geological events previously described, although forming a connected series, may be divided into periods, each marked by certain zoological characters. 1st. The modern, or human epoch; 
2 d. the elephantine, characterised by the preponderance of large pachydermata; 3d. the palæotherian, in which animals allied to the tapir prevailed, and Europe presented a system of gulfs and lakes.

2. Secondary Formations. - I hasten to the consideration of another geological epoch,- that which comprehends the Secondary Formations. Hitherto our attention has been principally directed to deposites confined within comparatively limited areas; the basins of lakes, gulfs, estuaries, and inland seas; the drifted accumulations of torrents, rivers, and inundations. We have now arrived on the shores of that ocean, of whose spoils the existing islands and continents are principally composed; the fathomless depths of the ancient seas are spread before us, and all the myriads of beings which sported in their waters, and lived and died in those profound abysses, remain, like the mummies of ancient Egypt, the silent yet eloquent teachers of their own eventful history.

A reference to the Tabular $\Lambda$ rrangement of the Strata (Pl. III. page 178), will show that the secondary formations constitute eight principal groups. I propose in this discourse, to explain the geological characters of the first two in the series, namely, the CHALK and the WeALDEN. The former is composed of strata that have been accumulated in the depths of a sea of great extent; the latter, of the sediments of an ancient delta; the one affording a striking illustration of the 
nature of oceanic, and the other of fluviatile deposites.

In the diagram, Plate III., the Wealden (3*) is represented as an intercalation between the Chalk and the Oolite $(3,4)$, because it is of limited extent, and where absent, as in the midland counties of England and on the continent, the chalk lies upon the oolite, as will be shown in the next lecture. As both the chalk and the wealden are fully developed in the south-east of England, the phenomena about to be described may be examined with but little inconvenience; and an extensive collection of their peculiar fossils may be seen in my museum.*

3. The Chalk Formation.-The pure white limestone, called Chalk, is known to every one; but in the nomenclature of geology, the term is applied to a group of deposites rery dissimilar in their lithological compositions, but agreeing in the character of the organic remains which they contain, and evidently referrible to the same epoch of formation. With this explanation, it will be convenient to employ the term in its extended sense. The Chalk formation is composed of four principal divisions. 1. The uppermost consists of Chalk, with and without flints. This limestone is generally white, but in some districts red, and in others yellow; flint nodules and veins abound in the upper, but seldom occur in the lower division. 2. Marl,

* See Descriptive Catalogue of the Mantellian Museum, Sro. 
an argillaceous limestone, which universally prevails beneath the white chalk; it sometimes contains a large intermixture of green sand, and then forms what is called Firestone, or Glauconite. 3. Galt, a stiff, blue or black clay, abounding in shells, which frequently possess a pearly lustre. 4. Shanklin, or Green Sand, a triple alternation of sands and sandstone with clays ; beds of chert and fuller's earth are found in some localities.

On the Continent, and in other parts of the world, indications of the series of depositcs here enumerated, occur; and, taken as a whole, the chalk formation may be described as extending over a great part of the British Islands, Northern France, Germany, Denmark, Sweden, European and Asiatic Russia, and of the United States of North America.* Over this vast extent, the organic remains of the chalk maintain certain general characters, sufficiently obvious to determine the nature of the formation.

Whether imbedded in pure white limestone, coarse sandstone, blue clay, loose sand, or compact rock, the fossils consist of the same species of shells, corals, sponges, echinites, belemnites, ammonites, and other marine exuviæ; fishes, reptiles, wood, and plants. The strata are well displayed along the Sussex and Kentish coasts, and those natural sections exhibit the manner in which the beds have

"Dr. Morton's Synopsis of the Cretaceous Groups of the United States, 1 vol. 8 vo. with plates. 
been disrupted, and thrown into an inclined position. (See Pl. V. fig. 1.) Near Devizes, in Wiltshire, the strata lie nearly horizontal, and in the following order:-1. White Chalk. 2. Glauconite. 3. Galt. 4. Shanklin Sands. (See Pl. V. fig. 2.)

4. Chalk And Flinto*-The white chalk is composed of lime and carbonic acid, and may have been precipitated from water holding lime in solution, from which an excess of carbonic acid was expelled. But some masses of chalk are composed of minute corals and shells, and whole layers, in many quarries, are formed of the ossicula of star-fish and other radiaria. The nodules and reins of flint which occur in the chalk, show that water holding silex in solution must have been very abundant at the cretaceous period. The power possessed by thermal waters of dissolving silicious earth, depositing flint, and occasioning the silicification of regetable substances, is strikingly exemplified in the Geysers of Iceland, as I have already explained (p. 74). The perfect fluidity of the silex before consolidation, is shown by the sharp impressions which the flints bear of shells and other marine bodies; and upon breaking the nodules, sponges, alcyonia, and other organic remains, are found

* See The Fossils of the Soutl Downs, or, Illustrations of the Geology of Sussex, 1 vol. 4to. with 42 plates. Geology of the South-East of England, l vol. Sro. Dr. Fitton's Memoirs on the Shanklin, or Green Sands, in which many of the fossils are beautifully delineated. 
enveloped, the silicious matter lraving so penetrated the delicate structure of the original, that polished sections display the minute organization of the inclosed zoophytes.

5. Flint Nodules.-Flints, or silicious nodules, occur in the chalk in horizontal rows, which present some degree of regularity, and are placed at unequal distances from each other. This arrangement has probably arisen from the chalk and flint having been held in suspension or solution in the same fluid, and erupted into the basin of the ocean: when consolidation took place, the silicious molecules separated from the cretaceous, on the well-known principles of chemical affinity; the sponges and other zoophytes acting as nuclei or centres, around which the silicious matter coagulated. This process receives illustration from the fact, that when different substances in a state of extreme division are mixed together, they have a tendency to separate, and re-arrange themselves in masses more nearly homogeneous; thus a separation of pounded flint from aluminous earth, in the materials prepared in the potteries, will take place, and silicious concretions be formed, if the mixture be not constantly agitated. The marked stratification of the chalk shows that it was poured out periodically; and it is not unusual to find veins of flint running through and filling up crevices in the strata beneath; an appearance that can only be attributed to the lower beds having been consolidated, and subsequently 
fissured, before the superincumbent stratum was precipitated.

6. Sulphuret of Iron.-Iron pyrites is the only metalliferous ore that occurs abundantly in the chalk of England. The large nodular masses that are found on the Downs and in the ploughed fields, are commonly termed thunderbolts. This mineral is sometimes found in octahedral crystals of great elegance and regularity, and frequently occupies the cavities of shells, and echini ; terebratula, and pectens, also occasionally occur in masses of this substance. The bones and scales of the fishes are invariably coloured with a ferruginous stain, arising from a curious chemical process; sulphuretted hydrogen was evolved during the course of putrefaction, but the sulphur entering into combination with the iron contained in the water, sulphuret of iron has formed, and thus the fossil fishes have derived the rich colour which so beautifully contrasts with the white chalk by which they are surrounded.

7. St. Peter's Mountain, Maestricht.I have described the usual lithological characters of the chalk, and if our observations were restricted to the deposites as they occur in England, the difference between the uppermost secondary formation and the superimposed tertiary would be most striking, both as regards the nature of the rocks and their organic remains. But, as I shall hereafter explain, the chalk of England appears to have been 
formed in the most profound depths of the sea, and we have rarely any intermixture of terrestrial or littoral productions; even pebbles are of unfrequent occurrence. At Castle Hill, near Newhaven (p. 208), and at Alum Bay, in the Isle of Wight (p. 206), the cerithia (Tab. XXII. fig. 4), turritella, and other tertiary shells, abound in the sand and clay spread over the surface of the chalk, in which no similar shells can be detected. On the Continent, however, there exist deposites which form a link between the tertiary and secondary; and in the valley of the Meuse a fine series of strata, the uppermost abounding in those genera of shells so plentiful in the tertiary, and passing imperceptibly into limestone with cretaceous fossils, and flint nodules, and finally into chalk. The quarries of St. Peter's Mountain have long been celebrated for their remarkable fossils; but the true geological characters of the strata were first determined by the able investigations of Dr. Fitton. In North America the researches of Dr. Morton have proved the existence of analogous deposites.

St. Peter's Mountain, in which the quarries are situated, is a cape or headland between the Meuse and the Jaar, and forms the extremity of a range of hills which bounds the western side of the valley of the Meuse. The beds of limestone present a total thickness of 500 feet. Excavations have for centuries been carried on, and from the immense quantities of stone removed, extensive caverns and 
galleries now traverse the heart of the mountain.* Shells, corals, crustacea, teeth of fishes, and other marine remains, are in profusion; with wood perforated by lithodomi, and the bones of a large and very remarkable reptile.

8. The Mosesaurus; or Fossil Reptile of Maestricht.-The large bones and teeth of an unknown animal. which were occasionally found in the limestone, had long since directed the attention of maturalists to the quarries of St. Peter's Mountain. In 1770 M. Hoffmann, who was forming a collection of organic remains, had the good fortune to discover a specimen, which has conferred additional interest on this locality : some workmen, on blasting the rock in one of the caverns of the interior of the mountain, perceived, to their astonishment, the jaws of an enormous animal attached to the roof of the cliasm. The discovery was immediately made known to M. Hoffmann, who repaired to the spot, and for weeks presided over the arduous task of separating from the rock the mass of stone containing the remains. His labours were at length repaid by the successful extrication of the specimen, which he conveyed in triumph to his house. Unfortunately, the canon of the cathedral, which stands on the mountain, claimed the fossil in right of being lord of the manor, and succeeded by a troublesome and expensive law-suit

* See Hist. Nat. de la Montagne de St. Pierre, by Faujas St. Fond, 1 vol. 4 to. with splendid engravings. 
in obtaining this precious relic. It remained in his possession for years, and Hoffmann died without regaining his treasure, or receiving any compensation. The French Revolution broke out, and the armies of the Republic advanced to the gates of Maestricht; the town was bombarded, but by desire of the committee of savans, who accompanied the French troops, the artillery were not allowed to play on that part of the city in which the celebrated fossil was known to be contained. In the meanwhile the canon, shrewdly suspecting why such peculiar favour was shown to his residence, concealed the treasure in a secret vault; but when the city was taken the French authorities compelled him to give up his ill-gotten prize, which was immediately transmitted to the Jardin des Plantes, at Paris, where it still forms one of the most striking objects in that magnificent collection. It is but just to add, that the relatives of Hoffmann were rewarded by the French Commissioners. The model of this specimen in my museum was presented to me by Baron Cuvier; it consists of the jaws, teetl, palate-bone, vertebræ, and os quadratum, a bone possessed by some reptiles, and in which the auditory cells are contained. There are portions of jaws with teeth of the mosæsaurus in the British Museum. The original was a reptile, holding an intermediate place between the Monitor and Iguana, about twenty-five feet long, and furnished with a tail of such construction as must have rendered it a power- 
ful oar, enabling the animal to stem the waves of the ocean, of which Cuvier supposes it to have been an inhabitant. The vertebræ before you belong to this creature, and were discovered in a chalk quarry near Lewes. This remarkable specimen was found a few days since, in the chalk of Kemp-town; it is a vertebra of the tail, partially invested with flint, which has consolidated around it without obscuring its essential characters. These teeth, from North America, collected by Dr. Morton, appear to be identical with those from Maestricht, and afford proof of the original extension of the ocean of the chalk over the area now occupied by the Atlantic.

9. Organic Remains of the Chalk.-The fossils of the chalk are very numerous, and comprise all the usual forms of marine existence, with the exception of cetacea. Certain genera and species appear restricted to certain subdivisions of the formation. Thus in the white chalk, there are many species of shells that do not occur in the other divisions of the strata. The marl and galt are also characterised by peculiar forms, and the Shanklin sands abound in shells and zoophytes, that are wanting in the other cretaceous strata. The genera and species must, therefore, have been spread over limited areas; in other words, the inhabitants of the chalk ocean had geographical limits assigned them, as is the case with existing species.

The mode of preservation varies in the different 
beds. The shells, and stony polyparia, and radiaria of the white chalk, are generally transmuted into carbonate of lime, with a spathose structure, doubtless the result of high temperature, acting under great pressure (see p. 79). The cavities are frequently filled with chalk, flint, or sulphuret of iron; in many instances they are hollow, or lined with crystals of carbonate of lime. The softer zoophytes are silicified, and there is scarcely a flint nodule in which their remains may not be traced. The bones of animals and the coverings of crustacea are in a friable state, and stained with sulphuret of iron. The teeth and scales of the fishes present a high polish, and are coloured by a ferruginous impregnation. Wood occurs in the state of lignite, and of brown friable masses, which quickly decompose; but when enveloped in flint, the structure is well preserved; like the fossil wood of the tertiary, it has evidently been drifted, and is perforated by lithodomi; the fissures are often filled with glittering pyrites.

In the galt, the nacreous covering of the shells is commonly preserved, and the ammonites and nautili of Folkstone rival in beauty the shells of the London basin, and, like them, are subject to decomposition. The green-sand fossils are generally silicified, and the whetstone pits of Devonshire are celebrated for the variety and chalcedonic state of the shells in which the sandstone abounds.

The organic remains of this formation already 
known, amount to many hundred species of shells, polyparia or corals, radiaria, \&c. The most distinctive zoological character, is the abundance of belemnites, echinites, and ammonites: the latter are the shells of an extinct race of cephalopoda, which appears for the first time in the chalk, no traces of their remains having been discovered in the tertiary formations. My collection, consisting of many thousand fossils from the chalk formations of England and America, displays the usual species, together with many that are exceedingly rare. I will illustrate this subject with a selection of a few specimens from each olass.

10. Fossil Vegetables.-The flora of the chalk, as I have already remarked, offers but little variety. Fuci, or sea-weeds, occur in some localities in great abundance. There is one species of Fucus (Fucoides Targionii) that abounds in the malm rock of Western Sussex, particularly at Bignor, the seat of John Hawkins, Esq., where almost every fragment of the rock is marked witl its meandering forms. Conferve occasionally are seen in the flints. Plants allied to Zostera occur in the chalk of the Isle d'Aix ; drifted wood abounds in the line of junction between the galt and green sand. In the quarry of Kentisly rag, of Mr. W. H. Bensted, of Maidstone, have been discovered fir-cones, leaves, large masses of perforated wood, and the stem of a plant allied to the Yucca, which Mr. Bensted lias, with great liberality, placed in my collection. I reserve a 
more particular description of these vegetable remains for the lecture on fossil botany.

11. Corals, Sponges, \&c.-I have already melltioned how numerous are the softer zoophytes in the flints. In the white chalk stony corals occur but rarely, while the Maestricht beds contain them in great abundance. A small turbinolia is not unusual in the English chalk, and I have several unique specimens of other genera; but the absence of the large madrepores, and corals of that class, is a remarkable fact, and accords with the evidence derived from other sources, to prove that we are examining the profound abyss of an ocean; for the economy of the living corals fits them to live only in waters of moderate depths. It would be tedious to repeat to you the names which naturalists have assigned to the fossil zoophytes of the chalk; let it suffice to observe, that the more delicate forms, as flustra, millepora, cellepora, \&c. are very abundant: the nature of these corals will be explained in a future lecture. There is one fossil zoophyte, known to collectors of Sussex pebbles by the name of petrified sea-anemone, from its supposed resemblance to the living actinia (Pl. II. fig. 12). The original of this fossil was, however, a very different creature. From an extensive suite of specimens, I have ascertained that it was of a subglobular form, of a tough jelly-like substance, with a central opening or stomach, from which numerous tubes radiated; these are exquisitely 
preserved in flint. The external surface often exhibits the remains of crucial spines, similar to those possessed by many alcyonia (Pl. I. fig. 10 ${ }^{c}$ ).

12. Radiaria; Crinoiden, \&c.-The Crinoidea, or lily-shaped animals, are but sparingly distributed

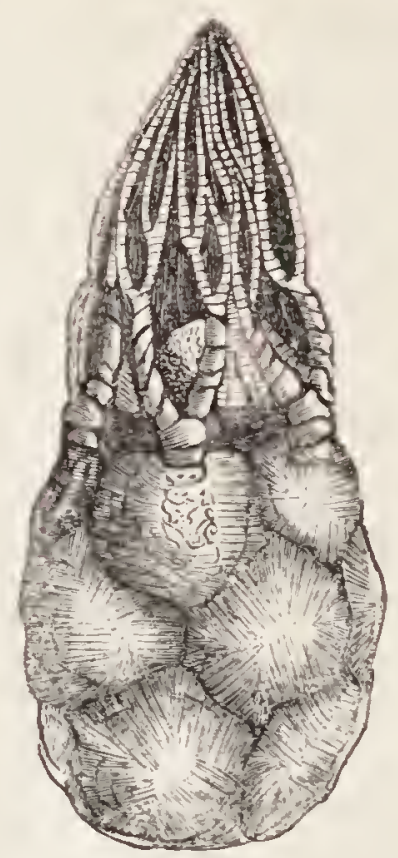

TAB. 30.- ArARSUPITE FROSI THE CHALK.

(Restored from Specimens presented by the Rev. H. Hoper, and G. A. Coombe, Esq. of Arundel.)

in the chalk-a circumstance, as you will hereafter find, strikingly contrasting with the zoological characters of the older secondary formations. Stems of encrinites occur in the chalk and galt; and there is a small species of apiocrinite, which is peculiar.* The most remarkable fossil of this class is the

* Geology of the South-East of England, p. 111. 
Marsupite, which I have thus named from its resemblance to a purse.

The Marsupite was a molluscous animal, of a sub-ovate form, having the mouth in the centre, and surrounded by arms or tentacula. The skeleton was composed of crustaceous, hexagonal plates, the arms, which are subdivided into numerous branches, of ossicula, or little bones; the whole was invested with a muscular tissue, or membrane. When Hoating, the cre ature could spread out the tentacula like a net, and by closing them, seize its prey and convey it to the mouth. This figure (Tab. 30) is restored from specimens which separately exhibit the parts here represented.

Asterice, or star-fist, are occasionally found in great perfection in the chalk; my friend, the Rev. Thomas Cooke, of Brighton, has discovered several remarkably fine impressions in flint, on the South Downs. The whetstone of Devonshire affords similar remains.

13. Echinites.-- Those singular creatures, the Echini, or sea-urchins, are too well known to require minute description. Their spherical shell, or skeleton, is made up of polygonal plates, closely fitted to each other; and the surface is divided vertically, by bands like the meridians of a globe, having rows of double perforations. They are studded over with papillæ, which vary in size from mere granular points to large well-defined tubercles. To these papillæ, spines, also presenting great variety 
of figure and decoration, are attached. These are the instruments of motion, and, as on the death of the animal, the tendons by which the spines were attached decompose, the extreme rarity of fossil specimens, with these processes affixed, is readily explained. The echini, both recent and fossil,

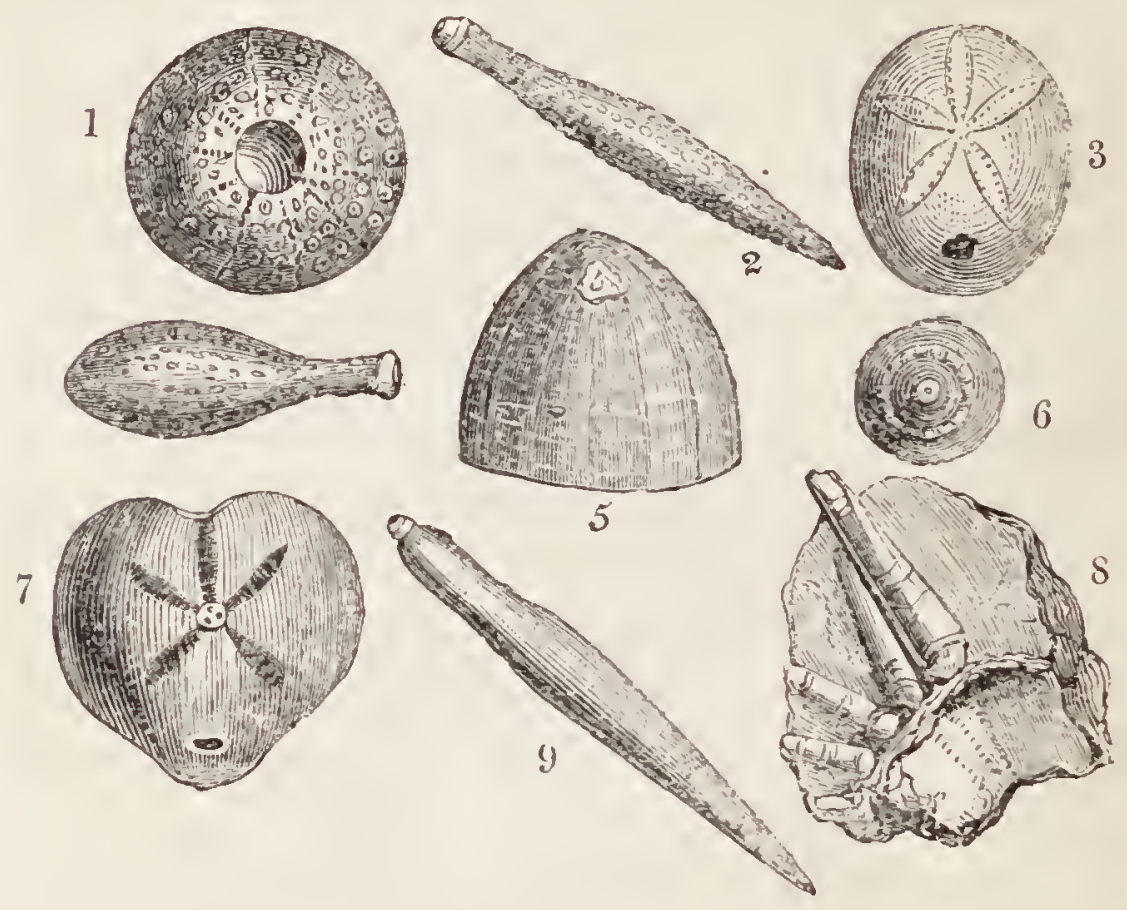

TAB. 31.-ECHiNites AND SPINES FROM THE ChALK.

Fig. 1. Cidaris diadema. 2, 4, 9. Spines of Cudares. 3. Nuclenlilcs. 5. Ananchyles cretosus. 6. Tubercle of a Cidaris. 7. Spalangus Cormarinum. 8. Spines and portion of the Shell of a Cidaris in flint.

differ greatly in form and structure; they are arranged into numerous sub-genera, for the convenience of study, but I can only notice a few of the usual varieties.

The helmet-shaped echinites (fig. 5) are ex- 
tremely abundant, and in some localities occur in shoals, and in every gradation from the young to the adult state. Silicious casts of echini, formed by the decomposition and removal of the shell from the flint with which they were filled, are common in gravel and on ploughed lands. The cordiform variety (fig. 7) is very abundant, and gives rise to the heart-shaped flints of our gravel-pits. The elliptical species (fig. 3) is common in the grcen sand. The hemispherical echini are bcautifully ornamented with papillæ: a small species (fig. 1) is not uncommon in the clialk and flints of $\mathrm{Kcnt}$; the larger varieties possess tubercles, surrounded by elegant margins (fig. 6), and are otherwisc richly ornamented. Some spines are slender and covered with asperities (fig. 2); others almost smooth (fig. 9), and club-shaped (fig. 4); it is seldom that the spines are found imbedded in contact with the shcll (fig. 8).

14. Shells of tile Ciralk.-Thic bivalve shells, or conchifera of the chalk, are very numerous; of one genus alone, Tcrebratula, above fifty species are enumerated. Oysters, scallops, arcas, tellens, and other familiar marine shells abound, but the species differ from the recent. With these known genera are many which, so far as our present knowledge of the inhabitants of the deep extends, are extinct. Two or three species of Cirrus, or Trochus, are not unusual in the white chalk; but the simple univalves are $\mathrm{fcw}$; and the only specimen 
of a large spiral univalve with which I am acquainted is a Dolium, figured by Sowerby, and belonging to Richard Weekes, Esq. of Hurstperpoint. The Maestricht beds, as I have before

1

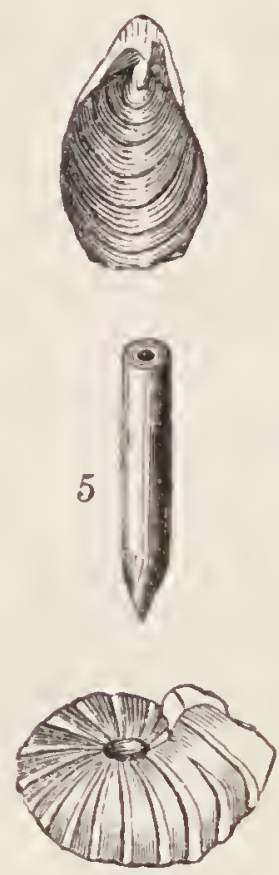

7
2
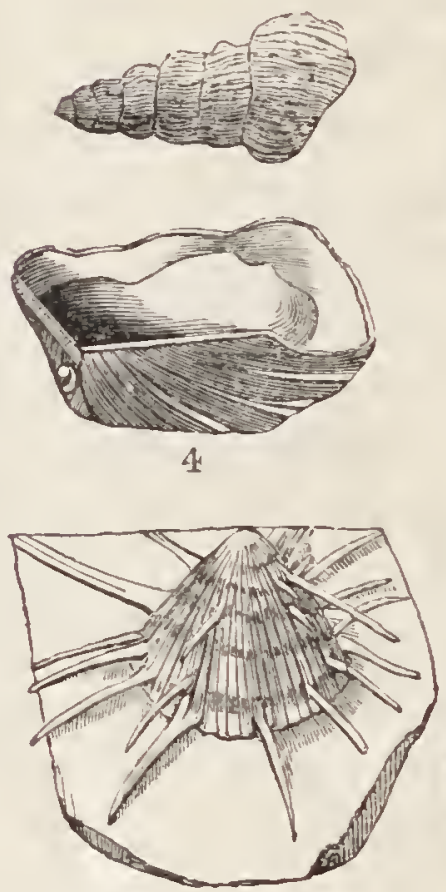

S
3
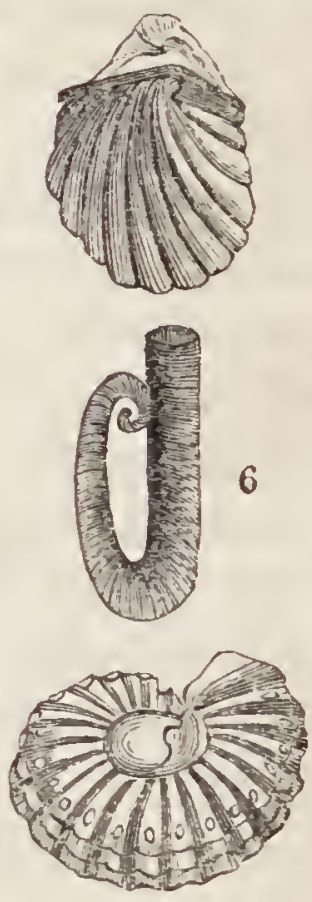

9

TAB. 32.-SHELLS OF THE ChaLK.

Fig. 1. Inoceramus concentricus. 2. Turrilites costatus. 3. Inoceramus sulcatus. 4. Inoceramus Lamarckii. 5. Belemnites Listeri. 6. Hamites. 7. Ammonites Mantellii. 8. Plagiostoma spinosum. 9. Ammonites Sussexiensis.

remarked, offer many exceptions to the usual characters of the chalk. A large volute (V.Faujasii) is often found in the flint nodules of St. Peter's Mountain, with baculites, ammonites, and other 
characteristic chalk fossils. In the marl at Hamsey, near Lewes, I have discovered a few genera of simple univalves not previously known. The subglobular terebratulæ, both the common and the striated varieties, are very abundant. Another bivalve equally numerous is an elegant shell, having one valve covered with long spines (Tab. 32, fig. 8), the Plagiostoma spinosum, ${ }^{*}$ a characteristic species of this formation. A bivalve with a fibrous structure, (Inoceramus, Tab. 32, fig. 4,) very brittle, and having crenulated hinges of a peculiar construction, presents numerous species; some of which are very small and delicately striated, and others two feet in diameter, and deeply furrowed. The substance of these shells closely resembles that of the recent pinna; from their fragility, fragments are very common in chalk, flint, and even in pyrites. The Galt contains two species of this genus, which appear to be restricted to that division of the chalk, and have been found in every locality; they are the Inoceramus concentricus (Tab. 32, fig. 1,) and I. sulcatus, (Tab. 32, fig. 3;) and a hybrid occurs in the Folkstone beds, partaking of the characters of both. The shells of the green sand amount to many

* Plagiostoma.-Viscount D'Archiac informs me that the shells of this genus are true spondyli, and that the triangular vacancy in the lower valve is occasioned by the loss of that portion of the hinge which characterises the recent spondylus. A species of Spherulite (S. Mortoni) occurs in the Susscx chalk: hippurites, so common in the cretaceous strata of the Continent, have not been noticed. 
hundred species: those of Devonshire are changed into silex, jasper, and chalcedony. Dr. Fitton has figured many of the shells from the Shanklin sand of Kent.*

15. Cephalopoda, and Chambered Shells. - The most peculiar and striking feature of the population of the ocean of the chalk, as contrasted with that of the tertiary and modern seas, is the immense preponderance of multilocular cephalopoda. In the tertiary, and in existing tropical seas, one genus, the Nautilus, occurs abundantly. The beauty, elegant form, and remarkable internal structure of the recent shell, have rendered it in all ages an object of admiration; yet the nature of the animal to which it belonged has but recently been ascertained. As Dr. Buckland has giren a lucid and highly interesting account both of the recent and fossil cephalopoda, $\uparrow$ I shall condense my remarks on this subject.

The Sepia, or cuttle-fish of our seas. is of an oblong form, composed of a jelly-like substance, covered with a tough skin; the mouth, which is central, is furnished with horny mandibles, much resembling the beak of a parrot. The animal has two large eyes, and eight arms, studded with rows of little cups or suckers, which are powerful instruments both of locomotion and prehension. The

* Dr. Fitton's Memoir on the Shanklin sands contains representations of the usual shells and zoophytes.

$\uparrow$ Bridgewater Essay, p. 333, et seq. 
soft body of the sepia is supported by a skeleton formed of a single bone of very extraordinary structure; in the state of dry powder it is the substance called pounce. The cuttle-fish has the power of secreting a dark-coloured fluid, or ink, which it ejects when pursued, and by thus rendering the water turbid, escapes from its enemies. This fluid is contained in a bag, and forms, when properly prepared, the sepia colour employed in the arts, and enters into the composition of Indian ink. This brief sketch of the natural history of the cuttle-fish, will enable us to understand the habits and economy of the beings whose fossil remains I am about to describe.

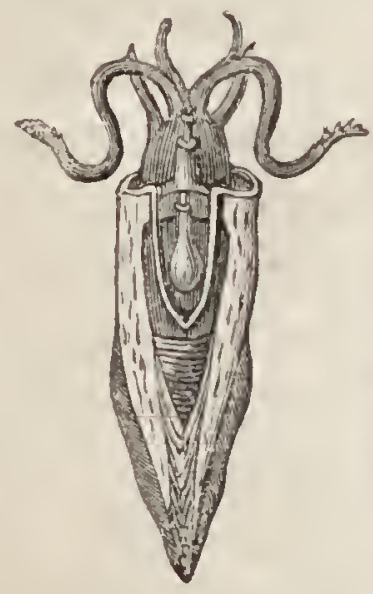

1

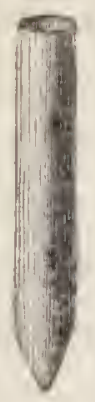

2

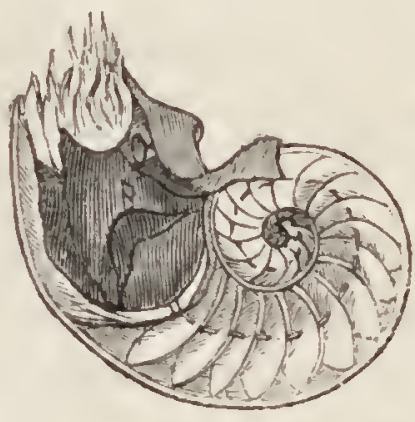

3

TAB. 33.-Belengite and NaUtilus.

Fig. 1. Belemno-sepia, restored, from Dr. Buckland. 2. Belemnites Listeri. 3. Section of the Shell, with the animal, of the recent Noutilus, from Professor Owen's Memoir.

16. The Belemite anin Nautilus.-One of the most common fossils of the chalk is an elongated 
conical stone, of a crystalline, radiated structure, and generally of a brown colour, called belemnite. The pits in Sussex, Kent, Norfolk, and indeed every locality of the chalk, contain these bodies; and some limestones on the Continent are almost wholly composed of them. The belemnite presents considerable variety of form, but in every species the structure consists of a spathose radiated substance, terminating in a point, (Tab.33, fig. 2,) and having at the opposite and largest end a conical cavity, in which is situated a shell of like form, divided into septa or chambers, as seen in the drawing (Tab. 33, fig. 1.). Dr. Buckland has admirably explained the nature of the belemnite, and given the solution of a problem which had long been attempted in vain. The belemnite is the bone of a creature allied to the cuttle-fish, and in this representation its situation in the body of the animal, and connexion with the ink-bag, are so clearly shown, as to require no further comment. I will only add, that the belemnite sometimes occurs with the laminated, external, horny sheath, - the conical, chambered shell, -the ink-bag, - and fibro-calcareous bone, - and that the inspissated contents of the bag, the fossil sepia, has actually been made use of by one of our first artists.

Nautilus.--In the sliell of the Nautilus we have a series of chamber's pierced through the middle by a siphunculus or tube, which extends to the remotest cell. This animal is of the nature of the sepia, 
and occupies the outer receptacle of the shell, having a membranous tube which lines the siphuncle. The chambers are internal air-cells, and the creature has the power of filling the siphuncle only, with a fluid secreted for the purpose, and of exhausting it; and the difference thus effected in the specific gravity of the animal and its shell enables the Nautilus to sink or swim at pleasure. If, therefore, you imagine a cuttle-fish placed in the outer chamber of a Nautilus, with its arms extended, and having a tube connected with the siphunculus, but neither ink-bag or bone, these being umecessary to an animal having the protection and mechanism of a chambered shell, you will have a tolerably correct idea of the recent and fossil Nautili. The Nautilus is essentially a grounddwelling animal, feeding on the marine plants which grow at the botton of the sea. "Rumphius states that it creeps with the shell above, and that by means of its tentacula it can make quick progress along the ground."*

17. The Ammonite, or Cornu Ammonis. The fossils called Ammonites, like the Belemnites, also first appear in the secondary formations; or more properly, no memorials of their race have been found in the tertiary deposites. The Ammonite, so called from its supposed resemblance to the horns of Jupiter Ammon, is a fossil chambered shell, coiled up in the form of a disk, bearing a close analogy to

* Dr. Buckland's Essay. 
the Nautilus, but differing in the situation of the siphunculus, and in the septa by which the interior is divided. In the Nautilus these partitions are entire, and their section presents a series of simple curves, (Tab. 33, fig. 3;) but in the Ammonite they possess every variety of sinuosity, and the external surface of the casts of the Ammonites commonly exhibits markings resembling the outlines of deeply fringed foliage. The shell of the Ammonite is generally decorated with flutings, ribs, or tubercles. I have placed before you Ammonites from the Galt of Folkstone, in which the shell remains,from Watchett, with the internal nacreous coat only, -while in this common species from Whitby the shell is altogether wanting, the specimen being a cast of the interior, formed of argillaceous iron-stone, a state in which these fossils are frequently found. In these examples from Mr. Bensted's quarry, the shells and partitions of the separate chambers having decomposed, casts have been formed, which fit into each other, and admit of being put together, so as to show the distinct shape of the Ammonite. Nautili also occur in this state; and I have a specimen for which I am indebted to Miss Pearson, of Clapham, in which the series is complete from the commencement to the outer cell. Nearly three liundred kinds of Ammonites are known in the secondary formations, certain species being restricted to particular deposites. Thus, for example, the chalk marl of Sussex abounds in two kinds of Ammonites, (Tab. 
32, fig. 7,9 ,) which either are very rare, or do not occur in the white chalk above, or in the blue clay below; and in every part of England, and on the Continent, these species are found in the same geological position. But I must again refer you to Dr. Buckland's Bridgewater Essay for some most important and highly interesting information on these subjects. I will add !but one remark; the membranous tube of the air-cells sometimes occurs in a fossil state, as may be seen in this Ammonite from the chalk marl of Lewes, which retains a large portion of the siphuncle; the black substance of these tubes has been analysed, and found to consist of animal membrane, permeated by carbonate of lime. Dr. Prout explains the black colour to have originated from decomposition; the oxygen and hydrogen of the animal membrane escaping, and carbon being evolved, as happens when vegetable matter is converted into coal, under the process of mineralization. The lime has taken the place of the oxygen and hydrogen, which existed in the pipe before decomposition.*

Ammonites vary in size from a few lines to twelve or fourteen feet in circumference; at low water on those parts of the Sussex coast where the chalk forms the base of the shore, enormous Ammonites are often seen imbedded. In some limestone districts, the marble is almost wholly composed of Ammonites, as in this polished slab from Somerset-

* Bridgewater Essay, p. 352. 
shire, which exposes the most beautiful and varied sections of the shells.

Baculites, Turrilites, Hamites, and other genera of multilocular shells, abound in the Chalk marl, Galt, and Shanklin sand. The Turrilite (Tab. 32, fig. 2,) may be described as an Anmonite twisted in a spiral, instead of a discoidal form: and the Hamite, (Tab.32, fig. 6,) as a similar structure in the shape of a hook, coiled up at the smaller extremity. These shells sometimes attain a large size; the Turrilite before you, which is the finest example known, would if perfect exceed two feet in length; it possesses traces of the siphuncle. Hamites of gigantic proportions have been found in the Shanklin sand of Kent, by Mr. Hills, the intelligent and indefatigable curator of the Chichester Museum. The first specimens of Turrilites, Hamites, and Scaphites, discovered in the British strata, were, in my early researclies, found in Hamsey marl-pits, near Lewes. The scaphite is of a boat-like form; but I must forbear entering on its description, as well as on that of many other interesting kinds of multilocular shells, hundreds of which are microscopic, and sometimes form entire masses of chalk, as Mr. Lonsdale's researches have shown.

18. Spirolinites.-There is however one genus which I cannot pass over without remark; it is called, from the disposition of - its chambers, the Spirolinite, and resembles the common Nautilus spirula, the crozier-shell of collectors, except that 
the coils, which in the recent shell are separate, are in close apposition in this fossil. Several species of

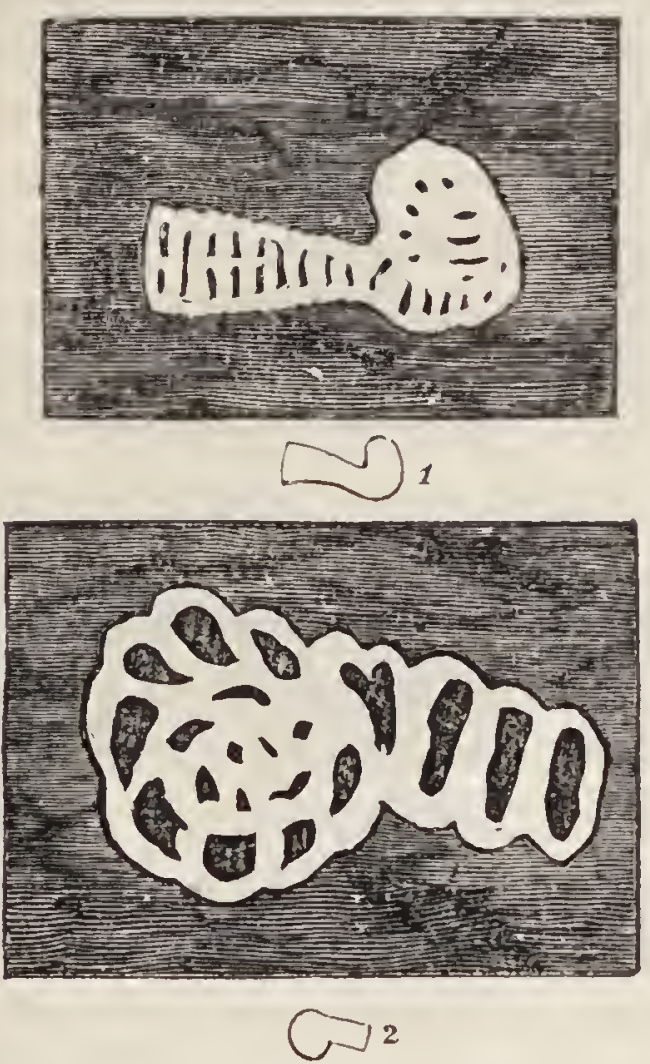

'TAB. 34.-Spirolinites ix Flint. Discovered By the Mareuis of Nortiampton.

Fig. 1. Spirolinites Lyellii. Fig. 2. S. Comploni.

this genus, previously unknown in the chalk, were discovered by the Marquis of Northampton some years since, in the pebbles on the Brighton shores; and in flints from the chalk at Kemp-town, and other places: these minute but most interesting objects having escaped the notice of less accurate and intelligent observers. My son has also collected 
several specimens from the flints around Chichester. I have great pleasure in laying before you enlarged
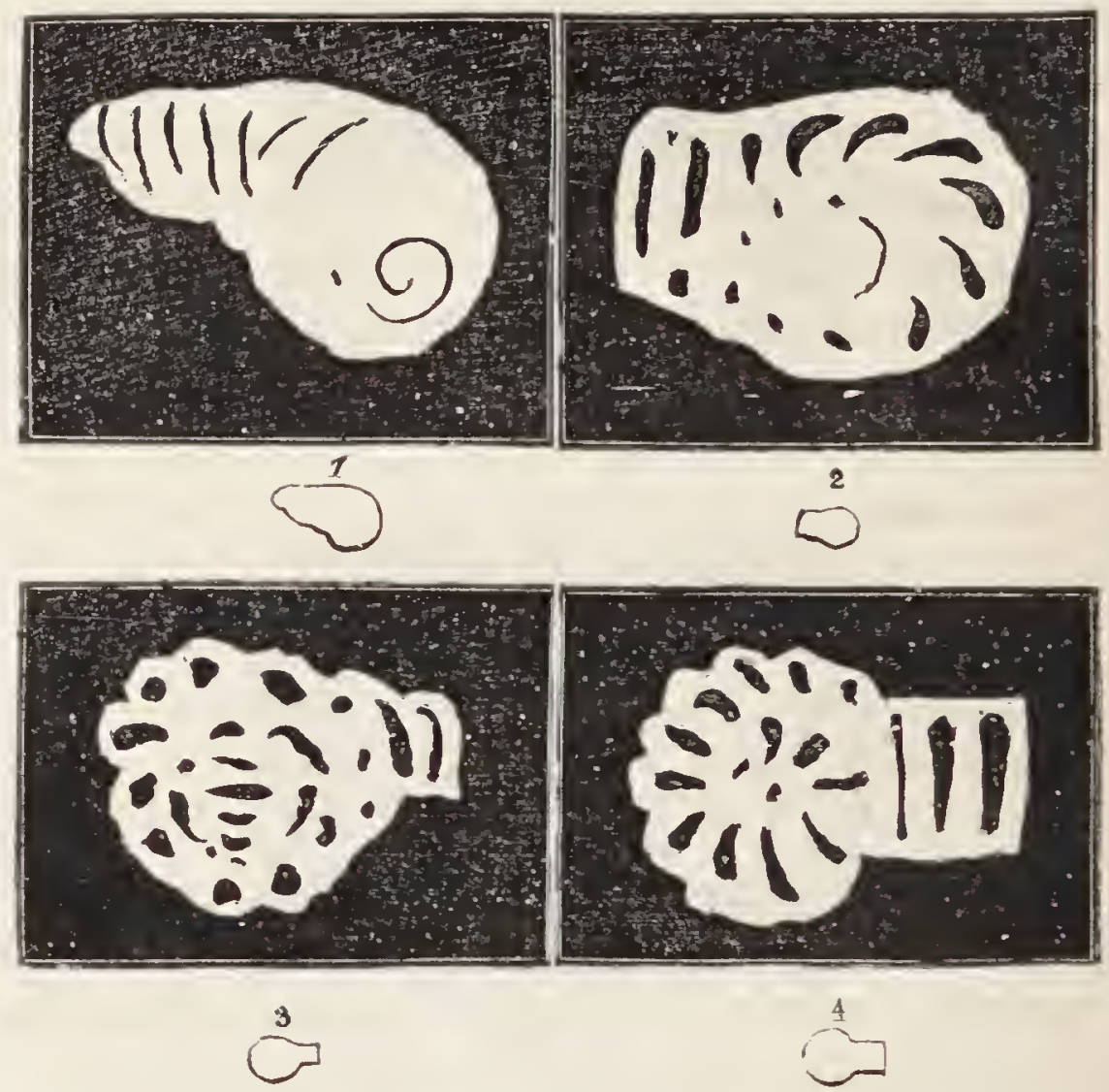

TA B. 35.-Fig. 1. Spirolinites Stolesii. 2. S. Mantellii. 3. S. Lyellii. 4. S. Comptoni.

drawings, by his Lordship, of four species; the smaller figures indicate the size of the originals.*

* Note on the Sussex Spirolinites, by the Marquis of Northampton:-

"I willingly comply with your desire to communicate a short note on the Sussex Spirolinites, one species of which you have heen pleased to distinguish by my name. I have found these fossils in flint at Brighton, Kemp- town, Rottingdean, Lewes, Hastings, Steyning, Chichester, West Stoke, and in the Isle of Wight; 
19. Infusoria in Fuint:-Among the almost innumerable diversity of forms in which those atoms of animal existence, the Infusoria (so called because many species abound in vegetable infusions), appear, many species like the Cypris, of which we have already spoken, possess shields or coverings, some of which are ferruginous, others calcareous, and many silicious; the ferruginous film seen on the surface of stagnant water is made up of Infusoria. The Infusoria

and one speeimen in France. I have discovered about two hundred of these minute chambered shells in flint, but only two in chalk. Some of the microscopie bodies extrieated from the chalk by Mr. Lonsdale, I am inclined to think are Spirolinites, but others are foraminifera. I have seen, as I believe, minute nummulites in the Sussex flint. The Spirolinites which I have collected constitute four distinct species. 1. The one to which you have been pleased to give the appellation of $S$. Comptoni. 2. Spirolinites Lyellii, distinguished by the horizontal chambers, one above the other, in the coiled portion. 3. S. Stokesii, which I name after our friend Charles Stokes, Esq.; and this name has the further advantage of pointing out the loeality, West Stoke, near Chichester, from which I obtained this unique specimen, and where other Spirolinites abound. The fourth you must allow me to designate $S$. Mantellii. The distinctive characters of these species are too obvious to require detailed description. The transverse chambers in S. Lyellii (Tab. 35, fig. 3 ) are a striking peculiarity of structure; in the specinen from Hastings, there appear indications of a siphuncle in the straight prolongation (Tab. 34, fig. 1). I am inclined to believe that there are other species in my collection, but the irregularity in the fractured sections of these minute chambered shells, renders it difficult to arrive at aceuratc conclusions on this point.

$$
\text { "Castle Ashby. }
$$

"Northampton." 
belong to many distinct families, some having a complex organization, with a nervous, muscular and circulating system, and digestive organs highly developed. As I shall revert to this subject in another lecture, I now only wish to call your attention to the remarkable fact, that the silicious cases, or skeletons, of this class of beings, have been discovered in a fossil state; and that some deposites, for instance the tripoli of Bilin in Bohemia, consist almost entirely of the silicious remains of Infusoria, of a species so minute, that a cubic inch of stone, weighing 220 grains, contains upwards of 41 millions of these skeletons.* The distinguished naturalist, Ehrenberg, to whom we are indebted for this wonderful discovery, has also detected the remains of these animalculæ in chalk-flints, semiopal, and other silicious substances; and the Rev. I. B. Reade, of Peckham, has observed in the flints of Surrey shields of Gaillonella, a form of infusorial animal well known to microscopic observers. I shall hereafter place before you representations of some of these objects, with which $\mathrm{Mr}$. Reade has kindly favoured me; it is sufficient for the present to have stated the fact, that entire masses of flint are composed of the fossilized remains of beings, as wonderful in their structure and organization, as any of the colossal forms of animal existence.

* See a translation of Ehrenberg's Observations on these Discoveries, in Taylor's Scientific Memoirs, Part III. 
20. Crustacea.-Species of several genera of crustacea have been extricated from the Sussex chalk; in some examples I have succeeded in removing the surrounding stone, and exposing the filiform antennæ, the abdominal segments, and the tails of Astacide. In the Galt, the crustacea hitherto discovered belong to very small species. I have obtained from Ringmer, near Lewcs, specimcns which, in the opinion of Dr. Leach, are extinct forms, related to Indian genera. In the Speeton clay of Yorkshire, Professor Phillips has discovered sevcral beautiful'species of Astacus. The Shanklin sands of Kent and Dorsetshire have yielded a few crustacean remains. In the limestone of St. Peter's Mountain, claws of a small kind of crab are frequently discovered, but no other vestiges of the animal. Faujas St. Fond and Latreille have very ingeniously explained this fact, by showing that the claws belonged to a parasitical species, which, like the common hermit-crab of our seas, had the body covered by a delicate membrane, the claws alone having a shelly case; hence the latter would be found in a fossil state, while of the other parts of the animal no traces would remain.

21. Fishes of the Chalk-Sharks. - The fossil fishes of the chalk were known only by the teeth, with which almost every quarry, abounds, until my researches in the chalk-pits around Lewes brought to light the extraordinary spccimens before vou, and showed how such delicate remains could 
be developed. The teeth are for the most part referrible to fishes allied to the shark; a family which in the ancient, as in the modern seas, appears to have becn confined by no geographical limits. Professor Agassiz, by whose genius and perseverance this department of Palæontology has been so successfully elucidated, has proposed a classification of fishes, founded upon the peculiar structure of the scales - an arrangement of great utility to the geologist, since the mutilated state in which ichthyolites frequently occur, had rendered futile the attempt to place them in existing orders and genera.*

The teeth are very abundant, particularly those belonging to the Lamna (Tab. 36. fig. 2,4); they possess a high polish, are in an excellent state of prescrvation, and occur but rarely in the flints. They are always single, arising from the cartilaginous nature of the jaws of the original. These examples of the recent shark show the number and variety of the teeth in an individual; by the decomposition of the jaw the teeth would be separated and drifted by the water, and therefore seldom, in a fossil state, exhibit any traces of their original position. It may, however, happen, that jaws with teeth will hereafter be discovered; as vertebræ, fin-bones, and even the shagreen-skin of sharks, are preserved in some specimens in my collection. The broad rugous 
teeth (fig. 6) are sometimes found in groups of twenty or thirty; they belong to a fish allied to the shark, in which the mouth was covered with these

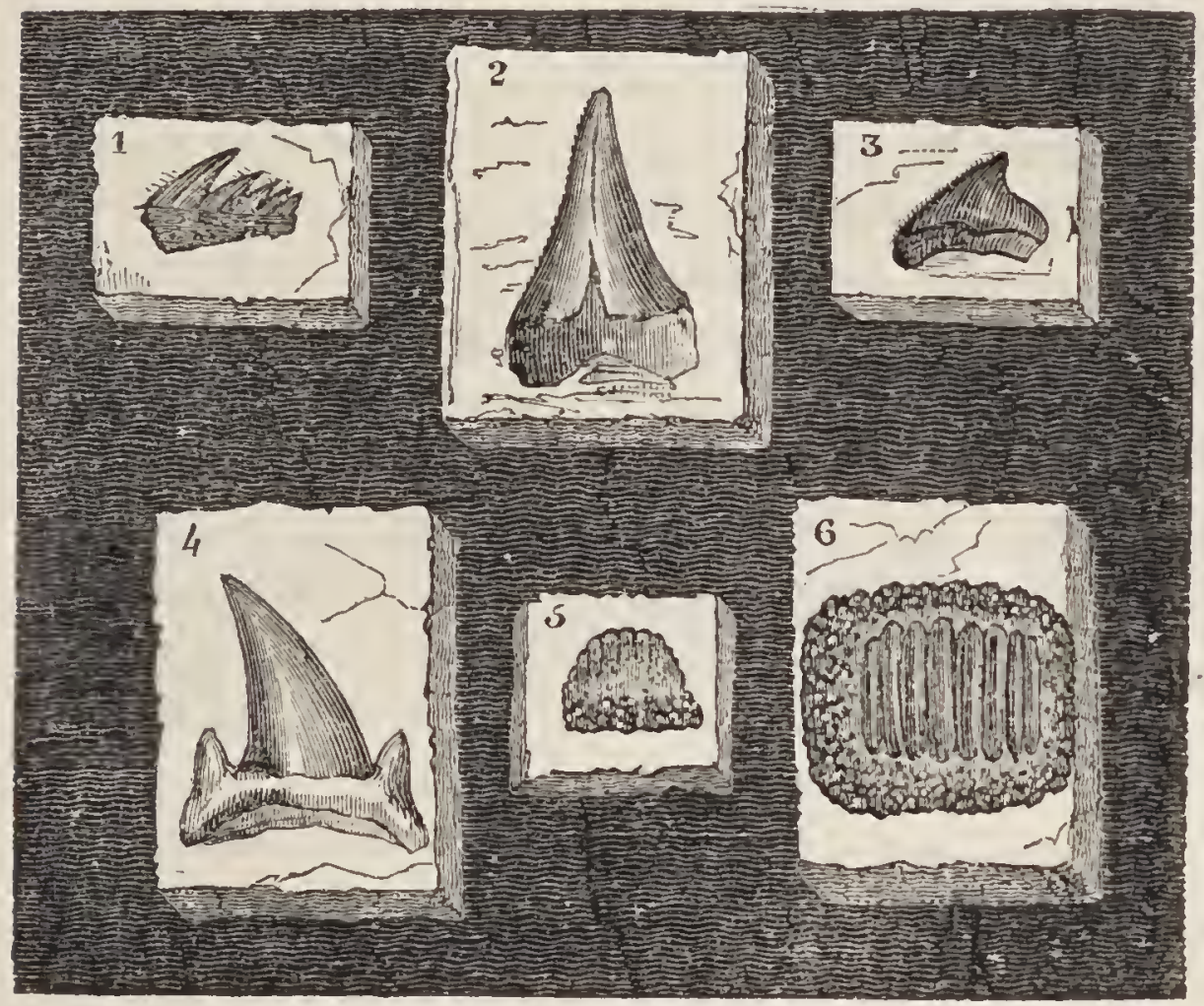

Tab. 36.-TeEth of Fisires alted to the SHark, From the SUSSEX ChaLK.

Fig. 1. Notidanus microdon. 2. Lamna Mantellii. 3. Galeus pristodontus. 4. Lamna appendiculala. 5. Plychodus allior. 6. Plychodus decurrens.

bony processes, like a tessellated pavement. The spines, fin-bones, or rays, with which fishes are furnished, also occur in the chalk; and I have one splendid specimen, in which even the tendinous 
expansion of the muscle that moved the fin-bone is preserved.* Some of those in my cabinet belong to the same genus as the dog-fish of our coast (Spinax Acanthias), which has a curved spine in front of the dorsal fin; I place before you a recent and fossil spine, to show their analogy. The mandible, or jaw-bone, of a very curious fish, the Climera, was one of my earliest discoveries in Hamsey marl-pit, and I have since found examples in the chalk of Lewes; other species have been discovered in the green sand of Kent, by Mr. Bensted, and in Kimmeridge clay, by Sir Plilip Egerton.†

Remains of large fishes, belonging to that division called by Agassiz, Sauroid, from their combining in their structure certain characters of reptiles, have been found in the chalk and green sand of Sussex and Kent. They consist of large, conical, striated teeth, bearing a resemblance to those of crocodiles, with which they were formerly confounded. Mr. Bensted has several from Maidstone, and $\mathrm{Mr}$. Rose, from the galt, near Cambridge.

22. Fossil Salmon, or Smelt.-But the most remarkable ichthyolites of the chalk, are the fishes belonging to the salmon family (Salmonidre), and closely related to the smelt (Osmerus). Many years since, I succeeded in extricating from the chalk the extraordinary specimen before you, of

* Fossils of the South Downs, Tab. xxxix.

+ The nature of these curious relics remained unknown, till 11. Buckland ascertained their analogy to the recent Chimera. 
which I published a lithograph, and described the fish under the name of Salmo Lewesiensis.*

The length of the fish is nine inches, and it stands nearly six inches in relief; the back is still attached to the chalk, and the dorsal fin exposed. There are other examples of the same species in my cabinet, which are almost equally perfect. These ichthyolites were obtained from the quarries in the immediate vicinity of Lewes, during my residence in that town. It is clear that the chalk must have surrounded the fishes while they were alive, and in actual progression, and by suddenly consolidating, have preserved their forms unaltered; for the body is round and uncompressed, the mouth open, and the fins and gills are expanded. Even to those whose curiosity has not previously been awakened to geological inquiries, the examination of these petrified inhabitants of the ocean cannot fail to excite deep interest, and I have seen the man of fashion, as well as the philosopher, gaze in mute astonishment on these "relics of a former world."

23. Macropoma and other Fishes. - I have already mentioned that the capsule of the eye remains in many specimens; this is particularly the case with those fishes (Beryx) which have some resemblance to the Dory (Tabs. 40, 41); and in a sauroid fish, the membranes of the stomach are

* Geology of the South-East of England, p. 135. A beautiful lithograph of this specimen, by Mr. Pollard, forms the embellishment of the Catalogue of the Mantellian Museum. 
invariably preserved. This fish, named Macropoma, (Tab. 38) by M. Agassiz, is, independently of the fact just stated, extremely remarkable in its organization. The operculum of the gills is very large, and the scales are studded with hollow tubes. In many recent fishes, there is a row of tubular scales, forming what is called the lateral line, through which flows a fluid that lubricates the surface of the body; in the Macropoma, every scale appears to have possessed such a mechanism.

Many of the most interesting chalk ichthyolites in my museum are figured, and occupy more than twenty folio plates, in the last livraisons of the splendid work of Agassiz, "Recherches sur les Poissons Fossiles." I will now place before you restored figures of seven species; for comparative anatomy enables us not only to reanimate the colossal nuammalia, and the palæotheria, but also to restore, with all the lineaments of life, the fishes which lived and died in the seas of the ancient world. These restorations have been drawn with great care by an eminent artist, M. Dinkel, of Munich. 

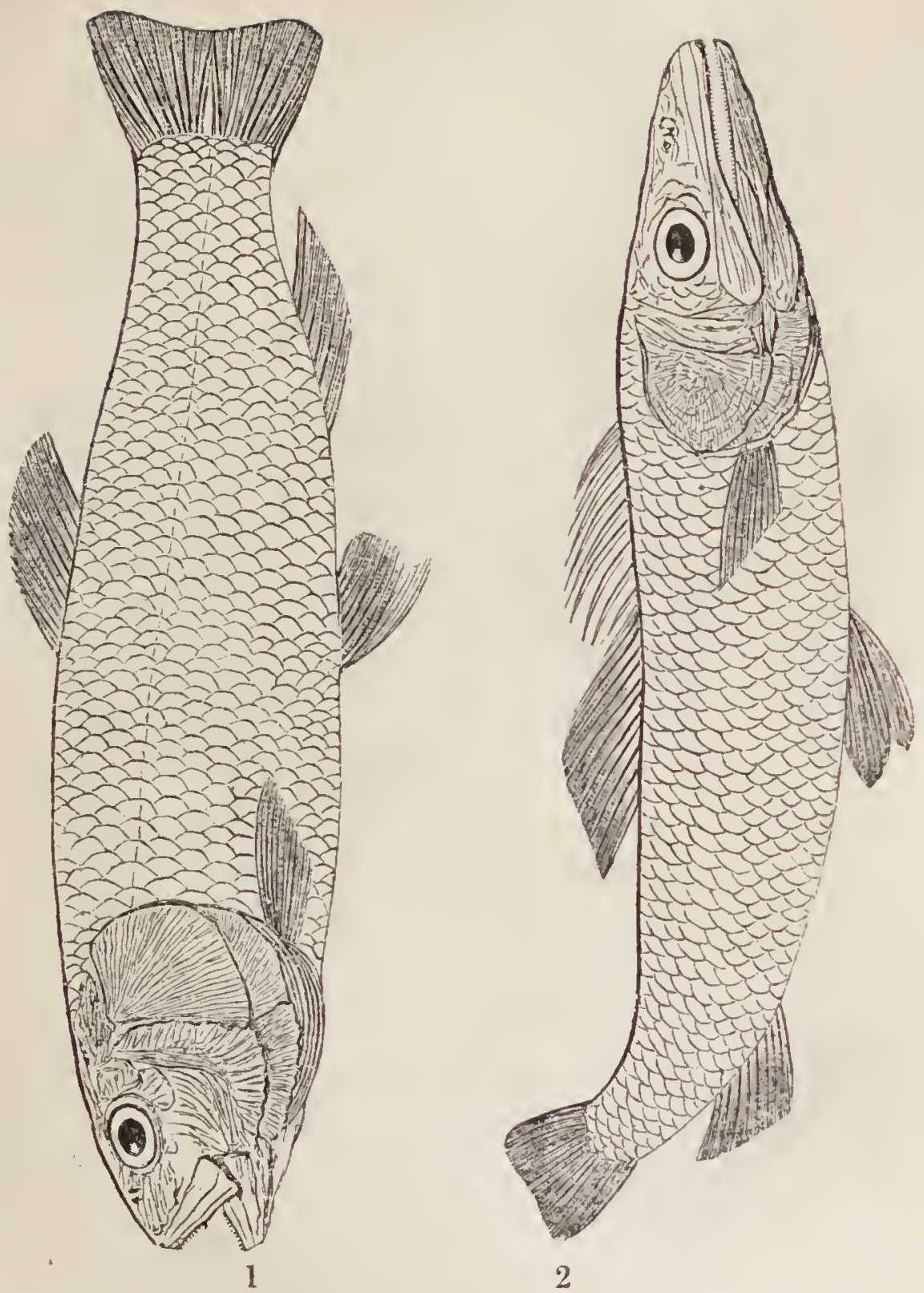

Tab. 37.-Fig. l. Osmeroides Mantelir. Length 12 inches. From Lewes Chalk-pits.

Fig. 2. Acrognathus boops. Natural size. Unique. From Lewes. 


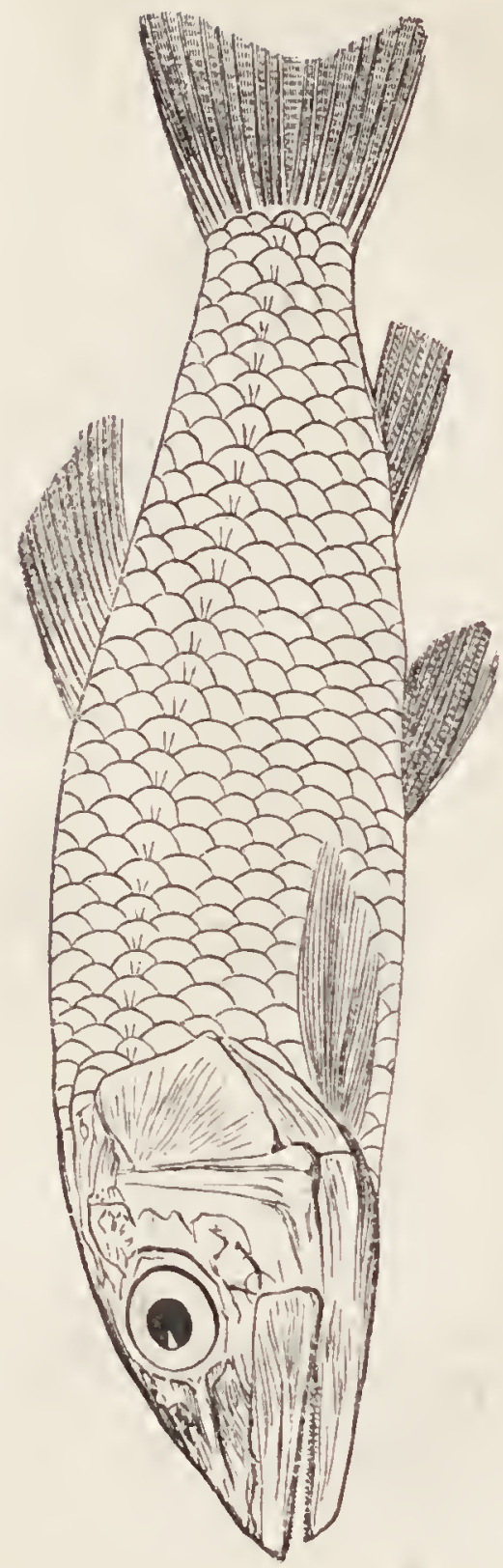

1

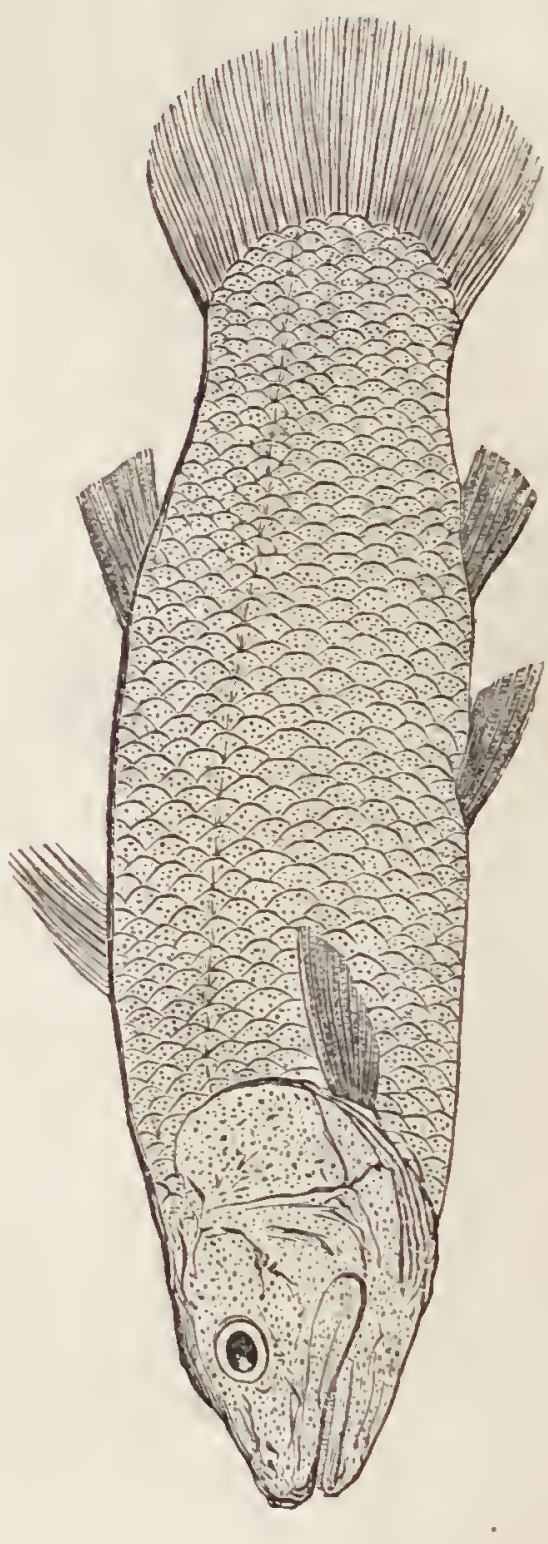

2

TA B. 38.-Fig. 1. AUloleris typus. - Length 6 inches. Unique. From Clayton Chalk-pit. Fig. 2. Macropoma Maxtridir.-Length 24 inches. From the Chalk quarries near Lewes. 


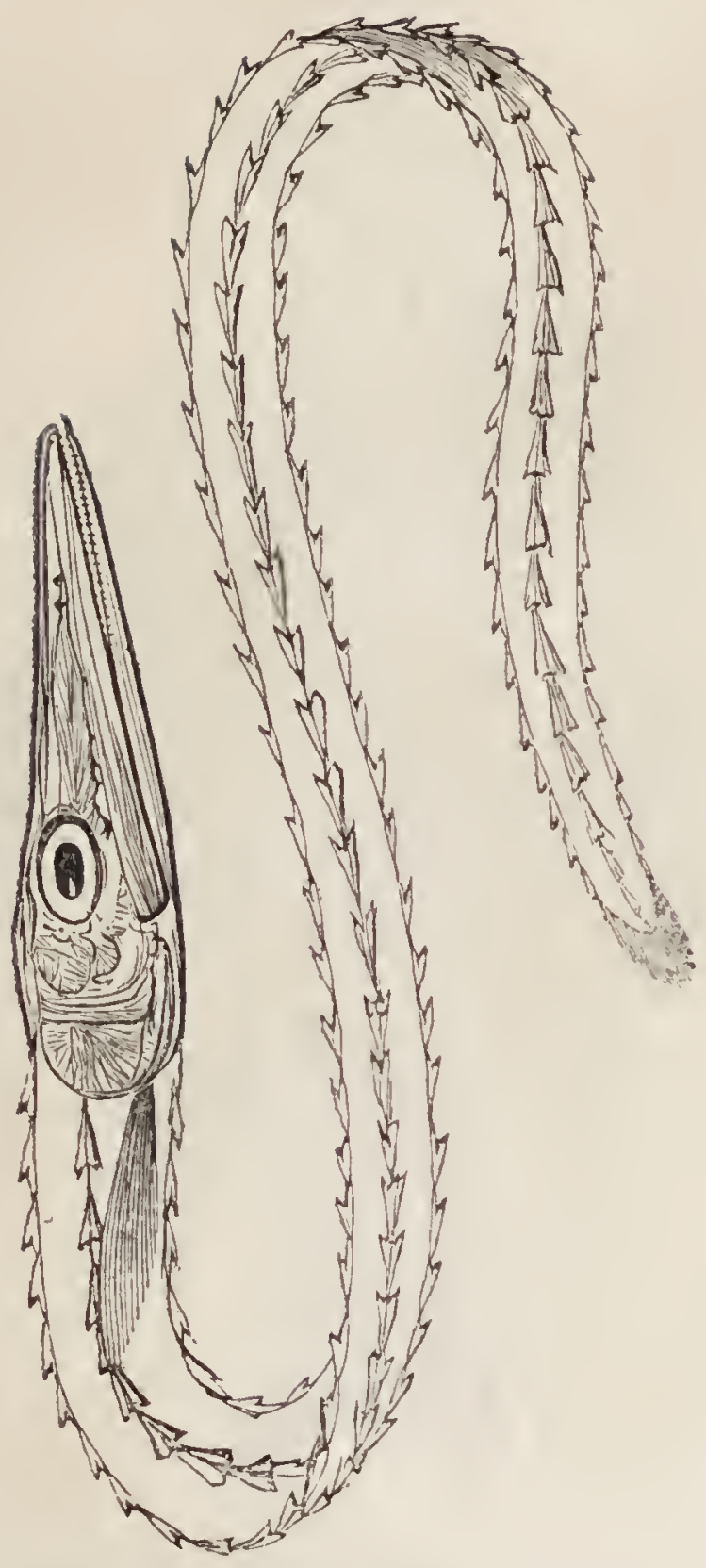

TA в. 39.-Dencetis elongatus-Length 16 inches. From Lewes.

This species occurs abundantly in the chalk at Preston, near Brighton. The outline represents the skeleton, from a specimen in my museum; the only instance in which the skull remains. 


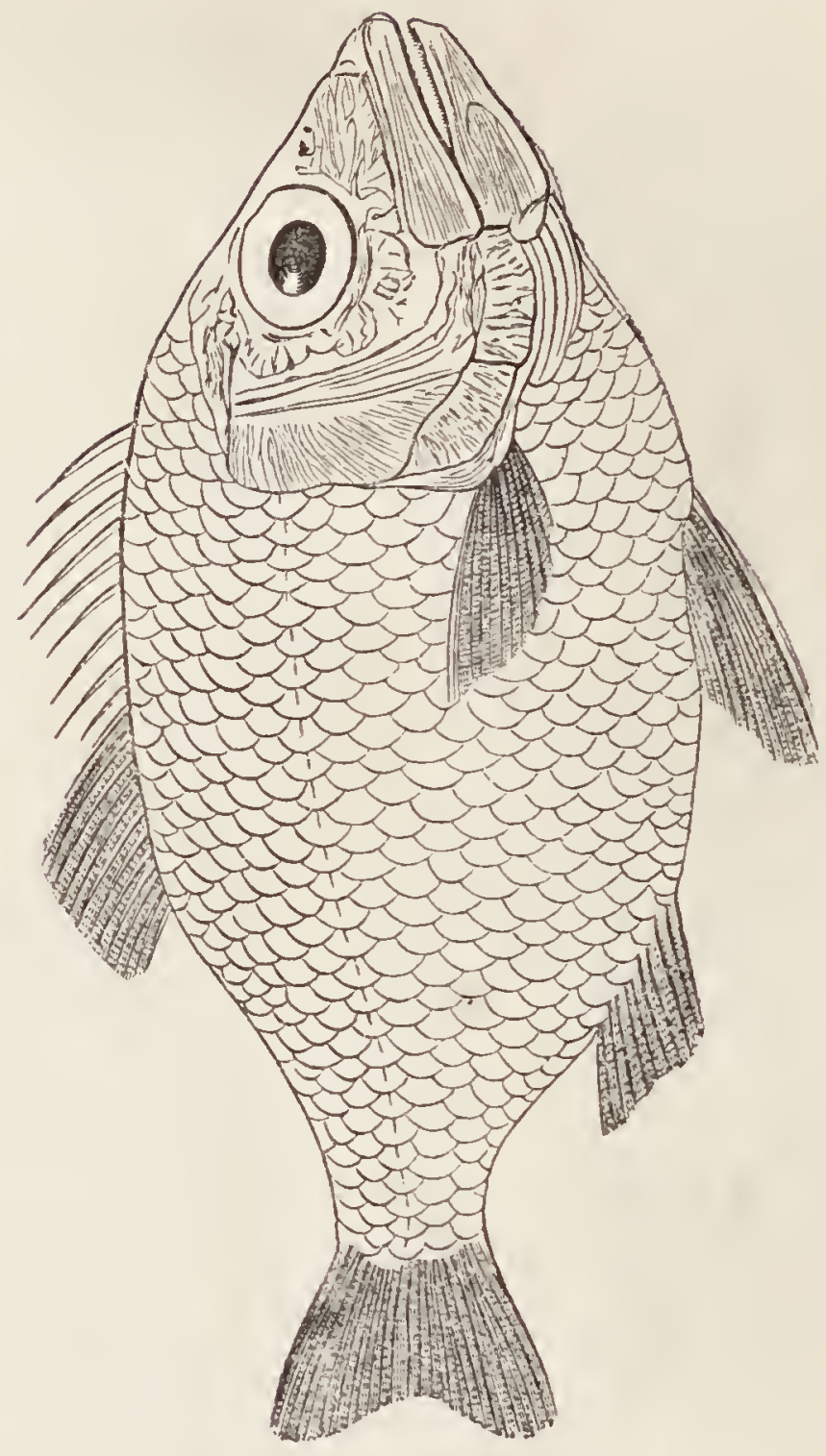

TAR. 40. - BERYX RADIANs. Lenoth 7 inches.-From the chalk-marl. near Lewes.

This species is generally found in the chalk-marl: specimens have been collected at Clayton, Steyning, and Arundel. 


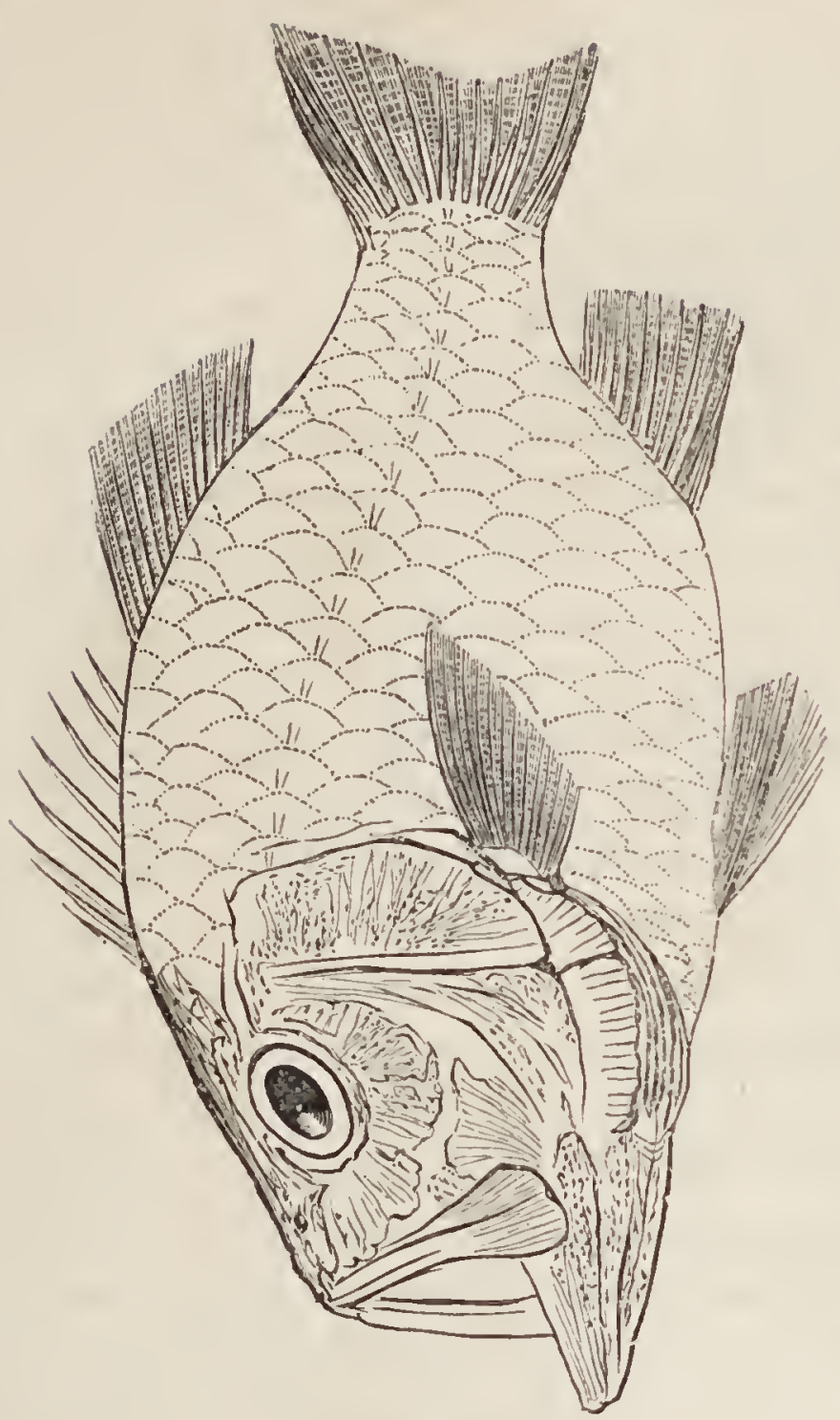

TAB. 41.-BERYX LEwesiensis, Length 12 inches.-Lewes chalk quarries.

This is the most abundant of the Sussex ichthyolites; and is called Johny Dory by the workmen. Detached scales are very frequent in all the pits of the South Downs, and also in those of Kent and Surrey. 
The fossil fishes discovered in the South Downs amount to upwards of forty species; and there are several undescribed from the chalk of Kent, in the splendid collections of Ichthyolites of Viscount Cole, and Sir P. M. Egerton.

In the other sub-divisions of this formation, both in England and elsewhere, remains of fishes occur. The slates of Glaris, in Switzerland, have long been celebrated for their ichthyolites, and by these remains M. Agassiz has ascertained that the strata belong to the chalk; although the stone in which they are imbedded, as may be seen in this fine suite of specimens (collected and presented to me by the distinguished geologists above named), is a compact bituminous slate, scarcely to be distinguished from some of the most ancient of the transition series; a character which is attributable to the effects of high temperature, as will hereafter be explained.

In concluding this cursory review of the fossil fishes of the chalk, it must be remarked that M. Agassiz has shown that all these ichthyolites belong to extinct forms; and that none of the species, and even but few of the genera, occur in the later deposites; a result perfectly in accordance with that derived from the examination of the shells and mollusca.**

24. Reptiles. - The remains of reptiles hitherto observed are but few, the most important is the Moscescurus Hoffmanni, of which I spoke when * Appendir I. 
describing the Maestricht deposites. The occurrence of the vertebræ of the same genus, if not species, in the Lewes chalk, and of the teeth and bones in the equivalents of this formation in North America, are facts of great interest. Through the kindness of Mr. Charlesworth, I have inspected portions of a large jaw with teeth from the Norfolk chalk, which bear a resemblance to those of the mosæsaurus; but the symmetrical, conical form of the teeth, and other characters, show that they belong either to an unknown reptile or to a sauroid fish. Bones of turtles are found in the white chalk of Sussex, and abundantly in the limestone of St. Peter's Mountain, and in the slate of Glaris; they belong to marine species. I have a mandible of a turtle from the Lewes chalk, figured by Dr. Buckland, (Essay, Pl. XLIV. fig. 3;) and a femur from Kent, discovered by Mr. Bensted. Teeth of crocodiles in the chalk of Meudon are mentioned by Cuvier; and very recently a specimen containing the vertebral column, ribs, and pelvis of a small lizard, in a beautiful state of preservation, has been found in a chalk-pit near Chatham, and is in the possession of Sir P. M. Egerton.

25. Review of the Characters of the Chalk Formation.- The characters of the chalk formation, as shown by these investigations, are those of a vast oceanic basin, filled with the debris thrown down by its waters, and enveloping the remains of its inhabitants; arenaceous beds 
prevailing in the lowermost-argillaceous in the middle-and cretaceous in the upper division of the series. Intrusions of thermal streams appear to have been abundant at certain periods; and throughout the entire epoch of its formation, the proofs are incontrovertible that its waters swarmed with living beings of the various orders of marine existence; the species being all, or almost all, extinct. The presence of fuci shows that it possessed a marine vegetation; and drifted wood, fir-cones, stems, and leaves, that its shores were bounded by dry land, of which the fossil reptiles also afford additional confirmation.

26. Geology of the South-East of ExgLAND.-From this survey of the vast marine formation of the chalk, we turn to the remarkable fluviatile deposites, of which the basin of that ocean, in the south-east of England, was compused; in other countries, as I shall again have occasion to remark, that basin was formed of the oolite and other marine strata. It will now be necessary to offer a few observations on the geology of the district in which the beds of the Wealden are so largely developed.

The deposites of the south-east of England constitute three principal groups. The first consists of the tertiary beds of sands, clays, and gravel, described in the previous lecture, which occupy depressions of the chalk. The second is the chalk, which forms the most striking feature in the 
physical geography of the country, constituting the South Downs, which from the bold promontory of Beachy-head, traverse the county of Sussex from east to west, and pass by Hampshire into Surrey. From Godalming the chalk extends by Godstone into Kent, where the range is called the North Downs; and terminates in the cliffs of Dover. The third group is spread over the area between the North and South Downs; the most elevated masses forming a range called the Forest-ridge, which traverses the district in a direction nearly east and west, and is composed of alternations of sandstone, sands, shales, and clays, with a deep valley on each flank, called the Weald; hence the geological designation of the whole series. From the central ridge of the Wealden, which varies in height from 400 to 800 feet, the strata diverge on each side towards the Downs, forming an anticlinal axis, and finally disappear beneath the lowermost beds of the chalk. (Vide the Section, Pl. V. fig. 1.) There are conclusive proofs that the Wealden strata were entirely covered by the chalk, and that their present position and appearance are attributable to changes which have taken place subsequently to the cretaceous epoch; the Wealden having been lifted up and forced through the chalk, and thus effected the partial destruction of that formation.*

27. Geological Phenomena between LonDON AND BRIGHTON. - The direct roads from

* See Geology of the South-East of England, Chapter XI. 
London to Brighton pass over the whole series of deposites comprised in the above sketch, as well as over those described in the first lecture. Proceeding from the Thames, the observer successively traverses the modern silt of the river-the ancient alluvium, containing remains of elephants and other large mammalia-and if he proceed by Reigate, his road, at Clapham and Tooting, lies over beds of clay and gravel, which are part of the ancient shores of the London basin. At Sutton he ascends the chalk hills of Surrey, and travels along elevated masses of the ancient ocean-bed just described. Arriving at the precipitous southern escarpment of the North Downs, a magnificent landscape, displaying the physical structure of the Weald, and its varied and picturesque scenery, suddenly bursts upon his view. At his feet lies the deep valley of Galt in which Reigate is situated, and immediately beyond the town is the elevated ridge of Shanklin sand, which stretching towards the west, attains at Leith-hill an altitude of one thousand feet; and to the east forms a line of sand-hills, by Godstone and Sevenoaks, through Kent, to the sea-shore. The Forest-ridge occupies the middle region, extending westward towards Horsham, and eastward to Crowborough-hill, its greatest altitude, and from thence to Hastings, having on each flank the Wealds of Kent and Sussex; while in the remote distance, the unbroken, undulating summits of the South Downs appear like masses of grey clouds on the verge of the horizon. 
Pursuing his route, the observer passes through Reigate, over the Galt, (see Pl. V. Section I. 2,) and Shanklin sands of Reigate-hill, (3,) and arrives at the commencement of the Wealden. The weald clay, (4,) containing limestone with fresh-watel shells, appears at Horley common; and while in the commencement of his journey the roads were made of broken chalk-flints, and at Reigate of cherty sandstone, the material here employed is the bluishgrey calcareous rock of the Weald. At Crawley $(5$,$) sand and sandstone appear, and the road is$ composed of grit and stone, containing fluviatile shells, bones, and plants. Crossing Tilgate Forest, and Handcross, over a succession of elevated ridges of sandstone, and of clay valleys, produced by alternations in the strata, he descends from the sandstone ridge at Bolney, and again journeys over a district of weald clay with fresl-water limestone (4, on the left). Shanklin sand, like that of Reigate, reappears at Hickstead (3, on the left), succeeded by a tract of Galt (2, on the left); and finally, entering a vale of chalk-marl, he reaches a defile in the South Downs, through which the road winds its way to Brighton; the traveller having in the course of his journey passed from one chalk range to the other, and traversed the ancient delta of the Wealden.*

28. The Wealden. - The tertiary basin of

* The reader will be able to follow this route by referring to the Section, Pl. V. fig. 1. 
London has afforded us an illustration of the process by which materials are accumulated, and organic remains imbedded, in an inland sea, - that of Paris, of marine and fresh-water sediments, deposited in a gulf open to the sea on one side, and fed by rivers and thermal springs on the other,the lacustrine formations of Auvergne, of the gradual precipitation of strata in the tranquil waters of lakes, - the chalk, of the operations which have taken place in the profound abyss of an ocean,while the series of deposites to which the term Wealden is applied, presents the most striking example of an ancient fluviatile formation hitherto discovered. Yet strange as it may appear, although the Wealden strata are spread over the whole area between the North and South Downs, a tract of country traversed daily by hundreds of intelligent persons from the metropolis, their peculiar characters were unknown fifteen years ago; ${ }^{*}$ the entire group

* "Until the appearance of Dr. Mantell's works on the Geology of Sussex, the peculiar relations of the sandstones and clays of the interior of Kent, Sussex, and Hampshire, were entircly misunderstood. No one supposed that these immense strata were altogether of a peculiar type, and interpolated amid the rest of the marinc formations, as a local fresh-water deposit, of which only very faint traces can be perceived in other parts of England."-Professor Phillips, Ency. Met. p.631. Art. Geology.

"It was not until the appearance of Dr. Mantell's Illustrations of the Geology of Sussex, in 1S22, that the full value of the evidence which this district affords was made to appear. In that excellent work the author clearly showed that the 
being supposed by geologists to belong to a series of marine clays and sands below the chalk.

Before entering upon the description of the strata, I would remind you of what has been stated in a previous lecture, of the effects of rivers, and the nature of modern fluviatile deposites (pp. 34, 35). We found the deltas of rivers to consist of clay (or indurated mud), alternating with beds of sand and sandstone (or consolidated sand), and containing leaves, branclies, and trunks of trees, fresh-water shells, works of art, bones of man, and of land animals, more or less rolled, - with boulders formed of fragments of rocks, transported by torrents from the hills, or washed out of the banks by the streams. Let us now suppose that by agencies already explained, a river lias disappeared, that the sea also has clianged its place, and the bed and delta of the river become dry land; that towns and villages have been built upon the now consolidated delta, and that its surface is clothed with woods and forests, or under cultivation. If sections of the strata were exposed, either by natural or artificial means, and the bones of man or animals, works of art, and remains of plants and shells, were visible in the clay or sand-stone, such appear-

extraordinary remains whieh he had diseovered in the beds of Tilgate Forest must have originated in a lake or estuary, and have been the produee of a elimate mueh warmer than that which is now enjoyed in England."-Dr.Fitton's Geology

IIastings, p. 14. 
ances would excite in us no surprise, because we are acquainted with the processes by which such accumulations of water-worn materials are formed. Should an inhabitant of the new country express his wonder how brittle shells, delicate leaves, and bones of animals had become imbedded in the solid rock, and if when we stated the manner in which those changes had been effected, he should not only refuse his assent, but insist that the shells, leaves, and bones, were merely accidental forms of the stone, should we not feel astonished at his ignorance and prejudice? yet not a century since, and such an opinion almost universally prevailed, and is even still entertained by many !* And farther, if our assumed personage admitted that the remains in question were fossil animals and vegetables, but asserted that they had been entombed in the strata by a deluge which had softened the crust of the earth, and engulfed in the sediment of its waters the remains of animated nature, - should we not reply, that as such a catastrophe must inevitably have mingled together all kinds of materials, and

* "At Hawkhurst, in the Weald of Kent, these stones (Sussex marble) abound. They consist of several laminæ, between which grow shells, or rather half-shells, having the appearance of periwinkles of different magnitudes, according to the time of their growth. These stones naturally grow in the earth, and the shells upon them, and are another certain proof that shells are generated in the earth, as well as in the sea, and that there is no necessary connexion between a shell and an animal." Natural History of England, p. 193, vol. i. 1759. 
the remains of animals and vegetables, whether of the land, the rivers, or the seas-the regular stratification of the delta, and the exclusive occurrence of land and fresh-water plants and animals, were fatal to such a supposition, and afforded conclusive evidence of the correctness of our explanation of the phenomena? - it is by such a train of reasoning that the fluviatile nature of the Wealden has been determined.

29. Wealden of the Sussex Coast. - From the distribution of the Wealden over the south-east of England, instructive sections have been formed by the action of the sea along the coast, between Beachy Head and Dover. From the stupendous cliffs of Beachy Head the chalk extends towards Southbourn, where beds of galt, glauconite, marl, and Shanklinsand successively emerge, forming the base of the shore, and abounding in their characteristic marine fossils. Passing over Pevensey Levels, the boundary of which, on the sea-side, is obscured by modem shingle, we arrive at Bexhill and Bulverhithe, and find the cliffs composed of finely laminated sandstone and clays; and those of St. Leonard, of similar strata, more extensively developed: sands and clays separated into very thin laminæ, alternate with conglomerates, indurated sand-rock, and a fine sandstone, called grit, of great compactness. At Hastings, strata of sand and clay, with interspersions of lignite, laminated shale, grit, and sandstone, constitute a lung line of high 
cliffs.* The general resemblance of these strata to fluviatile accumulations is most striking; the laminated structure of the clay and shales, the constant intermixture of minute portions of lignite, the absence of pebbles and shingle, and the alternations of mud and sand, are lithological characters constantly observable in river deposites. The nature of the organic remains in which the strata abound will be considered hereafter. In the interior of the country the quarries opened along the ridges, formed by the compact grit, afford various sections; and the valleys, eroded by the streams, expose the shales and laminated clays.

30. Pounceford.-Pounceford, on the estate of Lord Ashburnham, on the road to Burwash, in Sussex, presents several highly interesting sections of the argillaceous beds and limestones. Descending through a defile in the sandstones, we arrive at the bottom of a glen, along which a rapid stream, that bursts out from between the clay-partings, rushes to a distant and lower valley. On each side openings are made, to arrive at a greyish blue limestone, abounding in shells, which is employed on the roads, and converted into lime for agricultural purposes. When the stone lies deep, shafts are sunk from the surface, and after the extraction of the limestone, are deserted and filled up.

* See an excellent little volume on these cliffs, "A Guide to the Geology of Hastings," by W. H. Fitton, Esq. M.D. F.R.S. Sc. 
This spot is highly interesting and picturesque; incrusting springs, issuing from the limestone beds, deposit tufa on the mosses, equiseta, and land-shells: thousands of fossil shells are strewn over the clay and shale; and stems of plants, scales of fishes, and other remains, are seen imbedded in the stone; while the banks, where newly exposed, exhibit countless laminæ and alternations of shale, clay, and layers composed of testaceous remains.* In a visit to this place with Mr. Lyell, several new species of fossil shells were found in the bed of the stream, having been washed out of the banks of clay; and we collected teeth of crocodiles, bones of fresli-water turtles, and other reptiles. A spiral fresh-water shell (Tab.46, fig. 2,) was abundant in the clay; and a muscle, (named Mytilus Lyellii, to commemorate our excursion, Tab. 46, fig. 8, ) also a fluviatile species, was found by Mr. Lyell, in a mass of shale that had fallen into the stream.

As the grit, or calciferous sandstone, of the Wealden, forms an excellent road-material, the quarries along the principal lines leading from the metropolis to the south-eastern coast, are very numerous; and those spread over the area of Tilgate and St. Leonard's Forests have been extensively worked since the increased communication between London and Brighton. This district may be

* See Geology of the South-East of England, p. 22. 
described as bounded on the west by the London roads leading through Horsham, and on the east by those which pass by Linfield or Cuckfield; the Crawley road, as previously mentioned, traversing Tilgate Forest. These localities, particularly that of Tilgate, have acquired much celebrity for their organic remains, from having been the principal sources whence the specimens figured in my first work on the "Fossils of Tilgate Forest," * were derived; but every quarry throughout the Forest-range, from Loxwood in western Sussex, to Hastings, will be found to yield the peculiar remains of the Wealden, more or less abundantly.

31. Subdivision And Extent of the Wealden. - The Wealden may be divided into several groups, each characterized by the nature of the strata, and the prevalence of certain kinds of fossils; but throughout the whole series, the fluviatile nature of the formation is maintained: in the lowermost part of the series only, are there any intrusions of a marine or estuary nature. Although it is not within the scope of these lectures to enter upon minute details of stratification, it will be necessary, for the elucidation of the subject, to point out the principal subdivisions of this extensive system of deposites. $f$

* See Fossils of 'Tilgate Forest, p. 51.

+ Geology of the South-East of England, p. 1 S2. 
1. Weald Clay (the uppermost or latest deposil). Stiff blue clay, with septaria, argillaceous ironstone, and beds of shelly limestone, called Sussex or Petworth Marble. (See the Section, Pl. V. fig. 1. 4.)

2. Hastings Beds. Sand and sandstones, with calciferous grit, or Tilgate-stone, alternating with clays and limestones.

3. The Ashburnham Beds. Clays, shales, and bluish-grey limestones, and sandstones.

4. The Purbeck Bens. Clays, sandstones, and shelly limestones, called Purbeck Marble. Limestone, with layers of vegetable mould, and remains of trees in a vertical position-the petrified Forest of Portland.

Such is the assemblage of deposites which the term Wealden, first employed in this acceptation by my firend Mr. Martin,* is intended to denote. Clays or argillaceous sediments, with limestone ahnost wholly composed of fresh-water snail-shells, occupy the uppermost place in the series; sand and sandstones, with shales and lignite, prevail in the middle; while in the lowermost, argillaceous beds, with shelly marbles or limestones, again appear; and, buried beneath the whole, is a petrified forest, in which the trees are still standing, and the vegetable mould undisturbed! The upper clay-beds and marble form the deep valleys or Wealds of Kent and Sussex - the middle series, the forest-ridge. The Purbeck are obscurely seen in some of the deepest valleys of eastern Sussex, but emerge on the Dorsetshire coast and form the island or peninsula whose name they bear, and surmount the

* Martin's Geology of Western Sussex. 
northern brow of the Isle of Portland. At the back of the Isle of Wight, the Wealden beds appear beneath the Shanklin sands; and their characteristic fossils are continually washed up on the shore at Brook-point. Dr. Fitton* has traced the Wealden beds, or rather the lowermost division, the Purbeck, in the vale of Wardour, which is a valley of denudation, in the south of Wiltshire, like that of the South-east of England, on a small scale. In this valley the various members of the chalk occur in their regular order of superposition, resting on clay and Purbeck limestone, and having Portland stone beneath.t In France, on the coast of the Lower Boulonnais, and in the valley of Bray near Beauvais, strata of a like character are observable; the Sussex marble (lumachelle-à-paludines) and a fern peculiar to the Wealden, have been discovered by M. Graves of Beauvais, to whom I am indebted for specimens. It is probable that the Wealden may have extended over a still larger area, for the same fossil plant (lonchopteris Mantellii) has been found in strata beneath the green-sand, in Sweden, by Professor Nillson, who also informed me that many of the rocks and fossil plants from Tilgate Forest were analogous to specimens he had observed in the little island of Bornholm, off the Danish coast. Without relying upon these obser-

* Consult Dr. Fitton's Memoir "On the Beds below the Chalk;" Geological Transactions, 1837 .

+ Ibid. p. 424. 
vations, the Wealden may be considered as covering an area 200 miles in length, from west to east, and 220 miles from north-west to south-east; an extent but little exceeding the delta of the Ganges, or the Mississippi, and not equal to that of the Quorra, which forms a surface of 25,000 square miles, being equal to the half of England; the total thickness of the deposites averages about 2000 feet.*

32. Quarries of Tilgate Forest.-The quarries of Tilgate Forest, where the calciferous grit is worked, generally present the following series of deposites :-

1. Uppermost. Loam or clay-from one, to five or six fect in deptl. Destitute of fossils.

2. Sandstone-friable, of various shades of fawn, ycllow, and ferruginons colour; in laminæ, or thin layers, occasionally containing organic remains and pebbles,-eiglit feet thick.

3. Calciferous Grit, or Tilgate Stone-a very fine sandstonc, formed of sand cemented together by calcareons spar; it occurs in large masses of a concretional form, imbedded in beds of sand. This grit has evidently been formed by the percolation of water charged with calcarcous matter, into loose sand; it abounds in bones and tecth of reptiles; stems and leaves of plants; sliells, \&c.

4. Sandstone, with concretionary masses of grit and conglomerates formed of rolled pebbles of sandstone, jasper, quartz, indurated clay, bones, and teeth of reptiles and fishes; rolled masses of the grit and sandstone are found in this conglomerate; contains organic remains which are generally much water-worn.

5. Blue clay and marl-depth unknown.

* Dr. Fitton. 
Such is the general aspect of the quarries around Bolney, Cuckfield, Linfield, \&c. Near Horsham the fawn-coloured sandstone is of a more compact character, and possesses a slaty structure. 'The thin slates are used for roofing, and the thicker beds afford good paving-stone; their surfaces are sometimes deeply furrowed by ripple-marks-an appearance on which I will offer a few observations.

33. Ripple-marks on Sandstone.-The furrowed sandstone and grit which are used for paving in Horsham, Crawley, and other towns and villages on the Forest-ridge and Tilgate Forest, must have attracted the attention of most persons who liave travelled from Brighton to London. The surface of these slabs is similar to what may be observed on the sand along the sea-shore at low water, when the ripple from the receding waves has been well marked; and the appearance has arisen from a similar cause. (See p. 30.) In many instances the stone is so rough as to be employed in stable-yards, where an uneven surface is required to prevent the feet of animals from slipping in passing over. It sometimes happens that when a large area of a quarry is cleared from the soil which covers it, a most interesting appearance is presented, the whole surface being rippled over like the strand on the sea-shore; and the spectator is struck with the conviction that he is standing on the sands of some ancient delta or estuary, which are now turned into 
stone. Sometimes the furrows are deep, showing that the water was much agitated, and the ripple strong; in other instances the undulations are gentle, and intersected by cross ripples, proving a change in the direction of the waves. Some slabs are covered by slightly elevated, longitudinal ridges of sand, made up of gentle risings, disposed in a crescent-like manner; these have been produced by the rills which flow back into the sea, or river, at low water. In other examples, the surface is marked by angular ridges irregularly crossing each other, like the fissures in septaria; these have obviously been caused by deposition into crevices produced in sand or mud by desiccation. A considerable portion of stone, the flat, as well as the furrowed surfaces, is covered with small, subcylindrical markings, which are the trails formed by some species of vermes, or mollusca. The deepest furrows have generally a slight coating of bluish clay, charged with minute portions of lignite, and other vegetable matter; an appearance which has been occasioned by streams from the shore which have flowed over and coated the rippled sand. The furrowed sandstone presents an interesting example of the perfect similarity of a natural process in periods separated from each other by immense intervals of time.**

* For a particular account of the Wealden strata in the south-east of England, see Geology of the South-East of England. For their nature and distribution in Wilts, Sc. see Dr. Fitton's Memoir. 
34. Wealden of the Isle of Wight.-Deposites partaking of the character of those I have described, appear at the back of the Isle of Wight, and form the lowermost strata throughout the southern half of the island. Clay, identical with the Weald clay, and containing Sussex nuarble, may be seen at Sandover bay, within a few hundred yards of the chalk, and extending into Red-cliff; and also at the junction, on the east of Fresh-water bay, where the clay abounds in the minute shields of Cyprides. At Brook-point, the cliffs, which are about thirty feet high, are formed of clay, with inferior beds of soft sandstone; and contain lignite and regetable remains, strongly impregnated with pyrites. Trunks of trees, of a coaly blackness, are seen imbedded in the clay of the cliff, and scattered on the shore. In many of the stems the ligneous structure is beautifully preserved, and reined with pyrites-other portions resemble jet. The strand at low water is seen to be formed of these fossils; and upon removing the sea-weeds which grow on the shore, the petrified trees occur imbedded in masses of clay, which have become indurated, and are now in the state of an argillaceous rock: the stems are from onc to two feet in diameter, and eight or ten feet long. The knotty bark and ligneous fibre are very distinct.* Enormous bones are frequently found along the shore at

- From Mrr. Webster's interesting account of the Geology of the Isle of Wight. 
Sandover-bay and Brook-point, being washed out of the beds of the Wealden, which there form part of the basin of the British Channel.

35. Isle of PURBeck.-The Isle of Purbeck, on the Dorsetshire coast, is of an irregular oval form, about twelve miles in length, and seven in breadth. On the eastern promontory, the clialk is vertical, and beds of clay, sandstone, and limestone. are seen underlying the displaced strata of the chalk formation; towards the southern extremity of the island, the Portland limestone appears.*

Purbeck has long been celebrated for its quarries, which have been worked from time immemorial, and particularly during the middle ages; the compact varieties of limestone, which bear a good polish, having, under the name of Purbeck marble, been in great request for the religious edifices of that period; and there is scarcely a cathedral, or ancient church in the kingdom, that is not ornamented with columns, pavements, or sepulchral monuments, constructed of this material. The Purbeck limestone abounds in organic remains; and the marble is a congeries of small fresh-water snail-shells (Paludina), intermixed with the minute crustaceous coverings of a species of Cypris. How interesting is the reflection, that the beautiful clustercolumns, the richest ornaments of Chichester cathedral, are entirely composed of the shelly coverings

* Conybeare and Phillips. 
of snails which lived in the river of a country inhabited by colossal reptiles!

The vertical position into which so considerable a portion of the strata has been thrown, gives rise to interesting sections in the coves on the western side of the island; and, in the precipitous cliffs of those basins, the Chalk, Weald, Purbeck, and Portland strata, although vertical, may be seen in their regular order of succession. No fewer than nine sections of the beds between the chalk and Portland stone (the upper division of the oolite, of which I shall speak in the next lecture) are visible on the shore, within the short space of five miles, in the small bays by which the coast is indented.*

36. Isle of Portland-Petrified Forest.The island, or peninsula, of Portland is a bold headland, off Weymouth, about four miles and a half in length, and two in brealth, united to the mainland by the Chesil beach. It presents a precipitous escarpment on the north, and, declining towards the south, appears, on approaching it from the Dorchester coast, like an inclined plane, rising abruptly from the ocean. The southern extremity is flanked by low calcareous cliffs, which, from the constant action of the sea, are worn into hollows and caverns. The base of the island is formed of a blue clay (Kimmeridge clay), surmounted by thick beds of the oolitic limestone, known as the Portland stone,

* Dr. Fitton, p. 215. See Conybeare and Phillips' Geology of England, p. 159. 
and which are extensively quarried on the northern brow of the island.

On this oolitic limestone are fresh-water strata (the lowermost beds of the Wealden formation), which are characterised by phenomena of the

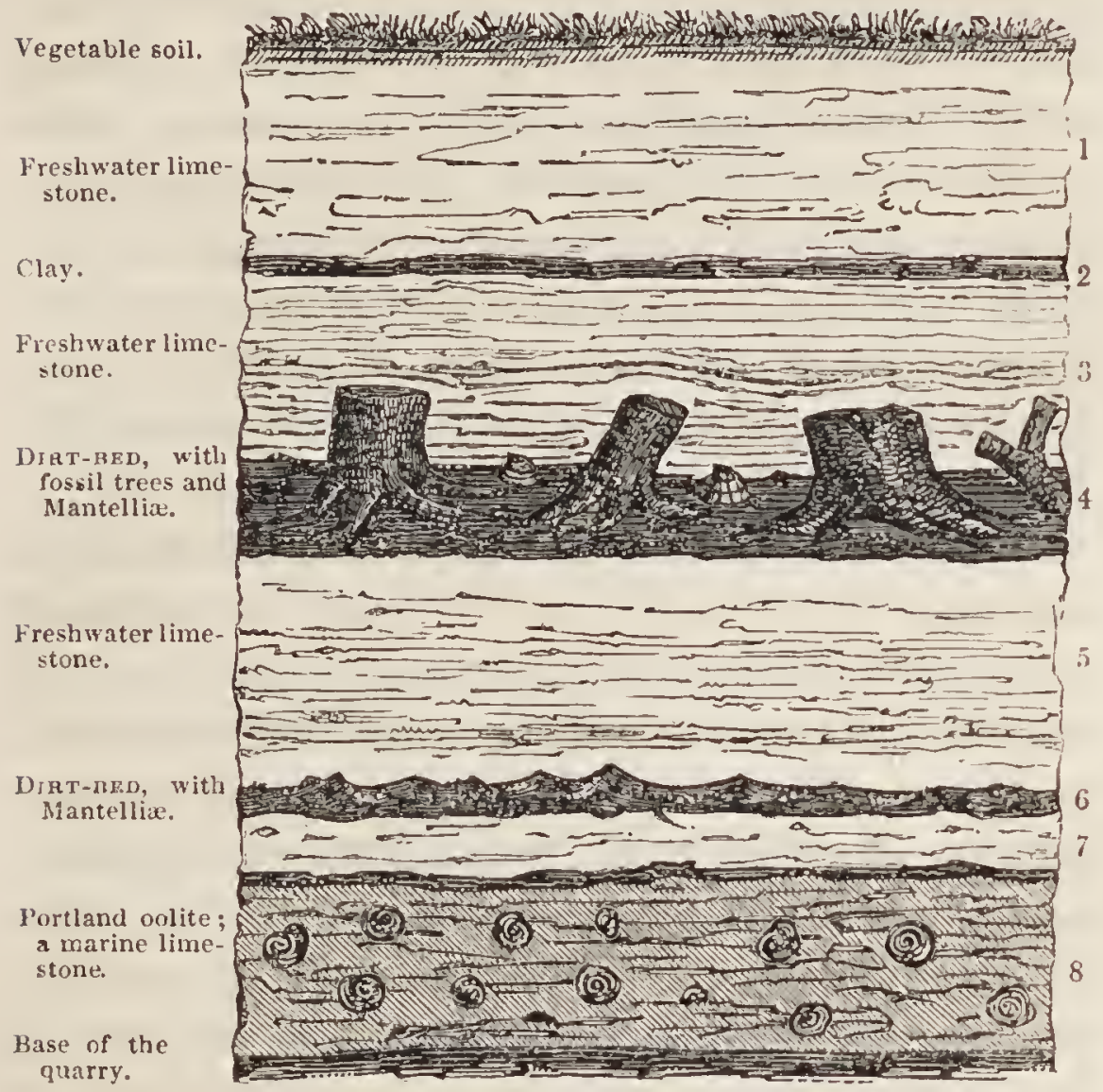

Total thickness about thirty feet.

Tab. 42.-Section of a Quarry in the Isle of Porteand.

(From Dr. Fitton's Memoir on the Stratabelow the Chalk.)

highest interest. Mr. Webster, in his admirable geological memoir on the Isle of Wight, first directed attention to these remarkable deposites. Upon the upper layer of marine limestone $(8)$, 
which abounds in ammonites, trigoniæ, and other characteristic shells of the oolite, is a fresh-water limestone, covered by a layer of bituminous earth, or vegetable mould (4), which (as you may perceive from these specimens, collected a few years since) is of a dark brown colour, contains a large proportion of earthy lignite, and, like the modern soil on the surface of the island, many water-worn stones. This layer is termed the Dirt-bed, by the workmen; and in and upon it are trunks and branches of coniferous trees, and plants allied to the recent Cycas and Zamia. Many of the trees, as well as the plants, are still erect, as if petrified while growing undisturbed in their native forests; having their roots in the soil, and their trunks extending into the upper limestone (see Tab.42). As the Portland stone lies beneath these strata, which are not muclı used for economical purposes, they are removed, and thrown by as rubbish. On my visit to the island in the summer of 1832 , the surface of a large area of the dirt-bed was cleared, preparatory to its removal, and a most striking phenomenon was presented to my vicw. The floor of the quarry was literally strewn with fossil wood; and I saw before me a petrified, tropical forcst, the trees and the plants, like the inhabitants of the city in Arabian story, bcing converted into stone, yet still maintaining the places which they occupied when alive! Some of the trunks were surrounded by a conical mound of calcareous mattcr, which had 
evidently once been earth, and had accumulated around the bases and roots of the trees. The stems were generally three or four feet high, their summits being jagged and splintered, as if they had been torn and wrencher off by a hurricane,-an appearance which many trees in this neighbourhood, after the late storm, strikingly resembled. Some of the trunks were two feet in diameter; and the united fragments of one tree measurcd upwards of thirty feet in length; in other specimens, branches were attached to the stem. In the dirt-bed, there werc many trunks lying prostrate, and fragments of branches. The fossil plants arc called Cycadeoidea by Dr. Buckland, from their analogy to the recent Cycas and Zamia, * but for which M. Adolphe Brongniart has established a new genus, named Mantellia. The plants occurred in the intervals between the trees; and the dirt-bed was so little consolidated, that I dug up with a spade, as from a parterre, several specimens that must have been on the very spot in which they grew, having, like the columns of Puzzuoli, preserved their erect position ('Tab.42.) amidst all the revolutions which the surface of the eartl has

* These plants are so common in green-houses, that their forms must be well known. In the conservatories of the Coliseum, in the Regent's Park, are fine examples of the Dracena, Yueca, Cyeas, and several speeies of palms, allied to the fossil plants of Tilgate Forest. The magnificent eollection of palms of the Messrs. Loddige, of Hackney, is referred to in my work on the Fossils of Tilgate Forest. 
subsequently undergone, and beneath the accumu. lated spoils of countless ages. The trees and plants are completely petrified by silex, or flint: you perceive that sparks are emitted upon striking a piece of steel with this fragment, of what was once a delicate plant. I may observe, that the common forms of the fossil Cycadere (Mantellia nidiformis of Brongniart), are called crows' nests by the quarry-men. I must not dwell longer on these extraordinary phenomena, but refer you to the memoirs of Mr. Webster, Dr. Fitton, and Dr. Buckland. From what has been stated, it is evident, that after the marine strata forming the base of the Isle of Portland were deposited at the bottom of a deep sea, and had become consolidated, the bed of that ancient ocean was elevated above the level of the waters, became dry land, and covered with forests. How long this new country existed, cannot be ascertained; but that it flourished for a considerable period is certain, from the number and magnitude of the trees of the petrified forest. In the Isle of Purbeck, traces of the dirt-bed, with the trunks of trees, are seen beneath the fresh-water limestones of the Weald; a proof, that before the deposition of the Purbeck marble could have taken place, the petrified forest must have sunk to the depth of many hundred feet.

37. Fossils of the Wealden.-The organic remains of the Wealden consist of leaves, stems and branches of plants of a tropical character, 
bones of enormous reptiles of extinct genera, of crocodiles, turtles, flying reptiles, and birds; fishes of several genera and species, and shells of a fluviatile character. The bones are, for the most part, broken and rolled, as if they had been transported from a distance. They are strongly impregnated with iron, and are commonly of a dark-brown colour; their cavities are frequently filled with white crystallized carbonate of lime. The specimens in the loose sand and sandstone are often porous and friable; those in the Tilgate grit, heavy, brittle, and well preserved. In fractured portions imbedded in the limestone, the interstices are filled with calcareous spar, and the cancellated structure of the bones is often permeated by the same substance. The fossil vegetables occur bituminized, and in the state of casts of sandstone; the stems and branches are some-. times silicified; carbonized leaves and twigs are abundant in some of the strata. The shells in the clays have undergone but little change, and in many examples, the epidermis still remains; in the limestone, the substance of the shell is converted into spathose carbonate of lime. With these general remarks, I pass on to the enumeration of the principal organic remains.

38. Fossil Vegetables.-From the abundance of carbonaceous remains of vegetables in many of the laminated shales and clays of the Wealden, and the occurrence of lignite, or brown-coal, in masses and layers, which sometimes alternate 
with beds of stone abounding in fresh-water bivalves, a striking analogy is presented to some of the divisions of the coal measures; and many years since, this resemblance gave rise to a search for coal at Bexhill, which, of course, proved abortive.* But notwithstanding the prevalence of vegetable matter in the strata, specimens exhibiting the nature of the original plants, in any tolerable degree of preservation, are rare; and, although my researches have been unremitting, I have obtained but few fossil plants that will admit of satisfactory conclusions as to their original structure. I shall defer to the lecture on fossil botany, a particular description of these remains, confining my present remarks to a brief account of the principal varieties, and the circumstances under which they occur.

Entire layers of the calciferous grit of 'Tilgate Forest are so full of minute portions of carbonaceous matter, $\uparrow$ as to acquire a dark mottled colour ; upon examining the imbedded particles, they appear to be the detritus of plants ground to pieces by agitation in sand and water. Specimens in my possession, show that the greater part have been derived from two elegant ferns, of extinct species, which are peculiar to the Wealden. The one is characterised

- by its slender and minutely divided leaflets (Sphenopteris Mantellii-Tilgate Fossils, Plate 3); the

* Geology of the South-East of England, p. xriii. Fossils of the South-Downs, p. 35.

+ Fossils of Tilgate Forest, Plate 3, Fig. 6. 
other by the distribution of the nervures of the leaves (Lonchopteris Mantellii - Tilgate Fossils, Plate 3), as you may perceive in the specimens before you. This plant has been found in the valley of Bray by M. Graves of Beauvais, and

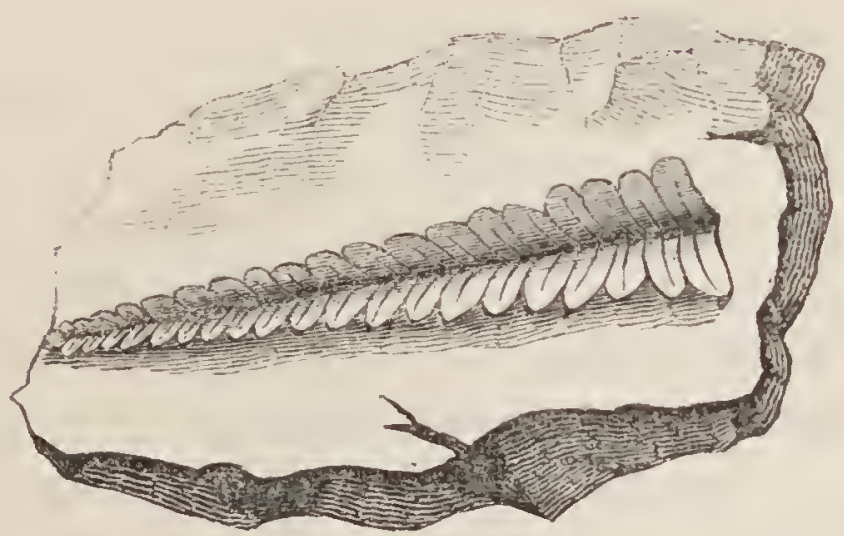

Tá. 43. -Leaflet of Lonchopteris Mantelif: Tilgate Forest. (A Fossil Fern, peculiar to the Wealden.)

in the lower Boulonnais in France, and in Sweden, in strata of the same epoch as the Wealden. These ferns probably did not exceed a few feet in height; I have one stem of the Sphenopteris which indicates a plant of about five or six feet. Several other species are associated with these remains; but the two plants I have named constitute by far the greatest proportion of the fossil vegetables of Tilgate Forest. Leaves of Cycadece, and seed-vessels of a species of Restiacea, occur in the ironstone of Heathfield; they are supposed to be of the same species as specimens from Bornholm. Among the z 2 
plants from Heathfield are impressions which bear a close resemblance to those of the foliage of the cypress; while others appear to be referrible to fuci. The stalks of a species of mare's-tail (Equisetum Lyellii*) abound in the blue limestone of Pounceford.

The stems of two plants, very distinct from each other, are the only vegetables of any considerable magnitude that occur throughout the Wealden of the south-east of England. I have not detected the slightest trace of wood like that of the forest of Portland, nor observed any indications of drifted and perforated masses like those which are so common in the sands and clays of the chalk, and other formations.

In my first publication on the fossils of Tilgate Forest, I described the plants which I now place before you. The first species consists of stems, with numerous tubular cavities, lined with quartz crystals, and presenting a structure decidedly analogous to the Cacti, or Euphorbiæ ; they have an external coating of carbonaceous matter, and, on the removal of this coaly crust, the outer surface has a remarkably eroded appearance. The stems vary from a few inches to two feet in circumference; I have seen fragments which, when united, gave a length of five feet. There are no indications of branches, but many of the specimens taper at each end, and are of a clavated form, as in some species of cactus.

* Geology of the South-East of England, p. 245. 
1)r. Fitton describes an interesting assemblage of these stems, which he fortunately observed before their removal, imbedded in clay, in a cliff to the east of the white-rock at Hastings : they were lying with their largest diameter in a horizontal position, and consisted of a silicious stem or nucleus, coated by lignite, which not only invested the stem, but also extended beyond each extremity. The stems, when cut and polished, exhibit the monocotyledonous* ${ }^{*}$ structure; Count Sternberg considers

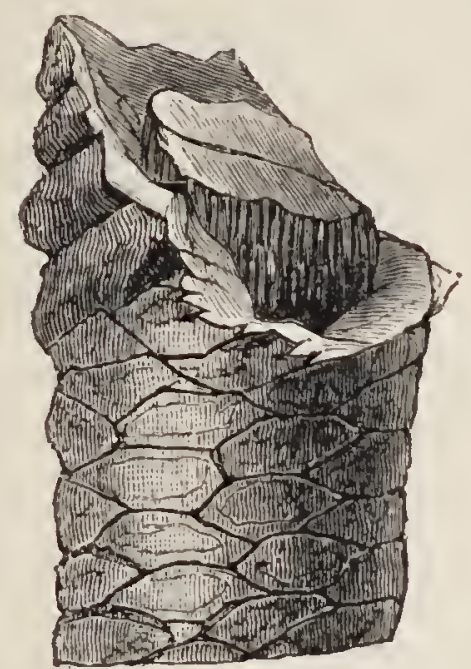

Tab. 44.-Portion of the Stem of Clatiraria Lyelit. Tilgate Forest.

them related to the palms. This fossil vegetable, from the characters above specified, has been named Endogenites erosa. The other plant (Clathraria Lyelliit

* Dr. Fitton has given beautiful engravings of these fossils in the Memoir already cited, Plates XIX. and XX.

$\dagger$ The structure of this plant will be described more minutely in a succeeding lecture. 
bears an analogy to the Yucca, and Dracæna or dragon-blood plant. Stems, with the markings of the bases of the leaves, point out the relation of this vegetable to the arborescent ferns, ${ }^{*}$ while its internal structure is essentially different. This interesting specimen exhibits an internal axis, surrounded by a false bark, the surface of which is scored with the markings derived from the attachment of the leaf-stalks. The Clathraria has only been found in the quarries in Tilgate Forest. I have fragments of stems indicating a large size.

SEed-Vessels.-Not only are the stems and leaves of plants and trees preserved in the Wealden beds, but even very delicate seed-vessels are sometimes found in the grit and sandstone. A small oval carpolithe (Tab. 45, fig. 1) is the most common. M. Adolphe Brongniart considers it probable, that this may belong to the Clathraria Lyellii. $\dagger$ The seed-ressels of coniferous trees also occur. These drawings (figs. 2, 3, 4) are from specimens belonging to my friend, Dr. Fitton, who has figured and described them in the valuable Memoir to which I have so often referred. Figs. 2 and 3 are copied inaccurately ; but I particularly claim your attention to fig. 4 , which is half the size of the original; this

* The reader may form an idea of the height and proportions of these elegant trees, by inspecting a specimen of tree-fern, forty-five feet high, from Bengal (Alsophila Brunoniana), on the staircase of the British Museum.

$\uparrow$ See Geology of the South-East of England, p. 246. 
beautiful cone was found imberlded in grit, in a quarry on Ashdown Forest, on the estate of Henry Shirley, Esq., and is remarkable for the double prominences on the scales.

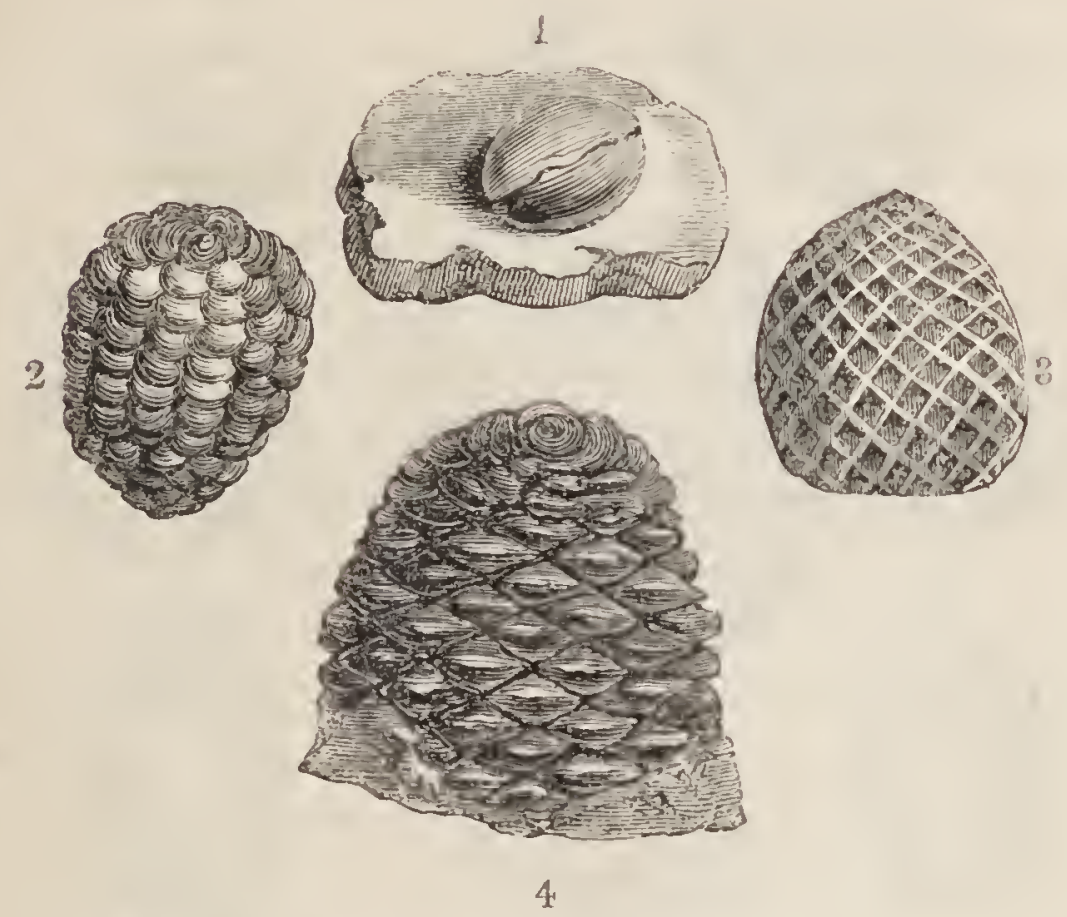

TaB. 45.-Fruits ANd Cones of THE Wealdex.

Fig. 1. Seed-ressel of Clathraria J.yellii. 2. Cone from the Isle of Purbeck. 3. Cone from Kent. 4. Cone from Pippingford.*

39. Fossil Shelts. - The shells of the Wealden, a series of the principal species of which I have placed before you, belong to but few gencra; and although whole tracts of country are composed of their remains, and many of the limestones are mere

* Figs. 2, 3, 4, are reduced one-half from Dr. Fitton's Memoir, Pl. XXII. 
conglomerates of shells, yet the species are but few; a character perfectly agreeing with that which pre. vails among the existing genera of our rivers. The
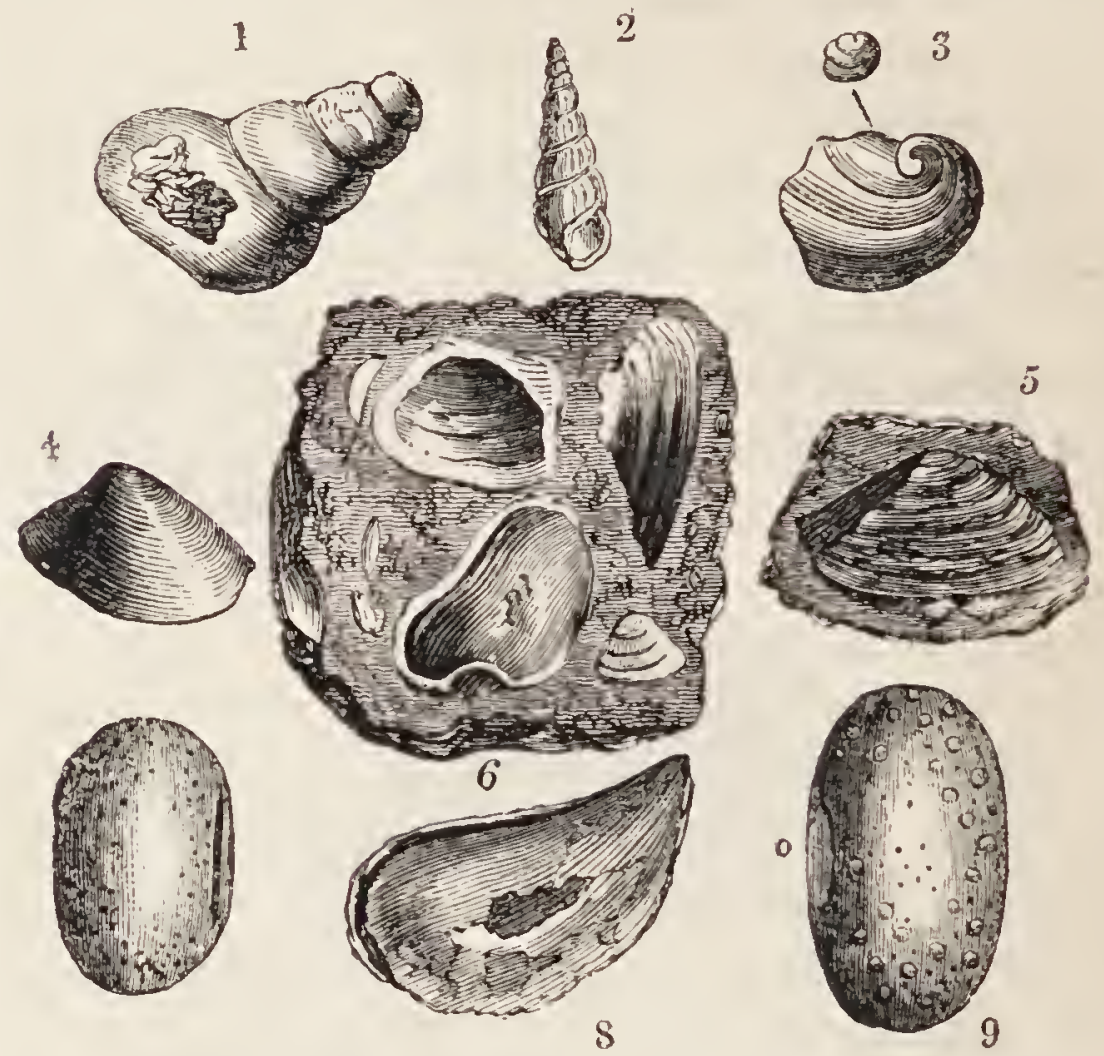

Tab. 46. - Sinells ayd Crustacea of the Wealden.

Fig. 1. Paludina Sussexiensis, from a slab of Sussex marble. 2. Melanupsis attenuala. 3. Neritina Fittoni. 4. Cyclas. 5. Psammobia tellinoides. 6. Unio Walteri, with other shells. 7, 9. Cypris granulosus, highly magnified. 8. Mytilus Lyeltii.

bivalve shells chiefly consist of muscles (referrible to a genus called Unio by conchologists), the casts of which are abundant in some of the sandstones; and several species of Cyclas, * that occur in myriads

* A genus of lacustrine, or freshwater bivalves. 
in the shales and clays, and resemble tertiary shells in their state of preservation. The shales of Pounceford are very like the clays of Castle Hill, Newhaven, in respect to the layers of shelly remains which occur between the strata. The grey limestones are wholly composed of Cyclades, imbedded in argillaceo-calcareous cement, in which univalves are of rare occurrence.

The calciferous grit near Hastings is full of Cyclades; but the shells are decomposed, and the casts or impressions of the interior alone remain. In the argillaceous septaria of the Weald clay, casts of small univalves, also destitute of their shells, abound. In Langton-green quarry, near Tunbridgewells, layers of argillaceous rock inclose impressions of numerous shells; and among others a remarkable species of Unio, (Tab. 46, fig. 6.) This spiral univalve, Melanopsis attenuata ('Tab. 46, fig. 2), belongs to a fresh-water genus; it occurs in the shale at Pounceford, in a beautiful state of preservation. This minute and elegant shell (Tab. 46, fig. 3,) is dispersed among small snail-shells in the grit of Tilgate Forest; I have named it Neritina Fittoni, in honour of my friend Dr. Fitton, whose able investigations have so fully elucidated the geological character and relations of the deposites below the chalk.

40. Sussex Marble; Fossil Cyprides.-The Weald-clay throughout its whole extent contains beds of limestone made up of a few species of 
the univalve, called Paludina (Tab. 46, fig. I), a fresh-water snail, common in rivers and lakes. The shells are sometimes decomposed, and their casts alone remain, the interstices being filled up with indurated marl, or calcareous concretions. In the coarser varieties are cavities left by the decomposition of the shells; in the compact masses the whole has been permeated with a crystalline calcareous infiltration, of various shades of grey, blue, and ochre, interspersed with pure white; polished slabs, displaying innumerable sections of the inclosed shells, rival in interest and beauty many foreign marbles. In these specimens you perceive the shells in relief on one side, and sections of the inclosed remains on the opposite polished surface ;* very few bivalves occur in this limestone, which, from its abundance in Sussex, is commonly known by the name of Sussex marble. The Petworth marble, and Bethersden stone of Kent, are from extensions of the same beds. In western Sussex, blocks of a beautiful marble mottled with green, blue, and grey, have been found; it is composed of large bivalves (Unio), and interspersed with a few univalves and fragments of reptiles, bones, \&c. The Purbeck marble, already described, only differs from that of Sussex in the size of the shells; the paludinæ in that limestone being of a very small species.

Cypris.-I have stated that the $\mathbf{W}$ ealden marbles

* Geology of the South-East of England, p. 1S4; ibid. p. 254. 
are principally composed of fresh-water shells; but other animal remains enter into their composition, and which although so minute as to elude common observation, possess a high degree of interest. It has been mentioned that certain crustaceous animals, (Cypris) abundant in fresh-water, having their bodies protected by shells or cases which they shed annually, occur in a fossil state in the lacustrine tertiary deposites (page 231); and I referred to the exhibition of the oxy-hydrogen microscope in illustration of the forms of the living species. The shields of various kinds of these microscopic creatures abound in the Wealden clay, ${ }^{*}$ septaria, and limestones; and entirely fill up the interstices between the shells of some varieties of Sussex marble. In these shales from near Lewes, septaria from Barcombe, and marble from Laughton, by the aid of a lens, hundreds of the shells of the cypris may be detected. Dr. Fitton, who has investigated the nature of these minute relics with his accustomed acumen, has discriminated several species. These enlarged drawings, from his illustrations, represent a variety in which the shells are studded with tubercles (Tab. 46, figs. 7, 9.) The natural size of these objects does not, as you observe in the specimens, exceed that of a pin's head, yet in certain formations entire layers of stone are composed of their consolidated remains, and they constitute

* Dr. Fitton's Memoir, Pl. XXI. figs. 1, 2, 3, 4. 
a large proportion of the mass of many beds of Sussex marble.

41. Fishes.-Bones, teeth, rays, and detached scales of fishes of the shark family, and of species allied to the large river-pikes of South America, are very abundant; but rarely any united portions of the skeleton, or scaly covering, are preserved; a circumstance arising from the drifted character of the Wealden deposites. Strong, thick, enamelled, lozenge-shaped scales, possessing a high polish, and having two processes of attachment, are very abundant in the sandstones, grit, and clays throughout the Wealden. At St. Leonard's and Tilgate Forest, the conglomerate contains immense numbers, associated with small hemispherical teeth, called fishes' eyes by the workmen. These scales belong to two species of Lepidotus, or bony-pike, of which genus a recent species inhabits the rivers of South America. It is rarely that any considerable number of the scales remain attached to each other in their natural position; but I have a few specimens in which large portions of the scaly covering retain their original character. These fishes must have attained a large size. In a specimen presented to me by my liberal friend, Robert Trotter, Esq. F. G. S. of Borde Hill, near Cuckfield, a large mass of the united scales is beautifully preserved; it belongs to that part of the body where the caudal fin commences, is twelve inches wide, and must therefore have belonged to a fish 
ten or twelve feet long, and three feet wide. Tricuspid teeth finely striated, and fin-bones of five or six species of genera belonging to the shark family, are of frequent occurrence. The fishes of the Wealden are entirely distinct from those of the Chalk.**

42. Reftiles of Tilgate Forest.†-It will doubtless excite your surprise to learn that the whole of the enormous bones, and teeth, I have placed on the table, belong to reptiles; and that not a vestige of the mammalia occurs in the Wealden. Even these teeth, which so strikingly resemble the incisors of the rhinoceros, and these bones of the feet and toes, so similar in their construction and magnitude to those of the hippopotamus, all belong to oviparous quadrupeds! Many of the specimens before you can be referred to certain extinct forms of Saurians ; but others are yet undetermined, in consequence of my want of leisure, and distance from any extensive collection of subjects of comparative anatomy. The study of the fossil bones of the Wealden

* The following fishes of the Wealden, in my museum, lave been named by M. Agassiz. Pycnodus microdon, Lepidotus Fittoni, L. Mantellii, Hybodus grossiconus, H. marginalis, H. polyprion. A small species, Lepidotus minor, occurs in the Purbeck limestone.

+ This lecture was illustrated by several hundred specimens of bones and teeth of reptiles from the Wealden; many of such enormous size, that the assemblage resembled an accumulation of the disjointed skeletons of gigantic elephants or mastodons. -G. F. R. 
is indeed no easy task; for while in many marine deposites, considerable portions of the skeletons, or even the entire forms, are often discovered; in the Wealden, with the exception of but three or four examples, every bone, tooth, and scale, has been found apart from each other; and as if to render the task still more perplexing, the relics of several different species are scattered, as it were, at random through the rocks. Every specimen, as I have before remarked, bears evidence of having been transported from a distance; it would seem as if the limbs and carcases of the animals were floated down the stream, and rolled backwards and forwards by the tides, and the bones broken before they became imbedded in the mud of the delta. "To collect these scattered fragments, and extricate them from the solid rock; to reunite them into a whole, and assign to each skeleton of the respective animals, the bones which once belonged to it, yet not to confound the different species together-such is the labour which the comparative anatomist has to perform, who undertakes to investigate the structure of the Wealden reptiles." I reserve for the next lecture some observations on the economy and habits of the reptile tribes, and will now describe the fossil relics before us.

43. Fossil Turtles.-The bones and plates of turtles are very common in the Purbeck limestone, and in the grit, sandstone, and shale of Tilgate Eorest. They are referrible to two or more fresh- 
water, and one marine species; the former appear to be analogous to an Emys, or fresh-water turtle, described by Cuvier, * that occurs in the Jura limestone at Soleure. It is a very flat species, and probably attained two feet in length. The ribs of a Trionyx (which is also a fresh-water turtle), occur in the shale of Pounceford, and grit of Tilgate; the surface of the ribs or dorsal plates is shagreened all over, as is usual in these turtles, which have no shelly covering, but only a thick, tough skin, or integument.

44. Plesiosaurus. Several bones, and vertebra of the neck and back of the extraordinary extinct reptile, called Plesiosaurus, ${ }_{+}^{+}$whose remains are found in such prodigious numbers in the lias, occur in the calciferous sandstone of Tilgate Forest, and prove that this animal was an inhabitant of the sea into which the river of the Wealden flowed.

45. Fossil Crocodiles. - The skeletons of the crocodiles, alligators, and gavials, those well-known reptiles of Egypt, India, and America, possess characters which render their fossil bones easily recognisable by the comparative anatomist. The peculiar structure of the teeth, as you may observe in this specimen, (Tab.47,) affords certain indications of the original animal. The teeth of the crocodile consist of a succession of cones, like a series of

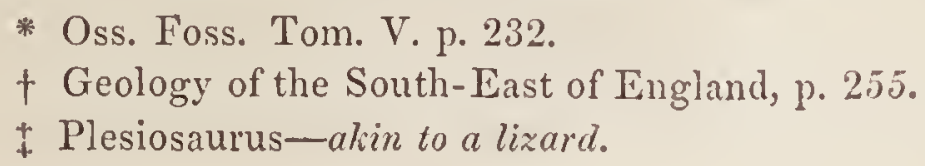


thimbles of various sizes, fitted into each other; they are striated externally, and have a prominent lateral ridge; as the outer tooth wears away, a

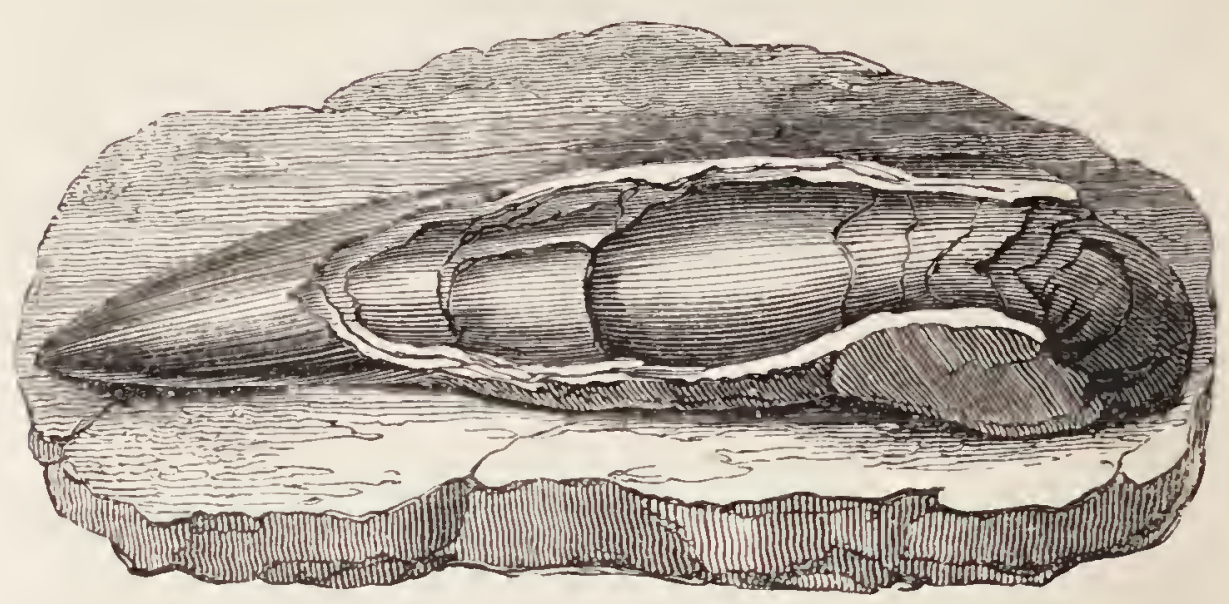

Tab. 47. -Tooth of Crocodile-Tilgate Forest.

new one is ready to supply its place; hence the teeth of the old crocodile are as fresh as those of the young animal but just escaped from its shell. The example before us, from the removal of a portion of the outer surface, offers an instructive example of the internal structure. Detached bones of several species of crocodiles are scattered through the Tilgate strata. From the difference observable in the form of the teeth they appear referrible to two kinds-the one belonging to that division of crocodiles, with long slender muzzles, named $G a$ vials; the other to a species of Crocodile, properly so called,* and resembling a fossil species found at

* Geology of the South-East of England, p. 263. 
Caen. Among the hundreds of teeth and bones, collected in the Wealden, no portions of the jaw, or any united parts of the skeleton, have been observed. In the Purbeck beds a specimen has recently been discovered that affords an interesting illustration of the osteology of one of the Tilgate species.

46. Tine Swanage Crocodile.-Swanage, or Swanwich, is a little town on the east of the Isle of Purbeck, the inhabitants of which carry on a brisk trade in the exportation of stone from the numerous quarries in its vicinity, there being a fine bay and good anchorage for vessels. The town stands at the mouth of the bay, about six miles.E.S.E. of Corfe Castle. The section, exposed by the coast, explains the geological structure of the country, and presents the following series:-First, beds above the chalk; secondly, chalk; and lastly, the freshwater strata beneath; the Purbeck limestone occupying the lowermost place in the series. I need not, in this place, dwell on the dislocations of these strata, and the causes by which they have been disconnected and thrown into their present position. A few months since the workmen employed in a quarry, in the immediate vicinity of Swanage, had occasion to split asunder a large slab of limestone, when, to their great astonishment, they perceived many bones and teeth of some animal, on the surfaces they had just exposed. As this was no ordinary occurrence, for although scales of fishes, shells, \&c. 
were frequently observed in the stone, bones had never before been noticed, both slabs were carefully preserved by the proprietor of the quarry; and fortunately my intelligent friend, Robert Trotter, Esq. F.G.S., of Borde Hill, Sussex, happening to visit Swanage a short time afterwards, heard of the discovery, and with that liberality and ardour for the advancement of science for which he is distinguished, purchased the specimens, and presented them to my collection. I have cleared away the stone, so far as the brittle state of the bones will permit without injury, and they are now rendered two as interesting groups of Saurian remains as exist in this country.

In these specimens a considerable portion of the left side of the lowcr jaw, with two teeth attached, is preserved; many teeth are scattered over the stone, and numerous dermal, or skin-bones, which are readily distinguished, not only, by their form, but also by their deeply pitted surface. The pelvis is nearly entire, and there are many bones of the spine, (caudal, and dorsal vertebre, and chevronbones, ) ribs, and some of the long bones of the extremities.

47. The Mega los aurus. *-The fissile limestone. of Stonesfield, of which I shall speak in the next lecture, has long been celebrated for the teeth and bones of a gigantic reptile, to which Dr. Buckland 
has given the name of Megalosaurus. In this place I will only state, that vertebræ, bones, and teeth of this animal have been found in thc Tilgate grit, and in the clays and sandstones of the Wealden, associated with the remains of turtles, crocodiles, and of the still more colossal oviparous quadruped the Iguanodon, which I now proceed to notice.

48. The IGUanodon.-It is now several years, since the discovery of a mutilated fragment of a tooth, led me to suspect the existence of a gigantic herbivorous animal in the strata of 'Tilgatc Forest, which subsequent researches confirmed.* This is the fragment: it is part of the crown of a tooth, rescmbling in its prismatic form the incisor of one of the herbivorous mammalia, worn by use. The enamel is thick in front and thin behind, and by this disposition a sharp cutting edge is maintained in every stage. Here, then, is a character, which if we bear in mind the principles of comparative anatomy cuforced in the second lecturc, (page 128,) will afford us certain indications as to the nature of the animal to which it belonged. The structure of the tooth, and its worn surface, prove that it is referrible to a species that fed on vegetables; the absence of a fang, and the appearance of the base, not broken, but indented, show that the shank has been absorbed from the pressure of a new tooth, which has grown

* "On the teeth of the Iguanodon, a newly-discovered fossil herbivorous reptile, from the strata of Tilgate Forest."-Philos. Trans. 
up and supplanted the old one; a process too familiar to require explanation.*
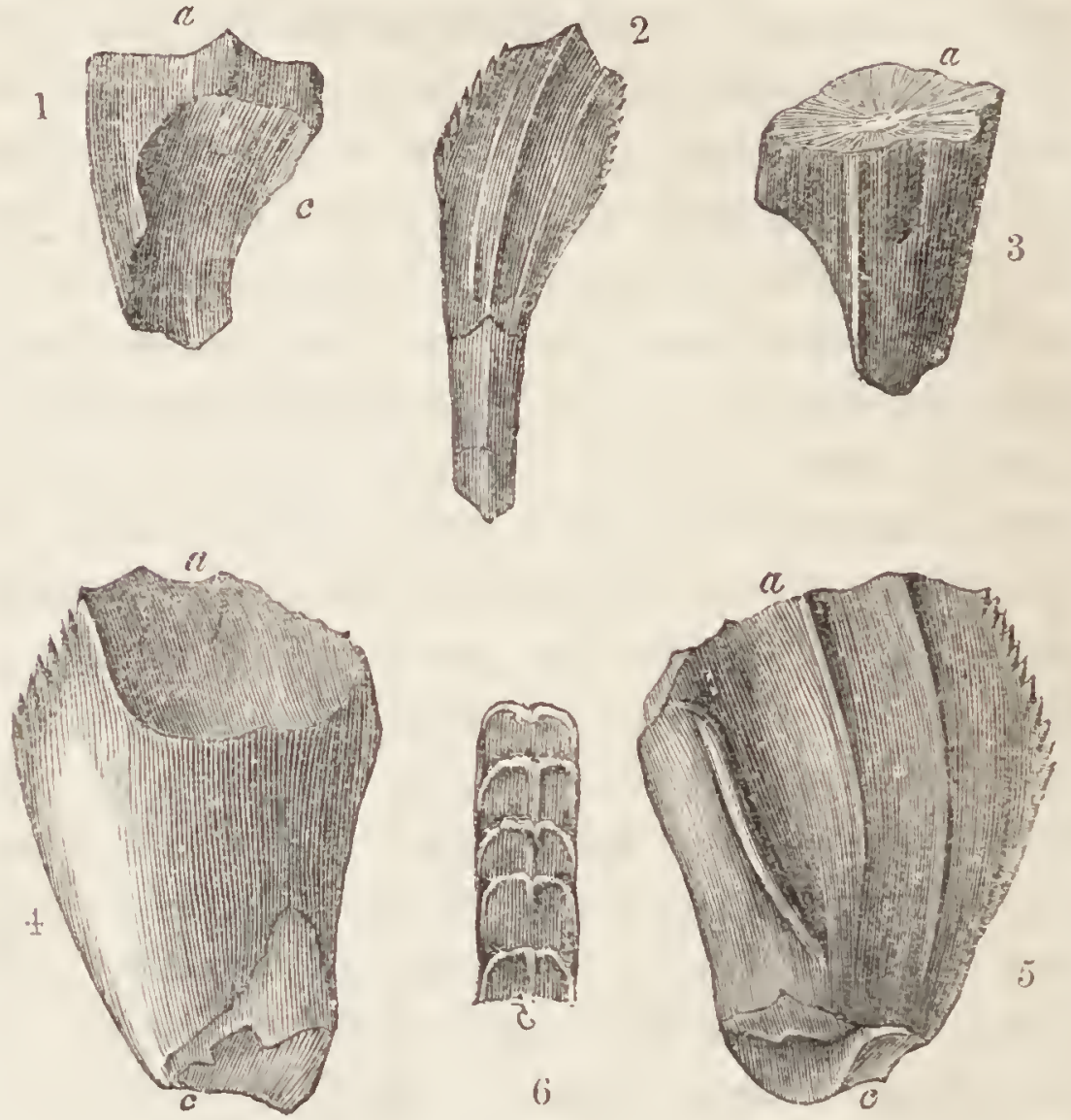

1AB. AS.-TeEtI OF THE IGUANONON, FROM TILGate Fosest.

̈igs. 1, 3. Tooth worn flat, and the fang absorbed. 2. Tooth of a young animul. 4. Inner, and 5, outer, surface of a tooth of an adult. 6. Lateral view of the serrated edge of fig. 5, magnified. a, The surface u'orn by mastication. c. The indentation produced by pressure of the new tooth.

* It camnot be requisite to notice the vulgar error that the first teeth in children have no fangs; it may however elucidate the remarks in the text, if the reader is reminded that the absence of fangs in the teeth shed in childhood, results from the absorption of the fang of the old teeth, occasioned by the pressure of those which are to supply their place. 
In the teeth before us we trace every gradation of this change, from the perfect form (Tab. 48, fig. 2,) - the partially worn specinen, (figs. 4, 5, ) to the mere stump, (figs. 1, 3,) in which the crown is worn flat, and the absorption of the fang complete. The teeth, when perfect, are of a prismatic form, and remarkable for the prominent ridges which extend down the front, and the selrated margins of the crown. (Tab. 48, fig. 6, the serrated edge magnified.)

But although by this mode of induction the grand division of the animal kingdom to which the original belonged was determined, a rigid comparison of the teeth with those of recent species was necessary, to arrive at more satisfactory results. In a fossil state, no teeth at all analogous had been noticed; and after a fruitless research through the collections of comparative anatomy in London, I found, in the jaws of a recent Iguana,* the type for which I had so long sought in vain. The Iguanas are land lizards, natives of many parts of America and the West Indies, and are rarely met with north or south of the tropics. They are from three to five feet in length, and feed on insects and vegetables, climbing trees, and chipping off the tender shoots. They nestle in the hollows of rocks, and deposit their eggs, which are like those of

* Prepared by Mr. Stutchbury, the intelligent curator of the Bristol Institution. 
turtles, in the sands or banks of rivers. The Iguana is furnished with a row of very small, closely-set, pointed teeth, with serrated edges, which are attached at the base, and by the outer surfaces of the fangs, to the jaw, the alveolar process forming an external parapet; there is no internal bony covering. The new teeth arise at the base of the old, and supplant them by occasioning the absorption of the fangs. The teeth of the Iguana closely resemble the perfect tooth, Tab. 48 , fig. 2 , except in size; those of the recent animal scarcely exceeding in magnitude the teeth of the common mouse. But in the Iguara the teeth never present a. worn surface; they are broken or chipped off by use, but not ground smooth as in the herbivora. The reason is obvious; none of the existing reptiles are furnished with cheeks or moveable coverings to their jaws, and therefore cannot perform mastication; their food or prey is seized by the teeth and tongue, and swallowed whole. But apart from this discrepancy, the teeth and mode of dentition of the fossil animal are so perfectly analogous to those of the Iguana, that I have named the original the IGUA NoDos, signifying an animal having teeth like the Iguana. In the course of the present summer a portion of jaw has been discovered, which confirms all the inferences that inany years since I ventured to deduce from the teeth alone.

From the gigantic size of the fossil teeth, as com- 
pared with the recent, I was led to infer that many of the colossal bones, collected from time to time, in Tilgate Forest, belonged to the same kind of animal. By comparing the bones with the skeleton of the Iguana, (presented me by Baron Cuvier,) I succeeded in determining many parts of the skeleton; and at length was enabled to restorc, as it were, the form of the Iguanodon, and ascertain its proportions; the correctness of my inferences was shortly to be put to the test, by a discovery in a neighbouring county.

49. The Maidstone: Iguanodon.* - In May, 1834, some workmen employed in a stone-quarry, in the occupation of Mr. W. H. Bensted, of Maidstone, observed in a mass of rock which they had blasted, several portions of what they supposed to be petrified wood; they preserved the largest piece for the inspection of Mr. Bensted, who at once perceived that it was a portion of bone belonging to some gigantic animal. He therefore gave directions that every fragment should be collected, and after much labour and research, succeeded in obtaining those pieces, which are now united, and form a specimen of the highest interest; he also cleared away part of the surrounding stone, so as to expose the bones, which I have since completely developed and joined togetlier.

The specimen consists of a considerable number of the bones, composing the inferior portion of the

* Appendix. 
skeleton of an Iguanodon, which, when living, must have been upwards of 60 feet in length. The bones are imbedded in the stone in a very confused manner, few of them being in their natural order of juxta-position, and all more or less flattened and distorted. The following are well displayed; and there are many fragments of others, which are too imperfect to admit of being determined.

Two thigh-bones, eaeh 33 inches long."

One leg-bone (tibia), 30 inches long.

Metatarsal and phalangeal bones of the hind feet; these muels resemble the corresponding bones in the Hippopotamus.

Two claw-bones (unguical phalanges), whieh were covered by the nail or elaw; these correspond with the unguical bones of the land tortoise.

Two finger, or metacarpal bones of the fore-feet, each 14 inches in length.

A radius, or bone of the fore-arm.

Several dorsal and caudal vertebre (bones of the spine and tail). Fragments of several ribs.

Two clavicles, or eollar-bones, each 28 inches in length, resembling the bone figured Plate IV. figs. 1, 2, Geology of the South-East of England. These bones are of a very singular form, and differ essentially from any known clavicle, yet it seems impossible to assign them to any other plaee in the skeleton.

Two large flat hatchet-shaped bones, whieh appear to belong to the pelvis, and are probably the ossa ilia.

* The femur of the Iguanodon is rery remarkable; it has a large troehanter opposite to the head of the bone, and a process on the inner side for the attachment of powerful adduetor muscles; the front of the lower extremity is deeply groored anteriorly, as in the toad; the shaft of the bone is subquadrangular. 
A chevron-bone, or one of the inferior spinous processes of a vertebra of the tail.

A portion of a tooth, and the impression of another.-The preservation of these teeth is most fortunate, as the identity of the animal with the Iguanodon of Tilgate Forest is thereby completely established.

The stone in which the bones are imbedded is of that hard varicty of the grey, arenaccous limestone, called Kentish rag, which is much employed in various parts of Kent, and in the west of Sussex, for building, and repairing roads. This Rag belongs to the Shanklin sands, and abounds in the marine shells which are characteristic of that division of the chalk formation. In the quarry in which the remains of the Iguanodon werc found, Mr. Bensted has discovered fossil wood perforated by lithodomi, or boring shells; impressions of lcares, stcms of trees, Ammonites, Nautili, $\mathcal{S}$ c.; large conical striated teeth, which arc referrible to those extinct fossil fishes, which M. Agassiz denominates Sauroid, or lizard-like; scales and teeth of several kinds of fishes, and, amoug these, a jaw or man. dible of that singular genus of fish, the Chimera.

The geological position of this specimen forms an exception to what has been previously remarked of the fossils of the Wealden; for while the bolles in the latter are found associated with terrestrial and fluviatile remains only, the Maidstonc specimen is imbedded in a marine deposit. This discrepancy, however, in no wise affects the arguments previously 
advanced, as to the fluviatile origin of the strata of the Wealden; it merely shows that part of the delta had subsided, and was covered by the chalk ocean, whilst the country of the Iguanodon was still in existence. The body of an Iguanodon was then drifted out to sea, and became imbedded in the sand of the ocean; in like manner, as at the present day, bones of land quadrupeds may not only be engulfed in deltas, but also in the deposites of the adjacent sea.

This specimen possesses a high interest, because it proves that the separate bones found in the strata of Tilgate Forest, and which I had assigned to the Iguanodon, solely from analogy, lave been correctly appropriated; and we obtain also a knowledge of many interesting facts relating to the structure and economy of the original. I can notice but one of these inductions. As the Iguana lives chiefly upon vegetables, it is furnished with long slender feet, by which it is enabled to climb trees with facility, in search of food. But no tree could liave borne the weight of the colossal Iguanodon, - its movements must have been confined to the land and water, and it is evident that its enormous bulk must have re. quired limbs of great strength. Accordingly we find, that the hind feet, as in the Hippopotamus, Rhinoceros, and other large mammalia, were composed of strong, short, massy bones, furnished witl claws, not hooked as in the Iguana, but compressed as in the land tortoises; thus forming a powerful support for the enornous leg and thigh. But the 
bones of the hands, or fore feet, are analogous to those of the Iguana, - long, slender, flexible, and armed with curved claws the exact counterpart of the nail-bones of the recent animal; thus furnishing prehensile instruments fitted to seize the palms, arborescent ferns, and dragon-blood plants, which probably constituted the food of the original. Here we have another interesting example of that admirable adaptation of structure to the necessities and conditions of every form of existence, which is alike manifest, whether our investigations be directed to the beings around us, or to the structure of those which have long since passed away.

Gigantic as must have been the animal discovered by Mr. Bensted, there are in my collection many bones which indicate yet more colossal proportions. A thigh bone, from the west of Sussex, (presented to me by J. Napper, Esq.) is 3 feet 8 inches long, and 35 inches round, at the largest extremity; and the shaft of another femur is 24 inches in circumference! The following is the result of a careful comparison of some of the fossil, with the corresponding bones of the Iguana, with the view of ascertaining the probable average size of the original animal, (vide Geol. of South-East of England, p. 315;) we should, however, bear in mind, that some individuals must have far exceeded this estimate, and, if they bore the proportions of the recent Iguana, have been upwards of 100 feet in length !

Length of the Iguanodon, from the snout to the 
tip of the tail, 70 feet. Circumference of the body, $14 \frac{1}{2}$ feet. Length of the tail, $52 \frac{1}{2}$ feet. Length of the hind foot, $6 \frac{1}{2}$ feet. Of course this calculation is offered but as an approximation; we cannot, however, for a moment doubt, that an animal possessing such a body, as to require a thigh bone eight inches in diameter, must have been of prodigious magnitude; such a thigh-bone, if covered with muscles and integuments, would be upwards of seven feet in circumference!

I will notice one other remarkable feature in the structure of the Iguanodon. The Iguanas are distinguished among the lizards by their exuberant dermal appendages; some have serrated processes or spines on the back, (as in this specimen from Barbadoes, presented to me by my friend R. I. Murchison, Esq., late President of the Geological Society;) other's on the tail; while many have warts and horny protuberances on the head and snout. The extraordinary relic I place before you, is the FOSSIL HORN of the Iguanodon, from Tilgate Forest.* It is composed of bone, and bears marks on its surface of the integunent with which it was invested; it is four inches high; the base, which is of an irregular elliptical form, is 3.2 inches by '2.1. In this additional analogy between the Iguanodon and the Iguana, we perceive another instance of

* This fossil was discovered by Mrs. Mantell; see Geology of the South-East of England, page 312, Plate III. fig. 5. Dr. Buckland has copied this figure in his Bridsewater Essay. 
that law of co-relation of form of which our researches have afforded so many examples.

I will only add, that the fossil plants with which the remains of the Iguanodon are associated, were furnished with tough, thick stems, like those of the palms, tree-ferns, yucca, \&c. These probably constituted the food of the original; and the peculiar structure of its teeth was evidently required, and admirably adapted, for the mastication of such vegetable productions.

50. The Hylzosaurus (Wealden Lizard).In the summer of 1832, I discovered, in Tilgate Forest, the remains of a reptile, not less extraordinary than the Iguanodon, and which I have named the Hylcosanmes, to denote its relation to the Wealden formation. A block of calciferous grit had been broken up by the quarry-men, and a great part of it thrown upon the road, as it was not supposed to contain any thing interesting. Accidentally visiting the quarry, I noticed indications of bones in several pieces of stone on the road-side, and therefore directed that the remaining portions should be collected, and sent to my residence. Having cemented the fragments together, and chiselled off the hard grit in which the bones were wholly imbedded, and to which they are still attached, I succeeded, after much labour, in displaying a considerable portion of the skeleton of a reptile, which blends the osteology of the crocodile with that of the lizard. The vertebræ of the neck, several of the 
back, many ribs, and the bones of the stermum, or chest, remain; there are also dermal, or skin-bones, which, in animals of this family, support the large scales. But the most extraordinary parts, are many enormous, angular, spinous bones, which lie in the direction of the vertebral column, and evidently extended originally like a serrated fringe along the back of the animal. Many of the existing lizards have remarkable appendages of this kind, particularly the Cyclura. This figure, from Dr. Harlan's valuable work, * shows how largely these curious processes are dereloped in some species.

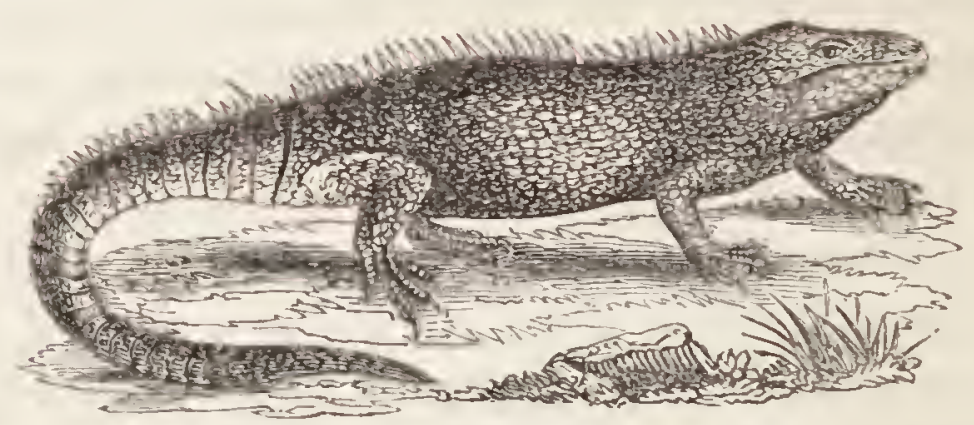

TAB. 49.-Cyclura carisata.

(A recent Lizard, allied to the Iguana. Dr. Harlan.)

The length of the Hylæosaurus was probably about twenty-five feet. In the same block of stone were masses of vegetable remains, with seed-ressels, and stems of Clathraria Lyellii.t I have lately

* Medical and Physical Researches, by R. Harlan, M.D., F.G.S., Svo. Philadelphia, 1835.

† Geology of the Soutli-East of England, p. 316, Pl. V. is an excellent lithograph of the specimen, by Mr. Pollard, of West-street, Brighton. 
obtained many bones of this extraordinary creature from a bed of elay near Crawley; and also a most interesting speeimen of the vertebral eolumn, eomprising nearly thirty vertebræ of the tail and baek, with many dermal and spinous bones, ribs, \&e. exhibiting very peeuliar osteologieal charaeters.

51. Flying Reptiles, or Pterodactyles. The remains of thin and slender bones, evidently adapted for an aninal eapable of flight, were among my earliest discoveries in the strata of Tilgate Forest. Some of these bones appear to belong to those singular extinct creatures, ealled Pterodactyles, or wing-toed reptiles, which had a beak like a bird, a long neek, and a wing, sustained principally on an elongated toe. It is sufficient merely to notice the oecurrenee of these remains in the Wealden; in the suceeeding leeture the subjeet will be resumed.

52. Fossil Birds. - In deseribing the fossil remains of the animals of the older tertiary epoeh, it was stated that several recent genera of birds were eontemporaneous with the Palæotheria (page 220); but no traces of this elass of animated nature had been found in the ehalk, or in strata of an earlier date. The discovery of the undoubted remains of birds in the strata of Tilgate Forest, beeame, therefore, a fact of great interest and importance in the physieal history of the globe. After seleeting the bones which appeared to be referrible to Pterodactyles, several remained whieh bore so 
striking a resemblance to those of Waders, that I ventured to describe them as such in my work on the Fossils of Tilgate Forest; and this opinion was corroborated by Baron Cuvier, to whom I showed the specimens on his last visit to England. Subsequently, I have obtained the inferior portion of a leg-bone (tarso-metatarsal), in which the oval cicatrix, or articulation for the hind-toe, is distinctly visible, and proves unquestionably that the bone belonged to some kind of wader, perhaps a heron; the position of the hind toe in birds, varying in accordance with the habits and economy of the respective orders* (page 123). These are the most ancient remains of this class of animals hitherto discovered.

53. The Country of the Iguanodon.-By this survey of the strata and organic remains of the Wealden, we have acquired data from which, by the principles of induction explained in a former lecture (page 34 ), we may obtain secure conclusions as to the nature of the country from whence those spoils were derived, the animals by which it was inhabited, and the vegetables that covered its surface. That country must have been diversified by hill and dale, by streams and torrents, the tributaries of its mighty river. Arborescent ferns, palms, and

* See a Memoir "On the Bones of Birds discovered in the Strata of Tilgate Forest," by the author, Geological Transactions, 1838, which contains some interesting remarks of Professor Owen, on the osteological characters of the fossil bones. 
yuccas, constituted its groves and forests, delicate ferns and grasses, the vegetable clothing of its soil ; and in its marshes, equiseta, and plants of a like nature, prevailed. It was peopled by enormous reptiles, among which the colossal Iguanodon and the Megalosaurus were the chief. Crocodiles and turtles, flying reptiles and birds, frequented its fens and rivers, and deposited their eggs on the banks and shoals; and its waters tecmed with lizards, fishes, and mollusca. But there is no evidence that Man ever set his foot upon that wondrous soil, or that any of the animals which are his contemporaries found there a habitation: on the contrary, not only is evidence of thcir existence altogether wanting, but from numberless observations made in every part of the globe, there are conclusive reasons to infer, that man and the existing races of animals were not created, till inyriads of years after the destruction of the Iguanodon country -a country, which language can but feebly portray, but which the magic pencil of a Martin, by the aid of geological research, has rescued from the oblivion of countless ages, and placed before us in all the hues of nature, with its appalling dragon-forms, its forests of palms and tree-ferns, and all the luxuriant vegetation of a tropical clime.**

54. Sequence of Geological Changes. - Let us review the sequence of those stupendous changes,

* See the Frontispiece; an engraving on steel, from an original painting of John Martin, Esq., K L. 
of which our examination of the geological phenomena of the south-east of England has afforded such incontrovertible evidence. From the facts brought before us, we learn that at a period in. calculably remote, there existed in the northern hemisphere an extensive island, or continent, possessing a climate of such a temperature, that its surface was clothed with coniferous trees, arborescent ferns, and plants allied to the Cycas and $\mathrm{Za}$ mia; and that the ocean which washed its shores was inhabited by turtles and reptiles of extinct genera. This island and its foresto suffered a partial subsidence, which was effected in such manner that many of the trees, although torn and rent, still retained their erect position; and the Zamire, and a considerable layer of the vegetable mould in which they grew, remained undisturbed. In this state an inundation of fresh-water covered the once flourishing forest, and deposited upon the soil and around the trees a calcareous mud, which gradually consolidated into fine limestone; water, holding flint in solution, percolated through the mass, and silicified the now submerged trees and plants. A further depression took place - a body of fiesh water, brought down by land-floods and rivers, overwhelmed the petrified forest, and heaped up accumulations of debris, which their parent streams had washed away from the rocks over which they had flowed. The country traversed by the rivers, like that of the submerged forest, enjoyed a tropical 
climate; it was clothed with palms, arborescent ferns, and plants allied to the yucca and the dracæna, and tenanted by enormous reptiles, crocodiles, and land and fresh-water turtles; and in its waters were various kinds of fishes, mollusca, and aquatic plants. The bones and teeth of the reptiles - the remains of the turtles-the teeth and scales of fishes-the shells of the snails and musclesthe stems, leaves, and even seed-vessels, of the trees, were carried down by the stream, and deposited in the mud of the delta, beneath which the petrified forest was now buried. This state continued for a long period: another cliange took place; the country and its inhabitants were swept away, and the delta, and the strata on which it reposed, were submerged to a great depth, and formed part of the bottom of a profound ocean, whose waters teemed with myriads of zoopliytes, shells, and fishes, of speeies that are now no more. Thermal waters, holding calcareous and silicious matter in solution, were poured into its basin, and, in its tranquil depths, layers of flint and chalk were deposited. And so rapidly were these depositions effected, that fishes, while in the act of swimming, were arrested in their progress, and beeame suddenly enveloped in a bed of rock. This epoeh was of considerable duration: at length elevatory movements began to take plaee, the bottom of the deep was slowly up-heaved, and as the elevation continued, the depositions which had formed in the 
basin of the ocean, and had become consolidated, were broken up, and as they approached the surface were acted upon by the waves; the chalk strata now began to suffer degradation and destruction, till at length the delta of the country of the Iguanodon emerger above the waters, and finally, even the ancient petrified forest was brought to view, and became dry land. At length some masses rose to an elevation of a few hundred feet above the level of the sea, and formed a group of islands; but, in the depressions of the strata beneath the waters, deposites went on, from the waste of the cliffs on the sea-shores. Large mammalia now inhabited such portions of the former ocean-bed as were clothed with vegetation, and as they died their bones and teeth were enveloped in the sediments of mud and gravel which were forming in the bays and estuaries. This era also passed away-the elevation continued-other portions of the bed of the chalkocean became dry land-and at length also those newer deposites, in which the remains of the manmoth and the elk, the last tenants of the country, were entombed. The oak, elm, ash, and other trees of modern Europe, sprang up where the palms and tree-ferns once flourished; the deer, boar, and horse, ranged where the mighty reptiles had once ruled sole monarchs of the country; and lastly, man appeared, and took possession of the soil. At the present time, a city stands on the deposites which contain the remains of the elephant 
and the elk; the hunteman courses, and the shepherd tends his flocks, on the elevated and rounded masses of the bottom of the ancient chalk-ocean; the farmer reaps his harvests upon the cultivated soil of the delta of the Iguanodon; and the architect seeks, beneath the petrified forest, for the materials with which to construct his edifices.

55. Retrospect of Geological Eras. Such is a plain enunciation of the results of our investigations; but I will embody these inductions in a more impressive form, by employing the metaphor of an Arabian writer, and imagining some higher intelligence from another sphere, to describe the physical mutations of which he may be supposed to have taken cognizance, from the period when the forests of Portland were flourishing, to the present time. Countless ages ere man was created, he might say, I visited these regions of the earth, and beheld a beautiful country of vast extent, diversified by hill and dale, with its rivulets, streams, and mighty rivers, flowing through fertile plains. Groves of palms and ferns, and forests of coniferous trees, clothed its surface; and I saw monsters of the reptile tribe, so huge that nothing among the existing races can compare with them, basking on the banks of its rivers and roaming through its forests; while, in its fens and marshes, were sporting thousands of crocodiles and turtles. Winged reptiles of strange forms shared with birds the dominion of the air, and the waters 
teemed with fishes, shells, and crustacea. And after the lapse of many ages I again visited the earth; and the country, with its innumerable dragon-forms, and its tropical forests, all had disappeared, and an ocean had usurped their place. And its waters teemed with nautili, ammonites, and other cephalopoda, of races now extinct; and innumerable fishes and marine reptiles. And countless centuries rolled by, and I returned, and, lo ! the ocean was gone, and dry land again appeared, and it was covered with groves and forests; but these were wholly different in character from those of the vanished country of the Iguanodon. And I beheld, quietly browsing, herds of deer of enormous size, and groups of elephants, mastodons, and other herbivorous animals of colossal magnitude. And I saw in its rivers and marshes the hippopotamus, tapir, and rhinoceros; and I heard the roar of the lion and the tiger, and the yell of the hyena and the bear. And another epoch passed away, and I came again to the scene of my former contemplations; and all the mighty forms which I had left had disappeared, the face of the country no longer presented the same aspect; it was broken into islands, and the bottom of the sea had become dry land, and what before was dry land had sunk beneath the waves. Herds of deer were still to be seen on the plains, with swine, and horses, and oxen; and wolves in the roods and forests. And I beheld human beings, clad in the 
skins of animals, and armed with clubs and spears; and they had formed themselves habitations in caves, constructed huts for shelter, inclosed pastures for cattle, and were endeavouring to cultivate the soil. And a thousand years elapsed, and I revisited the country, and a village liad been built upon the sea-shore, and its inhabitants supported themselves by fishing; and they had erected a temple on the neighbouring hill, and dedicated it to their patron saint. And the adjacent country was studded with towns and villages; and the downs were covered with flocks, and the valleys with herds, and the corn-fields and pastures were in a high state of cultivation, denoting an industrious and peaceful community. And lastly, after an interval of many centuries, I arrived once more, and the village was swept away, and its site covered by the waves; but in the valley and on the hills above the cliffs a beautiful city appeared ; with its palaces, its temples, and its thousand edifices, and its streets teeming with a busy population in the highest state of civilization; the resort of the nobles of the land, the residence of the monarch of a mighty empire. And I perceived many of its intelligent inhabitants gathering together the vestiges of the beings which had lived and died, and whose very forms were now obliterated from the face of the earth, and endeavouring, by these natural memorials, to trace the succession of those events of which I had been 
the witness, and which had preceded the history of their race.*

* The concluding portion of these remarks refers to the changes that have taken place on the Sussex coast, during the historical era. Before the Conquest, the greater part of the little fishing town of Brighthelmston (Brighthelm's-town) was situated below the cliffs, on a terrace of beach and sand, now covered by the waves. The church, dedicated to St. Nicholas, the patron saint of fishermen, was placed on an eminence, that it might serve as a land-mark. The inroads of the sea led to the erection of buildings on the high ground, and its progressive encroachment gradually diminished the area of the ancient town, till at length a sudden inundation, but little more than a century ago, swept away the houses, fortifications, and inclosures, that remained. ${ }^{a}$ The sea has, therefore, only resumed its former position at the base of the cliffs; the site of the old town having been an ancient bed of shingle, abandoned for ages by the ocean, perhaps contemporaneously with the retreat of its waters from the valley of the Ouse. Should the advancement of the sea be still progressive, Lewes Levels may again become an estuary, and the town of the Cliff, and the hamlet of Landport, regain the character from which their names were derired. See page 39.

a Illustrations of the Geology of Sussex, page 292. Geology of the South-East of England, page 23. Dallaway's Western Sussex, Vol. I. page 55 . 


\section{A P P E N I X.}

A. Page 17.-The Surface of the Moon.-The moon is the only planetary body placed sufficiently near us, to have the inequalities of its surface rendered distinctly visible with the telescope. Attendant on the earth, and liaving nearly the same density, we may reasonably infer that the mineral substances of which it is composed do not differ essentially from those on the surface of our own planet. Astronomers now generally admit that the moon is surrounded by a very clear atmosphere, but which is so low that it scarcely occasions a sensible refraction of the rays of light when it passes over the fixed stars. Many of the dark parts of the moon, particularly the part called Mare Crisium, appear to be covered with a fluid, which may probably be more transparent and less dense than water, as the form of the rocks and crater's are seen beneath it, but not so distinctly as in the lighter parts of the moon's surface. To examine the moon with a reference to its external structure, the defining power of the telescope should be of the first quality, sufficient to show the projections of the outer illuminated limb as distinctly as they appear when the moon is passing over the disk of the sun during a solar eclipse. With such a telescope, and a sufficient degree of light and of magnifying power, almost every part of the moon's surface appears to be volcanic, containing craters of enormous magnitude and vast depth: the shelving rocks, and the different internal ridges within them, mark the stations at which the lava has stood and formed a floor during different ermptions; while the cones in some of the craters resemble those formed within modern volcanoes. The largest mountain on the southern limb of the moon, like the largest volcanic cone on the earth, Chimborazo, VOL. I. * $\mathrm{B} \mathrm{B}$ 
lias no deep crater on its summit. There are indeed the outlines of the crater, but it is nearly filled up; while from the foot of this lunar mountain diverging streams of lavis seem to flow in different directions, to the distance of six hundred miles. The longest known current of modern lava on the earth is in Iceland; it extends sixty miles; but the volcanoes in that island bear no proportion to those of the moon in magritude.-Mr. Bakewell.

B. Page 52.-The Lake of the Solfatara.-Its temperature was, in the winter, in the warmest parts, above 80 deg. of Fahrenheit, and it appears to be pretty constant; for I have found it differ a few degrees only, in January, March, May, and the beginning of June; it therefore being nearly twenty degrees above the mean temperature of the atmosphere, must be supplied with heat from a subterraneous source. Kirclier has detailed in his Mundus Subterraneus various wonders respecting this lake, most of which are unfounded, such as that it is unfathomable, that it has at the bottom the lieat of boiling water, and that floating islands rise from the gulf. It must certainly be very difficult, or even impossible to fathom a source which rises with so much violence from a subterraneols excavation; and at a time when chemistry had made small progress, it was easy to mistake the disengagement of carbonic acid for an actual ebulition. The floating islands are real, but neither the Jesuit nor any of the writers who have since described this lake, have had a correct idea of their origin, which is exceedingly curious. The high temperature of this water, and the quantity of carbonic acid that it contains, render it peculiarly fitted to afford a pabulum or nourishment to regetable life; the banks of travertine are every where covered with reeds, lichens, conferva, and various kinds of aquatic vegetables. At the same time that the process of vegetable life is going on, the crystallizations of the calcareous matter, which is everywhere deposited in consequence of the escape of carbonic acid, likewise proceeds, and gives a constant milkiness to what from its tint would otherwise be a blue fluid. So rapid is the vegetation, owing to the decomposition of the carbonic 
acid, that even in winter masses of confervæ and lichens, mixed with deposited travertine, are constantly detached by the currents of water from the bank, and float down the stream, which being a considerable river, is never without many of these small islands on its surface. They are sometimes only a few inches in size, and composed merely of dark green conferva, or purple or yellow lichens; but, occasionally, are even several feet in diameter, and contain seeds and various species of common water-plants, which are usually more or less incrusted with marble. There is, I believe, no place in the world where there is a more striking example of the opposition or contrast of the laws of animate and inanimate nature, of the forces of inorganic chemical affinity, and those of the powers of life. Vegetables, in such a temperature, and everywliere surrounded by food, are produced with a wonderful rapidity; but the crystallizations are formed with equal quickness, and are no sooner produced than they are destroyed together. Notwithstanding the sulphureons exhalations from the lake, the quantity of vegetable matter generated there, and its heat, make it the resort of an infinite variety of insect tribes; and, even in the coldest days in winter, numbers of flies may be observed on the vegetables surrounding its banks, or on its floating islands. Their larva may also be seen there, sometimes incrusted and entirely destroyed by calcareous matter, as well as the insects themselves, and various species of shell-fish that are found amongst the vegetables which grow and are destroyed in the travertine on its banks. Snipes, ducks, and other water-birds, often visit these lakes, probably attracted by the temperature and the quantity of food in which they abound; but they usually confine themselves to the banks, as the carbonic acid disengaged from the surface would be fatal to thein, if they ventured to swim upon it when tranquil. In May 18-, I fixed a stick on a mass of travertine covered by the water, and examined it in the beginning of the April following, for the purpose of determining the nature of the depositions. The water was lower at this time; yet I had some difficulty, by means of a sharppointed hammer, in breaking the mass which adhered to the bottom of the stick; it was several inches in thickness. The upper part was a mixture of light tufa and leares of 
confervæ; below this was a darker and more compact travertine, containing black and decomposed masses of confcrva; in the inferior part, the travertine was more solid, and of a grey colour, but with cavities which $I$ have no doubt were produced by the decomposition of vegetable matter. I have passed many hours, I may say days, in studying the phenomena of this wonderful lake; it has brought trains of thought into my mind connected with the early changes of our globe; and I have sometimes reasoned from the forms of plants and animals preserved in marble in this thermal source, to the grander depositions in the secondary rocks, where the zoophytes or coral insects have worked upon a grand scale, and where palms and vegetables, now unknown, are preserved with the remains of crocodiles, turtles, and gigantic extinct saurian animals, which appear to have belonged to a period when the whole globe possessed a much higher tcmperature. I have likewise often bcen led, from the remarkable phenomena surrounding me in that spot, to compare the works of man with those of nature. 'The baths, erected there nearly twenty centuries ago, present only heaps of ruins, and eren the bricks of which they were built, though hardened by fire, are crumbled into dust; whilst the masses of travertine around, though formed by a variable source from the most perishablc materials, have hardened by time, and the most pcrfect remains of the grcatest ruins in the eternal city, such as the triumphal arches and the Colosseum, owe their duration to this somrce.

How marvellous are those laws by which the humblest types of organic existence are prescrved, thangh born anidst the sources of their destruction, and by which a species of immortality is given to generations floating, as it were, like evanesccnt bubbles on a stream raised from the deepest caverns of the earth, and instantly losing what may be called its spirit in the atmosphere.-Sir Humphrey Daiy's Last Duys of a Philosopher.

C. Page 54.-Caverns.-One of the most common appearances in limestonc carcrns, is the formation of what are called stalnctites, from a Greek word, signifying distil- 
lation, or dropping. To explain these, a brief description of the mode of their production will be necessary. Whellever water filters through a limestone rock, it dissolves a portion. of it; and on reaching any opening, such as a cavern, either at its sides or roof, it forms a drop, the moisture of which is soon evaporated by the air, leaving a small circular plate of calcareous matter; another drop succeeds in the same place, and adds, from the same cause, a fresh coat of incrustation. In time, these successive additions produce a long, irregular, conical projection from the roof, which is continually being increased by the fresh accession of water loaded with calcareous or chalky matter, which it deposits on the outside of the stulactite already formed, and trickling down, adds to its length by subsiding to the point, and being dried 11p as before; precisely in the same manner as during frosty weather, icicles, which are stalactites of ice, or frozen water, are formed on the edge of the eaves of a roof. When the supply of water holding lime in solution, is too rapid to allow of its evaporation at the bottom of the stalactite, it drops to the floor of the cave, and drying up gradually, forms, in like manner, a stalactite rising upwards from the ground, instead of hanging from the roof; these are called, for the sake of distinction, stalagmites.

It fiequently happens, where these processes are uninremupted, that a stalactite hanging from the roof, and a stalagmite formed immediately under it, from tlie superabundant water, increase till tley mite, and thus constitute a natural pillar, apparently supporting the roof of the grotto; it is to the grotesque forms assumed by stalactites, and these natural columns, that caverns owe the interesting appearances, described in such glowing colours by those who witness them for the first time.-Saturday Magazine, No. 42 .

D. Page 54.-Weyer's Cave.-This cave is situated in a ridge of limestone hills, running parallel to the blue mountains. A narrow and rugged fissure leads to a large cavern, where the most grotesque figures, formed by the percolation of water through beds of limestone, present 
themselves, while the eye, glancing onward, watches the dim and distant glimmers of the lights of the guides-some in the recess below, and others in the galleries above. Passing from these recesses, the passage conducts to a flight of steps that leads into a large cavern of irregular form, and of great beauty. Its dimensions are about thirty feet by fifty. Here the incrustations hang just like a sheet of water that has been frozen as it fell; there they rise into a beautiful stalactitic pillar, and yonder compose an elerated seat, surrounded by sparry pinnacles. Beyond this room is another, more irregular, but more beautiful. Besides having sparry ornaments in common with the others, overhead is a roof of the nost admirable and singular formation. It is entirely covered with stalactites, which are suspended from it like inverted pinnacles. They are of the finest material, and are most beautifully shaped and embossed. In another apartment, an immense sheet of transparent stalactite extends from the roof to the floor, which, when struck, emits deep and mellow sounds, like those of a muffled drum. Farther on is another vaulted chamber, which is one liundred feet long, thirty-six wide, and twenty-six ligh. Its walls are filled with grotesque concretions. The effect of the lights placed by the guides at various elevations, and leaving hidden more than they rereal, is extremely fine. At the extremity of another range of apartments, a magnificent hall, two hundred and fifty feet long, and thirty-three feet high, suddenly appears. Here is a splendid sheet of rock-work running up the centre of the room, and giving it the aspect of two separate and noble galleries; this partition rises twenty feet above the floor, and leaves the fine span of the arched roof untouched. There is a beautiful concretion here, which has the form and drapery of a gigantic statne; and the whole place is filled with stalagmitical masses of the most varied and grotesque character. The fine perspective of this room, four times the length of an ordinary church, and the amazing vaulted roof spreading overhead, without any support of pillar or column, produces a most striking effect. In another apartment, which has an elevation of fifty feet, there is at one end an elevated recess, omamented with a group of pendant stalactiles of unusual size, and singular beanty. 'They are as large as the pipes of a full- 
sized organ, and ranged with great regularity ; when struck, they emit mellow sounds of various keys, not unlike the tones of musical glasses. Other cavities, profusely studded with sparry incrustations, extend through the limestone rock. The length of this extraordinary group of caverns is not less than one thousand six hundred feet.-Abridged from "A Narrative of the Visit to the American Churches," by Drs. Reed and Matheson.

E. Page 70.-Recent Formation of Sandstone.From the Transactions of the Royal Geological Society of Cornwall, by Dr. Paris._- A sandstone occurs in various parts of the northern coast of Cornwall, which affords a most instructive example of a recent formation; since we here actually detect Nature at work in converting calcareous sand into stone. A very considerable portion of the northern coast of Cornwall is covered with a calcareous sand, consisting of minute particles of comminuted shells, which, in some places, has accumulated in quantities so great, as to have formed hills of from forty to sixty feet in elevation. In digging into these sand hills, or upon the occasional removal of some part of them by the winds, the remains of houses may be seen: and in some places, when the churchyards have been overwhelmed, a great number of human bones may be found. The sand is supposed to have been originally brought from the sea by hurricanes, probably at a remote period. At the present moment, the progress of its incursion is arrested by the growth of the arundo arenacea. The sand first appears in a slight but increasing state of aggregation on several parts of the shore in the Bay of St. Ives; but, on approaching the Gwythian river, it becomes more extensive and indurated. On the shore opposite Godrevy Island, an immense mass of it occurs, of more than a hundred feet in length, and from ten to twenty in depth, containing entire shells and fragments of clay-slate; it is singular that the whole mass assumes a striking appearance of stratification. In some places, it appears that attempts have been made to separate it, probably for the purpose of building, for several old houses in Gwythian are built of it. The rocks in the 
vicinity of this recent formation in the Bay of St. Ives, are greenstone and clay slate, alternating with each other. The clay slate is in a state of rapid decomposition, in consequence of which large masses of the Hornblende rock have fallen in various directions, and given a singular character of picturesque rudeness to the scene. 'This is remarkable in the rocks which constitute Godrevy Island. It is around the promontory of New Kaye, that the most extensive formation of sandstone takes place. Here it may be seen in different stages of induration, from a state in which it is too friable to be detached from the rock upon which it reposes, to a hardness so considerable that it requires a very violent blow from a sledge to break it. Buildings are here constructed of it ; the church of Cranstock is entirely built with it; and it is also employed for various articles of domestic and agricultural uses. The geologist who has previously examined the celebrated specimen from Guadaloupe, will be struck with the great analogy which this formation bears to it. Suspecting that masses might be found containing human bones imbedded, if a diligent search were made in the vicinity of those cemeteries which have been overwhelmed, I made some investigations in those spots, but, I regret to add, without success. The rocks upon which the sandstone reposes, are alternations of clay slate, and slaty limestone. The inclination of the beds is SS.W., and at an angle of 400 . Upon a plane formed by the edges of these strata, lies a horizontal bed of rounded pebbles, cemented together by the sandstone which is deposited immediately above them, forming a bed of from ten to twelve feet in thickness, and containing fragments of slate, and entire shells; and exhibiting the same appearance of stratification as that noticed in St. Ives Bay. Above this sandstone lie immense heaps of drifted sand. But it is on the western side of the promontory of New Kaye, in Fishel Bay, that the geologist will be most struck with the formation; for here no other rock is in sight. The cliffs, which are high, and extend for several miles, are entirely composed of it; they are occasionally intersected by veins and dykes of breccia. In the cavities, calcareous stalactites of rude appearance, opaque, and of a grey colour, hang suspended. The beach is covered with disjointed fragments, which have been 
detached from the cliffs above, many of which weigh two or three tons."

\section{F. Page 83.-Lithodomi, or Boring Mollusca; which} have the power of perforating rocks. - Every one who has walked by the sea-side must have observed the blocks and masses of the chalk rocks full of perforations; and if his curiosity have induced him to examine these with attention, he will have perceived that though many of the cavities are empty, some of them contain the shelly remains of the animals which once inhabited them. 'The power possessed by creatures so delicate, and with such fragile coverings, of excavating the solid rock, has naturally excited much speculation as to the mode by which the perforations are effected; and it is now generally admitted, that it is not by mechanical power only that the feeble inhabitants of the boring shells are able to form themselves a secure asylum in the rock, but by the secretion of a liquid which acts chemically on the stone, softens it, and renders it capable of being removed with facility. In a late volume of the Philosophical Transactions, there is an interesting paper on the economy of molluscous animals, by Mr. Gray, which throws much light on this subject. It appears that, althongh teredines, pholades, and other boring shells, are covered with short spines and striae, by means of which they were supposed capable of rasping stones, yet other mollusca which inhabit stony cavities are perfectly smooth. On the shore, near Kemptown, a pholas, which has a rasping apparatus, and a venus, wholly destitute of a rugous surface, may be seen in cavities of the chalk. Shells of this kind have not been observed to bore into any other substances (wood excepted) than shells, marl, chalk, limestone, and sandstone, consolidated by calcareous cement. Granite appears to resist all the dissolving powers of the mollusca. Thus, in the Plymouth Breakwater, in which limestone and granite are employed and placed side by side, the patella, or limpets, form their rounded holes in the former, while they do not in the slightest degree alter the surface of the latter, except by clearing off from it any adherent calcareous substance. 
G. Page 85.-Observations on the Temple of Serapis at Puzzuoli, near Naples; in a Letter to $W$. H. Fitton, M.D., from Charles Babbage, Esq.-This paper commences with a general description of the present state of the Temple of Serapis, and gives the measurement of the three marble columns which remain standing, and which, from the height of eleven feet to that of nineteen, are perforated on all sides by the Modiola lithophaga (of Lamarck); the shells of that animal remaining in the holes formed by them in the columns. A description follows of the present state of twenty-seven portions of columns, and other fragments of marble, and also of the several incrustations formed on the walls and columns of the temple.

From these and other data, Mr. Babbage concludes:-

1. That the temple was originally built at, or nearly at the level of the sea, for the convenience of sea-baths, as well as for the use of the hot spring which still exists on the land side of the temple.

2. That, at a subsequent period, the ground on which the temple stood, subsided slowly and gradually; the salt water, entering through a channel which connected the temple with the sea, or by infiltration through the sand, mixed itself with the water of the hot spring containing carbonate of lime, and formed a lake of brackish water in the area of the temple, which, as the land subsided, became deeper, and formed a dark incrustation.

The proofs are, that sea-water alone does not produce a similar incrustation; and that the water of the lot spring alone produces an incrustation of a different kind; also, that Serpulie are found adhering to this dark incrustation; and that there are lines of water-level at various heights from 2.9 feet to 4.6 feet.

3. The area of the temple was now filled up to the height of about seven feet with ashes, tufa, or sand, which stopped up the chammel by which sea-water had been admitted. The waters of the hot spring thus confined, converted the area of the temple into a lake, from which an incrustation of carbonate of lime was deposited on the columus and walls. The proofs are, that the lower boundary of this incrustation is irregular; whilst the npper is a line of water-level, and that there are many such lines at different heights; - that salt water has not been found to produce a similar incrus- 
tation;-that the water of the Piscina Mirabile, which is distant from the sea, but in this immediate neighbourhood, produces, according to an examination by Dr. Faraday, a deposit almost precisely similar;-that no remains of Serpulre, or other marine animals, are found adhering to it.

4. The temple continuing to subside, its area was again partially filled with solid materials; and at this period was subjected to a violent incursion of the sea. The hot-wa'er lake was filled up, and a new bottom produced, entirely covering the former, and concealing also the incrustation of carbonate of lime.

The proofs are, that the remaining walls of the temple are highest on the inland side, and decrease in height towards the sea-side, where they are lowest; - that the lower boundary of the space perforated by the marine I.thophagi is, on different columns, at different distances beneath the uppermost, or water-level line;-that several fragments of columns are perforated at the ends.

5 . 'The land continuing to subside, the accumulations at the bottom of the temple were submerged, and modiola attaching themselves to the columns and fragments of marble, pierced them in all directions. 'The subsidence continued until the parement of the temple was at least nineteen feet below the level of the sea.

The proofs are derived from the condition of the columns and fragments.

6. The ground on which the temple stood, appears now to have been stationary for some time, but it then began to rise. A fresh deposition of tufa, or of sand, was lodged, for the third time, within its area, leaving only the upper part of three large columns visible above it.

Whether this took place before or subsequently to the rise of the temple to its present level, does not appear; but the pavement of the area is at present level with the waters of the Mediterranean.

The author then states several facts, which prove that considerable alterations in the relative level of the land and sea have taken place in the immediate vicinity. An ancient sea-beach exists near Monte Nuovo, two feet above the present beach of the Mediterranean. The broken columns of the Temples of the Nymphs and of Neptune, remain at present standing in the sea. A line of perfora- 
tions of modiolæ, and other indications of a water-level four feet above the present sea, are observable on the sixth pier of the bridge of Caligula; and again on the twelfth pier, at the height of ten feet. A line of perforations by modiolæ is visible in a cliff opposite the island of Nisida, thirty-two feet above the present level of the Mediterranean. - Abstract of the Proceedings of the Geological Society; March, 1834.

\section{H. Page 110.-Irisn Euk; Cervus Megaceros.-Beds} of gravel and sand, containing recent marine shells and bolies of the Irish Elk, have been observed by Dr. Scouler in the vicinity of Dnblin, at an elevation of two hundred feet above the level of the sea. It is therefore manifest that this extinct quadruped, although found in peat-bogs and morasses at a comparatively recent period, must liave been an inhabitant of Ireland antecedently to some of the last changes in the relative position of the land and water. 'The discovery of a vast number of skeletons of the Elk in the small area of the Isle of Man, seems to indicate a great alteration in the extent of land and sea; for it is difficult to conceive that such herds of this gigantic race could exist in so limited a district; and it is therefore probable that the island was separated from the main land at 110 remote geological period by subsidences commensurate with the elevation of which Ireland affords such decisive evidence. -Address of Charles Lyell, Esq., President of the Geological Society of London, 1837.

I. Page 312.-A Tabular Arraxgenent of the Fossil Fishes of the Chalk Formation of the South-East of England, collected by Gideon Mantell, ll.d. F.r.s.

\section{(From Recherches sur les Poissons Fossiles, by M. Agassiz.)}

“Tout le monde sait que le Musée de M. le Dr. Mantell a Brighton est une collection classique pour la craie, et la formation Veldienne. Les soins minutieux que M. Mantell adonnés depuis bien des années à ce's fossiles, les ont rendus plus parfaits que tuus ceux des autres musées; car sourent il est parrenu à les detacher entierement de la roche dans laquelle ils se trouvaient, ou du moins à les produire en relief, en détachant toutes les matieres solides qui recouvraient les parties les mieux conserves de l'animal." 


\section{APPENDIX.}

Order I.-The Placoidians, (from $\pi \lambda \alpha \xi$, a broad plate.) The skin, covered irregularly with enamelled plates, sometimes of a large size, but frequently in the form of small points, as in the shagreen on the skin of Sharks, and the tubercles on the integuments of Rays.

Pтrсnodus latissimus. Mantell's South Down Fossils. Tab.xxxii. fig. 19. Agassiz, Poiss. Foss. Vol. iii. tab. 25.

polygyrus. Ibict. Tab. xxxii. fig. 23, 24.
memmillaris. Ibid. Tab. xxxii. fig. 18, 20, 25, 29.
decurrens. decurrens.

altior. South Down Fossils. Tab. xxxii. fig. 17, 21, 27.

Teeth, and perhaps vertebra, of the above species, and a few examples of their dorsal defences, (Ichthyodorutites of Dr. Buckland,) are the only remains hitherto discovered. (Agass. Poiss. Foss. Vol. iii. tab. 10a $10^{\mathrm{b}}$.) The teetl were referred to fishes of the genus Diodon, by previous authors, and the defences were called radii, or fin-bones of Balistes, and Siluri.

Teeth of a new species of Ptychodus have been discovered in the sand of New Jersey, United States, by Dr. Morton.-(Morton's Synopsis, Pl. 18, fig. 1, 2.) I hare named it Ptychodus Mortoni.

Prychonus,-spec. undetermined. Dorsal defences, and a beautiful example of a fin, are represented in the fossils of the South Downs. 'Tab. xxxiv. fig. S. Tab. xxxix. and Tab. xl. fig.3. GaLecs pristodontus. South Down Fossils. Tab. xxxii. fig. 12 to 16. Agass. Poiss. Foss. Vol. iii. tab. 26. fig. 14.

Notidanus microdon. Ibid. Tab. xxxii. fig. 22.

Lamsa appendiculata. Ibid. Tab. xxxii. fig. 2, 3, 5, 6, 9. acuminata. Ibid. Tab. xxxii. fig. 1.

Mantellii. Ibid. Tab. xxxii. fig. 4, 7, 8, 10.

- crassissima. Not figured.

Onontapsis raphiudon. Not figured.

SpIxax major. Agass. Poiss. Foss. Vol. iii. tab. 10. fig. 8, 14.

Psamonus asper. Poiss. Foss. Vol. iii. tab. 10. fig. 1, 3.

Acrodus transcersus. Poiss. Foss. Vol. iii. tab 10. fig $4,5$.

GYRodus angustus. Poiss. Foss. Vol.ii. tab. 66a. 1ig. 14, 15.

The above order of fishes is represented by five genera, of which one, containing twelve species, is extinct. 'The fishes of the genera Ptychodus, Galeus, and Lamna, are very widely distributed.

Order II.-The Ganoidians,-(yavos, splendom; from the brilliant surface of their enamel.) These are characterised by angular scales, formed of horny or bony plates, protected by a thick layer of enamel. 


\section{APPENDIX.}

Macropoma Mantellii. Tab. 38, page 308. Length 24 inches. South Down Fossils. Tab. xxxvii. and xxxviii. Agass. Poiss. Foss. Vol. v. tab. 60b. fig. 2.

Coprolites of: South Down Fossils. Tab. ix. fig. 5, 11. Agass. Poiss. Foss. Vol. ii. tab.65.

This Macropoma is perhaps the most remarkable of all the fossil fishes; in most examples the membranes of the stomach are preserved.

SPHCRODUS mammillaris. Not figured. From Clayton chalk-pit.

Dercetis elongatus. Tab. 39, page 309. Length 16 inches. South Down Fossils. Tab. xxxiv, fig. 10,11. ' Tab. xl. fig. 2. Agass. Poiss. Foss. Vol. ii. tab. 66a. fig. 1 to 8.

The above order comprehends three extinct genera, with three species. Another species of Dercetis has been found in the chalk of Westphalia.

Order III.-The Ctenoïdians, (krels, a comb.) The scales of this order are pectinated on their posterior margin, like the teeth of a comb, and are composed of lamina of horn or bone, but have no enamel.

Beryx Lewesiensis. (B. ornatus of Agassiz.) Tab.xli. page 311. Length 12 inches. South Down Fossils. Tab. xxxiy. fig. 6. Tab. xxxy. Tab. xxxvi. Agass. Poiss. Foss. Vol.iv. tab. $14 \mathrm{a}$.

- radians. Tab. 40, page 310 . Length 7 inches. History of the County of Sussex. Vol. ii. Part ii. p. 15. fig. 22. Agass. Poiss. Foss. Vol. iv. tab. 14 b. fig. 7 .

microcephalus. Agass. Poiss. Foss. Vol. iv. tab. tc. fig. 7 to 9.

'There are other'specics of Beryx in the chalk of Bohemia and Westphalia; and genera nearly related to Beryx, in the schist of Glaris. In England this order contains but three species of a genus, of which we know but one living species.

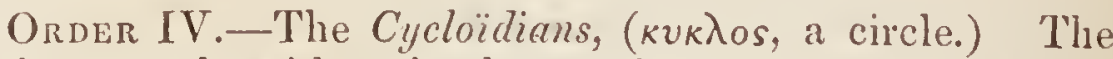
scales smooth, with a simple margin, composed of lamina of horn or bone without enamel.

Osyeroides Mrantellii. (Salmo? Leuesiensis of Mantell.) Tab. 37, page 207. Length 12 inches. South Down Fossils. Tab. xxx. fig. 12. Tab. xxxiv. fig. 3. Tab. xl. fig. 1. Agass. Poiss. Foss, Vol. r. tab. 600 .

To the above species belong the remarkable uncompressed specimens in my Museum. 


\section{APPENDIX.}

Osmeroides Lewesiensis. Agass. Poiss. Foss. Vol. v. tah.60c. (Salmo? Juewesiensis of Mantell.) This spceies is more elongated than $O$. Mantellii, and the number of rays in the dorsal fin is greater.

gramulatus. History of Lewes. Vol. i. platc xxix. fig. 13. The bones of the head, with the jaws and teeth, have alone been diseovered. Agass. Poiss. Foss.

Exchunus halosyon. Sonth Down Fossils. Tab. xxxiii. fig. 2, 3, 4. Tab. xliv. fig. 1, 2. Agass. Poiss. Foss. Vol. v. tab. 25. fig. 11 to 6 .

S.iurocephalus lanciforms. (Harlan.) South Down Fossils. Tab. xxxiii. fig. 7,6. Trans. Gcol. Soe. of Pennsylvania, vol. i. p. 83. Agass. Poiss. Foss. Vol. v. tab. 25. fig. 21 to 29 .

Saunodox Leanus. (Hays.) Trans. American Plilos. Society, vol. for 1830, plate 16. Agass. Poiss. Foss. Vol. v. tab. 25. fig. 17 to 20.

Hrpsodon Lewesiensis. South Down Fossils. Tab. xxxiii. fig. 8. Tab. xlii. fig. 1 to 5. Agrass. Poiss. Foss. Vol.v. tab. 25a.

From the resemblance of the teeth of this fish, to those of reptiles, it was supposed that the original belonged to an extinct genus of samrians; but in 1833, a considerable portion of the head, with the maxillre, many vertebra, \&c., were discovered in a block of chalk, near Lewes, and the true characters of this remarkable ichthyolite determined.

*** The following fishes have been naned by M. Agassiz, since the above table was constructed.

Acrogratuus boops. Tab. 37, page 307. Natural sizc. Agass. Poiss. Foss. Vol. iii. tab. 60a. fig. 1, 4. An unique specimen. from Sontherham quarry, ncar Lewes.

Aulolepis typus. Tab. 38, page 308. Length 6 inches. An unique spceimen, from Clayton chalk-pit, Sussex. One ncarly perfect example has alonc bcen found. Poiss. Foss. Vol. iii. tab. 60. fig. 5, 8.

Selonostomus cinctus. Agass. Poiss. Foss. Vol. ii. tab. 663. fig. 10 to 13. Curmera Agassizii. Agass. Poiss. Foss. Vol. iii. pl. 40. fig. 3,5. (Determined by Dr. Buckland.) The beaks or mandibles have alone been diseovered.

Mantellii. Agass. Poiss. Foss. Vol.iii. pl.40. fig. 1, 2. Two mandibles were found, many years since, in a block of chalk, near Lewes. This speeies also occurs in the Slianklin sand of Kent. A beak lias been found by Mr. IV. H. Bensted in the Iguanodon quarry, near Maidstone.

Tetrapteros minor. Lewes. Agass. Poiss. Foss. Vol. iii. tab. 60, fig. $1,4$.

Caturus similis. Ágass. Poiss. Foss. Vol. ii. tab. 66a. fig. 9.

Acrotemus faba.Poiss. Foss. Vol.ii. tab. 66a. fig. 16, 18. 


\section{G L O S S A R Y.}

Explanations of many scientific terms, not inserted in the Glossary, will he found in the text, by consulting the Index.

\footnotetext{
Acephala............ Molluscous animals without a head, as the oyster, \&ic. Atge ................ A family of sea-weeds.

Alluvium........... Waterworn materials.

Aluminum .......... Metallic base of clay.

Amorphous .......... Shapeless.

Amygdaloid......... Cellular volcanic rock, the cavities of which are filled with other substances.

Antenna ........... The feelers of insects.

Anthracife ........... Stonc or cannel coal.

Anthracotherium. An extinct animal, allied to the Palæotheria, found in Anthracite.

Arenaceous ......... Formed of sand.

Argitlaceous ....... Formed of clay.

Astrea .............. A genus of corals.

Augite .............. A mincral found in many volcanic rocks.

Basatt ............. Ancient lava, composed of Augite and Felspar, frequently columinar.

Basin .............. A depression of, or concavity in, strata.

Betemnite........... The bone of an animal allied to the cuttle-fish.

Bitumen ............. Mineral pitch or tar.

Btende ............... Sulphuret of zinc, occurring in primary and secondary rocks.

Branchice.......... The respiratory apparatus of aquatic animals.

Breccia............... Conglomerate of pebbles or fragmented rocks.

Calc sinter ........ Deposition from thermal springs charged with carbonate of lime.

Calcaire Grossicr. A tertiary limestone.

Calcium ............. Metallic base of lime.

Campannlaric.... Arborescent corals, with bell-shaped cells : p. 475.

Carbon .............. The elementary substance of charcoal and the dianond.

Carbonate of Lime. Lime and earbonic acid.

Carboniferous...... Belonging to coal.

Cephalopoda ....... Mollusea, with the organs of motion around their heads. Caryophillia ....... Branched stellular coral.

Centrifugal ......... A force directed from the centre to the circumference.
} 


\section{GLOSSARY.}

Cetacea.............. Marine mammalia, as the whale, porpoise, \&c.

Chalcedony ......... A species of silex, nanied from Chalcedon, a city of Asia, near which it is found in great abundance.

Chert A silicious mineral allied to flint and chalcedony.

Choanite ........... A zoophyte of the chalk.

Cilia ................. Hair-like vibratory organs.

Cirrus .............. A fossil shell of the chalk. See Geol. S. E. E., 1, 125.

Cornbrash........... A coarse shelly limestone.

Conchoidal ......... Shelly.

Concretion ......... A coalition of separate particles.

Coleoptera .......... Insects having wing-cascs, as beetles.

Conformable ....... Applied to parallel strata lying upon each other.

Condyle ............ An articulating surface or joint.

Conglomerate ...... Fragments cemented together.

Coniferce ........... Trees bearing cones, as the fir, pine, \&c.

Cotyledons ......... Seed-lobes of plants.

Crag ................. A tertiary deposit; from a provincial term (used in Suffolk and Norfolk) to denote gravel.

Crater .............. The vent of a volcano.

Crateriform......... Having the form of a crater.

Crinoidea........... Lily-shaped animals.

Crustacea............ Animals allied to the crab, lobster, \&c.

Cryptogamia...... Plants with concealed fructification, as mosses, ferns, \&c.

Crystalline ......... Presenting the structure of crystals.

Crystals ............ Synmetrical forms assumed by nineral substances.

Cyathiform ......... Cup-shaped.

Cycadea ............ A genus of plants allied to the palms and ferns.

Delta .............. Alluvial deposites formed by rivers.

Denudation......... Strata exposed by the action of water.

Detritus ........... Disintegrated materials of rocks.

Dicotyledonous ... Plants with seeds having two lobcs.

Didelphis............ A marsupial animal, allied to the Opossum.

Diluvium............ A term formerly employed to designate ancient alluvial deposites.

Dip ............... The inclination of strata.

Diptera ........... Insects having two wings.

Discoidal............ In the form of a disk.

Dyke.................. An intrusion of melted matter into rents or fissures of solid rocks.

Earth's Crust...... That portion of the solid surface of the eartl wlich is accessible to human observation.

Echinus Sea-urchin.

Elytra .............. Wing-cases of insects.

Encrinite........... A genus of crinoidea.

Eocene .............. The dawn of the present epoch; the early tertiary.

Ephemeron ......... The creature of a day.

Escarpment........ The steep cliff of a ridge of land.

Exuvia ........... Organic remains.

Fault................ Interruption of the continuity of strata with displacement.

Fauna ............. The zoology of a particular country.

Felspar.............. A mineral which entcrs into the composition of many primary rocks.

Ferruginous ...... Impregnated with iron.

Flora .............. The botany of a particular country.

Flustra............... A genus of Polyparia; p. 460.

VOL. I. 


\section{GLOSSARY.}

Formalion

Fungia

Gall

Gelatinnus

Gnrgonin

Gneiss

Greensand, or )

Shanklin Sand\}

Greenstone ......... A trap rock.

Greyureke ......... A transition rock; a conglomerate indurated by heat.

Grit Coarse-grained calciferous sandstone.

Gypsum

Sulphate of lime.

Hamiles ........... Hook-shaped shells, of a genus of Cephalopoda.

Hemiptera ......... Insects witl wings, half horny and lialf membraneous.

Hylcosnurus ...... The Wealden lizard.

7Iymenoptera..... Inscets witl membraneous wings.

Telhyosnurus ...... Fish-like lizard

Iguanodon ......... Extinct colossal lizard, having teeth like those of the Iguana.

Imbricaled ......... I aid one over the other like scales.

Induction ........ The derivation of a principle from facts.

Infusurin........... Microscopic animals, found in infusions, \&c.

Inoceramus........ A bivalve shell of the chalk, liaving a fibrous structure. See Geol. S. E E., p. 127.

Invertebraled Animals. Animals without vertebræ, as worms, \&c.

Kimmeridge Clay. A blue clay of the Oolite.

Laeustrine ........ Bclonging to a lake.

Lamellated ......... Covered with thin plates or scales.

Lamina ........... The thin layers of which a stratum is composed.

Laminaled ......... Strata formed of very thin layers.

Lapilti .............. Volcanic ashes, in which minute globnlar concretions prevail.

Lepidoplern........ Insects with scaly wings.

Lias ................. A provincial term, applied to a group of strata situated between the Oolite and the New Red Sandstone.

Lignite. Carbonized wood.

Lithodomi ......... Mollusca which perforate stone.

Lithological ...... The stony character of a mineral mass.

Lithophytes........ Stony plants; a term applied to corals.

Littoral ........... Bclonging to the shore.

Loess................ An alluvial tertiary deposit on the banks of the Rline.

Lophiodon ........ Fossil animal, allied to the Tapir, so named from eminences on the teeth.

Lyeopodiacea ...... The family of Club MIosses.

Madrepore ......... A genus of stcllular corals.

Mammalia ......... Animals which give suck to their young.

Mammillaled ...... Studded with mammilla, or rounded protnberances.

Nammoth ........... An extinct genus of quadrmped, allied to the elepliant.

Marl................. A mixture of clay and lime.

Marsupial ......... Applicd to animals having a pouch, as the kangaroo.

Ifarsupite ......... A genus of crinoidea of the chalk. 
Mastodon.......... An extinct genus of quadrupeds, allied to the elephant, having tuberculated teeth.

Matrix. The substance in which a fossil is imbedderl.

Mcandrinc........ A genus of eorals, with meandering eclls, as the brain-stone coral.

Megalosaurus..... Gigantic lizard; an extinet Saurian, allicd to the Mronitor.

Megalony $x$........ An extinct quadruped, allicd to the sloth.

Meteorites ......... Mincral masses which fall from the atmosplicrc.

Megalherium ...... An extinet gigantie quadruped, allied to the sloth.

Mica ............... A simple mineral, one of the component parts of granite.

Miocene ............ Middle Tertiary series.

Molares ............ Grinding teeth.

Motlnsca............ Soft aninals-destitute of a hony structure.

Monitor ............ A genus of lizards, inliabiting the tropies.

Monocotytcdonous Plants having seeds with but one lobe.

Multitocular...... Many-chambercd shells, as the Nautilus.

Mruschelkalk....... A limestone of the red sandstone formation.

New Red Sandstone A group of strata betwecn the magncsian limestone and the lias.

Nodulc .............. A rounded mineral mass, as a flint.

Normal................ The natural, or original condition.

Nuctens ............. A eentre, or point, round which other materials collect.

Nummulite ......... An internal multilocular shell.

Obsidian ........... A glassy lava.

Old Rcd Sundstone A group of strata lying between the earboniferous herls and the Silurian system.

Oolile ............... A limestone group, eomposed of an aggregation of spheroidal grains.

Organic Remains. Thic relics of animals and plants.

Orlhoceratite ....... A straight, fossil multilocular shell

Ossicula ............. Small bones.

Ovate................. Iigg shaped.

Oxide ............... The combination of oxygen with a metallic substance.

Pachydcrmata...... Thick-skinned animals, as tlic rlinoeeros, $8 \mathrm{c}$.

Palceontology ...... The science which treats of the structure of extinct animals.

Palcotherium..... An extinet quadruped, allicl to the Tapir.

Paludina........... A genus of fiesh-water mollusea.

Peclunculus......... A genus of bivalvc shells.

Peperino ........... A volcanie aggregatc.

Petrotcum ........... Mineral oil.

Pisolite.............. Minerals having a structure resembling peas agglutinated together.

Planorbis........... A genus of diseoidal fresh-water shells.

Plastic clay......... A tertiary deposit.

Ptesiosaurus ....... An extinct marine animal, allied to the lizard.

Plioccne ............ More recent, nodern tertiary.

Polyparia .......... Corals.

Porphyry ............ A species of ancient lava.

Prccipilate......... The chemieal scparation and deposit in a solid form of a substance hcld in solution by water.

Producla ........... A genus of fossil, bivalve, marine shells, found in the lower secondary rocks, and allied to the Terebratula.

Plerodactylcs ...... A genus of extinct winged rcptiles.

Pumice.............. A light spongy lava.

Pyriform ............ Pear-shaped.

Pyrites ............... Sulphuret of iron. 
Quarlz ............. A mineral composed of pure silex.

Ramose............. Branched.

Reticulated ......... Resembling net-work.

Ruminanls ........ Animals which ruminate, as the ox, \&c.

Saurian ........... A division of the family of the lizards.

Scaphite ............. An extinct genus of Cephalopoda, of a boat-like form.

Scorice .............. Volcanic cinders.

Sedimentary ....... Deposited by water.

Seplaria ............ Nodular masses of clay, having crevices filled witl spar.

Sertularia ........... A genus of arborescent corals.

Shale................. Slaty clay.

Silex ................... Flint.

Silica ............... The base of flint.

Silicious ............ Flinty.

Silicified ............. Changed to flint.

Silt .................. Fluviatile deposites of mud, \&c.

Spatangus .......... A genus of the sea-urchip.

Spheroidal .......... Having the form of a spheriod; oblong, or oblate.

Spirifera ........... An extinct genus of biralve shells.

Stalactite............ Pendant masses of carbonate of lime.

Stalagmite .......... Calcareous concretions formed on the floors of caverns

Stellular ............ Having star-like markings.

Stratum ............ A layer of any deposit.

Stratified ............ Deposited in layers.

Syenite.............. A species of granite in which hornblende supplies the place of mica.

Tentacula .......... Fcclers.

Tertiary ............. Applied to formations or strata newer than the chalk.

Testacea ............. Shells.

Trach;te ............ Lava composed chiefly of felspar.

Trap rocks ......... Ancient volcanic rocks, the name of which is derived from a Swedish word, Trapp $\iota$ - a stair.

Trilobile ........... An extinct family of Crustacea, the body being divided into tliree lobes, whence the name.

Tulipera........... Organ-pipe coral.

Tuff ................ Earthy volcanic rock.

Tufa................A calcareous precipitate from water.

Turbinated ......... Applied to shells havilig a spiral screw-shaped form.

Turrilite ............ A spiral multilocular sliell of the chalk; p. 296.

Unconformable.... Applied to strata lying in a different plane to those on whicl they rest.

$V$ eins............... Fissures in rocks, filled up by mincral substances.

Vermes .............. Worms.

Vertebrated......... Having a flexible osseous spinal column.

$V$ esicular............ Full of vesicles or cells.

Zoophytes ......... Animal plants applied to corals, \&c.

END OF VOL. I. 


$$
c
$$




